NIST NCSTAR 1-1

Federal Building and Fire Safety Investigation of the World Trade Center Disaster

\title{
Design, Construction, and Maintenance of Structural and Life Safety Systems
}

\author{
H. S. Lew \\ Richard W. Bukowski \\ Nicholas J. Carino
}


. 
Federal Building and Fire Safety Investigation of the World Trade Center Disaster

\section{Design, Construction, and Maintenance of Structural and Life Safety Systems}

\section{H. S. Lew}

Richard W. Bukowski

Nicholas J. Carino, retired

Building and Fire Research Laboratory

National Institute of Standards and Technology

September 2005

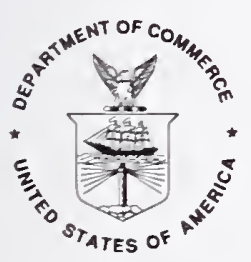

U.S. Department of Commerce

Carlos M. Gutierrez, Secretary

Technology Administration

Michelle O'Neill, Acting Under Secretary for Technology

National Institute of Standards and Technology

William Jeffrey, Director 


\section{Disclaimer No. 1}

Certain commercial entities, equipment, products, or materials are identified in this document in order to describe a procedure or concept adequately or to trace the history of the procedures and practices used. Such identification is not intended to imply recommendation, endorsement, or implication that the entities, products, materials, or equipment are necessarily the best available for the purpose. Nor does such identification imply a finding of fault or negligence by the National Institute of Standards and Technology.

\section{Disclaimer No. 2}

The policy of NIST is to use the International System of Units (metric units) in all publications. In this document, however, units are presented in metric units or the inch-pound system, whichever is prevalent in the discipline.

\section{Disclaimer No. 3}

Pursuant to section 7 of the National Construction Safety Team Act, the NIST Director has determined that certain evidence received by NIST in the course of this Investigation is "voluntarily provided safety-related information" that is "not directly related to the building failure being investigated" and that "disclosure of that information would inhibit the voluntary provision of that type of information" (15 USC 7306c).

In addition, a substantial portion of the evidence collected by NIST in the course of the Investigation has been provided to NIST under nondisclosure agreements.

\section{Disclaimer No. 4}

NIST takes no position as to whether the design or construction of a WTC building was compliant with any code since, due to the destruction of the WTC buildings, NIST could not verify the actual (or as-built) construction, the properties and condition of the materials used, or changes to the original construction made over the life of the buildings. In addition, NIST could not verify the interpretations of codes used by applicable authorities in determining compliance when implementing building codes. Where an Investigation report states whether a system was designed or installed as required by a code provision. NIST has documentary or anecdotal evidence indicating whether the requirement was met, or NIST has independently conducted tests or analyses indicating whether the requirement was met.

\section{$\underline{\text { Use in Legal Proceedings }}$}

No part of any report resulting from a NIST investigation into a structural failure or from an investigation under the National Construction Safety Team Act may be used in any suit or action for damages arising out of any matter mentioned in such report (15 USC 281a; as amended by P.L. 107-231).

National Institute of Standards and Technology National Construction Safety Team Act Report 1-1 Natl. Inst. Stand. Technol. Natl. Constr. Sfty. Tm. Act Rpt. 1-1, 278 pages (September 2005) CODEN: NSPUE2

\section{U.S. GOVERNMENT PRINTING OFFICE \\ WASHINGTON: 2005}

For sale by the Superintendent of Documents, U.S. Government Printing Office Internet: bookstore.gpo.gov — Phone: (202) 512-1800 - Fax: (202) 512-2250 Mail: Stop SSOP, Washington, DC 20402-0001 


\section{ABSTRACT}

The collapse of World Trade Center (WTC) 1, 2, and 7 resulted from structural damage from direct and indirect effects of aircraft impact and the ensuing fires. Thus, for collapse analyses of these buildings, knowledge of the physical state of the structural and fire safety systems prior to the aircraft impact is essential. To obtain information for the collapse analysis of the buildings, National Institute of Standards and Technology reviewed design and construction documents, correspondence, and memoranda related to the building projects; interviewed individuals involved in the design, construction, and maintenance of the buildings; obtained information from regulatory and emergency services agencies of New York City; and reviewed books and published journal and magazine articles related to the WTC building projects.

Information obtained from various sources are synthesized and summarized in this report. Specifically, this report presents (1) provisions used to design and construct the structural, fire protection and egress systems of the buildings; (2) tests performed to support the design of these systems; (3) criteria that governed the design of the structural and fire protection systems; (4) methods used to proportion structural members and other components of the buildings; (5) innovative features, technologies and materials that are incorporated in design and construction of the structural and fire protection systems;

(6) details of deviations to the contract documents granted by Port Authority of New York and New Jersey; (7) fabrication and inspection requirements at the fabrication yard; and (8) inspection protocols during construction.

This report also documents the fuel system for the diesel generators that supplied emergency power to many of the tenants in WTC 7.

Findings from the synthesis of the information collected and resulting issues are presented.

Keywords: Buildings, codes, construction, design, egress. elevators, fire, loads, maintenance, regulations, standards, World Trade Center. 
This page intentionally left blank. 


\section{TABLE OF CONTENTS}

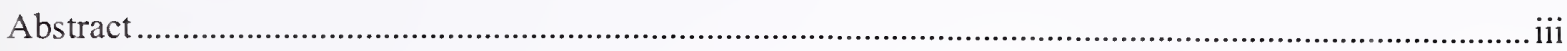

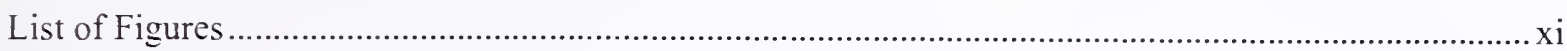

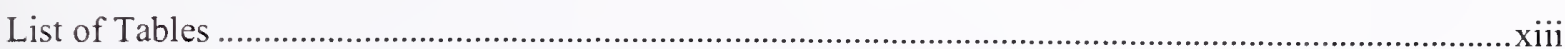

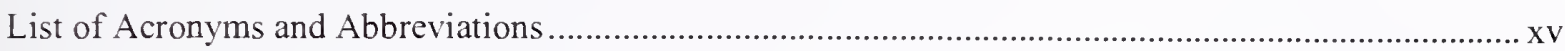

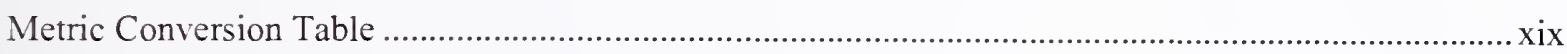

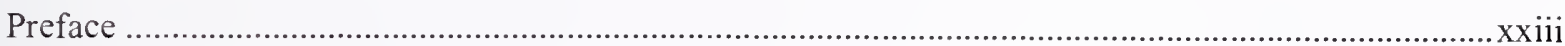

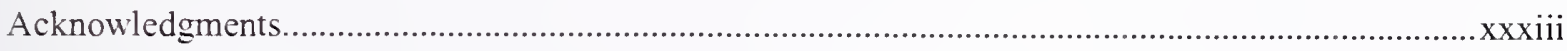

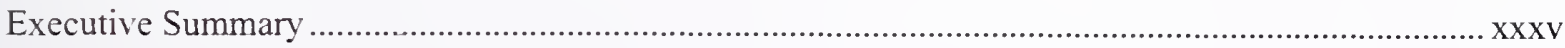

\section{Chapter 1}

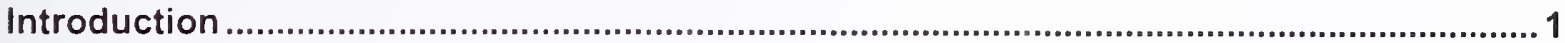

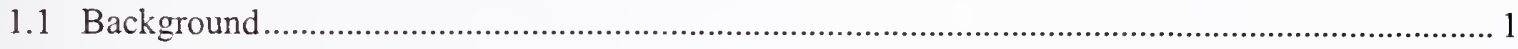

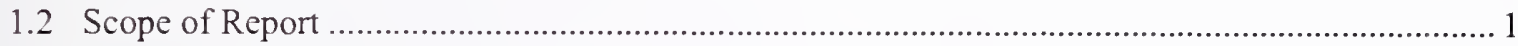

1.3 Design and Construction Requirements for WTC 1, 2, and 7 ........................................... 4

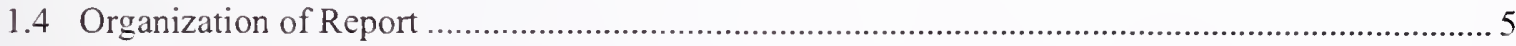

\section{Chapter 2}

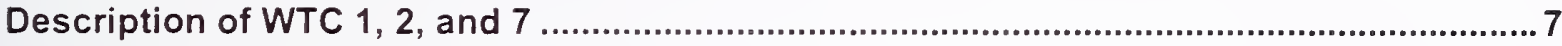

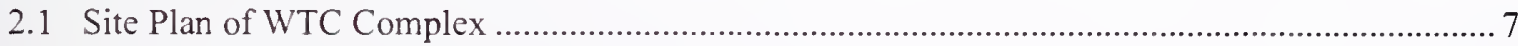

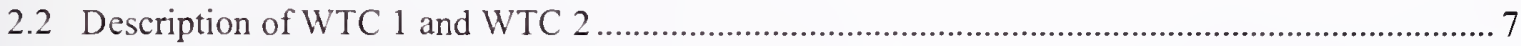

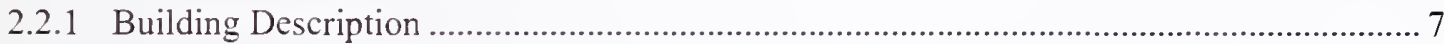

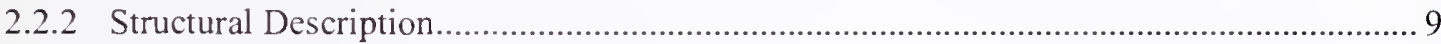

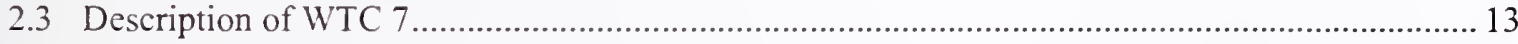

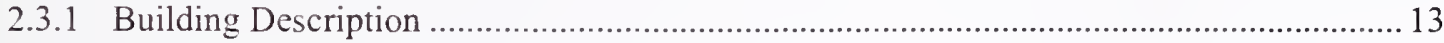

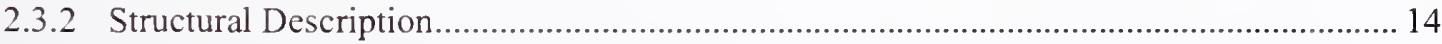

\section{Chapter 3}

Development of Building Codes ............................................................................. 37

3.1 Building Code Development in the United States ................................................................... 37

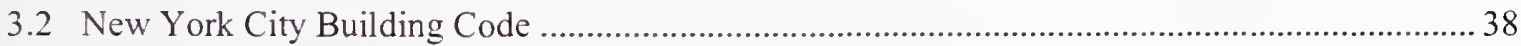

3.3 Port Authority Policies for Design and Modifications to Buildings .........................................40

3.3.1 Procedures for PANYNJ Owned Projects ........................................................................ 40

3.3.2 Review of Tower Plans by New York City Department of Buildings ............................. 41 
3.3.3 Procedures for Tenant Alteration Projects............................................................... 42

\section{Chapter 4}

Code Provisions for Structural Design

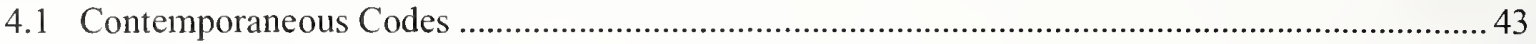

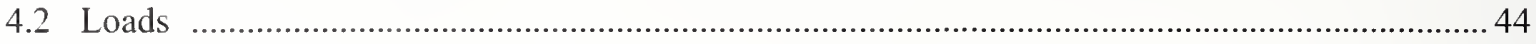

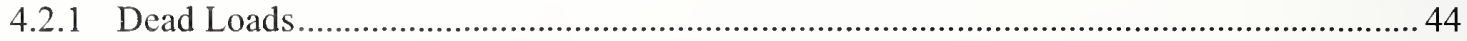

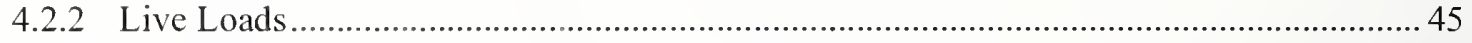

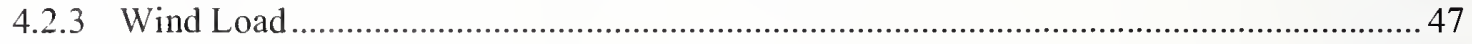

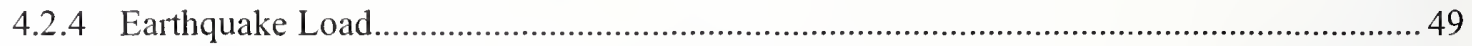

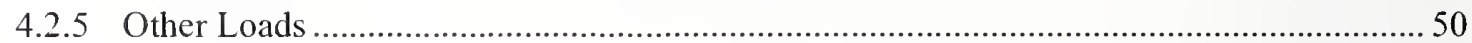

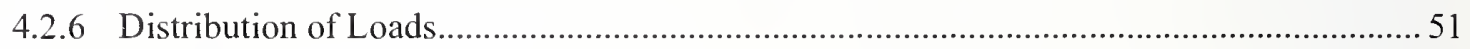

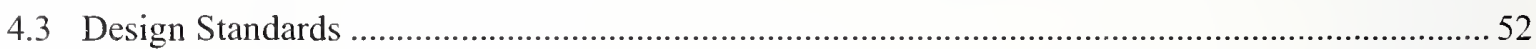

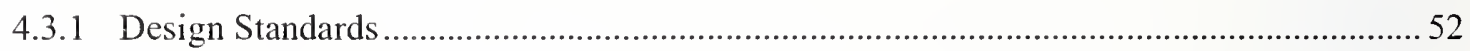

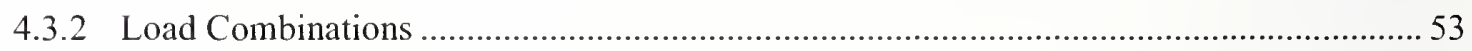

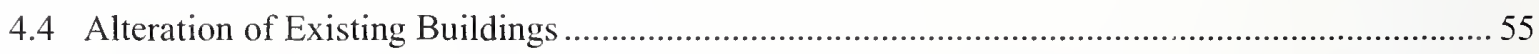

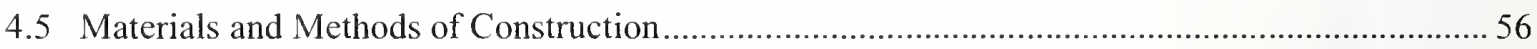

4.6 Stability, Bracing, and Secondary Stresses ................................................................... 58

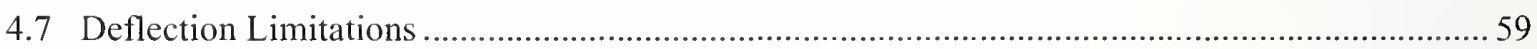

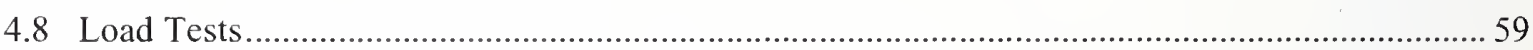

\section{Chapter 5}

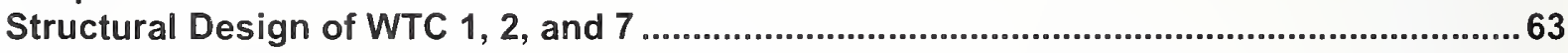

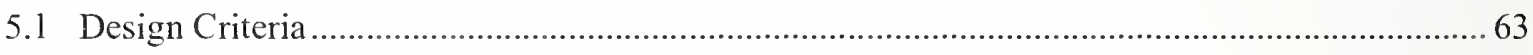

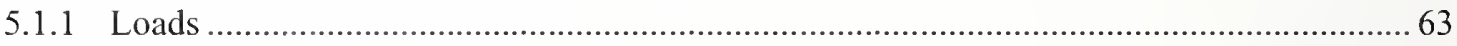

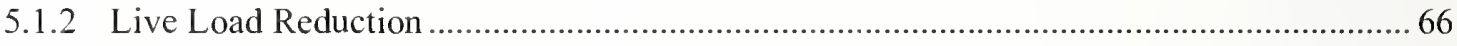

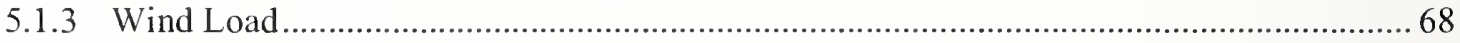

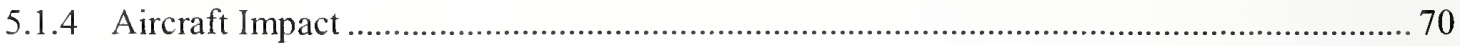

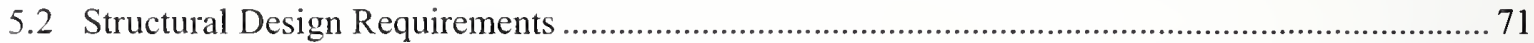

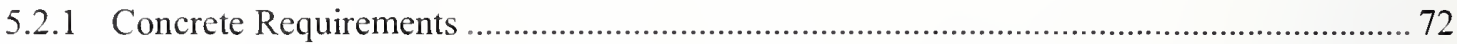

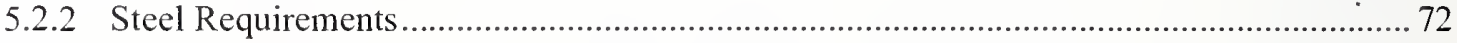

5.2.3 Methods Used to Proportion Structural Members ...................................................... 73

\section{Chapter 6}

Innovative Features Incorporated in Structural Design ..............................................8 87

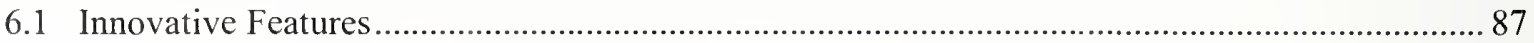

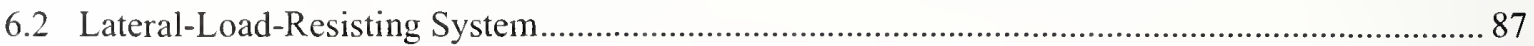




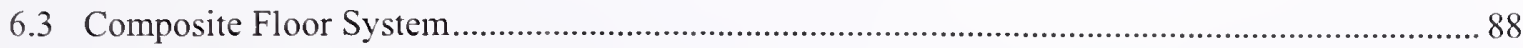

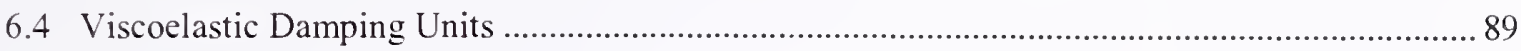

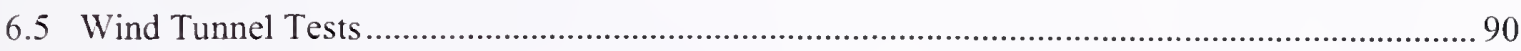

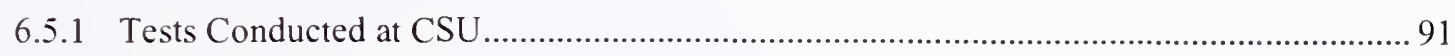

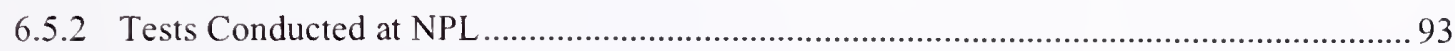

\section{Chapter 7}

Fabrication and Construction Inspections and Deviations ............................................99

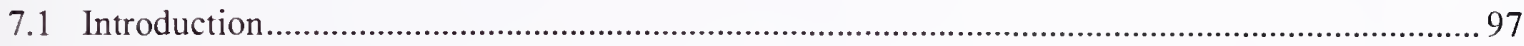

7.2 Fabrication Inspection Requirements for WTC 1 and WTC 2 ......................................... 97

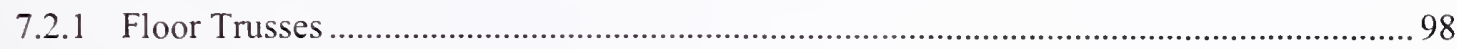

7.2.2 Box Core Columns and Built-Up Beams ................................................................ 98

7.2.3 Exterior Columns from Elevation $363 \mathrm{ft}$ to the 9th Floor Splice .................................... 100

7.2.4 Exterior Columns Above the 9th floor Splice ......................................................... 100

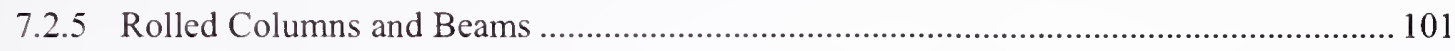

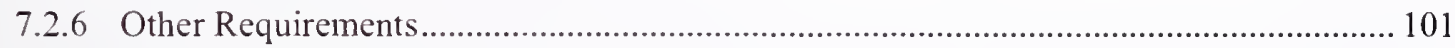

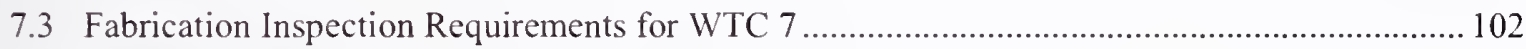

7.4 Inspection During Construction ................................................................................. 102

7.4.1 Erection Marks and Marking System WTC 1 and WTC 2 ........................................ 103

7.4.2 Quality Control and Inspection Program for WTC 1 and WTC 2 2.............................. 104

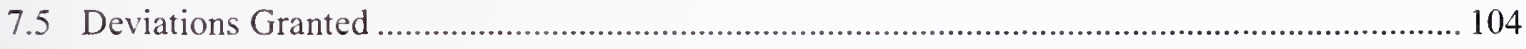

7.5.1 Deviations Relating to Fabrication and Erection Tolerances ..................................... 105

7.5.2 Deviations Relating to Defective Components ....................................................... 105

7.5.3 Deviations Relating to Alternate Fabrication and Erection Procedures ......................... 106

7.5.4 Deviations Relating to Product Substitutions ............................................................ 106

7.5.5 Deviations Relating to lnspection Practice .............................................................. 107

\section{Chapter 8}

Structural Maintenance and Modifications During Occupancy....................................109

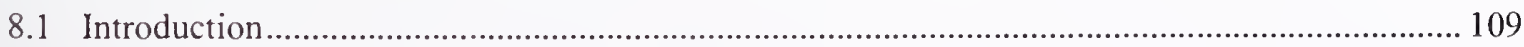

8.2 Tenant Construction Review Manuals .............................................................................. 109

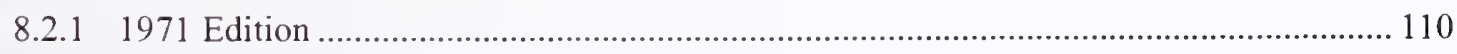

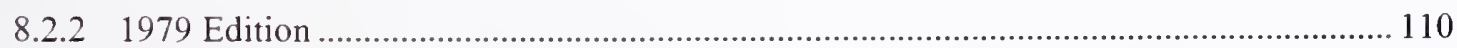

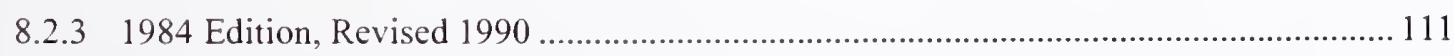

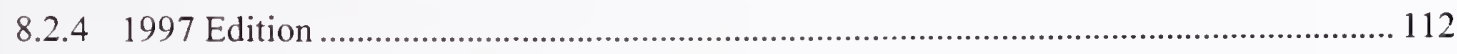

8.3 Standards for Structural Integrity Inspection of the WTC Towers ....................................... 112 


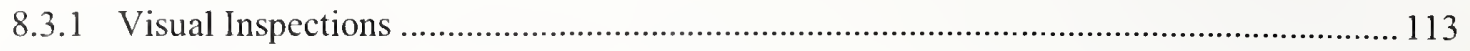

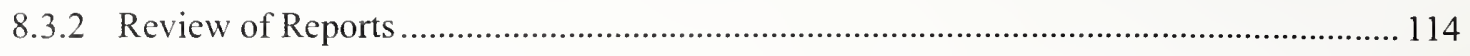

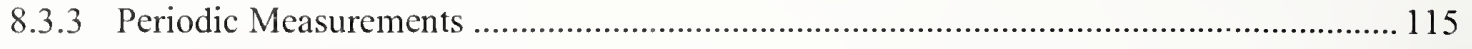

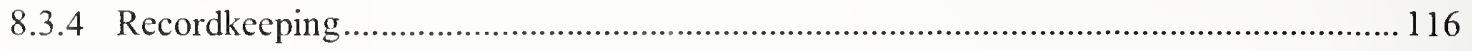

8.4 Standards for Architectural and Structural design ................................................................ 117

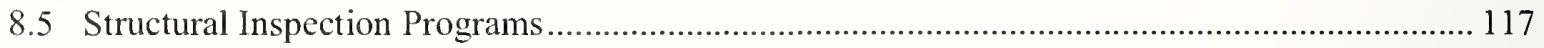

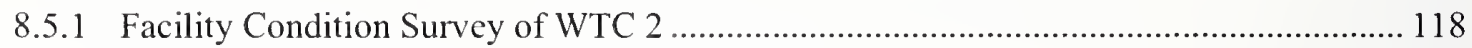

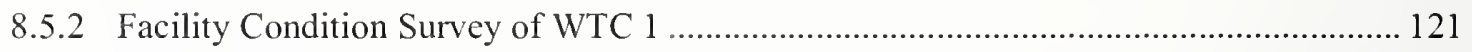

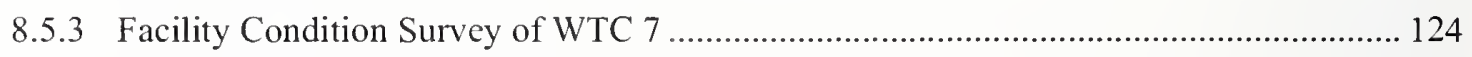

8.5.4 Due Diligence Condition Survey of WTC 1 and WTC 2 …...................................... 124

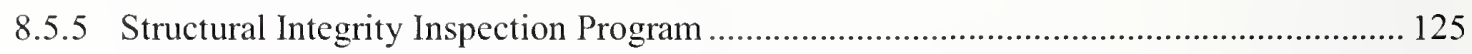

8.5.6 Summary of Structural Integrity Inspection Programs ............................................... 133

8.5.7 Modifications and Repairs to Structural Framing Systems of WTC 1, 2, and 7 ............ 133

\section{Chapter 9}

Comparison of Fire Safety Codes and Practices ............................................................141

9.1 Comparison of Fire Provisions in Building Codes ................................................................ 141

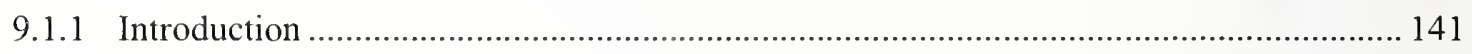

9.1.2 Interrelation of Codes, Standards, and Practices .................................................... 142

9.1.3 Comparison of New York City and Contemporary Building Codes ............................. 142

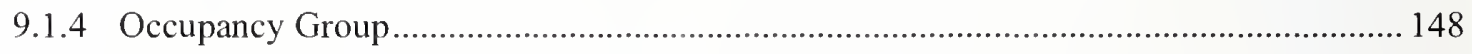

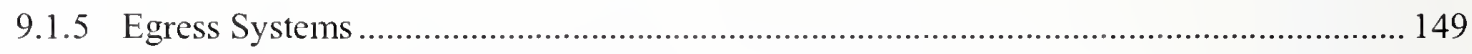

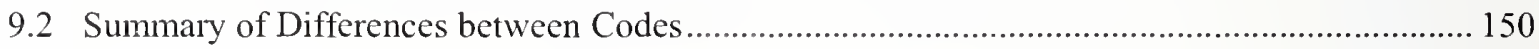

\section{Chapter 10}

Influence of Codes and Standards on the Design and Construction of WTC 1 and WTC 2

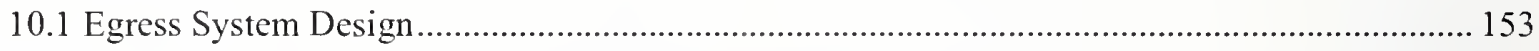

10.1.1 Egress Provisions from Windows on the World ................................................... 154

10.1.2 Egress Provisions from Top of the World ................................................................ 158

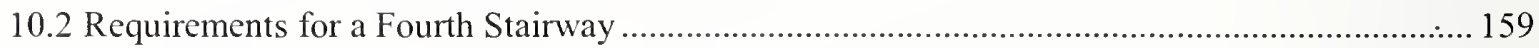

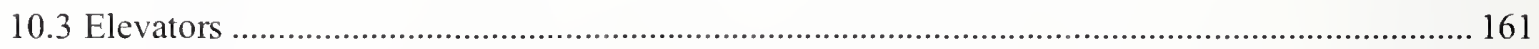

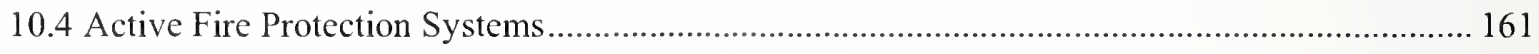

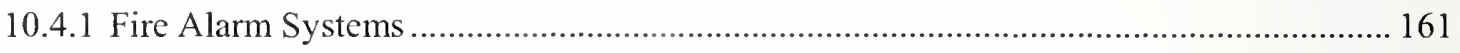

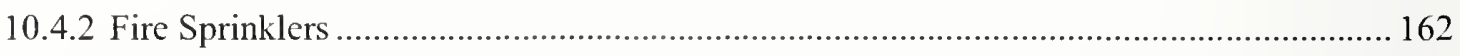

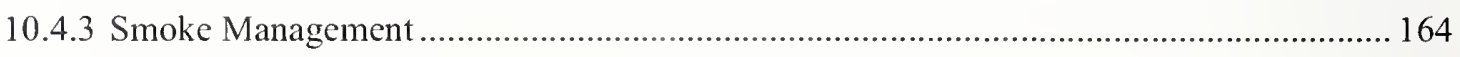


10.5 Design and Construction of Fire Safety and Egress Systems .............................................. 164

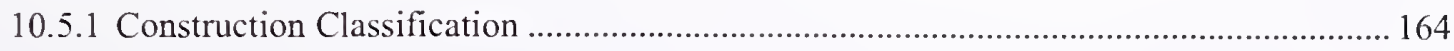

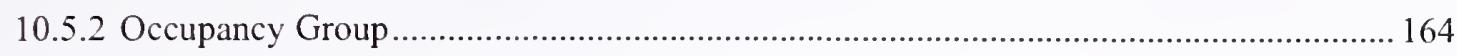

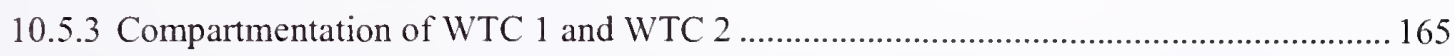

10.5.4 Construction of Partitions and Shaft Enclosures ..................................................... 166

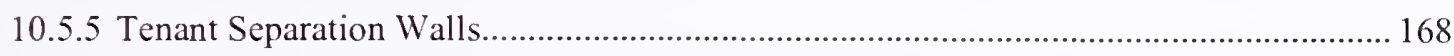

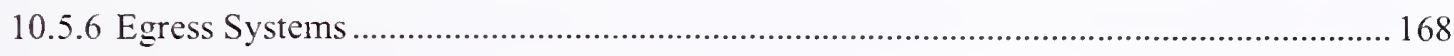

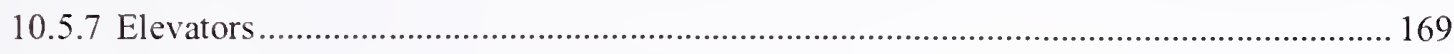

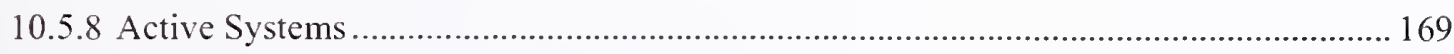

\section{Chapter 11}

Maintenance and Modifications to Fire Safety Systems ..............................................171

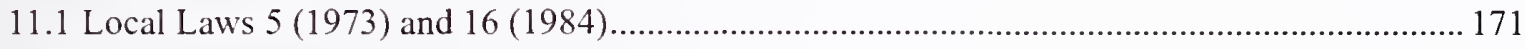

11.2 Code Compliance Summary Following the 1993 Bombing ................................................ 172

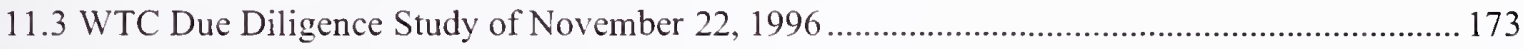

\section{Chapter 12}

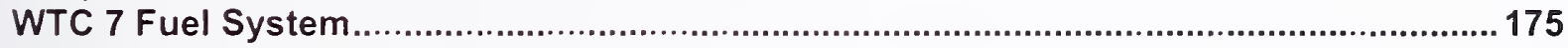

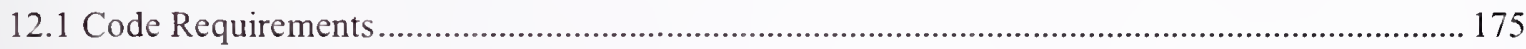

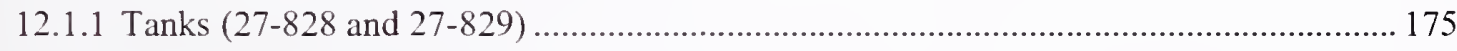

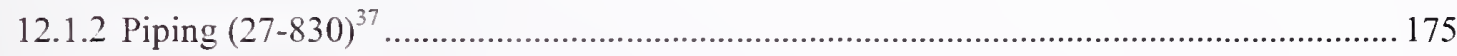

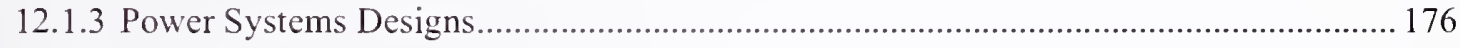

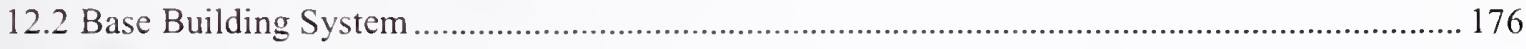

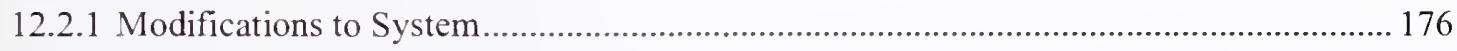

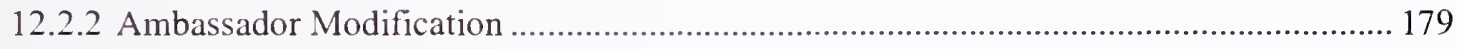

12.2.3 American Express Modification ............................................................................ 179

12.2.4 Mayor`s Office of Emergency Management (OEM) Modification............................... 179

12.2.5 Salomon Brothers Emergency Power System ............................................................ 179

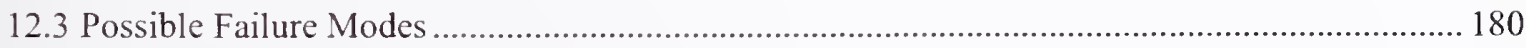

\section{Chapter 13}

Findings

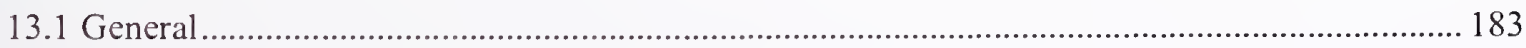

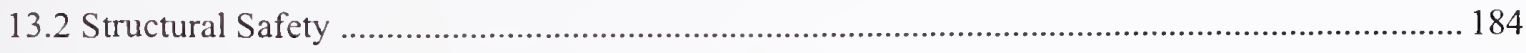

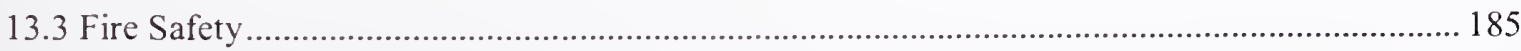


Chapter 14

References.

Appendix A

Supporting Documents for Chapter 1

Appendix B

Supporting Documents for Chapters 2 and 3

207 


\section{LIST OF FIGURES}

Figure $\mathrm{P}-1$. The eight projects in the federal building and fire safety investigation of the WTC disaster. $\mathrm{XXV}$

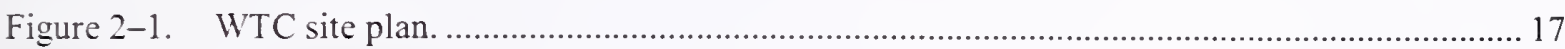

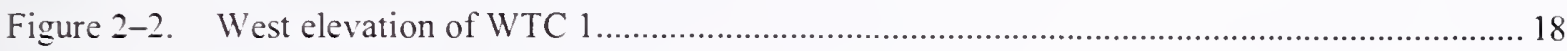

Figure 2-3. Elevation of exterior wall from foundation to floor 9............................................... 19

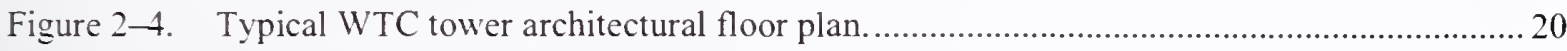

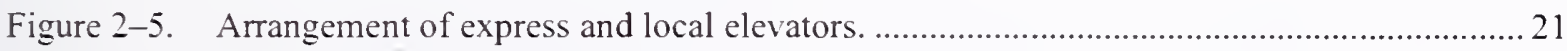

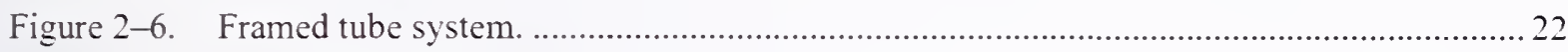

Figure 2-7. Cross section of perimeter columns...................................................................... 23

Figure 2-8. Typical WTC tower exterior wall tree panel.............................................................2 24

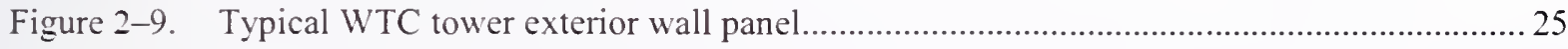

Figure 2-10. Elevation of exterior wall frame illustrating staggered panel construction........................26

Figure 2-11. Typical welded box members and rolled shapes between floor 83 and floor $86 \ldots \ldots \ldots \ldots . . . . .26$

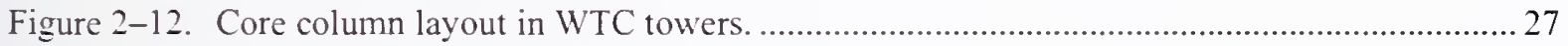

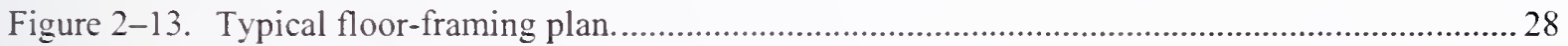

Figure 2-14. Prefabricated floor panel used in WTC 1 and WTC 2 ...........................................29

Figure 2-15. Typical WTC floor truss framing zone..................................................................... 30

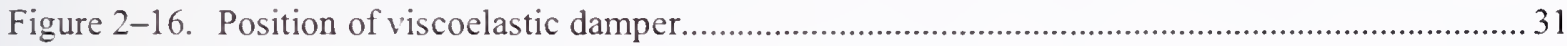

Figure 2-17. Perimeter column wall panel and steel truss floor modules............................................ 32

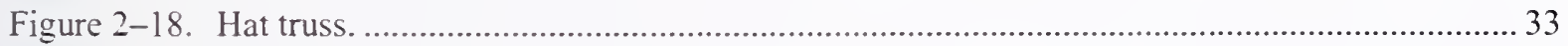

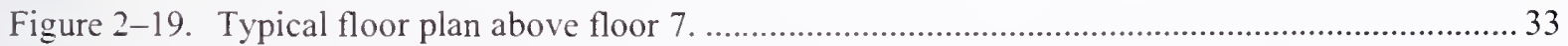

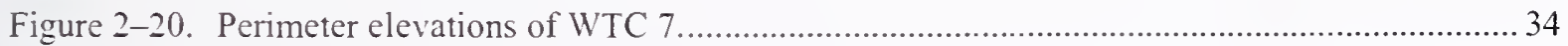

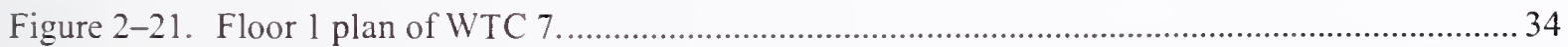

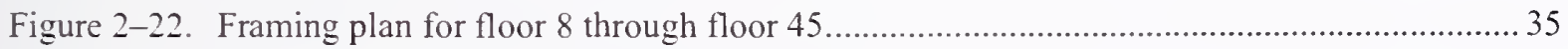

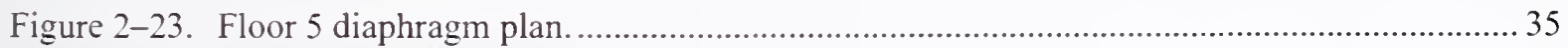

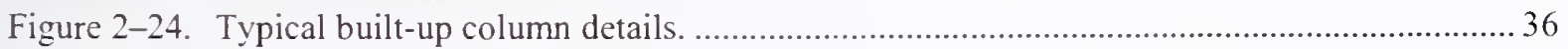

Figure 2-25. Schematic view of transfer trusses and girders between floors 5 and $7 \ldots \ldots \ldots \ldots \ldots \ldots \ldots \ldots \ldots . . . . . . . . . . .36$

Figure 4-1. Reduced live load as a function of floor location based on the percentage method (for

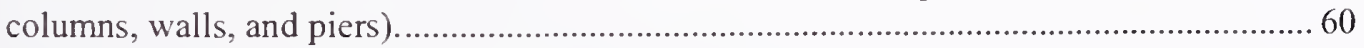

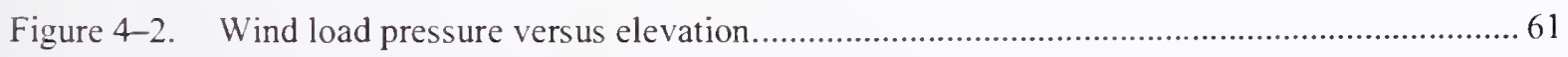


Figure 5-1. Design dead load criteria for WTC 1 and WTC 2: floor inside of core.......................... 74

Figure 5-2. Design partition load criteria for WTC 1 and WTC 2: floor inside of core.......................75

Figure 5-3. Design dead load criteria for WTC 1 and WTC 2: floor outside of core.......................... 76

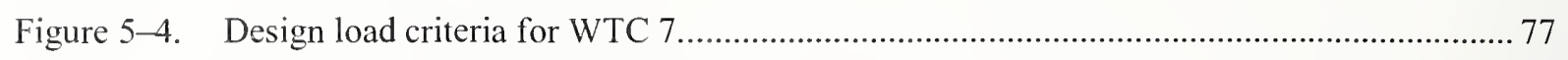

Figure 5-5. Design live-load criteria for WTC 1 and WTC 2: floor inside of core.............................. 78

Figure 5-6. Design live-load criteria for WTC 1 and WTC 2: floor inside of core............................ 79

Figure 5-7. Design live-load criteria for WTC 1 and WTC 2: column inside of core..........................80

Figure 5-8. Design live-load criteria for WTC 1 and WTC 2: floor outside of core.......................... 81

Figure 5-9. Design live-load criteria for WTC 1 and WTC 2: column outside of core....................... 82

Figure 5-10. Live-load reduction criteria for WTC 1 and WTC 2 ................................................ 83

Figure 5-11. Live-load reduction criteria for floors inside of core, except for tenant areas. ..................84

Figure 5-12. Live-load reduction criteria for floors inside of core, tenant areas. ................................. 85

Figure 5-13. Live-load reduction criteria for floors outside of core ................................................. 86

Figure 6-1. Wide-flange beam member with Type B damping unit................................................ 94

Figure 6-2. Wind directions that produced the greatest displacements at the top of the tower

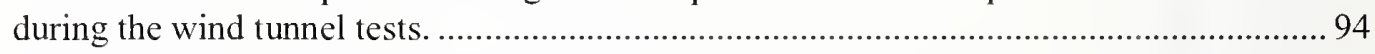

Figure 6-3. Definition of grid system and tower configurations for wind tunnel tests at Colorado State University. .95

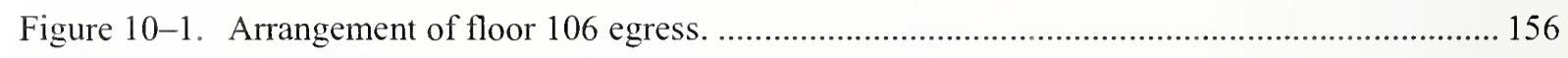

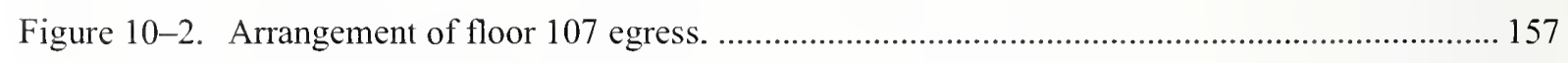

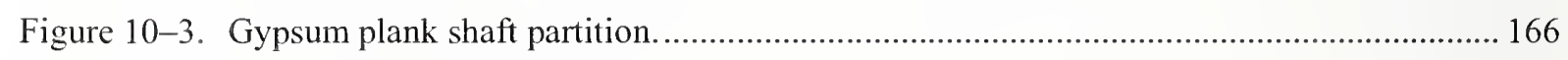

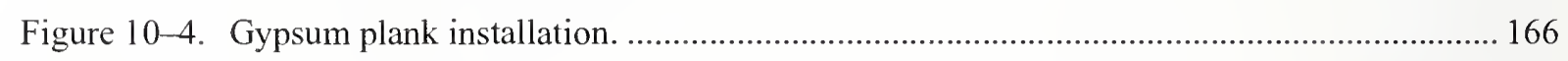

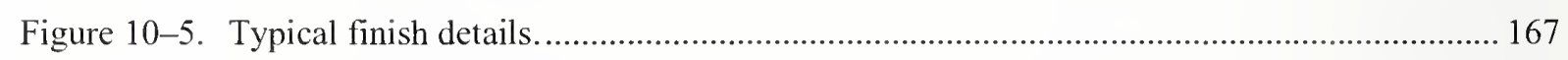

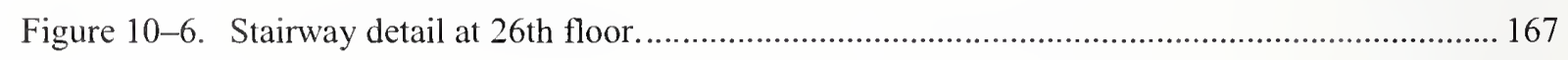

Figure 12-1. Section plan showing the final locations of the fuel oil distribution components. ........... 178 


\section{LIST OF TABLES}

Table P-1. Federal building and fire safety investigation of the WTC disaster...............................xxiv

Table P-2. Public meetings and briefings of the WTC Investigation. xxvii

Table 4-1. Examples of dead loads given in NYC Building Code and BOCA Code 45

Table 4-2. Comparison of uniform live load values. Examples of minimum uniformly distributed live loads. 46

Table 4-3. Reduced live load for beams and girders. 48

Table 4-4. Base shears and overturning moments from reviewed codes for a building the height of WTC towers $(1,368 \mathrm{ft})$. 48

Table 4-5. Design standards for concrete and steel. .53

Table 4-6. Compliance requirements for alterations. .55

Table 4-7. Excerpts of inspection requirements for materials and assemblies in Article 10 of 1968 NYC Building Code.

Table 4-8. Excerpts of inspection requirements for methods of construction in Article 10 of 1968 NYC Building Code.

Table 5-1. Live loads used in design of WTC 1 and WTC 2.

Table 5-2. Percentage of live load per the 1968 NYC Building Code.

Table 5-3. Base shears and overturning moments based on the 1968 NYC Building Code and wind tunnel tests.

Table 8-1. Summary of Structural Integrity Inspections Completed for WTC 1 and WTC 2........... 127

Table 8-2. Measured first mode natural frequencies for WTC 1 ................................................ 131

Table 8-3. Summary of natural frequency test results for floors of WTC 1, March 1971............... 132

Table 8-4. Summary of natural frequency test results for floors of WTC 1 and WTC 2, March 1995.

Table 12-1. Summary of modifications to base emergency power system in WTC 7. 
This page intentionally left blank. 


\section{LIST OF ACRONYMS AND ABBREVIATIONS}

\section{Acronyms}

$3 \mathrm{M}$

Minnesota Mining and Manufacturing Company

$\mathrm{ACI}$

American Concrete Institute

AIA

American Institute of Architects

AISC

American Institute of Steel Construction

ASME

American Society of Mechanical Engineers

ASTM

ASTM International

$\mathrm{AWCI}$

Association of Wall and Ceiling Industries

AWS

American Welding Society

$\mathrm{BBC}$

Basic Building Code

BOCA

Building Officials and Code Administrators International

$\mathrm{CMU}$

concrete masonry unit

Con Edison

Consolidated Edison

CSU

Colorado State University

FDNY

New York City Fire Department

FSES

Fire Safety Equivalency Systems

GA

Gypsum Association

HVAC

heating, ventilating, and air conditioning

IBC

International Building Code

$\mathrm{JB} \& \mathrm{~B}$

Jaros, Baum \& Bolles

KKE

Karl Koch Erecting Company

LERA

Leslie E. Robertson Associates

LL

Local Law

MER

Mechanical Equipment Room

MCC

Municipal Code of Chicago

MIT

Massachusetts Institute of Technology

NBC

National Building Code

NFPA

National Fire Protection Association

NIST

National Institute of Standards and Technology 
NPL National Physical Laboratory

NYC New York City

OEM Office of Emergency Management

PANYNJ Polt Authority of New York and New Jersey

PCF Pacific Car \& Foundry Co.

PDM Pittsburgh-Des Moines Steel Company

P.L. Public Law

PONYA Port of New York Authority (in 1972 PONYA changed to PANYNJ)

RJA Rolf Jensen \& Associates

RS Reference Standard

SBCCI Southern Building Code Congress International, Inc., published Southern Standard Building Code

SFRM sprayed fire-resistive material

SHCR Skilling, Helle, Christiansen, \& Robertson (structural engineers)

SII Structural Integrity Inspection

SSPC Steel Structures Painting Council

TRCC Tishman Realty \& Construction Company

UBC Uniform Building Code

UL Underwriters' Laboratories, Inc.

USC United States Code

WSHJ Worthington, Skilling, Helle \& Jackson

WTC World Trade Center

WTC $1 \quad$ World Trade Center 1 (North Tower)

WTC 2 World Trade Center 2 (South Tower)

WTC $7 \quad$ World Trade Center 7

\section{Abbreviations}

$\begin{array}{ll}{ }^{\circ} \mathrm{C} & \text { degrees Celsius } \\ { }^{\circ} \mathrm{F} & \text { degrees Fahrenheit } \\ \mathrm{cfm} & \text { cubic foot per minute } \\ \mathrm{cps} & \text { cycles per second } \\ F_{y} & \text { yield strength of steel } \\ \mathrm{ft} & \text { foot }\end{array}$




$\begin{array}{ll}\mathrm{ft}^{2} & \text { square foot } \\ \text { gal } & \text { gallon } \\ \text { gph } & \text { gallons per hour } \\ \text { in. } & \text { inch } \\ \text { in. }^{2} & \text { square inch } \\ \mathrm{kip} & \text { a force equal to 1,000 pounds } \\ \mathrm{ksi} & 1,000 \text { pounds per square inch } \\ \mathrm{kW} & \text { kilowatt } \\ \mathrm{L} & \text { liter } \\ \mathrm{lb} & \text { pound } \\ \mathrm{m} & \text { meter } \\ \mu \mathrm{m} & \text { micrometer } \\ \mathrm{min} & \text { minute } \\ \mathrm{mph} & \text { miles per hour } \\ \mathrm{pcf} & \text { pounds per cubic foot } \\ \mathrm{plf} & \text { pounds per linear foot } \\ \mathrm{psf} & \text { pounds per square foot } \\ \mathrm{psi} & \text { pounds-force per square inch } \\ \mathrm{s} & \text { second } \\ & \end{array}$


This page intentionally left blank. 


\section{Metric Conversion TABLE}

To convert from

to

Multiply by

AREA AND SECOND MONENT OF AREA

square foot $\left(\mathrm{ft}^{2}\right)$

square meter $\left(\mathrm{m}^{2}\right)$

square inch (in. $\left.{ }^{2}\right)$

square inch (in. ${ }^{2}$ )

square yard $\left(\mathrm{yd}^{2}\right)$

\section{ENERGY (includes WORK)}

kilowatt hour $(\mathrm{kW} \cdot \mathrm{h})$

quad (1015 BtuIT)

therm (U.S.)

ton of TNT (energy equivalent)

watt hour $(\mathrm{W} \cdot \mathrm{h})$

watt second $(W \cdot s)$

\section{FORCE}

dyne (dyn)

kilogram-force $(\mathrm{kgf})$

kilopond (kilogram-force) (kp)

kip ( 1 kip $=1,000 \mathrm{lb}$ )

kip ( $1 \mathrm{kip}=1,000 \mathrm{lbf}$ )

pound-force (lbf)

\section{FORCE DIVIDED BY LENGTH}

pound-force per foot (lbf/ft)

pound-force per inch (lbf/in.)

\section{HEAT FLOW RATE}

calorieth per minute (calth/min)

calorieth per second (calth/s)

kilocalorieth per minute (kcalth/min)

kilocalorieth per second (kcalth/s) square meter $\left(\mathrm{m}^{2}\right)$

square centimeter $\left(\mathrm{cm}^{2}\right)$

square meter $\left(\mathrm{m}^{2}\right)$

joule $(J)$

joule $(J)$

joule (J)

joule $(\mathrm{J})$

joule (J)

joule (J)

newton $(\mathrm{N})$

newton $(\mathrm{N})$

newton $(\mathrm{N})$

newton $(\mathrm{N})$

kilonewton $(\mathrm{kN})$

newton $(\mathrm{N})$

newton per meter $(\mathrm{N} / \mathrm{m})$

newton per meter $(\mathrm{N} / \mathrm{m})$

watt (W)

watt (W)

watt (W)

watt (W)
1.0 E-05

$1.459390 \mathrm{E}+01$

$1.751268 \mathrm{E}+02$

9.290304 E-02

6.4516 E-04

$6.4516 \mathrm{E}+00$

$8.361274 \mathrm{E}-01$

$3.6 \mathrm{E}+06$

$1.055056 \mathrm{E}+18$

$1.054804 \mathrm{E}+08$

$4.184 \mathrm{E}+09$

$3.6 \mathrm{E}+03$

$1.0 \mathrm{E}+00$

$9.80665 \mathrm{E}+00$

$9.80665 \mathrm{E}+00$

$4.448222 \mathrm{E}+03$

$4.448222 \mathrm{E}+00$

$4.448222 \mathrm{E}+00$

6.973333 E-02

$4.184 \mathrm{E}+00$

$6.973333 \mathrm{E}+01$

4. $184 \mathrm{E}+03$ 
To convert from

\section{LENGTH}

foot ( $f t)$

inch (in)

inch (in.)

micron (m)

$y \operatorname{ard}(\mathrm{yd})$

\section{MASS and MOMENT OF INERTIA}

kilogram-force second squared per meter $\left(\mathrm{kgf} \cdot \mathrm{s}^{2} / \mathrm{m}\right)$

pound foot squared $\left(\mathrm{lb} \cdot \mathrm{ft}^{2}\right)$

pound inch squared $\left(\mathrm{lb} \cdot\right.$ in. $\left.^{2}\right)$

ton, metric (t)

ton, short $(2,000 \mathrm{lb})$

\section{MASS DIVIDED BY AREA}

pound per square foot $\left(\mathrm{lb} / \mathrm{ft}^{2}\right)$

pound per square inch

(not pound force) $\left(1 \mathrm{~b} / \mathrm{in}^{2}\right.$ )

\section{MASS DIVIDED BY LENGTH}

pound per foot $(\mathrm{lb} / \mathrm{ft})$

pound per inch (lb/in.)

pound per yard (lb/yd) to

Multiply by

meter (m)

3.048 E-0 1

meter $(\mathrm{m})$

$2.54 \mathrm{E}-02$

centimeter $(\mathrm{cm})$

$2.54 \mathrm{E}+00$

meter $(\mathrm{m})$

$1.0 \mathrm{E}-06$

meter $(\mathrm{m})$

$9.144 \mathrm{E}-01$ kilogram $(\mathrm{kg})$

kilogram meter squared $\left(\mathrm{kg} \cdot \mathrm{m}^{2}\right)$

kilogram meter squared $\left(\mathrm{kg} \cdot \mathrm{m}^{2}\right)$

kilogram $(\mathrm{kg})$

kilogram ( $\mathrm{kg})$

kilogram per square meter $\left(\mathrm{kg} / \mathrm{m}^{2}\right)$

kilogram per square meter $\left(\mathrm{kg} / \mathrm{m}^{2}\right)$
$9.80665 \mathrm{E}+00$

$4.214011 \mathrm{E}-02$

2.926397 E-04

$1.0 \mathrm{E}+03$

$9.071847 \mathrm{E}+02$

$4.882428 \mathrm{E}+00$

$7.030696 \mathrm{E}+02$

$1.488164 \mathrm{E}+00$

$1.785797 \mathrm{E}+01$

$4.960546 \mathrm{E}-01$ kilogram per meter $(\mathrm{kg} / \mathrm{m})$

kilogram per meter $(\mathrm{kg} / \mathrm{m})$

kilogram per meter $(\mathrm{kg} / \mathrm{m})$

\section{PRESSURE or STRESS (FORCE DIVIDED BY AREA)}

$\begin{array}{lll}\text { kilogram-force per square centimeter }\left(\mathrm{kgf} / \mathrm{cm}^{2}\right) & \text { pascal }(\mathrm{Pa}) & 9.80665 \mathrm{E}+04 \\ \text { kilogram-force per square meter }\left(\mathrm{kgf} / \mathrm{m}^{2}\right) & \text { pascal }(\mathrm{Pa}) & 9.80665 \mathrm{E}+00 \\ \text { kilogram-force per square millimeter }\left(\mathrm{kgf} / \mathrm{mm}^{2}\right) & \text { pascal }(\mathrm{Pa}) & 9.80665 \mathrm{E}+06 \\ \text { kip per square inch }(\mathrm{ksi})\left(\mathrm{kip} / \mathrm{in.}^{2}\right) & \text { pascal }(\mathrm{Pa}) & 6.894757 \mathrm{E}+06 \\ \text { kip per square inch }(\mathrm{ksi})\left(\mathrm{kip} / \mathrm{in.}^{2}\right) & \text { kilopascal }(\mathrm{kPa}) & 6.894757 \mathrm{E}+03 \\ \text { pound-force per square foot }\left(\mathrm{lbf} / \mathrm{ft}^{2}\right) & \text { pascal }(\mathrm{Pa}) & 4.788026 \mathrm{E}+01 \\ \text { pound-force per square inch }(\mathrm{psi})\left(\mathrm{lbf} / \mathrm{in}^{2}{ }^{2}\right) & \text { pascal }(\mathrm{Pa}) & 6.894757 \mathrm{E}+03 \\ \text { pound-force per square inch }(\mathrm{psi})\left(\mathrm{lbf} / \mathrm{in}^{2}{ }^{2}\right) & \text { kilopascal }(\mathrm{kPa}) & 6.894757 \mathrm{E}+00 \\ \text { psi (pound-force per square inch) }\left(\mathrm{lbf} / \mathrm{in}^{2}{ }^{2}\right) & \text { pascal }(\mathrm{Pa}) & 6.894757 \mathrm{E}+03 \\ \text { psi (pound-force per square inch) }\left(\mathrm{lbf} / \mathrm{in} .{ }^{2}\right) & \text { kilopascal }(\mathrm{kPa}) & 6.894757 \mathrm{E}+00\end{array}$




\section{To convert from}

\section{TEMPERATURE}

degree Celsius $\left({ }^{\circ} \mathrm{C}\right)$

degree centigrade

degree Fahrenheit $\left({ }^{\circ} \mathrm{F}\right)$

degree Fahrenheit $\left({ }^{\circ} \mathrm{F}\right)$

kelvin $(\mathrm{K})$

\section{TEMPERATURE INTERVAL}

degree Celsius $\left({ }^{\circ} \mathrm{C}\right)$

degree centigrade

degree Fahrenheit $\left({ }^{\circ} \mathrm{F}\right)$

degree Fahrenheit ( $\left.{ }^{\circ} \mathrm{F}\right)$

degree Rankine $\left({ }^{\circ} \mathrm{R}\right)$

\section{V'ELOCITY (includes SPEED)}

foot per second (ft/s)

inch per second (in./s)

kilometer per hour $(\mathrm{km} / \mathrm{h})$

mile per hour $(\mathrm{mi} / \mathrm{h})$

mile per minute $(\mathrm{mi} / \mathrm{min})$

\section{YOLUME (includes CAPACITY')}

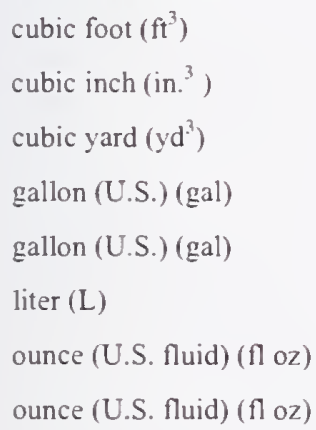

\section{Multiply by}

kelvin $(\mathrm{K})$

degree Celsius $\left({ }^{\circ} \mathrm{C}\right)$

degree Celsius $\left({ }^{\circ} \mathrm{C}\right)$

kelvin $(\mathrm{K})$

degree Celsius $\left({ }^{\circ} \mathrm{C}\right)$

$\mathrm{T} / \mathrm{K}=\mathrm{t} /{ }^{\circ} \mathrm{C}+273.15$

$\mathrm{t} /{ }^{\circ} \mathrm{C} \approx \mathrm{t} / \mathrm{deg}$. cent.

$\mathrm{t}^{\circ} \mathrm{C}=\left(\mathrm{t} /{ }^{\circ} \mathrm{F}-32\right) / 1.8$

$\mathrm{T} / \mathrm{K}=\left(\mathrm{U}^{\circ} \mathrm{F}+459.67\right) / 1.8$

$\mathrm{t} /{ }^{\circ} \mathrm{C}=\mathrm{T} / \mathrm{K} 2273.15$

$\begin{array}{ll}\text { kelvin }(\mathrm{K}) & 1.0 \mathrm{E}+00 \\ \text { degree Celsius }\left({ }^{\circ} \mathrm{C}\right) & 1.0 \mathrm{E}+00 \\ \text { degree Celsius }\left({ }^{\circ} \mathrm{C}\right) & 5.555556 \mathrm{E}-01 \\ \text { kelvin }(\mathrm{K}) & 5.555556 \mathrm{E}-01 \\ \text { kelvin }(\mathrm{K}) & 5.555556 \mathrm{E}-01\end{array}$

meter per second $(\mathrm{m} / \mathrm{s})$

$3.048 \mathrm{E}-01$

meter per second $(\mathrm{m} / \mathrm{s})$

meter per second $(\mathrm{m} / \mathrm{s})$

kilometer per hour $(\mathrm{km} / \mathrm{h})$

meter per second $(\mathrm{m} / \mathrm{s})$

$2.54 \mathrm{E}-02$

$2.777778 \mathrm{E}-01$

$1.609344 \mathrm{E}+00$

$2.68224 \mathrm{E}+01$

2.831685 E-02

$1.638706 \mathrm{E}-05$

$7.645549 \mathrm{E}-01$

3.785412 E-03

$3.785412 \mathrm{E}+00$

$1.0 \mathrm{E}-03$

$2.957353 \mathrm{E}-05$

$2.957353 \mathrm{E}+01$ 
This page intentionally left blank. 


\section{PREFACE}

\section{Genesis of This Investigation}

Immediately following the terrorist attack on the World Trade Center (WTC) on September 11, 2001, the Federal Emergency Management Agency (FEMA) and the American Society of Civil Engineers began planning a building performance study of the disaster. The week of October 7, as soon as the rescue and search efforts ceased, the Building Performance Study Team went to the site and began its assessment. This was to be a brief effort, as the study team consisted of experts who largely volunteered their time away from their other professional commitments. The Building Performance Study Team issued its report in May 2002, fulfilling its goal "to determine probable failure mechanisms and to identify areas of future investigation that could lead to practical measures for improving the damage resistance of buildings against such unforeseen events."

On August 21, 2002, with funding from the U.S. Congress through FEMA, the National Institute of Standards and Technology (NIST) announced its building and fire safety investigation of the WTC disaster. On October 1, 2002, the National Construction Safety Team Act (Public Law 107-231), was signed into law. The NIST WTC Investigation was conducted under the authority of the National Construction Safety Team Act.

The goals of the investigation of the WTC disaster were:

- To investigate the building construction, the materials used, and the technical conditions that contributed to the outcome of the WTC disaster.

- To serve as the basis for:

- Improvements in the way buildings are designed, constructed, maintained, and used;

- Improved tools and guidance for industry and safety officials;

- Recommended revisions to current codes, standards, and practices; and

- Improved public safety.

The specific objectives were:

1. Determine why and how WTC 1 and WTC 2 collapsed following the initial impacts of the aircraft and why and how WTC 7 collapsed;

2. Determine why the injuries and fatalities were so high or low depending on location, including all technical aspects of fire protection, occupant behavior, evacuation, and emergency response;

3. Determine what procedures and practices were used in the design, construction, operation, and maintenance of WTC 1, 2, and 7; and

4. Identify, as specifically as possible, areas in current building and fire codes, standards, and practices that warrant revision. 
NIST is a nonregulatory agency of the U.S. Department of Commerce's Technology Administration. The purpose of NIST investigations is to improve the safety and structural integrity of buildings in the United States, and the focus is on fact finding. NIST investigative teams are authorized to assess building performance and emergency response and evacuation procedures in the wake of any building failure that has resulted in substantial loss of life or that posed significant potential of substantial loss of life. NIST does not have the statutory authority to make findings of fault nor negligence by individuals or organizations. Further, no part of any report resulting from a NIST investigation into a building failure or from an investigation under the National Construction Safety Team Act may be used in any suit or action for damages arising out of any matter mentioned in such report (15 USC 281 a, as amended by Public Law 107-231).

\section{Organization of the Investigation}

The National Construction Safety Team for this Investigation, appointed by the then NIST Director, Dr. Arden L. Bement, Jr., was led by Dr. S. Shyam Sunder. Dr. William L. Grosshandler served as Associate Lead Investigator, Mr. Stephen A. Cauffman served as Program Manager for Administration, and Mr. Harold E. Nelson served on the team as a private sector expert. The Investigation included eight interdependent projects whose leaders comprised the remainder of the team. A detailed description of each of these eight projects is available at http:/wtc.nist.gov. The purpose of each project is summarized in Table $\mathrm{P}-1$, and the key interdependencies among the projects are illustrated in Fig. $\mathrm{P}-1$.

Table P-1. Federal building and fire safety investigation of the WTC disaster.

Technical Area and Project Leader

Analysis of Building and Fire Codes and Practices; Project Leaders: Dr. H. S. Lew and Mr. Richard W. Bukowski

Baseline Structural Performance and Aircraft Impact Damage Analysis; Project Leader: Dr. Fahim H. Sadek

Mechanical and Metallurgical Analysis of Structural Steel; Project Leader: Dr. Frank W. Gayle

Investigation of Active Fire Protection Systems; Project Leader: Dr. David D. Evans; Dr. William Grosshandler Reconstruction of Thermal and Tenability Environment; Project Leader: Dr. Richard G. Gann

Structural Fire Response and Collapse Analysis; Project Leaders: Dr. John

L. Gross and Dr. Therese P. McAllister

Occupant Behavior, Egress, and Emergency Communications; Project Leader: Mr. Jason D. Averill

Emergency Response Technologies and Guidelines; Project Leader: Mr. J. Randall Lawson

Project Purpose

Document and analyze the code provisions, procedures, and practices used in the design, construction, operation, and maintenance of the structural, passive fire protection, and emergency access and evacuation systems of WTC 1,2, and 7. Analyze the baseline performance of WTC 1 and WTC 2 under design, service, and abnormal loads, and aircraft impact damage on the structural, fire protection, and egress systems.

Determine and analyze the mechanical and metallurgical properties and quality of steel, weldments, and connections from steel recovered from WTC 1, 2, and 7.

Investigate the performance of the active fire protection systems in WTC 1, 2, and 7 and their role in fire control, emergency response, and fate of occupants and responders.

Reconstruct the time-evolving temperature, thermal environment, and smoke movement in WTC 1,2, and 7 for use in evaluating the structural performance of the buildings and behavior and fate of occupants and responders.

Analyze the response of the WTC towers to fires with and without aircraft damage, the response of WTC 7 in fires, the performance of composite steel-trussed floor systems, and determine the most probable structural collapse sequence for WTC 1, 2, and 7.

Analyze the behavior and fate of occupants and responders, both those who survived and those who did not, and the performance of the evacuation system.

Document the activities of the emergency responders from the time of the terrorist attacks on WTC 1 and WTC 2 until the collapse of WTC 7, including practices followed and technologies used. 


\section{NIST WTC Investigation Projects}

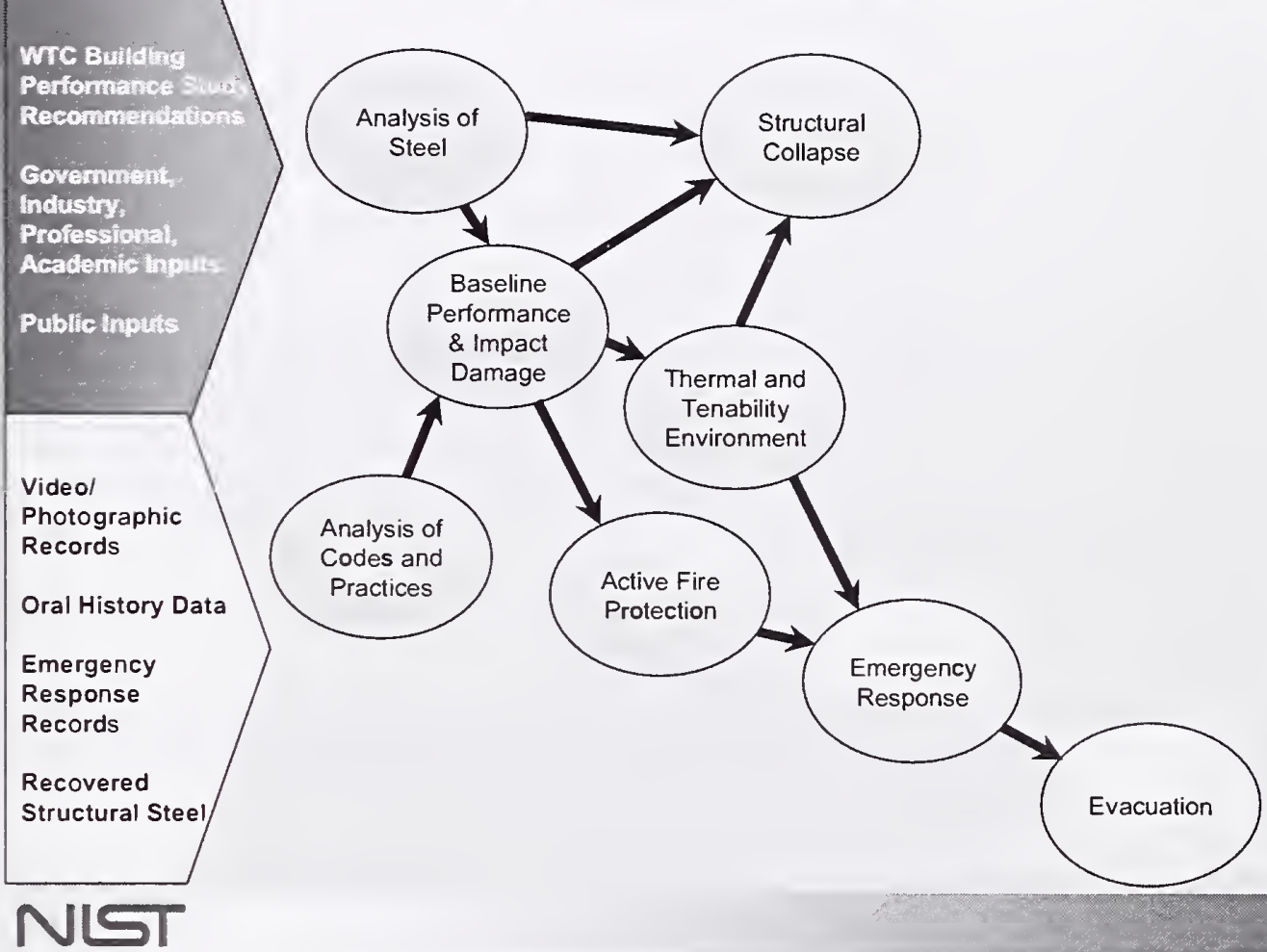

Figure P-1. The eight projects in the federal building and fire safety investigation of the WTC disaster.

\section{National Construction Safety Team Advisory Committee}

The NIST Director also establishcd an advisory committee as mandated under the National Construction Safety Team Act. The initial members of the committee were appointed following a public solicitation. These were:

- Paul Fitzgerald, Executive Vice President (retired) FM Global, National Construction Safety Team Advisory Committee Chair

- John Barsom, President, Barsom Consulting, Ltd.

- John Bryan, Professor Emeritus, University of Maryland

- David Collins, President, The Preview Group, Inc.

- Glenn Corbett, Professor, John Jay College of Criminal Justice

- Philip DiNenno, President, Hughes Associates, Inc. 
- Robert Hanson, Professor Emeritus, University of Michigan

- Charles Thornton, Co-Chairman and Managing Principal, The Thornton-Tomasetti Group, Inc.

- Kathleen Tierney, Director, Natural Hazards Research and Applications Information Center, University of Colorado at Boulder

- Forman Williams, Director, Center for Energy Research, University of California at San Diego

This National Construction Safety Team Advisory Committee provided technical advice during the Investigation and commentary on drafts of the Investigation reports prior to their public release. NIST has benefited from the work of many people in the preparation of these reports, including the National Construction Safety Team Advisory Committee. The content of the reports and recommendations, however, are solely the responsibility of NIST.

\section{Public Outreach}

During the course of this Investigation, NIST held public briefings and meetings (listed in Table P-2) to solicit input from the public, present preliminary findings, and obtain comments on the direction and progress of the Investigation from the public and the Advisory Committee.

NIST maintained a publicly accessible Web site during this Investigation at http://wtc.nist.gov. The site contained extensive information on the background and progress of the Investigation.

\section{NIST's WTC Public-Private Response Plan}

The collapse of the WTC buildings has led to broad reexamination of how tall buildings are designed, constructed, maintained, and used, especially with regard to major events such as fires, natural disasters, and terrorist attacks. Reflecting the enhanced interest in effecting necessary change, NIST, with support from Congress and the Administration, has put in place a program, the goal of which is to develop and implement the standards, technology, and practices needed for cost-effective improvements to the safety and security of buildings and building occupants, including evacuation, emergency response procedures, and threat mitigation.

The strategy to meet this goal is a three-part NIST-led public-private response program that includes:

- A federal building and fire safety investigation to study the most probable factors that contributed to post-aircraft impact collapse of the WTC towers and the 47-story WTC 7 building, and the associated evacuation and emergency response experience.

- A research and development (R\&D) program to (a) facilitate the implementation of recommendations resulting from the WTC Investigation, and (b) provide the technical basis for cost-effective improvements to national building and fire codes, standards, and practices that enhance the safety of buildings, their occupants, and emergency responders. 
Table P-2. Public meetings and briefings of the WTC Investigation.

\begin{tabular}{|c|c|c|}
\hline Date & Location & Principal Agenda \\
\hline June 24,2002 & New York City, NY & $\begin{array}{l}\text { Public meeting: Public comments on the Draft Plan for the } \\
\text { pending WTC lnvestigation. }\end{array}$ \\
\hline August 21,2002 & Gaithersburg. MD & Media briefing announcing the formal start of the Investigation. \\
\hline December 9.2002 & Washington, DC & $\begin{array}{l}\text { Media briefing on release of the Public Update and NIST request } \\
\text { for photographs and videos. }\end{array}$ \\
\hline April 8, 2003 & New York City, NY & $\begin{array}{l}\text { Joint public forum with Columbia University on first-person } \\
\text { interviews. }\end{array}$ \\
\hline April 29-30.2003 & Gaithersburg, MD & $\begin{array}{l}\text { NCST Advisory Committee meeting on plan for and progress on } \\
\text { WTC Investigation with a public comment session. }\end{array}$ \\
\hline May 7,2003 & New York City, NY & Media briefing on release of May 2003 Progress Report. \\
\hline August $26-27,2003$ & Gaithersburg, MD & $\begin{array}{l}\text { NCST Advisory Committee meeting on status of the WTC } \\
\text { investigation with a public comment session. }\end{array}$ \\
\hline September 17, 2003 & New York City, NY & $\begin{array}{l}\text { Media and public briefing on initiation of first-person data } \\
\text { collection projects. }\end{array}$ \\
\hline December 2-3, 2003 & Gaithersburg. MD & $\begin{array}{l}\text { NCST Advisory Committee meeting on status and initial results } \\
\text { and release of the Public Update with a public comment session. }\end{array}$ \\
\hline February 12, 2004 & New York City. NY & $\begin{array}{l}\text { Public meeting on progress and preliminary findings with public } \\
\text { comments on issues to be considered in formulating final } \\
\text { recommendations. }\end{array}$ \\
\hline June 18,2004 & New York City, NY & Media/public briefing on release of Jlme 2004 Progress Report. \\
\hline June 22-23. 2004 & Gaithersburg, MD & $\begin{array}{l}\text { NCST Advisory Committee meeting on the status of and } \\
\text { preliminary findings from the WTC Investigation with a public } \\
\text { comment session. }\end{array}$ \\
\hline August 24.2004 & Northbrook, 1L & $\begin{array}{l}\text { Public viewing of standard fire resistance test of WTC floor } \\
\text { system at Underwriters Laboratories, lnc. }\end{array}$ \\
\hline October 19-20,2004 & Gaithersburg, MD & $\begin{array}{l}\text { NCST Advisory Committee meeting on status and near complete } \\
\text { set of preliminary findings with a public comment session. }\end{array}$ \\
\hline November 22, 2004 & Gaithersburg, MD & $\begin{array}{l}\text { NCST Advisory Committee discussion on draft annual report to } \\
\text { Congress, a public comment session, and a closed session to } \\
\text { discuss pre-draft recommendations for WTC Investigation. }\end{array}$ \\
\hline April 5, 2005 & New York City, NY & $\begin{array}{l}\text { Media and public briefing on release of the probable collapse } \\
\text { sequence for the WTC towers and draft reports for the projects on } \\
\text { codes and practices, evacuation, and emergency response. }\end{array}$ \\
\hline June 23,2005 & New York City, NY & $\begin{array}{l}\text { Media and public briefing on release of all draft reports for the } \\
\text { WTC towers and draft recommendations for public comment. }\end{array}$ \\
\hline $\begin{array}{l}\text { September 12-13, } \\
2005\end{array}$ & Gaithersburg, MD & $\begin{array}{l}\text { NCST Advisory Committee meeting on disposition of public } \\
\text { comments and update to draft reports for the WTC towers. }\end{array}$ \\
\hline $\begin{array}{l}\text { September } 13-15 \\
2005\end{array}$ & Gaithersburg, MD & $\begin{array}{l}\text { WTC Technical Conference for stakeholders and technical } \\
\text { community for dissemination of findings and recommendations } \\
\text { and opportunity for public to make technical comments. }\end{array}$ \\
\hline
\end{tabular}

- A dissemination and technical assistance program (DTAP) to (a) engage leaders of the construction and building community in ensuring timely adoption and widespread use of proposed changes to practices, standards, and codes resulting from the WTC Investigation and the R\&D program, and (b) provide practical guidance and tools to better prepare facility owners, contractors, architects, engineers, emergency responders, and regulatory authorities to respond to future disasters.

The desired outcomes are to make buildings, occupants, and first responders safer in future disaster events. 


\section{National Construction Safety Team Reports on the WTC Investigation}

A final report on the collapse of the WTC towers is being issued as NIST NCSTAR 1. A companion report on the collapse of WTC 7 is being issued as NIST NCSTAR 1A. The present report is one of a set that provides more detailed documentation of the Investigation findings and the means by which these technical results were achieved. As such, it is part of the archival record of this Investigation. The titles of the full set of Investigation publications are:

NIST (National Institute of Standards and Technology). 2005. Federal Building and Fire Safety Investigation of the World Trade Center Disaster: Final Report on the Collapse of the World Trade Center Towers. NIST NCSTAR 1. Gaithersburg, MD, September.

NIST (National Institute of Standards and Technology). 2006. Federal Building and Fire Safety Investigation of the World Trade Center Disaster: Final Report on the Collapse of World Trade Center 7. NIST NCSTAR 1A. Gaithersburg, MD.

Lew, H. S., R. W. Bukowski, and N. J. Carino. 2005. Federal Building and Fire Safety Investigation of the World Trade Center Disaster: Design, Construction, and Maintenance of Structural and Life Safety Systems. NIST NCSTAR 1-1. National Institute of Standards and Technology. Gaithersburg, MD, September.

Fanella, D. A., A. T. Derecho, and S. K. Ghosh. 2005. Federal Building and Fire Safety Investigation of the World Trade Center Disaster: Design and Construction of Structural Systems. NIST NCSTAR 1-1A. National Institute of Standards and Technology. Gaithersburg, MD, September.

Ghosh, S. K., and X. Liang. 2005. Federal Building and Fire Safety Investigation of the World Trade Center Disaster: Comparison of Building Code Structural Requirements. NIST NCSTAR 1-1B. National Institute of Standards and Technology. Gaithersburg, MD, September.

Fanella, D. A., A. T. Derecho, and S. K. Ghosh. 2005. Federal Building and Fire Safety Investigation of the World Trade Center Disaster: Maintenance and Modifications to Structural Systems. NIST NCSTAR 1-1C. National Institute of Standards and Technology. Gaithersburg, MD, September.

Grill, R. A., and D. A. Johnson. 2005. Federal Building and Fire Safety Investigation of the World Trade Center Disaster: Fire Protection and Life Safety Provisions Applied to the Design and Construction of World Trade Center 1, 2, and 7 and Post-Construction Provisions Applied after Occupancy. NIST NCSTAR 1-1D. National Institute of Standards and Technology. Gaithersburg, MD, September.

Razza, J. C., and R. A. Grill. 2005. Federal Building and Fire Safety Investigation of the World Trade Center Disaster: Comparison of Codes, Standards, and Practices in Use at the Time of the Design and Construction of World Trade Center 1, 2, and 7. NIST NCSTAR 1-1E. National Institute of Standards and Technology. Gaithersburg, MD, September.

Grill, R. A., D. A. Johnson, and D. A. Fanella. 2005. Federal Building and Fire Safety Investigation of the World Trade Center Disaster: Comparison of the 1968 and Current (2003) New 
York City Building Code Provisions. NIST NCSTAR 1-1F. National lnstitute of Standards and Technology. Gaithersburg, MD, September.

Grill, R. A., and D. A. Johnson. 2005. Federal Building and Fire Safety Investigation of the World Trade Center Disaster: Amendments to the Fire Protection and Life Safety Provisions of the New York City Building Code by Local Laws Adopted While World Trade Center 1, 2, and 7 Were in Use. NIST NCSTAR 1-1G. National Institute of Standards and Technology. Gaithersburg, MD, September.

Grill, R. A., and D. A. Johnson. 2005. Federal Building and Fire Safety Investigation of the World Trade Center Disaster: Post-Construction Modifications to Fire Protection and Life Safety Systems of World Trade Center I and 2. NIST NCSTAR 1-1H. National Institute of Standards and Technology. Gaithersburg, MD, September.

Grill. R. A.. D. A. Johnson. and D. A. Fanella. 2005. Federal Building and Fire Safety Investigation of the World Trade Center Disaster: Post-Construction Modifications to Fire Protection, Life Safety, and Structural Systems of World Trade Center 7. NIST NCSTAR 1-1I. National Institute of Standards and Technology. Gaithersburg, MD, September.

Grill, R. A., and D. A. Johnson. 2005. Federal Building and Fire Safety Investigation of the World Trade Center Disaster: Design, Installation, and Operation of Fuel System for Emergency Power in World Trade Center 7. NIST NCSTAR 1-1J. National lnstitute of Standards and Technology. Gaithersburg, MD, September.

Sadek, F. 2005. Federal Building and Fire Safety Investigation of the World Trade Center Disaster: Baseline Structural Performance and Aircraft Impact Damage Analysis of the World Trade Center Towers. NIST NCSTAR 1-2. National lnstitute of Standards and Technology. Gaithersburg, MD, September.

Faschan, W. J., and R. B. Garlock. 2005. Federal Building and Fire Safety Investigation of the World Trade Center Disaster: Reference Structural Models and Baseline Performance Analysis of the World Trade Center Towers. NIST NCSTAR 1-2A. National Institute of Standards and Technology. Gaithersburg, MD, September.

Kirkpatrick, S. W., R. T. Bocchieri, F. Sadek, R. A. MacNeill, S. Holmes, B. D. Peterson, R. W. Cilke, C. Navarro. 2005. Federal Building and Fire Safety Investigation of the World Trade Center Disaster: Analysis of Aircraft Impacts into the World Trade Center Towers, NIST NCSTAR 1-2B. National lnstitute of Standards and Technology. Gaithersburg, MD, September.

Gayle, F. W.. R. J. Fields, W. E. Luecke, S. W. Banovic, T. Foecke, C. N. McCowan, T. A. Siewert, and J. D. McColskey. 2005. Federal Building and Fire Safety Investigation of the World Trade Center Disaster: Mechanical and Metallurgical Analysis of Structural Steel. N1ST NCSTAR 1-3. National Institute of Standards and Technology. Gaithersburg, MD, September.

Luecke, W. E., T. A. Siewert, and F. W. Gayle. 2005. Federal Building and Fire Safety Investigation of the World Trade Center Disaster: Contemporaneous Structural Steel Specifications. NIST Special Publication 1-3A. National Institute of Standards and Technology. Gaithersburg, MD, September. 
Banovic, S. W. 2005. Federal Building and Fire Safety Investigation of the World Trade Center Disaster: Steel Inventory and Identification. NIST NCSTAR 1-3B. National Institute of Standards and Technology. Gaithersburg, MD, September.

Banovic, S. W., and T. Foecke. 2005. Federal Building and Fire Safety Investigation of the World Trade Center Disaster: Damage and Failure Modes of Structural Steel Components. NIST NCSTAR 1-3C. National Institute of Standards and Technology. Gaithersburg, MD, September.

Luecke, W. E., J. D. McColskey, C. N. McCowan, S. W. Banovic, R. J. Fields, T. Foecke, T. A. Siewert, and F. W. Gayle. 2005. Federal Building and Fire Safety Investigation of the World Trade Center Disaster: Mechanical Properties of Structural Steels. NIST NCSTAR 1-3D. National Institute of Standards and Technology. Gaithersburg, MD, September.

Banovic, S. W., C. N. McCowan, and W. E. Luecke. 2005. Federal Building and Fire Safety Investigation of the World Trade Center Disaster: Physical Properties of Structural Steels. NIST NCSTAR 1-3E. National Institute of Standards and Technology. Gaithersburg, MD, September.

Evans, D. D., R. D. Peacock, E. D. Kuligowski, W. S. Dols, and W. L. Grosshandler. 2005. Federal Building and Fire Safety Investigation of the World Trade Center Disaster: Active Fire Protection Systems. NIST NCSTAR 1-4. National Institute of Standards and Technology. Gaithersburg, MD, September.

Kuligowski, E. D., D. D. Evans, and R. D. Peacock. 2005. Federal Building and Fire Safety Investigation of the World Trade Center Disaster: Post-Construction Fires Prior to September 11, 2001. NIST NCSTAR 1-4A. National Institute of Standards and Technology. Gaithersburg, MD, September.

Hopkins, M., J. Schoenrock, and E. Budnick. 2005. Federal Building and Fire Safety Investigation of the World Trade Center Disaster: Fire Suppression Systems. NIST NCSTAR 1-4B. National Institute of Standards and Technology. Gaithersburg, MD, September.

Keough, R. J., and R. A. Grill. 2005. Federal Building and Fire Safety Investigation of the World Trade Center Disaster: Fire Alarm Systems. NIST NCSTAR 1-4C. National Institute of Standards and Technology. Gaithersburg, MD, September.

Ferreira, M. J., and S. M. Strege. 2005. Federal Building and Fire Safety Investigation of the World Trade Center Disaster: Smoke Managenent Systems. NIST NCSTAR 1-4D. National Institute of Standards and Technology. Gaithersburg, MD, September.

Gann, R. G., A. Hamins, K. B. McGrattan, G. W. Mulholland, H. E. Nelson, T. J. Ohlemiller, W. M. Pitts, and K. R. Prasad. 2005. Federal Building and Fire Safety Investigation of the World Trade Center Disaster: Reconstruction of the Fires in the World Trade Center Towers. NIST NCSTAR 1-5. National Institute of Standards and Technology. Gaithersburg, MD, September.

Pitts, W. M., K. M. Butler, and V. Junker. 2005. Federal Building and Fire Safety Investigation of the World Trade Center Disaster: Visual Evidence, Damage Estimates, and Timeline Analysis. NIST NCSTAR 1-5A. National Institute of Standards and Technology. Gaithersburg, MD, September. 
Hamins, A., A. Maranghides, K. B. McGrattan, E. Johnsson, T. J. Ohlemiller, M. Donnelly, J. Yang, G. Mulholland, K. R. Prasad, S. Kukuck, R. Anleitner and T. McAllister. 2005. Federal Building and Fire Safety Investigation of the World Trade Center Disaster: Experiments and Modeling of Structural Steel Elements Exposed to Fire. NIST NCSTAR 1-5B. National Institute of Standards and Technology. Gaithersburg, MD, September.

Ohlemiller, T. J., G. W. Mulholland, A. Maranghides, J. J. Filliben, and R. G. Gann. 2005. Federal Building and Fire Safety Investigation of the World Trade Center Disaster: Fire Tests of Single Office Workstations. NIST NCSTAR 1-5C. National Institute of Standards and Technology. Gaithersburg, MD. September.

Gann, R. G., M. A. Riley, J. M. Repp, A. S. Whittaker, A. M. Reinhorn, and P. A. Hough. 2005. Federal Building and Fire Safety Investigation of the World Trade Center Disaster: Reaction of Ceiling Tile Systems to Shocks. NIST NCSTAR 1-5D. National Institute of Standards and Technology. Gaithersburg, MD, September.

Hamins, A., A. Maranghides, K. B. McGrattan, T. J. Ohlemiller, and R. Anleitner. 2005. Federal Building and Fire Safety Investigation of the World Trade Center Disaster: Experintents and Modeling of Multiple Workstations Burning in a Compartment. NIST NCSTAR 1-5E. National Institute of Standards and Technology. Gaithersburg, MD, September.

McGrattan, K. B., C. Bouldin, and G. Forney. 2005. Federal Building and Fire Safety Investigation of the World Trade Center Disaster: Coniputer Simulation of the Fires in the World Trade Center Tovers. NIST NCSTAR 1-5F. National Institute of Standards and Technology. Gaithersburg, MD, September.

Prasad, K. R., and H. R. Baum. 2005. Federal Building and Fire Safety Imvestigation of the World Trade Center Disaster: Fire Structure Interface and Thernal Response of the World Trade Center Towers. NIST NCSTAR 1-5G. National Institute of Standards and Technology. Gaithersburg, MD, September.

Gross, J. L., and T. McAllister. 2005. Federal Building and Fire Safety Investigation of the World Trade Center Disaster: Structural Fire Response and Probable Collapse Sequence of the World Trade Center Towers. NIST NCSTAR 1-6. National Institute of Standards and Technology. Gaithersburg, MD, September.

Carino, N. J., M. A. Starnes, J. L. Gross, J. C. Yang, S. Kukuck, K. R. Prasad, and R. W. Bukowski. 2005. Federal Building and Fire Safety Investigation of the World Trade Center Disaster: Passive Fire Protection. NIST NCSTAR 1-6A. National Institute of Standards and Technology. Gaithersburg, MD, September.

Gross, J., F. Hervey, M. Izydorek, J. Mammoser, and J. Treadway. 2005. Federal Building and Fire Safety Investigation of the World Trade Center Disaster: Fire Resistance Tests of Floor Truss Systenis. NIST NCSTAR 1-6B. National Institute of Standards and Technology. Gaithersburg, $\mathrm{MD}$, September.

Zarghamee, M. S., S. Bolourchi, D. W. Eggers, Ö. O. Erbay, F. W. Kan, Y. Kitane, A. A. Liepins, M. Mudlock, W. I. Naguib, R. P. Ojdrovic, A. T. Sarawit, P. R Barrett, J. L. Gross, and 
T. P. McAllister. 2005. Federal Building and Fire Safety Investigation of the World Trade Center Disaster: Component, Connection, and Subsystem Structural Analysis. NIST NCSTAR 1-6C. National Institute of Standards and Technology. Gaithersburg, MD, September.

Zarghamee, M. S., Y. Kitane, Ö. O. Erbay, T. P. McAllister, and J. L. Gross. 2005. Federal Building and Fire Safety Investigation of the World Trade Center Disaster: Global Structural Analysis of the Response of the World Trade Center Towers to Impact Damage and Fire. NIST NCSTAR 1-6D. National Institute of Standards and Technology. Gaithersburg, MD, September.

McAllister, T., R. W. Bukowski, R. G. Gann, J. L. Gross, K. B. McGrattan, H. E. Nelson, L. Phan, W. M. Pitts, K. R. Prasad, F. Sadek. 2006. Federal Building and Fire Safety Investigation of the World Trade Center Disaster: Structural Fire Response and Probable Collapse Sequence of World Trade Center 7. (Provisional). NIST NCSTAR 1-6E. National Institute of Standards and Technology. Gaithersburg, MD.

Gilsanz, R., V. Arbitrio, C. Anders, D. Chlebus, K. Ezzeldin, W. Guo, P. Moloney, A. Montalva, J. Oh, K. Rubenacker. 2006. Federal Building and Fire Safety Investigation of the World Trade Center Disaster: Structural Analysis of the Response of World Trade Center 7 to Debris Damage and Fire. (Provisional). NIST NCSTAR 1-6F. National Institute of Standards and Technology. Gaithersburg, MD.

Kim, W. 2006. Federal Building and Fire Safety Investigation of the World Trade Center Disaster: Analysis of September 11, 2001, Seismogram Data. (Provisional). NIST NCSTAR 1-6G. National Institute of Standards and Technology. Gaithersburg, MD.

Nelson, K. 2006. Federal Building and Fire Safety Investigation of the World Trade Center Disaster: The Con Ed Substation in World Trade Center 7. (Provisional). NIST NCSTAR 1-6H. National Institute of Standards and Technology. Gaithersburg, MD.

Averill, J. D., D. S. Mileti, R. D. Peacock, E. D. Kuligowski, N. Groner, G. Proulx, P. A. Reneke, and H. E. Nelson. 2005. Federal Building and Fire Safety Investigation of the World Trade Center Disaster: Occupant Behavior, Egress, and Emergency Communication. NIST NCSTAR 1-7. National Institute of Standards and Technology. Gaithersburg, MD, September.

Fahy, R., and G. Proulx. 2005. Federal Building and Fire Safety Investigation of the World Trade Center Disaster: Analysis of Published Accounts of the World Trade Center Evacuation. NIST NCSTAR 1-7A. National Institute of Standards and Technology. Gaithersburg, MD, September.

Zmud, J. 2005. Federal Brilding and Fire Safety Investigation of the World Trade Center Disaster: Technical Documentation for Survey Administration. NIST NCSTAR 1-7B. National Institute of Standards and Technology. Gaithersburg, MD, September.

Lawson, J. R., and R. L. Vettori. 2005. Federal Building and Fire Safety Investigation of the World Trade Center Disaster: The Emergency Response Operations. NIST NCSTAR 1-8. National Institute of Standards and Technology. Gaithersburg, MD, September. 


\section{ACKNOWLEDGMENTS}

The National Institute of Standards and Technology (NIST) would like to acknowledge the Port Authority of New York and New Jersey (PANYNJ) for its assistance in collecting and duplicating design and construction documents of World Trade Center (WTC) 1,2 and 7, and making available office spaces for NIST investigation team members during the course of the investigation. Saroj Bhol of PANYNJ is acknowledged for his efforts in response to document requests by NIST.

The authors wish to acknowledge the following colleagues at NIST: Dat Duthinh who helped to catalogue design and construction data, and Harold "Bud" Nelson who was helpful in providing detailed information on the fire safety systems of WTC 1,2, and 7. 
This page intentionally left blank. 


\section{EXECUTIVE SUMMARY}

\section{E.1 INTRODUCTION}

One of the four primary objectives of the National Institute of Standards and Technology (NIST) Investigation of the World Trade Center (WTC) disaster is to determine the procedures and practices that were used in the design, construction, operation. and maintenance of the structural, passive and active fire protection, and emergency and evacuation systems of WTC 1,2, and 7 and the impacts these had on the buildings over their life, up to the attacks of September 11, 2001.

To accomplish this objective, relevant information was collected by reviewing design and construction documents, correspondence, and memoranda related to the building projects; and tenant alterations; interviewing individuals involved in the design, construction, and maintenance of the buildings; obtaining information from regulatory and emergency services agencies of New York City; and reviewing books and published journal and magazine articles related to the WTC building projects. Information obtained from various sources was synthesized and summarized in this report. Specifically, this report presents:

1. Provisions used to design and construct the structural, fire protection, and egrcss systcms of the buildings;

2. Tests performed to support the design of these systems;

3. Criteria that governed the design of the structural and fire protection systems;

4. Methods used to proportion structural members and other components of the buildings;

5. Innovative features, technologies, and materials that were incorporated in the design and construction of the structural and fire protection systems;

6. Details of deviations to the contract documents granted by the Port Authority of New York and New Jersey (PANYNJ or Port Authority);

7. Fabrication and inspection requirements at the fabrication yard; and

8. Inspection protocol during construction.

9. Alterations made to the buildings to accommodate specific needs of tenants or to respond to changes to the Building Code of New York City as implcmented in Local Laws (LL) and interpreted in rules.

This report also addresses the fuel systems for the diesel generators that supplied emergency power to many of the tenants in WTC 7. 


\section{E.2 DESCRIPTION OF WTC 1, 2, AND 7}

The WTC complex was located at lower west side of Manhattan, New York City, near the Hudson River. The complex was composed of seven buildings (referred to in this report as WTC 1 through WTC 7). The two towers, WTC 1 (North Tower) and WTC 2 (South Tower), were each 110 stories high. WTC 3 (Marriott Hotel) was 22 stories. WTC 4 (South Plaza Building) and WTC 5 (North Plaza Building) were both nine-story office buildings. WTC 6 (U.S. Customs House) was an eight-story office building. These six buildings were built around a 5 acre WTC Plaza. WTC 7 was a 47-story office building that was built just north of the six-building WTC site.

The first six buildings on the sixteen-acre site were developed by the Port Authority. Groundbreaking for WTC 1 and WTC 2 was in 1966, and the first tenant began to occupy WTC 1 in December 1970 and WTC 2 in January 1972. Construction of the other buildings continued during the 1970s and the 1980s. WTC 7 was developed by a consortium comprising the Seven World Trade Company, and Silverstein Development Corporation, and was completed in 1987.

The NIST Investigation is focused only on WTC 1,2, and 7.

\section{WTC 1 and WTC 2}

Although the WTC towers were similar, they were not identical. The height of WTC 1 at the roof level was $1,368 \mathrm{ft}$ above the Concourse level, was $6 \mathrm{ft}$ taller than WTC 2, and supported a $360 \mathrm{ft}$ tall antenna for television and radio transmission. Each tower had a square plan with the side dimension of approximately $207 \mathrm{ft}$. The corners of the tower were chamfered $6 \mathrm{ft} 11 \mathrm{in}$. Each tower had a core service area of approximately $135 \mathrm{ft}$ by $87 \mathrm{ft}$. All elevators and three egress stairs were located within the core, although on any given floor the arrangements of the elevators and the location of the stairs varied. Placing all service systems within the core provided a nearly column-free floor space of approximately $31,000 \mathrm{ft}^{2}$ per floor outside the core. The two towers had about 10 million $\mathrm{ft}^{2}$ of rentable floor area.

The towers were designed as a "framed-tube" structural system with closely spaced exterior perimeter columns connected by spandrel beams around the perimeter at each floor level. The core was designed as a conventional frame with a grid of columns interconnected with beams.

The exterior walls were composed of box-shaped welded steel columns and spandrel beams comprised of a steel plate. Each building face consisted of 59 columns spaced at $3 \mathrm{ft} 4 \mathrm{in}$. on center. As part of the framed-tube system, the exterior columns were designed structurally such that they resisted the total lateral loads and about 50 percent of gravity loads. Below floor 7, the columns were combined in groups of three to form single base columns which wcre spaced $10 \mathrm{ft}$ on center and extended to the footings. An important architectural feature of the towers was the uniform look of the exterior walls, presented by the uniform width of the exterior columns up the height of the buildings. This was produced by maintaining a constant exterior dimension the columns and changing the strength of the steel with height. Thus, twelve different grades of steel, with yield strengths ranging from $36 \mathrm{ksi}$ to $100 \mathrm{ksi}$, were used for the exterior columns. The external cladding, which covered the columns and spandrel beams, consisted of aluminum sheets. The window openings were infilled with glass fitted into aluminum covers and sealed with neoprene gaskets. 
The core columns were of two types: welded box columns for the lower floors and rolled wide flange shapes for the upper floors. They were designed to support about 50 percent of gravity loads. Below floor 7 to the foundation, where there were fewer perimeter columns in the outer walls, bracings were used in the outer perimeter of the core area to increase lateral stiffness. In the lower part of the towers, the outer core columns were designed to resist a portion of the lateral forces. Hidden within the building, the core columns were thicker and larger on the lower floors. Thus, core columns used fewer grades of steel. The box columns were either $36 \mathrm{ksi}$ or $42 \mathrm{ksi}$. Core wide flange columns were one of four grades, yield strengths ranging from $36 \mathrm{ksi}$ to $50 \mathrm{ksi}$, but most (approximately 90 percent) were primarily $36 \mathrm{ksi}$ or $42 \mathrm{ksi}$ steel.

The floor system of WTC 1 and WTC 2 was composed of concrete-steel composite members. The area inside the cores and on the mechanical floors was framed with rolled structural steel shapes with welded shear studs acting compositely with normal-weight concrete slabs. The thickness of the slabs varied from 4.5 in. to 8 in. depending on design loads. The area outside the core, typically on tenant floors, was framed with steel trusses acting compositely with 4 in. thick lightweight concrete slabs cast on $1 \frac{1}{2}$ in., 22 gauge fluted metal deck. The trusses consisted of double angle top and bottom chords with round bar webs. Some floors, immediately adjacent to the mechanical floors, used a hybrid of beam and truss framing acting compositely with the concrete slab.

Fire protection of exposed structural steel members in the WTC towers was provided by applied fire resistive materials. They were either sprayed fire-resistive materials (SFRMs), gypsum wallboards, or a combination of the two, depending upon the type of structural members, to meet the requirements of Construction Classification of $1 \mathrm{~B}$ of the 1968 New York City (NYC) Building Code. All floor trusscs and beams were protected with SFRM. The columns inside the core were either covered with gypsum wall board or a combination of gypsum wall board and SFRM. For the exterior columns, vcrmiculite plaster was applied to the side of the column facing the interior of the building, whereas SFRM was applied to other three faces. No fire resistive material was specified for the underside of the metal deck, which was in contact with the concrete slab above. For typical tenant floors, the ceiling was suspended from the steel trusses. The space between the ceiling and the floor above was used for the mechanical and electrical systems.

Elevators were the primary mode of routine ingress and egress from the towers for tens of thousands of people daily. In order to minimize the total floor space needed for elevators, each tower was divided vertically into three zones by skylobbies, which served to distribute passengers among express and local elevators. In this way, the local elevators within a zone were placed on top of one another within a common shaft. Local elevators serving the lower portion of a zone were terminated to return to the space occupied by those shafts to leasable tenant space. People transferred from express elevators to local elevators at the skylobbies which were located on the 44th and 78th floors in both towers. Each tower had 99 passenger and 7 freight elevators, all located within the core of the building.

\section{WTC 7}

WTC 7 was a 47-story commercial office building constructed by Silverstein Properties as a tenant alteration on land owned by the Port Authority. The overall dimensions of WTC 7 were approximately $330 \mathrm{ft}$ long, $140 \mathrm{ft}$ wide, and $610 \mathrm{ft}$ high. It contained about 2 million $\mathrm{ft}^{2}$ of rentable floor area. The building was constructed over a pre-existing electrical substation owned by Consolidated Edison 
(Con Edison). The original plans for the Con Edison Substation included supporting a high-rise building, and the foundation was sized for the planned structure. However, the final design for WTC 7 had a larger footprint than originally planned.

Above floor 7, the building had typical steel framing for high-rise construction. The floor systems had composite construction with steel beams of $50 \mathrm{ksi}$ yield strength supporting concrete slabs on metal deck, with a floor thickness of $5.5 \mathrm{in}$. The core and perimeter columns supported the floor system and carried their loads to the foundation. Above floor 7, the perimeter moment frame resisted wind forces. Below floor 7 , a combination of moment and braced frames around the perimeter and a series of braced frames in the core resisted the wind load.

Columns above floor 7 did not align with the foundation columns, so braced frames, transfer trusses, and transfer girders were used to transfer loads between these column systems, primarily between floors 5 and 7. Floors 5 and 7 were heavily reinforced concrete slabs on metal decks, with thicknesses of 14 in. and 8 in., respectively.

Core columns were primarily rolled wide-flange shapes with a yield strength of either $36 \mathrm{ksi}$ or $50 \mathrm{ksi}$, while the exterior columns were typically rolled W14 shapes with a yield strength of $36 \mathrm{ksi}$.

\section{E.3 CODE PROVISIONS FOR STRUCTURAL DESIGN}

The design of WTC 1, 2, and 7 was based on the 1968 edition of the NYC Building Code. As an interstate compact under the U.S. Constitution, the Port Authority was not subjected to any state or local building codes. In May 1963, the Port of New York Authority (PONYA or Port Authority) instructed the architect and structural engineer to prepare their designs for WTC 1 and WTC 2 in accordance with the NYC Building Code. At that time, the 1938 edition of that Code was in effect. In September of 1965, the PONYA instructed the architect and structural engineer to revise their designs for WTC 1 and WTC 2 to comply with the second and third drafts of the new NYC Building Code that was under development. Prior to issuance of this instruction, the Port Authority recognized that the draft version of the new NYC Building Code had incorporated advanced techniques and the Port Authority favored the use of advanced techniques in the design of the WTC towers. By adopting the draft versions of the new NYC Building Code, WTC 1 and WTC 2 could be classified as Type 1-B Construction, and several features related to egress such as the elimination of the fire tower and the reduction of the number of egress stairs required from six to three with narrower doors were incorporated into the final design.

The new Code was adopted on December 6, 1968. Subsequently, the NYC Building Code was amended by numerous Local Laws to improve safety requirements or to incorporate technological advances, some of which had impacts on the towers. When WTC 7 was designed, the 1968 Building Code was in effect and the Local Laws impacting fire, life safety, and structural arrangements were in place, so these were incorporated into the original design of that building.

To put the design of WTC 1, 2, and 7 into the context of building codes and practices of the time, the structural provisions of the 1968 edition of the NYC Building Code were compared with the structural provisions in a number of contemporaneous codes, as well as in the 2001 edition of the NYC Building Code, which is currently in effect. Specifically, the following codes were selected for comparison of the structural provisions: the 1964 New York State Building Construction Code (NYSBC 1964); the 1965 Building Officials and Code Administrators (BOCA) Basic Building Code (BOCA/BBC 1965); the 1967 
Municipal Code of Chicago Relating to Buildings (MCC 1967); and the 2001 edition of the NYC Building Code (NYCBC 2001). The 1964 New York State Building Construction Code was selected for comparison, as it would have been a governing building code outside New York City limits. The 1965 BOCA Basic Building Code was selected. as it was typically adopted by local jurisdictions in the northeastern region of the United States. The 1968 NYC Building Code is compared with the 1967 Municipal Code of Chicago to see whether there are any substantial differences in the structural and fire safety requirements of the two codes. In the late 1960 s and early 1970 s, several tall buildings wcre built in Chicago, including the Sears Tower (110 stories) and the John Hancock Tower (100 stories). The 2001 edition of the NYC Building Code is compared with the 1968 version to examine the extent to which Local Laws have modified the code provisions.

Structural provisions include those concerning design loads, such as dead loads, live loads (including live load reduction), wind loads, earthquake loads, and other loads. They also include provisions concerning what is called "structural work" in the NYC Building Codes (this term is not used in the other codes). The scope of "structural work" includes, but is not limited to, materials and methods of construction, design methods including design load combinations, and the materials of construction including concrete, masonry, steel, and wood. Structural provisions also include those for foundation design and construction.

With respect to structural design provisions, the major changes from the 1968 to the 2001 edition of the NYC Building Code are the inclusion of seismic design requirements and updating of standards. Of the codes contemporaneous with the 1968 NYC Building Code examined for this investigation, only the BOCA Basic Building Code had seismic design requirements, which were adopted from the 1962 edition of the Uniform Building Code (UBC). Taller buildings have longer periods of vibration, which means lower seismic design forces. Also, since New York City is in an area of moderate seismicity (UBC Zone 2A), additional seismic detailing requirements are minimal to non-existent.

The alternate live load reduction provisions for columns, walls, and piers of the 1968 and 2001 NYC Building Codes are the same as in the Chicago Municipal Code. The New York State Building Code has more liberal live load reduction provisions for upper portions of buildings. The NYC Building Codes also have live load reduction provisions based on contributory floor area and live-to-dead load ratio. For live-to-dead load ratios of 0.625 or less, the New York City code provisions may yield higher live load reduction for columns, walls, and piers than allowed by the other codes. For beams and girders, the live load reduction provisions of the NYC Building Code are comparable to those of the New York State Building Code and the BOCA Basic Building Code. The Chicago Municipal Code has more conservative requirements. The maximum live load reduction allowed for beams and girders in the Chicago Municipal Code is 15 percent, compared with 40 percent in the other codes.

When the wind load provisions in the codes are compared, the largest shear force at the base of a building is obtained from the BOCA Basic Building Code when the height of the building is taken equal to 1,368 ft (i.e., the height of WTC 1). Similarly, the largest overturning moment at the base of a building with the height of the WTC towers is also obtained from the BOCA Basic Building Code. Thus, the NYC Building Code does not have the most stringent wind load provisions.

The 1968 NYC Building Code requires that weights of partitions be considered in two ways: (1) using line loads at locations shown on plans or (2) using the equivalent uniform load. Equivalent uniform loads must be used in areas where the locations of partitions are not shown on plans, or in areas where partitions 
can be relocated. The 1964 New York State Building Construction Code did not have a specific provision in this regard. The 1967 Municipal Codc of Chicago prescribed a minimum partition load of 20 psf. The BOCA Basic Building Code required consideration of the actual weight of the partitions or an equivalent uniform load of at least 20 psf.

The primary materials design standards refercnced by the 1968 NYC Building Code, the Chicago Municipal Code, and the BOCA Basic Building Code are the 1963 edition of the American Concrete Institute's (ACI's), Building Code Requirements for Reinforced Concrete (ACI 318), and the American Institute of Steel Construction's, Specifications for the Design, Fabrication and Erection of Structural Steel for Buildings (AISC 1963). The New York State Building Code, being a performance code, does not adopt any specific standards by reference. The 2001 NYC Building Code adopts the 1989 edition of ACI 318, AISC 1989, Specifications for Structural Steel Buildings - ASD and Plastic Design, and AISC-LRFD 1993, Load and Resistance Factor Design Specifications for Structural Steel Buildings.

The NYC Building Codes have extensive and quite rigorous foundation design and construction requirements. The foundation related provisions of the other codes are less extensive and typically less rigorous.

The NYC Building Codes prescribe testing and inspection requirements for all materials, assemblies, forms and methods of construction. The other three codes require that materials and methods of construction meet the criteria of generally accepted standards. With respect to foundations, only the NYC Building Codes have specific requirements for foundation inspection.

\section{E.4 STRUCTURAL DESIGN OF WTC 1, 2, AND 7}

For WTC 1 and WTC 2 the design criteria were established referencing provisions of the 1968 NYC Building Code as minimum. The design dcad loads and live loads specified in the design criteria were greater than or equal to corresponding design loads in the Building Code. Live load reduction requirements given in the design criteria were equal to or more stringent than Code requirements.

Wind forces on the towers were determined based on a series of wind tunnel tests that were conducted at the Colorado State University and the National Physical Laboratory, Teddington, Middlesex, United Kingdom. Such tests were permitted by the Code to determine wind prcssures in lieu of those tabulated in the Code. The code prescribed base shear and overturning moment occur simultaneously on the same face of the tower, and these values are the same for all four faces. The base shear and the overturning moment obtained from the wind tunnel tests represent the largest values related to most unfavorable wind direction; so, they may not occur simultaneously on the same face of the tower. Thus, the base shear value obtained from the wind tunnel tests is about 42 percent greater than that obtained using the code prescribed wind pressure values, whereas the overturning moments obtained from the wind tunnel tests is about 65 percent greater than that obtained using the code prescribed wind pressure values.

The allowable stress method in the 1963 American Institute of Steel Construction (AISC) Specification for the Design, Fabrication, and Erection of Structural Steel for Buildings was used to proportion the exterior columns and spandrels for the combined effects of axial compression, bending moment, and shear due to gravity and wind forces. Composite floor trusses were designed based on the AISC Specification. The allowable stress method was also used to proportion the members in the hat trusses that were located between the 107th floor and the roof in WTC 1 and WTC 2. In the core area, composite 
steel beams, columns, and their connections were designed by the appropriate requirements in the 1963 AISC Specification. The ultimate strength method in the 1963 edition of the ACI Building Code Requirements for Reinforced Concrete was used to design the concrete floor slabs in WTC 1 and WTC 2.

For WTC 7, the project specifications required that the structural steel be designed in accordance with the 1968 edition of the NYC Building Code, edited and amended through January 1, 1985, and the 1978 edition of the AISC Specification for the Design, Fabrication, and Erection of Structural Steel for Buildings. Design load criteria for WTC 7, listed on one of the structural drawings, show that the design values for the superimposed dead loads could not be ascertained, since the actual materials used for partitions, flooring. and ductwork were not specified. The live loads in the design criteria were equal to those in the 1968 NYC Building Code at the floors where the type of occupancy was noted. No documents were found that indicated what live load reduction was used.

No design criteria or calculations including wind load analysis of WTC 7 were available for this investigation. However, a wind tunnel study of WTC 7 was carried out in 1983 by the University of Western Ontario at the request of the structural engineer of record.

\section{E.5 INNOVATIVE FEATURES INCORPORATED IN STRUCTURAL DESIGN}

A number of innovative features were incorporated in the structural design of WTC 1 and WTC 2. They were incorporated in both the lateral-load-resisting system and the gravity-load-carrying system.

These features include the following:

- Application of the framed-tube system to resist lateral loads.

- Uniform exterior column geometry (14 in. by 14 in. cross-section) was maintained over most of the height of the 110-story buildings by using twelve different grades of steel.

- Use of deep spandrel plates as beam elements connecting perimeter columns.

- Use of long-span composite steel trusses for the floor systems. Composite action was achieved between the steel trusses and the concrete floor slab by extending the truss diagonals above the top chord into the slab.

- Application of viscoelastic dampers connecting the floor trusses to the perimeter framed tube system to control dynamic response.

- Use of wind tunnel test data to establish the wind loads used in the design of the towers.

\section{E.6 FABRICATION AND CONSTRUCTION INSPECTIONS AND DEVIATIONS}

The contract documents for WTC 1 and WTC 2 between the Port of New York Authority and the steel fabricators and erector, and the construction contract specifications for WTC 7, indicate that inspection programs were instituted at the steel fabrication sites. The inspection requirements were listed in the contract documents. However, the records of inspections for both the WTC 1 and WTC 2 and the WTC 7 projects were not available to the investigation. The records for WTC 1 and WTC 2, which were kept in 
WTC 1 were destroyed, and the records for WTC 7 were discarded by the general contractor after retaining them for 7 years.

\section{WTC 1 and WTC 2}

Fabrication and inspection requirements were contained in the contracts for the floor trusses, box core columns and built-up beams, members of the exterior wall, and rolled columns and beams. In general, the inspection requirements from the specifications for the various contracts were at a minimum equivalent to those in the 1968 NYC Building Code. The Code contains provisions that govern the fabrication and inspection of materials used in buildings. However, in a number of cases, the contract requirements were more comprehensive and stringent than the corresponding provisions in the Code The Code refers to the requirements in the 1963 AISC Specification for the Design, Fabrication, and Erection of Structural Steel for Buildings (AISC 1963). The AISC Specification contained minimum fabrication requirements for the following:

- Straightening of materials

- Gas cutting

- Planing of edges

- Riveted and bolted construction - holes

- Riveted and high strength bolted construction - assembling

- Welded construction

- Finishing

- Tolerances

Specific inspection requirements during fabrication of various structural members were covered in the contract documents between PONYA and individual fabricators.

\section{WTC 7}

The contract specification for WTC 7 required that structural steel for WTC 7 was to be fabricated in accordance with the applicable requirements in the 1968 NYC Building Code, the 1963 AISC Specification for the Design, Fabrication, and Erection of Structural Steel for Buildings, and other specifications related to bolts, welds, and painting. The specification also notes that there was a separate contract for testing and inspection. This contract was not found. However, specific requirements for inspection of shop and field welds by a testing agency were included in the specification. 


\section{E.7 INSPECTION PROTOCOL DURING CONSTRUCTION}

\section{WTC 1 and WTC 2}

Karl Koch Erecting Co., the company that performed the structural steel erection work for WTC 1 and WTC 2, developed a quality control and safety program. This program included information on ten different key areas that were to be addressed during construction, including:

- Survey control

- Control of construction and erection loads

- Field welding

- Bolting of structural steel

- Control of stud welding operations

- Erection procedures

- Control of workmanship

- Control of erection tolerances

- As-built drawings

- Safety programs

\section{WTC 7}

The WTC 7 specifications contained general erection requirements for fasteners, anchor bolts, column bases, installation, and bracing. The specification did not include any requirements for inspection.

\section{E.8 DEVIATIONS GRANTED BY PANYNJ}

The Port Authority approved numerous deviations in the fabrication and erection of structural members in WTC 1 and WTC 2. The Office of the Construction Manager at the Port Authority approved deviations to the contract documents after the structural engineer of record; Skilling, Helle, Christiansen, and Robertson (SHCR), reviewed the details of the deviations and recommended approval. In many cases, SHCR submitted alternative methods, which were incorporated into the deviation.

The deviations that were granted for the structural members and their materials may be categorized into the following groups:

- Deviations relating to fabrication/erection tolerances (box columns, box beams, and floor trusses) 
- Deviations relating to defective components (column trees and floor trusses)

- Deviations relating to alternative fabrication/erection procedures (core columns, floor trusses, exterior wall columns, and beam seats)

- Deviations relating to product substitutions (exterior wall)

- Deviations relating to inspection practice (exterior wall and welds).

Fabrication and erection inspections identified many deviations from the contract drawings and specifications. Many deviation requests were based on inspection results.

\section{E.9 STRUCTURAL MAINTENANCE AND MODIFICATIONS DURING OCCUPANCY}

Both architectural and structural modifications were made to meet the occupancy needs of individual tenants throughout the history of occupancy of WTC 1, 2, and 7. PONYA, later PANYNJ, reviewed all modifications to maintain the structural integrity of the buildings and to ensure that modifications were compatible with existing building conditions. In order to guide tenants in their modification process, the PONYA issued Tenant Alteration Review Manual in 1971 and updated the manual periodically through 1997.

In anticipation of structural degradation, the PANYNJ issued in 1986 the Standard for Structural Integrity Inspection of the World Trade Center Towers $A \& B$ to guide periodic inspection of structural members. Deteriorated and damaged members were identified for repair. The standard was used by consultants who were retained by PANYNJ for systematic examination of WTC 1 and WTC 2.

In 1998, the PANYNJ issued the Standards for Architectural and Structural Design for modification works. The standards included not only the design guide, but also included specifications and standard details to be used in modification works. Tenants proposing any modifications were required to follow the specified standards.

Apart from the repairs following the 1993 bombing of WTC 1, most of the structural modifications in WTC 1 and WTC 2 were performed to accommodate tenant requirements. Openings were cut in existing floors to construct new stairways linking two or more floors, and floor systems were reconstructed over previously cut openings. In a number of cases, floor trusses outside of the core area and steel beams in the core area had to be reinforced due to heavy loads imposed by tenant requirements. All such modifications were reviewed and approved by the structural engineer of record (SHCR).

Similar to WTC 1 and WTC 2, most of the structural modifications in WTC 7 were done to accommodate tenant requirements. Horizontal members of the floor framing system were strengthened due to increased loading from high-density files. Strengthening of these beams and girders was achieved by welding cover plates to the bottom flanges, the underside of the top flanges, or both. In some cases, new beams were introduced to carry a portion of the new load. 


\section{Structural Integrity Inspection Program}

In 1986, PANYNJ implemented an inspection program to detect, record, and correct any signs of distress, deterioration, or deformation that could signal structural problems. This structural integrity inspection program contained detailed guidelines on inspection, record-keeping, and follow-up procedures.

Inspection findings were to be categorized as "Immediate," "Priority," or "Routine." Repairs falling into the "Immediate" category included possible closure of the area and/or structure affected until interim remedial action could be implemented. The "Priority" category was for those conditions where no immediate action was required, or for which immediate action had been completed, but for which further investigation, design, and implementation of interim or long-term repairs were to be undertaken on a priority basis (i.e., taking precedence over all other scheduled work). Repairs falling into the "Routine" or "non-priority" category were to be undertaken as part of a scheduled major work program or other scheduled project, or when routine facility maintenance was to be performed, depending on the type of repair that was required. An important requirement in the inspection program was that where inspection procedures involved the removal of fireproofing, such fireproofing was to be properly replaced on completion of inspection.

In general, the structural integrity inspections findings indicated that the structural systems of WTC 1,2, and 7 were in good condition. The inspections resulted in numerous routine and some priority recommendations for repairs, as outlined in the inspection standard. According to the PANYNJ, all of the construction records on repairs following the inspections were lost on September 11, 2001. Thus, it cannot be determined whether all of the recommended repairs were performed.

\section{Repair Work Following the 1993 Explosion}

The explosion of February 26, 1993, occurred on Level B2 near the center of the south wall of WTC 1 and adjacent to IVTC 3 (Vista Hotel). Structural steel columns, diagonal braces, and spandrel beams in the vicinity of the blast were damaged. Concrete floor slabs at Levels B1 and B2 and unreinforced masonry walls were also damaged over a large area.

The explosion severely bent and tore out the diagonal brace between columns. Spandrel beams at level Bl were also damaged by the blast. A crack developed along the field splice in a column. Ultrasonic testing determined that the crack extended across the full width of the weld on the south face of the column and at each end of the weld on the north face. Magnetic-particle testing procedure determined that the crack extended across the east face of the column. The explosion also damaged floor beams at levels B1 and B2. Concrete spandrel beams at level B3 also sustained damage. Masonry walls in WTC 1 were breached over distances of approximately $50 \mathrm{ft}$ to the east and $120 \mathrm{ft}$ to the west of the blast origin.

The diagonal bracing members between levels B1 and B2 that were damaged by the explosion were removed and replaced with new members. New plates were added to the damaged spandrel beam at level B1. Also, the cracked weld on the south face of the spandrel beam at level B1 was removed and replaced.

Six different inspections were performed before and after repairs were made to WTC 1. No anomalies were detected in the welds used to repair structural members. 


\section{E.10 CODE PROVISIONS FOR DESIGN OF THE FIRE SAFETY AND EGRESS SYSTEMS}

The fire safety provisions of the 1968 NYC Building Code (NYCBC 1968) were compared with four other building codes: the 1964 New York State Building Construction Code (NYSBC 1964), the 1965 BOCA Basic Building Code (BOCA/BBC 1965), the 1967 Municipal Code of Chicago Relating to Buildings (MCC 1967), and the 2001 edition of the NYC Building Code (NYCBC 2001). In addition, comparisons were made to the 1966 edition of National Fire Protection Association (NFPA) 101, Code for Safety to Life in Buildings and Structures. While not a building code, NFPA 101 is widely adopted for its requirements for life safety in fires.

The NYC Building Code was regularly amended by local laws, two of which, Local Law 5 (1973) and Local Law 16 (1984), had a significant influence on WTC 1 and WTC 2, even though the buildings were completed and occupied at the time of adoption. It is normal practice not to apply building code changes to existing buildings except for major renovations or change in primary use, but the Port Authority chose to follow the revised provisions and to retrofit the buildings as required under the new provisions. The resulting changes to WTC 1 and WTC 2 are discussed primarily in the sections on modifications to the building systems.

While New York City developed its own building code, their code development committees were influenced by the same forces that bore on the model codes. Thus, there were relatively few differences between the NYC Building Code and the others.

\section{Construction Classification}

In Construction Classifications, the 1968 Building Code, the New York State Building Code, and the 1965 BOCA all recognized Class 1A or Class 1B (with the same fire resistance ratings for building elements) for most unsprinklered buildings of unlimited height, while the 1967 Chicago Code recognized only 1A. New York City imposed a $75 \mathrm{ft}$ height limit on unsprinklered buildings with the adoption of Local Law 16 (1984).

\section{Active Systems}

At the time of construction, sprinklers were primarily for property protection and were rare even in high-rise buildings (except for underground spaces). Fire alarm systems were mostly manually initiated but there was concern about smoke being recirculated through the heating, ventilating, and air conditioning (HVAC) systems, so smoke detectors controlled dampers at return shafts to prevent this. This is the arrangement of the fire alarm system originally installed in the towers. Voice communication systems were a response to phased evacuation with the recognition that it was necessary to provide . instructions to occupants who were relocated or held within the building at least until they were told to leave. Requirements for voice systems first appeared in national standards in the mid-1980s, at the same time as NYC adopted LL 16 (1984). 


\section{Technical Standards}

All building codes rely on referenced technical standards to provide the details of design, installation, operation, and maintenance of required systems. Most building codes reference national (consensus) standards as published, but New York City cites their own reference standards that are based on these national standards but are often highly modified. For example, fire alarm systems and fire sprinkler systems are addressed in Reference Standard (RS) 17, with Class E fire alarm systems (required in office occupancies) covered in RS 17-3A and general fire alarm system requirements in RS 17-5. The former is entirely written by a NYC code committee, and the latter is based on NFPA 72 (National Fire Alarm Code) but highly modified by the deletion of many sections and modification of many others. One major modification is that RS 17 does not include the "Survivability" section for high-rise voice communication systems that requires duplicate communication trunks so that loss on one trunk does not result in loss of communication with a floor. However the voice communication system installed in WTC 1 and WTC 2 was consistent with the National Fire Alarm Code (NFPA 72) in addition to RS 17 and had redundant trunks run in Stairways A and C.

\section{Egress Systems}

Prior to 1988, all building codes determined egress capacity by the (22 in.) Units of Exit Width method, which New York City still uses. In 1988, other codes changed to a method involving an allowance of width per person, which provides credit for non-standard widths of corridors and doors, but for standard dimensioned components yields the same results. Another difference in egress design is that New York City applies the occupant load factor for business occupancies ( $100 \mathrm{ft}^{2}$ per person) to the net floor area while other codes use the gross floor area. Other codes use net for some and gross for others. The NYC Building Code allows doubling stair capacity allowances with one or tripling of the stair capacity on floors with two or more horizontal exits where other codes only allow doubling for one horizontal exit (see discussion of Windows on the World).

\section{Miscellaneous Details}

There are a number of detail differences between the NYC Building Code and the other building codes. The NYC Building Code has no requirements for fire extinguishcrs since they require occupant hose reels. The 1968 NYC Building Code was the first code to include smoke developed ratings for finish materials in addition to flame spread. Now, all of the codes have similar requirements.

\section{Specifications for the Original Buildings}

No contemporaneous documentation has been found that provides the rationale for the decision to select Class 1B for the WTC towers. This decision, however, appears to have been made by the architect-ofrecord on the basis of economics.

As stated above the primary occupancy group was Group E (Business) with the Windows on the World space in WTC 1 being Group F (Assembly). While there was a Port Authority cafeteria on the 44th floor, employee cafeterias not open to the public are specifically exempted from assembly classification because they do not increase occupant load and are only used intermittently. Incidental mercantile spaces such as 
news stands and coffee bars at the concourse level are also exempt from reclassification in most building codes.

The NYC Building Code and Port Authority practice required partitions to separate tenant spaces from each other and from common spaces such as the corridors that served the elevators, stairs, and other common spaces in the building core. Fire rated partitions are intended to limit fire spread on a floor, to prevent spread of fire in one tenant space to that of another, partitions separating tenant space from exit access corridors were permitted to be $1 \mathrm{~h}$, although the Port Authority specified them to be $2 \mathrm{~h}$, allowing dead ends to extend to $100 \mathrm{ft}$ (rather than $50 \mathrm{ft}$ with $1 \mathrm{~h}$ partitions), which permitted more flexibility in tenant layouts. Partitions separating tenant spaces (so-called demising walls) were required to be $1 \mathrm{~h}$ (see Sec. 10.4.5). Enclosures for vertical shafts, including stairways and transfer corridors, elevator hoistways, and mechanical or utility shafts were required to be of $2 \mathrm{~h}$ fire rated construction. Protection of vertical shafts is intended to limit the spread of fire and smoke from floor to floor.

The primary egress system for the office spaces was the three stairways located in the building core. These included two 44 in. (designated A and C) and one 56 in. wide (designated B) stairs which provided exactly the code required capacity for an occupant load of 390 per floor $\left(39,000 \mathrm{ft}^{2}\right.$ net at $100 \mathrm{ft}^{2}$ per person). The layout within the building core was consistent with the Building Code requirements for maximum travel distance (200 ft unsprinklered, $300 \mathrm{ft}$ sprinklered) and, while the separation was consistent with New York City requirements ( $15 \mathrm{ft}$ and later $30 \mathrm{ft}$ ), it was short of the more common requirements found in all current building codes (one-half the diagonal of the space served if unsprinklered, or one-third the diagonal if sprinklered) on some of the floors where the transfer corridors brought the stair access closer together.

There were 99 passenger elevators in each tower, arranged in three vertical zones to move occupants in stages to skylobbies on the 44 th and 78 th floors. These were arranged as express (generaliy larger cars that moved at higher speeds) and local elevators in an innovative system first introduced in WTC 1 and WTC 2. There were 8 express elevators from the concourse to the 44 th floor and 10 express elevators from the concourse to the 78 th floor as well as 24 local elevators per zone, which served groups of floors in those zones. There were seven freight elevators, only one of which served all floors. All elevators had been upgraded to incorporate firefighter emergency operation per American Society of Mechanical Engineers (ASME) A17.1 and Local Law 5 (1973).

Consistent with practice at the time, the original fire alarm system in WTC 1 and WTC 2 was a manual system with four smoke detectors on each tenant floor, positioned to monitor for smoke entering the HVAC returns and arranged to stop the fans to prevent smoke circulation to non-fire areas. Local Law 5 (1973) included retroactive requirements for fire alarm systems and emergency voice communication systems in business occupancies over $100 \mathrm{ft}$ in height. Subsequently, such systems were installed in WTC 1 and WTC 2 with the required fire command center located in the underground parking garage, where it was destroyed by the blast in the 1993 bombing, rendering most fire safety features inoperable. Following the 1993 bombing, the fire command stations were relocated to the tower building lobbies, with a third monitoring location in the Port Authority offices. The lobby location (within sight of the elevators) is specified in the NYC Building Code for fire command centers required in high-rise buildings. There are no code requirements for off-site monitoring of fire alarm systems in this occupancy. 


\section{Modifications to the Fire and Life Safety Systems}

The general practice is that buildings are governed by the building code in force at the time the building permits are issued except in the rare case of the adoption of retroactive requirements. Local Laws 5 (1973) and 16 (1984) were adopted after completion of WTC 1 and WTC 2 but did contain some retroactive provisions. However, the Port Authority chose to implement virtually all of the provisions of LL 5/73 and LL 16/84, which drove most of the modifications to the fire and life safety systems that occurred over the life of the buildings. These modifications included the complete sprinklering of the buildings and several upgrades to the fire alarm system.

After the passage of Local Law 5, the Port Authority implemented a program to retrofit sprinklers and to offer tenants the option of sprinklering or compartmentation consistent with Local Law 5 provisions. Sprinklering of WTC 1 and WTC 2 was undertaken in three phases: Phase 1 was the sprinklering of below grade spaces completed with the original construction. Phase 2 was begun after Local Law 5 was adopted and included the installation of sprinkler risers and other infrastructure and the installation of sprinklers in corridors, storage rooms, lobbies, and smaller tenant spaces for tenants not selecting the compartmentation option. Phase 3 involved sprinklering the remaining tenant spaces, initially as tenants changed, and later on negotiated schedules. This process was underway when, in 1984, Local Law 16 was adopted, which required sprinklers in new high-rise buildings, including offices. Under Local Law 16 (1984) all floor spaces had to either be subdivided in accordance with the compartmentation requirement or sprinklered by February 8, 1988. A 1997 report states that there were four floors and the skylobbies (all in WTC 1) left to be sprinklered and that the installation of sprinklers at these floors was underway (Coty 1997). An October 1999 report states that sprinklering of the tenant floors was completed and sprinklering of the skylobbies was "currently underway" (PANYNJ 1999).

Issues identified after completion of the buildings that were not related to amendments to the NYC Building Code that were addressed during the occupancy included the extension of the tenant separation walls to run slab to slab, upgrading of the fireproofing to $1 \frac{1}{2}$ in. on the floor trusses, and correction of the egress deficiencies for Windows on the World by creating three areas of refuge on each floor with $2 \mathrm{~h}$ separations, each including a stair. These issues were identified through various independent reviews conducted by PANYNJ and contractors hired by PANYNJ to conduct "due diligence" surveys. One example was the surveys conducted in 1996 by Rolf Jensen and Associates and Jaros, Baum \& Bolles which identified inconsistencies with the code and programs to address them, which are discussed in this report in detail.

\section{Innovations in Fire and Life Safety Features}

Little about the towers' fire and life safety features would be considered novel or innovative. The fire alarm systems as originally provided and as upgraded over the life of the buildings were of high quality and state-of-the-art, but followed accepted practice as it evolved in those years. Similarly, the fire sprinkler system was high quality and state-of-the-art, following accepted practice with a few features following New York City practice that differed from the rest of the nation. This included manually operated fire pumps with a so called "standpipe telephone system" to communicate with the pump operator. Most codes and standards specify automatic fire pumps.

Two features that were novel (and thus innovative) were the use of lightweight trusses in the floor system with fire protection of sprayed fire-resistive material on steel bars (rather than angles). Another was the 
shaft enclosure system of reinforced gypsum planks with applied steel channels that formed the framing. While gypsum shaft enclosure systems are now common, this particular arrangement was not used before or since.

\section{Fuel System for Emergency Generators in WTC 7}

Several of the tenants in WTC 7 installed generators to supply critical operations with continuous power. These generators were installed on several floors within the building $(5,7,8$, and 9$)$ and fed from small ( 275 gal) "day tanks" near the generators. These day tanks were kept full by an automatic system of piping running to primary storage tanks $(24,000$ gal) located under the loading dock or a 6,000 gal tank in a 1st floor storage room associated with the generators for the Mayor's Office of Emergency Management on the 7 th floor. Details of the system design and installation are found in NIST NCSTAR 1-1 J. ${ }^{1}$

\section{E.11 FINDINGS}

The findings of this report are grouped into three categories: (1) general; (2) factors related to structural safety; and (3) factors related to fire safety.

\section{E.11.1 General}

Finding 1: The NYC Department of Buildings reviewed the WTC tower drawings in 1968 and provided comments to the PANYNJ concerning the plans in relation to the 1938 NYC Building Code. The architect-of-record submitted to the PANYNJ responses to those comments, noting how the drawings conformed to the 1968 NYC Building Code. All six comments made by the NYC Department of Buildings dealt with egress issues, but none questioned the large occupant loads for Windows on the World in WTC 1 or Top of the World in WTC 2.

Finding 2: In 1993, the PANYNJ and the NYC Department of Buildings entered into a memorandum of understanding that restated the PANYNJ's longstanding stated policy to ensure that its facilities in the City of New York meet and, where appropriate, exceed the requirements of the NYC Building Code. The agreement also provided specific commitments to the NYC Department of Buildings regarding procedures to be undertaken by the PANYNJ to ensure that buildings owned or operated by the PANYNJ are in conformance with the Building Standards contained in the NYC Building Code. Some salient points included in this agreement and the 1995 enhancement to the agreement are:

- Each project would be reviewed and examined for compliance with the Code.

- All plans would be prepared, sealed, and reviewed by New York State licensed professional engineers or architects.

- The PANYNJ engineer or architect approving the plans would be licensed in the State of New York and would not have assisted in the preparation of the plans.

\footnotetext{
This reference is to one of the companion documents from this Investigation. A list of these documents appears in the Preface
} to this report. 
- The person or firm performing the review and certification of plans for WTC tenants may be the same person or firm providing certification that the project had been constructed in accordance with the plans and specifications unless the proposed alteration would "change the character of the occupancy group under paragraph 27-237 of the NYC Building Code which would have been applicable to such space had such space been located in a privately owned building."

- Deviations from the Code, acceptable to the PANYNJ, would be submitted to the NYC Department of Buildings for review and concurrence. Disagreements between the PANYNJ and the NYC Department of Buildings over such deviations from the Code would be referred to the Port Authority Board of Commissioners for resolution.

Finding 3: While the PANYNJ entered into agreements with the NYC Department of Buildings in the 1990s with regard to conformance of PANYNJ buildings constructed in New York City to the NYC Building Code and sought review and concurrence as required by the agreements, the PANYNJ was not required to yield, and appears not have yielded, approval authority to New York City. The PANYNJ was created as an interstate entity "body corporate and politic," under its charter, pursuant to Article 1 Section 10 of the U.S. Constitution permitting compacts between states, and like many other nongovernmental and quasi-governmental entities in the United States is not subject to building and fire safety code requirements of any governmental jurisdiction.

Finding 4: State and local jurisdictions do not require retention of documents related to the design, construction, operation, maintenance, and modifications of buildings, with few exceptions. These documents are in the possession of building owners, contractors, architects, engineers, and consultants. Such documents are not archived for more than about 6 years to 7 years, and there are no requirements that they be kept in safe custody physically remote from the building throughout its service life. In the case of the WTC towers, the PANYNJ and its contractors and consultants maintained an unusually comprehensive set of documents, a significant portion of which had not been destroyed in the collapse of the buildings but could be assembled and provided to the investigation. In the case of WTC 7, several key documents could not be reviewed since they were lost in the collapse of the building.

Finding 5: Consistent with the practice at the time the (code) architect of record was responsible for specifying the fire protection and designing the egress system in accordance with the prescriptive provisions of the Building Code. The architect and owner engaged the services of structural engineers to perform the structural design and to ensure that his/her design was properly implemented. At that time the fire protection engineering profession was not sufficiently mature to require the same standard of care employed with the structural design. There is no reason to believe that the involvement of a fire protection engineer at that time would have resulted in any differences in the design or pcrformance of the fire protection systems. However, the technical base and sophistication of the practice of fire protection engineering today is well advanced of where it was then. Today, particularly when designing a building employing innovative features, the involvement of a fire protection engineer in a role similar to the structural engineer, and under the overall coordination of the Design Professional in Responsible Charge is central to the standard of care. Further, when designing the structure of selected tall buildings or selected other buildings to resist fires, or evaluating the fire resistance of such structures, it is essential for the structural engineer and the fire protection engineer to jointly provide the nccded standard of care. 


\section{E.11.2 Structural Safety}

\section{Applicable Building Codes}

Finding 6: Although not required to conform to New York City codes, the PANYNJ adopted the provisions of the proposed 1968 edition of the NYC Building Code, more than 3 years before it went into effect. The proposed 1968 edition allowed the PANYNJ to take advantage of less restrictive provisions and of technological advances compared with the 1938 edition, which was in effect when design began for the WTC towers in 1962. The 1968 code:

- Changed partition loads from 20 psf to one based on weight of partitions per unit length (that reduced such loads for many buildings including the WTC buildings); and

- Permitted wind tunnel tests using models to establish design values for the wind load.

Many of these newer requirements, instituted in the 1968 NYC Building Code, are contained in current model codes and building regulations.

\section{Structural Integrity}

Finding 7: Building codes lack explicit structural integrity provisions to mitigate progressive collapse. Federal agencies have developed guidelines to mitigate progressive collapse and routinely incorporate such requirements in the construction of new federal buildings. The United Kingdom incorporates such code requirements for all buildings. New York City adopted by rule in 1973 a requirement for buildings to resist progressive collapse under extreme local loads. The rules, which were adopted after the WTC towers were built but before WTC 7 was built, applied specifically to buildings that used precast concrete wall panels and not to other types of buildings.

Finding 8: Building codes lack minimum structural integrity provisions for the means of egress (stairwells and elevator shafts) in the building core that are critical to life safety. In most tall buildings the core is designed to be part of the vertical gravity load carrying system of the structure. However, in many of those buildings, especially in regions whcre earthquakes are not dominant, the core may not be part of the lateral load carrying system of the structure. Thus, the core may be designed to carry only vertical gravity loads with no capacity to resist lateral loads, i.e., overturning moment and shear loads. In such situations, the structural designer may prefer the use of partition walls over structural walls in the core area to reduce building weight. The decision to have the core carry a specified fraction of the lateral design loads or be made part of a dual system to carry lateral loads, each of which would enhance the structural integrity of the core if structural walls were used, is left to the discretion of the structural engineer. Alternatively, stairway/elevator cores built with concrete or reinforced concrete block, which are not part of the lateral load carrying system, may be able to provide sufficient structural integrity if they meet some appropriate performance criteria for impact resistance. In the case of the WTC towers, the core had $2 \mathrm{~h}$ fire-rated partition walls with little structural integrity and the core framing was required to carry only gravity loads. Had there been a minimum structural integrity requirement to satisfy normal building and fire safety considcrations, it is conceivable that the damage to stairways, especially above the floors of impact, may have been less extensive. 
Finding 9: Standards and code provisions for conducting wind tunnel tests and for the methods used in practice to estimate design wind loads from test results do not exist. Building codes allow the determination of wind pressures from wind tunnel tests for use in design. Such tests are frequently used in the design of tall buildings. Results of two sets of wind tunnel tests conducted for the WTC towers in 2002 by independent commercial laboratories as part of insurance litigation, and voluntarily provided to NIST by the parties to the litigation. show large differences, of as much as about 40 percent, in resultant forces on the structures, i.e., overturning moments and base shears. Independent reviews by a NIST expert on wind effects on structures and a leading engineering design firm contracted by NIST indicated that the documentation of the test results did not provide sufficient basis to reconcile the differences. Wind loads were a major governing factor in the design of structural components that made up the frame-tube steel framing system.

\section{E.11.3 Fire Safety}

\section{Applicable Building Codes}

Finding 10: Although not required to conform to New York City codes, the PANYNJ adopted the provisions of the proposed 1968 edition of the NYC Building Code, more than 3 years before it went into effect. The 1968 edition allowed the PANYNJ to take advantage of less restrictive provisions compared with the 1938 edition that was in effect when design began for the WTC towers in 1962. The 1968 code:

- Eliminated a fire tower ${ }^{2}$ as a required means of fire department access;

- Reduced the number of required stairwells from 6 to 3 and the size of doors leading to the stairs from 44 in. to 36 in.(by increasing stairway and door capacity allowances);

- Reduced the required fire rating of the shaft walls in the building core from $3 \mathrm{~h}$ to $2 \mathrm{~h}$; and

- Permitted a $1 \mathrm{~h}$ reduction in fire rating for all structural components (columns from $4 \mathrm{~h}$ to $3 \mathrm{~h}$ and floor framing members from $3 \mathrm{~h}$ to $2 \mathrm{~h}$ ) by allowing the owner/architect to select Class $1 \mathrm{~B}$ construction for business occupancy and unlimited building height.

Many of these newer requirements, instituted in the 1968 NYC Building Code, are contained in current codes.

Finding 11: In 1993, the PANYNJ adopted a policy providing for implementation of fire safety recommendations made by local government fire departments after a fire safety inspection of a PANYNJ facility and for the prior review by local fire safety agencies of fire safety systems to be introduced or added to a facility. Later that year, the PANYNJ entered into an agreement with the New York City Fire Department (FDNY), which reiterated the policy adopted by the PANYNJ, recognized the right of FDNY to conduct fire safety inspections of PANYNJ properties in the City of New York, provided guidelines for FDNY to communicate needed corrective actions to the PANYNJ, ensured that new or modified fire

2 A fire tower (also called a smoke-proof stair) is a stairway that is accessed through an enclosed vestibule that is open to the outside or to an open ventilation shaft providing natural ventilation that prevents any accumulation of smoke without the need for mechanical pressurization. 
safety systems are in compliance with local codes and regulations, and required third-party review of such systems by a New York State licensed architect or engineer.

\section{Standard Fire-Resistance Tests}

Finding 12: Code provisions with detailed procedures to analyze and evaluate data from fire resistance tests of other building components and assemblies to qualify an untested building element do not exist. Based on available data and records, no technical basis has been found for selecting the SFRM used (two competing materials were under evaluation) or its thickness for the large-span open-web floor trusses of the WTC towers. The assessment of the fireproofing thickness needed to meet the $2 \mathrm{~h}$ fire rating requirement for the untested WTC floor system evolved over time:

- In October 1969, the PANYNJ directed the fireproofing contractor to apply $1 / 2$ in. of fireproofing to the floor trusses.

- In 1999, the PANYNJ issued guidelines requiring that fireproofing be upgraded to $1 \frac{1}{2} \mathrm{in}$. for full floors undergoing alterations.

- Unrelated to the WTC buildings, an International Conference of Building Officials Evaluation Service report (ER-1244), re-issued June 1, 2001, using the same SFRM recommends a minimum thickness of $2 \mathrm{in.} \mathrm{for} \mathrm{"unrestrained} \mathrm{steel} \mathrm{joists"} \mathrm{with} \mathrm{"lightweight}$ concrete" slab.

Finding 13: Code provisions that require the conduct of a fire resistance test if adequate data do not exist from other building components and assemblies to qualify an untested building element are needed. Instead, several alternate methods based on other fire-resistance designs or calculations or alternative protection methods are permitted with limited guidance on detailed procedures to be followed. Both the architect-of-record (in 1966) and the structural-engineer-of-record (in 1975) stated that the fire rating of the floor system of the WTC towers could not be determined without testing. NIST has not found evidence indicating that such a test was conducted to determine the fire rating of the WTC floor system. The PANYNJ has informed NIST that there are no such test records in its files.

Finding 14: Use of the "structural frame" approach, in conjunction with the prescriptive fire rating, would have required the floor trusses, the core floor framing, and perimeter spandrels in the WTC towers to be $3 \mathrm{~h}$ fire-rated, like the columns for Class 1B construction in the 1968 NYC Building Code. Neither the 1968 edition of the NYC Building Code which was used in the design of the WTC towers, nor the 2001 edition of the code, adopted the "structural frame" requirement. The "structural frame" approach to fire resistance ratings requires structural members, other than columns, that are essential to the stability of the building as a whole to be fire protected to the same rating as columns. This approach, which appeared in the Uniform Building Code (a model building code) as early as 1953, was carried into the 2000 International Building Code (one of two current model codes) which states: "The structural frame shall be considered to be the columns and the girders, beams, trusses and spandrels having direct connections to the columns and bracing members designed to carry gravity loads." The WTC floor system was essential to the stability of the building as a whole since it provided lateral stability to the columns and diaphragm action to distribute wind loads to the columns of the frame-tube system. 
Finding 15: A technical basis to establish whether the construction classification and fire rating requirements in modern building codes are risk-consistent with respect to the design-basis hazard and the consequences of that hazard is needed. The fire rating requirements, which were originally developed based on experience with buildings less than about 20 stories in height, have generally decreased over the past 80 years since historical fire data for buildings suggested considerable conservatism in those requirements. However, for tall buildings, the likely consequences of a given threat to an occupant on the upper floors are more severe than the consequences to an occupant, say, on the first floor. It is not apparent how the current height and area tables in building codes consider the technical basis for the progressively increasing risk to an occupant on the upper floors of tall buildings that are much greater than about 20 stories in height where access by firefighters without the availability of firefighter elevators is limited by physiological factors. The maximum required fire rating in current codes applies to any building more than about 12 stories in height. There are no additional categories for buildings above, for example, 40 stories and 80 stories, where different building classification and fire ratings requirements may be appropriate, recognizing factors such as the time required for stairwell evacuation without functioning elevators (e.g., due to power failure or major water leakage), the time required for first responder access without functioning elevators, the presence of skylobbies and/or refuge floors, and limitations on the height of elevator shafts. The 110-story WTC towers, initially classified as Class IA based on the 1938 NYC Building Code, were classified as Class $1 \mathrm{~B}$ before being built to take advantage of the provisions in the 1968 edition of the code. This re-classification permitted a reduction of $1 \mathrm{~h}$ in the fire rating of the components (columns from $4 \mathrm{~h}$ to $3 \mathrm{~h}$ and floor framing members from $3 \mathrm{~h}$ to $2 \mathrm{~h}$ ).

\section{Fire Performance of Structures}

Finding 16: Rigorous field application and inspection provisions and regulatory requirements to ensure that the as-built condition of the passive fire protection, such as SFRM, conforms to conditions found in fire resistance tests of building components and assemblies is needed. For example, provisions are not available to ensure that the as-applied average fireproofing thickness and variability (reflecting the quality of application) is thermally equivalent to the specified minimum fireproofing thickness. In addition, requirements are not available for in-service inspections of passive fire protection during the life of the building. The adequacy of the fireproofing of the WTC towers posed an issue of some concern to the PANYNJ over the life of the buildings, and the availability of accepted requirements and procedures for conducting in-service inspections would have provided useful guidance

Finding 17: Structural design does not consider fire as a design condition, as it does the effects of dead loads, live loads, wind loads, and earthquake loads. Current prescriptive code provisions for determining fire resistance of structures-used in the design of the WTC towers and WTC 7-are based on tests using a standard fire that may be adequate for many simple structures and for comparing the relative performance of structural components in more complex structures. A building system with $3 \mathrm{~h}$ rated columns and $2 \mathrm{~h}$ rated girders and floors could last longer than $3 \mathrm{~h}$ or shorter than $2 \mathrm{~h}$ depending upon the performance of the structure as a 3-dimensional system in a rcal fire. The standard tests cannot be used to evaluate the actual performance (i.e., load carrying capacity) in a real fire of the structural component, or the structure as a whole system, including the connections between components. Performance-based code provisions and standards are not available for use by engineers, as an alternative to the current prcscriptive fire rating approach, to (1) evaluate the system performance of tall-building structures under real fire scenarios, and (2) enable risk consistent design with appropriate thickness of passive protection being provided where it is needed on the structure. Standards devclopment organizations, including the 
American Institute of Steel Construction, have initiated development of performance-based provisions to consider fire effects in structural design.

Finding 18: Detailed procedures to select appropriate design-basis fire scenarios to be considered in the performance-based design of the sprinkler system, compartmentation, and passive protection of the structure are needed. The standard fire in current prescriptive fire resistance tests is not adequate for use in performance-based design. While the NFPA 5000 model building code contains general guidance on design fire scenarios (the IBC Performance Code contains no such guidance), the details of the scenarios are left to the fire engineer and regulatory official. The three major scenarios that are not considered adequately are: frequent but low severity events (for design of sprinkler system), moderate but less frequent events (for design of compartmentation), and a maximum credible fire (for design of passive fire protection on the structure). The maximum credible fire scenario for passive protection of structures would assume that the sprinkler system is compromised or overwhelmed and that there is no active firefighting, as is explicitly considered for U.S. Department of Energy facilities. These building-specific representative fire scenarios are similar in concept, though not identical, to the approach used in building design where the performance objectives and design-basis of the hazard are better defined (e.g., a twolevel design that includes an operational event with a 10 percent probability of occurrence in 50 years and a life safety event with a 2 percent probability of occurrence in 50 years). The design-basis fire hazards for the WTC towers and WTC 7 are unknown, and it is difficult to evaluate the performance of the fire protection systems in these buildings under specific fire scenarios.

Finding 19: Code provisions to ensure that structural connections are provided the same degree of fire protection as the more restrictive protection of the connected elements are needed. The provisions that were used for the WTC towers and WTC 7 did not require specification of a fire-rating requirement for connections separate from those for the connected elements. It is not clear what the fire rating of the connections were when the connecting elements had different fire ratings and whether the applied fireproofing achieved that rating.

Finding 20: A technical basis to establish whether the minimum mechanical and durability related properties of SFRM are sufficient to ensure acceptable in-service performance in buildings is needed. While minimum bond strength requirements exist, there are no serviceability requirements for such materials to withstand typical shock, impact, vibration, or abrasion effects over the life of a building. There are existing testing standards for determining many of these properties, but the technical basis is insufficient to establish serviceability requirements. Knowledge of such serviceability requirements is relevant to determine the post-impact fireproofing condition of the WTC towers.

Finding 21: Validated and verified tools for use in performance-based design practice to analyze the dynamics of building fires and their effects on the structural system that would allow engineers to evaluate structural performance under alternative fire scenarios and fire protection strategies are needed. Existing tools are either too simplified to adequately capture the performance of interest or too complex and computationally demanding and lack adequate validation. While considerable progress has been made in recent years, significant work remains to be done before adequate tools are available for use in routine practice. NIST has had to further develop and validate existing tools to investigate the fire performance of the WTC towers and WTC 7. 


\section{Compartmentation and Sprinklers}

Finding 22: Building fire protection is based on a four-level hierarchical strategy comprising detection, suppression (sprinklers and firefighting), compartmentation, and passive protection of the structure.

- Detectors are typically used to activate fire alarms and notify building occupants and emergency services.

- Sprinklers are designed to control small and medium fires and to prevent fire spread beyond the typical water supply design area of about $1,500 \mathrm{ft}^{2}$.

- Compartmentation mitigates the horizontal spread of more severe but less frequent fires and typically requires fire-rated partitions for areas of about 7,500 $\mathrm{ft}^{2}$. Active firefighting measures also cover up to about $5,000 \mathrm{ft}^{2}$ to $7,500 \mathrm{ft}^{2}$.

- Passive protection of the structure seeks to ensure that a maximum credible fire scenario, with sprinklers compromised or overwhelmed and no active firefighting, results in burnout, not overall building collapse. The intent of building codes is also for the building to withstand local structural collapse until occupants can escape and the fire service can complete search and rescue operations.

Compartmentation of spaces is a key building fire safety requirement to limit fire spread. The WTC towers initially had $1 \mathrm{~h}$ fire-rated partitions separating tenants (demising walls) that extended from the floor to the suspended ceiling, not the floor above (the ceiling tiles were not fire rated). Over the years, these partitions were replaced with partitions that were continuous from floor to floor (separation wall) as required by the 1968 NYC Building Code. Some partitions had not been upgraded by 1997, and a consultant recommended to the PANYNJ that it develop and implement a survey program to ensure that the remediation process occurred as quickly as possible. It appears that with fcw exceptions, nearly all of the floors not upgraded were occupied by a single tenant, and it is not clear whether separation walls would have mattered in terms of meeting the 1968 code. The PANYNJ adopted guidelines in 1998 that required such partitions to provide a continuous fire barrier from top of floor to underside of slab.

Finding 23: Building codes typically require $1 \mathrm{~h}$ fire-rated tenant scparations but do not impose minimum compartmentation requirements (e.g., 13,000 $\mathrm{ft}^{2}$ ) for buildings with large open floor plans to mitigate the horizontal spread of fire. This is the case with both the 1968 NYC Building Code, which did not require sprinklers in occupied spaces on or above the ground floor, and the 2001 NYC Building Code, which requires sprinklcrs in Group E (Business) buildings over $100 \mathrm{ft}$ in height. The sprinkler option was chosen for the WTC towers in preference to the compartmentation option in meeting the subsequent requirements of Local Law 5 adopted by New York City in 1973. Thus, if there was only one tenant on a WTC floor there would be no horizontal compartmentation requirement. Conversely, if there were a large number of tenants on a WTC floor, it would be highly compartmented with separation walls. The affected floors in the WTC towers were mostly open-with a modest number of perimeter officcs and conference rooms and an occasional special purpose area. Some floors had two tenants and those spaces, like the core areas, were partitioned (slab to slab). Photographic and videographic evidence confirms that even non-tenant space partitions (such as those that divided spaces to provide corner conference rooms) provided substantial resistance to fire spread in the affected floors. For the duration of about 50 to $100 \mathrm{~min}$ prior to collapse of the WTC towers that the fires were active, the presence of undamaged $1 \mathrm{~h}$ 
fire-rated compartments may have assisted in mitigating fire spread and consequent thermal weakening of structural components.

Finding 24: State and local building regulations are needed that require installation of sprinklers in existing buildings on a reasonable time schedule, not as an option in lieu of compartmentation.

Functioning sprinklers can provide significant improvement in safety for most common building fires and prevent them from becoming large fircs. NYC promulgated local laws in 1973 and 1984 to encourage installation of sprinklers in new buildings and is now considering a law to require sprinklers in existing buildings. The WTC towers were fully sprinklered by 2001, about 30 years after their construction. Sprinklering of the tenant floors in the WTC towers was completed by October 1999, while sprinklering of the skylobbies was still underway at that time. The sprinkler system was installed in three phases. Phase 1 was completed during initial building construction and included the sub-grade areas. Phase 2 was completed in 1976, in compliance with Local Law 5, and included sprinklering the corridors, storage rooms, lobbies, and certain tenant spaces. Phase 3 was begun in 1983 and completed in 2001 and resulted in fully sprinklering the buildings.

Finding 25: Modern building codes allow a lower fire rating for structural elements when a building is sprinklered. This trade-off provides an economic incentive to encourage installation of sprinklers. Sprinklers provide better intervention against small and medium fires, fires which are more likely to occur than a WTC disaster, as long as the water supply is not compromised and there is redundant technology in place. The required technical basis is not available to establish whether the "sprinkler trade-off" in current codes adequately considers fire safety risk factors such as: (1) the complementary functions of sprinklers and fire-protected structural elements, (2) the different fire scenarios for which each system is designed to provide protection, and (3) the need for redundancy should one system fail. It is noteworthy that the British Standards Institution has established a group to review all the sprinkler trade-offs contained in their standards. No such formal review has yet been initiated in the United States. Although the classification and fire rating of the WTC towers did not take advantage of the sprinkler-tradeoff since such provisions were not contained in the 1968 NYC Building Code, had such provisions existed, they would have permitted a lower fire rating for many WTC building elements.

\section{Use of Elevators in Emergencies}

Finding 26: With a few special exceptions, building codes in the United States do not permit the use of fire-protected elevators for routine emergency access by first responders or as a secondary method (after stairwells) for emergency evacuation of building occupants. The use of elevators by first responders would additionally mitigate counterflow problems in stairwells. While the United States conducted research on specially protected elevators in the late 1970s, the United Kingdom along with several other countries that typically utilize British standards have required such "firefighter lifts," located in protected shafts, for a number of years. Without functioning elevators (e.g., due to a power failure or major water leakage), first responders carrying gear typically require about a minute per floor to reach an incident using the stairs. While it is difficult to maintain this pace for more than about the first 20 stories, it would take a first responder about an hour to reach, for example, the 60th floor of a tall building if that pace could be maintained. Such a delay, combined with the resulting fatigue and physical effects on first responders that were reported on September 11, 2001, would make firefighting and rescue efforts difficult even in tall building emergencies not involving a terrorist attack. Each of the WTC towers had 106 elevators, and WTC 7 had 38 elevators. By code, the elevators could not be used for fire service access or 
occupant egress during an emergency since they were not fire-protected, nor were they located in protected shafts. The elevators were equipped through normal modernization with fire service recall. Most were damaged by the aircraft impacts; though prior to the impact in WTC 2 the elevators were functioning and contributed greatly to the much faster initial evacuation rate in WTC 2. 
This page intentionally left blank. 


\section{Chapter 1 \\ INTRODUCTION}

\section{$1.1 \quad$ BACKGROUND}

On September 11, 2001, the 110-story twin towers of the World Trade Center (WTC) complex ${ }^{1}$ (WTC 1 and WTC 2) were each attacked by a hijacked Boeing 767 airplane. The first airplane struck WTC 1 at 8:46 a.m. Eastern Daylight Time, and the second airplane struck WTC 2 at 9:03 a.m. Eastern Daylight Time. The impact of the airplanes caused severe damage to the buildings and significant fire. WTC 1 collapsed at 10:29 a.m. and WTC 2 at 9:59 a.m. Debris from the collapse of the towers caused severe damage to surrounding buildings of the WTC complex (WTC 3 through WTC 7). WTC 7, a 47-story office building, burned unattended for about $7 \mathrm{~h}$ before collapsing at 5:20 p.m.

As stated in the Preface, the National Institute of Standards and Technology (NIST) Investigation is comprised of eight interdependent projects (refer to Table P-1). This report presents the results of Project 1 "Analysis of Building and Fire Codes and Practices." The project was carried out to support one of the four primary objectives of the NIST Investigation, which is to determine the procedures and practices that were used in the design, construction, operation, and maintenance of the WTC 1, 2, and 7 (for other objectives, see the Preface). This report documents criteria used to design and construct the buildings and maintenance of the structural and fire safety systems. It also addresses innovative systems and materials that were incorporated into the design and construction process. Based on this information, NIST has identified procedures and practices for which improvements are recommended.

\subsection{SCOPE OF REPORT}

The assessment of the criteria, procedures, and practices that were used in the design, construction, operation, and maintenance of WTC 1,2, and 7 involved reviewing the design and construction documents of these buildings, including design drawings, specifications, and design calculations. In addition, since the 1968 New York City (NYC) Building Code was adopted by the Port of New York Authority (whose name was changed to the Port Authority of New York and New Jersey [PANYNJ or Port Authority] in 1972, and is subsequently referred to as the Poit Authority herein) for design and construction of the WTC 1,2, and 7, review of relevant provisions of that code and similar provisions of other contemporaneous codes was necessary to place in context the design and construction practices that were used for WTC 1, 2, and 7.

Traditionally, owners and designers of major construction projects maintain the design and construction documents. In the case of the WTC buildings, the design and construction documents that were kept at the Port Authority office in WTC 1 were destroyed when the tower collapsed. Thus, available copies of design and construction documents of WTC 1,2, and 7 had to be assembled from various sources that were associated with the WTC projects.

1 The WTC complex was composed of seven buildings. They are referred to as WTC 1 through WTC 7 in this report. For specific details, see Sec. 2.1. 
NIST obtained a considerable amount of information (design drawings, shop drawings, specifications, project correspondence, and inspection reports) related to WTC 1 and WTC 2 from the structural engineering firm involved in the original design and subsequent modifications to WTC 1 and WTC 2. The Port Authority provided construction related files for WTC 1, 2, and 7, mostly pcrtaining to tenant alteration projects, wherein tenants modified parts of the buildings to meet their needs. No document was obtained from the general contractor of WTC 1, 2, and 7 who had discarded the construction documents after retaining them for about 7 years. As a result, records were not available from the general contractor pertaining to changes to the structural and fire safety systems that were made during construction.

The information collected enabled NIST to document the following:

- Factors related to the design and construction of structural systems:

- Provisions used to design and construct the buildings.

- Criteria used to proportion structural members and other components of the buildings, including structural connections.

- Innovative systems, technologies, and materials that were incorporated in the design and construction.

- Tests performed to support the design, such as wind tunnel tests and tests of structural assemblies.

- Deviations granted by the Port Authority, including the justification for those deviations.

- Special fabrication and inspection requirements.

- Inspection protocols used during construction.

- Technical problems that occurred during construction of the buildings and their resolution.

- Comparison of the structural provisions in the 1968 New York City (NYC) Building Code with other contemporaneous code provisions:

- Differences between the 1968 NYC Building Code and the contemporaneous building codes of New York State, Chicago, and Building Officials and Code Administrators, International (BOCA), and the 2001 NYC Building Code.

- Maintenance of and modifications to the structural system:

- Guidelines used by the Port Authority for inspection, repair, and modifications.

- Structural integrity inspection programs during the occupancy of the buildings.

- Any significant modifications to and/or repairs of the original structural framing system by the owner or tenants during original construction and occupancy. 
- Factors related to the design and construction of the fire protection and egress systems:

- Provisions used to design and construct the fire protection and egress systems of the buildings.

- Building regulations adopted after the issuance of the certificates of occupancy that were applied to the buildings retroactively, including any provisions of New York City Local Laws, and any permits issued or special inspections required resulting from the installation of special hazards or equipment in the buildings.

- Comparison of the fire safety provisions in the 1968 NYC Building Code with other contemporaneous code provisions:

- Differences between the 1968 NYC Building Code and the contemporaneous building codes of New York State, Chicago, and Building Officials Conference of America (BOCA), and the 2001 NYC Building Code.

- Evolution of the life safety provisions in the NYC Building Code since the design of WTC 1 and WTC 2.

- Maintenance of and modifications to the fire protection and egress systems:

- Guidelines used by the Port Authority for inspection, repair, and modifications to fire protection and egress systems.

- Any repairs and modifications made to the passive and active fire protection systems from initial occupancy to September 11, 2001.

- The fuel system for emergency power in WTC 7 to determine:

- Locations of emergency power generating systems.

- Size and locations of the fuel storage tanks and distribution systems.

- Specific fire protection systems used for the fuel storage and distribution systems.

- Normal and emergency operating procedures.

- Maintenance history.

This report provides an overview and comparison of building codes in use at the time when WTC 1,2, and 7 were designed and constructed. It includes a description of the buildings as designed and relates features of the buildings to the code requirements and accepted practices of the time. Also presented is the evolution of codes during the time the buildings were in use and a description of how the buildings were modified and upgraded over the same period. Even though many of the new code requirements did not apply to existing buildings, in several instances these new approaches were incorporated and systems upgraded accordingly. Also identified were some issues that were not consistent with code requirements, such as the sprayed fire-resistive materials and tenant separation walls that were eventually addressed by 
upgrade projects. The upgrades were performed on change of tenancy over many years. The reader should note that the documentation of certain systems and their condition and arrangement on September 11,2001 are included in other reports. Specifically, the elevators and egress stairs are discussed in NIST NCSTAR 1-7, and the fire alarm, sprinkler, and smoke management systems in NIST NCSTAR 1-4. These references are to the companion documents from this Investigation. A list of these documents appears in the Preface to this report.

\subsection{DESIGN AND CONSTRUCTION REQUIREMENTS FOR WTC 1, 2, AND 7}

For most buildings constructed in the United States, building codes adopted by local jurisdictions establish minimum requirements for design and construction. However, because the Port Authority is an interstate entity, which was established in 1921 under a clause in the U.S. Constitution, its construction projects are not required to comply with any state or local building code. For the design of the WTC towers, which began in 1962, the Port Authority in May 1963 instructed the architect and engineers to prepare their designs of WTC 1 and WTC 2 to comply with the NYC Building Code. ${ }^{2}$ While not specifically stated in the 1963 letter to the architect, the 1938 edition of the Code was in effect at that time. In areas where the Code was not explicit or where technological advances made portions of the 1938 Code obsolete, the Port Authority also directed the architect and engineers to propose designs "based on acceptable engineering practice." When such situations occurred, the Port Authority required the architect and engineers to inform the Planning Division of the WTC. The Port Authority established a special WTC office that reviewed and approved plans and specifications, issued deviations, and conducted inspections during construction instead of the city agencies that would normally perform these duties.

In September 1965, the Port Authority instructed the architect and engineers to revise their designs for WTC 1 and WTC 2 to comply with the second and third drafts of the NYC Building Code that was under development and to undertake any design modifications necessary to comply with the new code provisions. ${ }^{3}$ Prior to issuance of this instruction, the Port Authority recognized that the draft version of the new NYC Building Code had incorporated advanced techniques, and the Port Authority favored the use of advanced techniques in the design of the WTC towers. ${ }^{4}$ By adopting the draft versions of the new NYC Building Code, the Port Authority had an option of classifying WTC 1 and WTC 2 as Type 1-B Construction instead of Type 1-A Construction (see Sec. 9.1.3 for definition and fire protection requirements of Construction Type), and several architectural features related to egress were modified in the final design (see Sec. 10.1). This relaxation of code requirements allowed the Port Authority to gain economic advantage. 5 The new NYC Building Code (NYC BC 1968) was enacted by the City Council on October 22, 1968, approved by the Mayor on November 6, 1968, and became effective on December 6, 1968.

2 Letter dated May 15, 1963 from Malcolm P. Levy (Chief, Planning Division, World Trade Department, PANYNJ) to Minoru Yamasaki (architect, Minoru Yamasaki \& Associates) (See Appendix A).

3 Letter dated September 29, 1965 from Malcolm P. Levy (Chief, Planning Division, World Trade Department, PANYNJ) to Minoru Yamasaki (architect, Minoru Yamasaki \& Associates) (See Appendix A).

4 Memorandum dated June 22, 1965 from John M. Kyle (Chief Engineer, PANYNJ) to Malcolm P. Levy (Chief, Planning Division, World Trade Department, PANYNJ) (See Appendix A).

Memorandum dated January 15, 1987 fromLester S. Feld (Chief Structural Engineer, World Trade Department) to Robert J. Linn (Deputy Director, Physical Facilities, World Trade Department) (See Appendix A). 
The Port Authority also required that all design concepts were to be reviewed before the final design by the Chief Engineer of the Port Authority and by the appropriate New York City agencies. A letter in 1975 from the architect-of-record for the WTC project to the Port Authority indicates that the New York City Building Department reviewed the design drawings of WTC 1 and WTC 2 in February $1968 .{ }^{6}$

Unlike WTC 1 and WTC 2, which were developed and owned by the Port Authority, WTC 7 was developed on land owned by the Port Authority, but the building was owned by Seven World Trade Company and Silverstein Development Corporation, General Partners. It was designed and constructed as a "Tenant Alteration Project" of the Port Authority. When IVTC 7 was designed in the mid-1980s, the 1968 NYC Building Code with amendments was in effect. The Project Specifications for WTC 7, issued in 1984, required that the structural steel be designed in accordance with the then current NYC Building Code.

The Port Authority developed a tenant alteration process for any modifications to leased spaces in WTC 1 and IVTC 2 to maintain structural integrity and fire safety. In 1971, the Port Authority issued the first edition of a set of requirements, Tenant Construction Review Manual (see NIST NCSTAR 1-1C, Appendix A), shortly after the first tenants occupied WTC 1 in December 1970 and before initial occupancy of WTC 2 in 1972. The manual contained the technical criteria to be used in planning alterations (architectural, structural, mechanical, electrical, and fire protection) to suit the needs of tenants. The manual included applicable standards to be used by tenants and their agents and review criteria to be used by the Engineering Department of the Port Authority. Alteration designs were to be completed by registered design professionals, and at the completion of the work, as-built drawings were to be submitted to the Port Authority. The 1968 NYC Building Code was referenced, and specific code provisions were referenced in various checklists. The review manual was updated in 1979, 1984, 1990, and 1997. at which times changes that had been made to the NYC Building Code were incorporated. In 1998, the manual was complemented by Architectural and Structural Design Guidelines, Specifications, and Standard Details (see NIST NCSTAR 1-1C, Appendix F), which dealt specifically with alterations to WTC 1 and WTC 2. Since WTC 7 was built as a "tenant alteration project," its design and construction followed the requirements in the 1984 edition of the Tenant Construction Review Manual. Any modifications to the building after initial occupancy were carried out in accordance with the manual.

\subsection{ORGANIZATION OF REPORT}

This report is organized in fourteen chapters:

- Chapter 1 covers the background and the scope of the report.

- Chapter 2 presents architectural and structural descriptions of WTC 1, 2, and 7.

- Chapter 3 presents the evolution of building codes in the United States, the development of the building code of New York City, and design requirements and policies of the Port Authority of New York and New Jersey.

${ }^{6}$ Letter dated February 18, 1975 from Joseph H. Solomon (Architect, Emory Roth \& Sons) to Malcolm P. Levy (General Manager, World Trade Center Operations) (See Appendix A). 
- Chapter 4 provides an overview and comparison of building codes in use at the time WTC 1, 2, and 7 were designed and constructed. Also presented is the evolution of codes during the time the buildings were in use and how the buildings were modified and upgraded over the same period. The structural code provisions compared include the 1964 New York State Building Construction Code, the 1965 BOCA model building code, and the 1967 Municipal Code of Chicago. A comparison was also made between the 1968 NYC Building Code and the current (2001) NYC Building Code.

- Chapter 5 presents the criteria for structures used to design WTC 1,2, and 7.

- Chapter 6 presents innovative features incorporated in the structural design of WTC 1 and WTC 2.

- Chapter 7 presents the protocols for inspection of steel members during fabrication and erection, and deviations that were requested by fabricators and the erector and granted by the Port Authority.

- Chapter 8 covers structural maintenance and modifications to WTC 1,2, and 7 during occupancy.

- Chapter 9 compares the fire safety provisions in the 1964 New York State Building Construction Code (NYSBC 1964), the 1965 BOCA model building code (Basic Building Code), and the 1967 Municipal Code of Chicago (MCC 1967). A comparison was also made between the 1968 NYC Building Code and the current (2001) NYC Building Code. This chapter also describes various construction classifications of buildings.

- Chapter 10 describes passive and active fire protection systems used in WTC 1, 2, and 7, and egress provisions in the WTC towers.

- Chapter 11 presents maintenance of and modifications to fire safety systems in WTC 1, 2, and 7 during occupancy.

- Chapter 12 presents the fuel system distribution for emergency power generators in WTC 7.

- Chapter 13 presents the findings of this report.

- Chapter 14 covers the reference cited in this report. 


\section{Chapter 2 \\ DESCRIPTION OF WTC 1, 2, AND 7}

\section{$2.1 \quad$ SITE PLAN OF WTC COMPLEX}

The World Trade Center (WTC) complex was located in Manhattan, New York City, near the Hudson River. The complex was comprised of seven buildings (referred to in this report as WTC 1 through WTC 7). Figure 2-1 depicts the locations of these buildings relative to the surrounding streets. The two towers, WTC 1 (North Tower) and WTC 2 (South Tower), were each 110 stories high. WTC 3 (Marriott Hotel) was 22 stories. WTC 4 (South Plaza Building) and WTC 5 (South Plaza Building) were both ninestory office buildings. WTC 6 (U.S. Customs House) was an eight-story office building. These six buildings were built around a 5-acre WTC Plaza. WTC 7 was a 47 -story office building which was built just north of the six-building WTC site. There was a six-story subterranean structure below a large portion of the WTC Plaza and WTC 1,2,3, and 6. In order to build this subterranean structure, a bentonite slurry wall was built surrounding the perimeter of the subterranean structure prior to excavation. The slurry wall was replaced section by section with reinforced concrete wall which served as a continuous foundation wall for the subterranean structure. The reinforced concrete wall was temporarily supported by rock anchors to provide lateral stability. The permanent lateral support was provided by the subterranean floor slabs. The application of slurry wall technology was considered to be an innovative idea (ENR 1964).

The first six buildings on the site were developed by the Port Authority. Groundbreaking for WTC 1 and WTC 2 was in 1966, and the first tenant began to occupy WTC 1 in December 1970 and WTC 2 in January 1972. Construction of other buildings continued during the 1970 s and the 1980 s. $^{7}$ Construction of the last building, WTC 7, was completed in 1987. It was developed by a consortium of Seven World Trade Company and Silverstein Development Corporation.

\subsection{DESCRIPTION OF WTC 1 AND WTC 2}

\subsubsection{Building Description}

WTC 1 and WTC 2 (also known as North Tower and South Tower) each consisted of a 110-story structure above the Concourse level (109-story above the Plaza level) and 6-story structure below the Concourse level. ${ }^{8}$ Although the towers were similar, they were not identical. The height of WTC 1 at the roof level was 1,368 ft above the Concourse level, $6 \mathrm{ft}$ taller than WTC 2, and WTC 1 supported a $360 \mathrm{ft}$ tall antenna for television and radio transmission. Figure 2-2 shows the west elevation of WTC 1, and Fig. 2-3 shows a typical exterior wall from the foundation to floor 9.

\footnotetext{
7 A brochure entitled "The World Trade Center" published by the Port of New York Authority, New York, NY and "World Trade Center Fact Sheet" published by the Port Authority of New York and New Jersey, New York, NY, April 1994.

8 The architectural and structural descriptions and dimensions of the WTC buildings in this report are based on the design drawings of these buildings obtained from the Port Authority of New York and New Jersey.
} 
Each tower had a square plan with the side dimension of approximately $207 \mathrm{ft}$. The exterior columns (perimeter columns) were placed with respect to the column reference lines, wherein the geometric centers of the exterior columns were offset from the column reference lines (see Sec. A-A, Fig. 2-9). The four reference lines surrounding the base of the tower established the footprint of the building. The column reference lines were spaced at $207 \mathrm{ft} 2 \mathrm{in}$. The corners of the tower were chamfered $6 \mathrm{ft} 11$ in.

Each tower had a core service area of approximately $135 \mathrm{ft}$ by $87 \mathrm{ft}$. All elevators were located within the core. Three stairs were also located within the core except at the mechanical floors where the stairs were located outside the structural core area (the area enclosed by the four corner columns of the core). For detailed descriptions of the stair locations, see Table 2-1, NIST NCSTAR 1-7. A typical architectural floor plan in the tower is shown in Fig. 2-4. As can be seen in this figure, placing all service systems within the core provided nearly a column-free floor space of approximately $31,000 \mathrm{ft}^{2}$ per floor outside the core. The long axis of the core in WTC 1 was oriented in the east-west direction, while the long axis of the core in WTC 2 was oriented in the north-south direction. Design wind forces were different for the two towers (the presence of one tower had an effect on the wind pressures on the other tower, see NIST NCSTAR 1-2), and that resulted in somewhat different lateral-force resisting system design. Thus, the two towers appear similar, but they were structurally different.

The exterior walls were composed of steel columns and spandrel beams. Above the 7th floor level, the columns were welded steel plate box columns of an approximately 14 in. square section. Each building face consisted of 59 columns spaced at $3 \mathrm{ft} 4$ in. on center. Adjacent columns were interconnected at each floor level by deep spandrel plates, typically 52 in. deep. As seen in Fig. 2-3, below floor 7, the columns are combined in groups of three to form single base columns which are spaced $10 \mathrm{ft}$ on center. The external cladding, which covers the columns and spandrel beams, consisted of aluminum sheets. The window openings were infilled with glass fitted into aluminum frames and sealed with neoprene gaskets.

Fire protection of structural steel members in the WTC towers was provided by fire resistive materials, either sprayed fire-resistive materials (SFRMs), gypsum wallboards, or a combination of the two, depending upon the type of structural members. All floor trusses and beams were protected with SFRM. The columns inside the core were either covered with gypsum wall board or a combination of gypsum wall board and SFRM. For the exterior columns, vermiculite plaster was applied to the side of the column facing the interior of the building, whereas SFRM was applied to the other three faces. No fire resistive material was applied to the underside of the metal deck, which was in contact with the concrete slab above. For a detailed discussion of the passive fire protection of steel members, see NIST NCSTAR 1-6A.

For typical tenant floors, the ceiling was suspended from the steel trusses. The space between the ceiling and the floor above was used for the mechanical and electrical systems.

Elevators were the primary mode of routine ingress and egress from the towers for tens of thousands of people on a daily basis. In order to minimize the total floor space needed for elevators, each tower was divided into three zones by the skylobbies, which served to distribute passengers among express and local elevators (for details, see NIST NCSTAR 1-7). In this way, the local elevators within a zone were placed on top of one another within a common shaft. Figure 2-5 shows the elevator riser diagram for WTC 1 and WTC 2. People transferred from express elevators to local elevators at the skylobbies which were located on the 44th and 78th floors in the both towers. Each tower had 99 elevators within the core of the building, including seven freight elevators, most serving a particular zone, and dedicated express 
elevators that served the restaurant, bars, and meeting rooms on floors 106 and 107 of WTC 1, as wcll as the observation deck in WTC 2. The concept of multiple elevators in a common shaft was first used in the WTC towers and has since become the norm for buildings taller than about 50 stories. This approach allowed an increase of useable space in WTC 1 and WTC 2 from 62 percent to 75 percent per floor (Sullivan 1964).

The architectural design was performed by Minoru Yamasaki \& Associates, with Emory Roth \& Sons, P.C. serving as the architect of record. The structural engineer of record was the firm of Skilling, Helle, Christiansen, Robertson (SHCR). Jaros, Baum \& Bollers were the mechanical engineers, and Joseph R. Loring \& Associates were the electrical engineers. Tishman Construction Corporation was the general contractor. The foundation of the towers was designed by the Engineering Department of the Port of New York Authority (see footnote 6).

\subsubsection{Structural Description}

As described above (Sec. 2.2.1), both WTC 1 and WTC 2 were 116 stories above the foundation (110 stories above grade and 6 stories below grade). The buildings were square in plan, $207 \mathrm{ft} 2 \mathrm{in}$. by $207 \mathrm{ft} 2 \mathrm{in}$. (based on column reference lines), and with story heights of typically $12 \mathrm{ft}$. The core area was approximately $135 \mathrm{ft}$ by $87 \mathrm{ft}$ in plan. (Approximate dimensions are stated as the dimensions on the architectural and structural drawings are given in reference to "column reference lines," and they do not necessarily coincide with the centroid of the column cross section.)

Each tower was comprised of five structural systems: a framed tube for the exterior walls above grade, simple frames (beams and columns with simple connections) for the core, braced frames for the exterior walls below grade, composite floor framing, and hat trusses at the roof level. As a framed-tube system, the exterior walls of each tower, comprised of closely spaced columns that were connected by spandrel beams around the perimeter at each floor level, were designed to resist all lateral loads. The resistance to lateral load was provided by the caltilever action of the tube. All columns of a frame-tube building experience mainly axial forces. For a square framed-tube building, the exterior columns on the faces normal to the wind direction are either in tension or in compression. The columns in the windward-side wall are in tension, and the columns in the leeward-side wall are in compression. The sidc walls are analogous to the web of a beam, mainly in shearing action. Thus, the axial forces in columns of the side walls vary from the windward side in tension to the leeward side in compression. Figure 2-6 illustrates the axial force distribution in columns. The figure also shows the shear-lag effect due to the in-plane flexibility of the spandrel beams. The shear lag effect increases the column loads near the corners and decreases in the center region of the walls that are perpendicular to the direction of wind. Analyses of the towers under wind loads indicate that the patterns of the axial force distribution in the columns due to wind loads are similar to those shown in Fig. 2-6 (NIST NCSTAR 1-2). Typical cross sections of the exterior walls are shown in Fig. 2-7. As seen in the figure, they were constructed of steel built-up columns and spandrel beams comprised of plates.

Since the lateral loads are resisted mainly by the exterior walls in a framed tube system, the interior core columns do not contribute to the over-all lateral stiffness of the building. For the WTC towers, both the exterior columns and the core columns were designed to support an approximately equal amount of the total gravity loads (see NIST NCSTAR 1-2). In the typical WTC tower floor plan, the area inside the core was framed with structural steel shapes acting compositely with formed concrete slabs. Most of the 
floor beam members were connected to columns by simple connection. The columns in the interior core of the towers were designed to carry mainly the gravity (vertical) loads, except in the atrium area (below floor 7 to the foundation), where there were fewer perimeter columns in the outer walls; bracings were used in the outer perimeter of the core area to increase lateral stiffness. In the lower part of the towers, the outer core columns were designed to resist a portion of the lateral forces.

\section{Exterior Walls}

The exterior wall columns, built-up of steels plates, from the foundation level up to Elevation $363 \mathrm{ft}$ (column splice point below floor 7, see Fig. 2-3) were spaced $10 \mathrm{ft}$ on center, and they were connected by spandrels. Bctween the Concourse Level and the foundation, these columns were braced diagonally to form braced frames in the plane of the exterior walls (Fig. 2-3). Between Elevation $363 \mathrm{ft}$ and floor 7, single exterior wall columns spaced $10 \mathrm{ft}$ on center transitioned to three columns spaced $3 \mathrm{ft} 4 \mathrm{in}$. on center (Fig. 2-8) to form "tree" assemblies.

Between floors 9 and 107, the perimeter structure consisted of closely spaced, built-up box columns. Each building face consisted of 59 columns. The columns were fabricated by welding plates of steel to form an approximately 14 in. square section (Fig. 2-7). The columns were interconnected at each floor level by $52 \mathrm{in.} \mathrm{deep} \mathrm{spandrel} \mathrm{plates} \mathrm{to} \mathrm{form} \mathrm{a} 10 \mathrm{ft}$ wide and $36 \mathrm{ft}$ tall panel (Fig. 2-9). Heavy end, or "butt" plates of 1.375 in. to 3 in. thick were welded to the top and bottom of each column. Fillet welds were used inside the columns along three edges, with a groove weld on the fourth, outside edge. The exterior walls were erected by connecting the prefabricated panels. The panels were field-bolted to adjacent panels with dual splice plates (see Fig. 2-7), and columns were bolted to the adjacent columns, using ASTM International (ASTM) A 325 bolts except for the heaviest butt plates, where ASTM A 490 bolts were used. Other than at the mechanical floors, panels were staggered so that only one third of the columns were spliced (i.e., connected) in any one story (Fig. 2-10). At the mechanical floors, the perimeter columns were spliced at the same level (i.e. floors 74 and 77). These splices were both welded and bolted.

At each corner of the building, the spandrel plate connected the column on one face of the building to the column on the other face at each floor level. The corner spandrel plates between two floors were interconnected by a box-shape vertical member. The vertical members were attached to the corner spandrels at alternate stories and thus, they are not continuous from the top of the building to the foundation. The corner vertical members were attached to the building during the construction period to aid hoisting of construction material.

Fourteen grades of steel were specified in the design documents for the perimeter columns, with minimum yield strengths of $(36,42,45,46,50,55,60,65,70,75,80,85,90$, and 100) ksi. Twelve grades of steels were actually used (see NIST NCSTAR 1-3). Twelve grades of steel were specified for the spandrels, with the same strength levels as the columns, but without the two highest strength steels. The structural engineering plans indicate that the flanges and webs of a given column section consist of a single grade (i.e., minimum yield strength) of steel, but each column and spandrel within a single prefabricated panel could be fabricated from different grades of steel. The use of different grades of steel facilitated in maintaining uniform exterior dimensions of the exterior columns throughout the building as well as equalize the dead load stresses and shortening of very tall steel columns. 
Columns in the upper stories were typically fabricated of thinner steel plates, as thin as 0.25 in., with the grade of steel dictated by the calculated gravity and wind loads. In this manner, the gravity load on the lower stories was minimized. In the lower stories the perimeter column webs were often more than 2 in. thick.

The spandrels formed an integral part of the columns; there was no inner web plate at spandrel locations. Spandrels were generally specified with a yield strength lower than that of the column webs and flanges, as well as a heavier gauge than the adjacent inner webs.

\section{Core Columns}

As stated above, the core columns were designed to support approximately 50 percent of the gravity loads. The core columns were of two types: welded box columns and rolled wide flange shapes (Fig. 2-11). The columns in the lower floors were primarily very large box columns, as large as 12 in. by 52 in., comprised of welded plates up to 7 in. thick. In the upper floors, the columns shifted to the rolled wide-flange shapes. The transition floors are indicated in Fig. 2-12 for each of the core columns. Core columns were typically spliced at three-story intervals. Diagonal bracing was used at the mechanical floors and in the area of the hat truss. Steel used for core box columns was either $36 \mathrm{ksi}$ or $42 \mathrm{ksi}$. Core wide flange columns were specified to be one of four grades, but were primarily $36 \mathrm{ksi}$ and $42 \mathrm{ksi}$ steel; only about 1 percent of all the core columns were made of $45 \mathrm{ksi}$ or $50 \mathrm{ksi}$ steel.

\section{Foundation}

For the core columns, a column base plate distributed the column load to a steel grillage compriscd of two-layers of steel beams. The steel grillage, in turn, distributed the column load to the reinforced concrete spread footings, which were directly in contact with the bedrock.

For the exterior columns, a large steel base plate, ranging from 7 to $9 \mathrm{ft}^{2}$, was used to transfer the individual column load to the reinforced concrete wall footing. The wall footing was placed around the perimeter of the tower. The concrete footing was in direct contact with the bedrock.

\section{Floor Framing System}

The floor system of a framed-tube structure is designed for four main functions. First, it supports the vertical gravity loads on the floor and transfers these loads to the external and core columns. Second, as a diaphragm it distributcs wind loads to the side walls of the framed tube structure. Third, it, togcther with the external frame, provides the stiffness to resist torsional motion of the building. Fourth, it provides lateral support to the columns, thereby, keeping the columns stable. The effectiveness of the framed-tube action is dependent on the inplane stiffness of the floor framing system. If the floor inplane stiffness is low (flexible diaphragm), the framed tube action cannot be developed effectively, and the structure behaves like a moment-resisting frame. On the other hand, if the inplane floor stiffness is high (rigid diaphragm), wind loads are distributed to the columns in the side frames, and the structure behaves like a framed tube. For WTC 1 and WTC 2, the floor system was comprised of concrete-steel composite members as described below. A typical trussed-framed floor framing is shown in Fig. 2-13. Analyses of the inplane stiffness showed that the typical floor system of WTC towers behaved as a stiff diaphragm 
(see NIST NCSTAR 1-2A), and the WTC towers behaved more like a framed tube than a momentresisting frame.

The floor inside the core and the mechanical floors were framed with structural steel shapes with welded shear studs, acting compositely with normal-weight concrete slabs. The thickness of concrete slab in these floors varied from 4.5 in. to 8 in. depending upon the design load requirements. The area outside the core (typically tenant floors) was framed with steel trusses, acting compositely with 4 in. thick lightweight concrete slabs cast on 11/2 in., 22 gauge fluted metal deck. The trusses consisted of double angle top and bottom chords with round bar webs. The composite action was achieved by the shear connection provided by the web bar extending above the top chord and into the slab in the form of a "knuckle" (see Fig. 2-14). Parcd trusses, spaced at $6 \mathrm{ft} 8$ in. on center, were supported at every other exterior column. The metal deck which spanned parallel to the main trusses was directly supported by transverse bridging trusses spaced at $13 \mathrm{ft} 4 \mathrm{in}$. and intermediate deck support angles spaced at $6 \mathrm{ft} 8 \mathrm{in}$. from the transverse bridging trusses. The typical floor consisted of three truss zones; a long-span zone, a short-span zone, and a two-way zone (see Fig. 2-15). The span of the trusses was about $35 \mathrm{ft}$ in the shortspan zone and $60 \mathrm{ft}$ in the long-span zone.

The floor trusses were pre-assembled into floor panels. The prefabricated floor panels were typically $20 \mathrm{ft}$ wide, containing two sets of double trusses in the interior and a single truss along each edge. In addition, the bottom chord of each pair of trusses was attached to perimeter spandrels with viscoelastic dampers (see Fig. 2-16). The main purpose of these dampers was to supplement the steel frame in limiting wind-induced building oscillations.

Pairs of flat bars (straps) extended diagonally from the top chord of the floor trusses to the perimeter columns (see Fig. 2-13). Once in place, 4 in. of lightweight concrete was placed on the steel deck. Figure 2-17 shows an assembled floor panel before the concrete was placed.

The minimum yield strengths of the steel for the design of the floor trusses were specified to be $36 \mathrm{ksi}$ and $50 \mathrm{ksi}$ for different parts of the trusses. According to the fabrication drawings prepared by Laclede Steel Company, both $36 \mathrm{ksi}$ and $50 \mathrm{ksi}$ steels were specified.

\section{Hat Trusses}

At the top of each tower (floor 107 to the roof), an assembly of hat trusses interconnected the core columns and the exterior wall panels (see Fig. 2-18). Diagonals of the hat truss were typically W12 or W14 wide flange members. In addition, four diagonal braces (18 in. by $26 \mathrm{in.} \mathrm{box} \mathrm{beams} \mathrm{spanning} \mathrm{the}$ $35 \mathrm{ft}$ gap, and $18 \mathrm{in}$. by $30 \mathrm{in}$. box beams spanning the $60 \mathrm{ft}$ gap) and four horizontal floor beams connected the hat truss to each perimeter wall at the floor 108 spandrel. The hat truss was designed primarily to provide a base for antennae atop both towers, although only the WTC 1 antenna was actually built. The hat truss also controlled the expansion and contraction of the tower due to unequal column temperatures, although not specifically designed for this purpose. 


\subsection{DESCRIPTION OF WTC 7}

\subsubsection{Building Description}

WTC 7 was a 47 -story commercial office building, completed in 1987. Its location relative to the WTC Plaza is shown in Fig. 2-1. It contained approximately 2 million $\mathrm{ft}^{2}$ of floor area. A typical floor plan above floor 7 is shown in Fig. 2-19. WTC 7 was connected to the WTC complex with a $120 \mathrm{ft}$ wide elevated plaza at floor 3 , and a $22 \mathrm{ft}$ wide pedestrian bridge, also at floor 3 .

The overall dimensions of WTC 7 were approximately $330 \mathrm{ft}$ long, $140 \mathrm{ft}$ wide, and $610 \mathrm{ft}$ high. The building was constructed over a pre-existing electrical substation owned by Consolidated Edison (Con Edison). The original plans for the Con Ed Substation included supporting a high-rise building, and the foundation was sized for the planned structure. However, the final design for WTC 7 had a larger footprint than originally planned. The building elevations are shown in Fig. 2-20. Over the years, numerous structural modifications were made throughout the building, mainly to suit its largest tenant, Salomon Brothers Inc. (later to become Salomon Smith Barney, now CitiGroup), who leased 25 of the 47 floors. One of the more substantial modifications was the addition of a penthouse that was used to house the chiller plant and the cooling towers for Salomon Brothers. Also, large portions of the 41st and 43rd floor slabs and the floor framing were removed on the east side of the building to accommodate trading floors for Salomon Brothers. The removed floor areas were subsequently restored after the trading activity was moved to another venue.

Above floor 7, the building had typical steel framing for high-rise construction. The floor systems had composite construction with steel beams supporting concrete slabs on metal decks, with a floor thickness of $5.5 \mathrm{in}$. The core and perimeter columns supported the floor systcm and carried their loads to the foundation. The perimeter moment frame also resisted wind forces. Columns above floor 7 did not align with the foundation columns, so braced frames, transfer trusses, and transfer girders were used to transfer loads between these column systems, primarily between floors 5 and 7 . Floors 5 and 7 were heavily reinforced concrete slabs on metal decks, with thicknesses of 14 in. and 8 in., respectively.

The architectural design was performed by Emory Roth \& Sons, P.C. The structural engineer of rccord was the Office of Irwin G. Cantor, P.C. Syska \& Hennessy, P.C. was the mechanical engineer. Tishman Construction Corporation was the general contractor.

\section{Consolidated Edison Substation}

The Con Edison Substation was constructed in 1967 and consisted of a stecl framed structure with castin-place concrete floors and walls. It was placed on the northern portion of the site and extended approximately $40 \mathrm{ft}$ north of the north facade of WTC 7, as shown in Fig. 2-21. Its southern boundary was irregular, but extended approximately one-third to two-thirds of the width of WTC 7. The Con Edison Substation was three stories high.

The substation's lateral system consisted of a moment framc along the northern row of interior columns. Along the south edge of the substation there was a braced frame. This braced frame was coincident with the north side of the WTC 7 core. Lateral loads from WTC 7 were passed directly from the core above to the Con Edison braced frame below. There were also two moment frames within the substation, oriented in the north-south direction, one on each end of the WTC 7 core. 
The WTC 7 columns, which were within the perimeter of the substation, were supported by substation columns. During the construction of WTC 7, heavy plates were welded to the tops of the existing substation columns, which then supported the new building columns.

The exterior columns above the Con Edison structure that did not align with the columns of the Con Edison structure were supported by a series of transfer girders. The arrangements of the transfer girders are described in detail in Sec. 2.3.2.

\subsubsection{Structural Description}

\section{Typical Floor Systems above Floor $7^{9}$}

The typical floor framing system, shown in Fig. 2-22, was composed of rolled steel wide-flange beams with composite metal decking and concrete slabs. Floors 8 through 45 had essentially the same framing plan, but the core layout varied over the height of the building.

Floors 8 through 45 had floor slabs with a total thickness of 5.5 in. that were composed of 3 in., 20 gauge metal deck with 2.5 in., normal weight concrete of 3,500 psi. There was one layer of $6 \times 6 \mathrm{~W} 1.4 \times \mathrm{W} 1.4$ welded wire fabric within the concrete. The structural design drawings show a second layer of welded wire fabric placed over girders at the slab edges. The fastening requirements for the metal deck are not shown on the drawings. The drawings contain a note calling for 1.5 in., 20 gauge deck with 4 in. concrete topping ( 5.5 in. total) in the elevator lobbies, where there was a 3 in. floor finish specified by the architect.

Typical floor framing for floors 8 through 20 and floors 24 through 45 consisted of 50 ksi wide-flange beams and girders. A grid of beams and girders spanned between the core columns. Core girders ranged in size from W16x31 to W36x135, depending on the span and load. (W16x31 describes a steel wideflange beam, sometimes referred to as an ' $\mathrm{I}$ ' beam; the nomenclature indicates the cross section is nominally $16 \mathrm{in}$. deep and weighs $31 \mathrm{lb}$ per lineal foot.) Beams spanned directly between the core and the exterior of the building, at approximately $9 \mathrm{ft}$ on center: On the north and east sides, the typical beam was a W24x55 with 28 shear studs, spanning $53 \mathrm{ft}$. On the south side, the typical beam was a W16x26 with 24 shear studs spanning $36 \mathrm{ft}$. Between the exterior columns were moment connected girders that formed part of the lateral-load-resisting system of the building. On floors 10, 19, and 20, a portion of the floor framing was reinforced with plates attached to the bottom flange. Certain connections at these floors were also reinforced.

Floors 21 to 23 had slightly heavier steel framing than the typical floors. Core girders were generally one size class larger than the typical floor; the beams between the core and the south facade were W16x31 instead of W16x26. There were additional studs on the W24x55 beams on the north and west sides.

Most of the beams and girders were made composite with the slabs through the use of shear studs. Typically, the shear studs were $0.75 \mathrm{in}$. in diameter by $5 \mathrm{in}$. long, spaced $1 \mathrm{ft}$ to $2 \mathrm{ft}$ on center.

9 Structural descriptions are determined from the design drawings. 


\section{Floor Framing of Other Floors}

The remaining floors, floors 1 to 7 and floors 46 to 47, were atypical. Floor 1 was built adjacent to the Con Edison substation and included the truck ramp for the WTC complex (see Fig. 2-21). The floor was framed with steel beams that were encased in a formed concrete slab. The floor slab was $14 \mathrm{in}$. The southeast portion of the floor above the WTC truck ramp had a 6 in. formed concrete slab. The floor slabs for floors 2, 3, 4, and 6 had a 3 in., 20 gauge metal deck with 3 in. normal weight concrete, for a total thickness of 6 in. Floors 2 and 3 were also partial floors adjacent to the substation. In addition, they had a floor opening on the south side to form the atrium above the ground level lobby. Floor 4 was above the substation and had a large opening over most of the south side of the building to form a double-height space above the 3 rd floor lobby. Floor 5 had an 11 in. thick slab of normal weight concrete on top of 3 in., 18 gauge steel deck for a total slab thickness of 14 in. The slab was heavily reinforced with \#7 reinforcing bars spaced at 12 in. on center in both directions on top and \#9 reinforcing bars spaced at 12 in. on center on bottom. This floor also had steel WT sections embedded in the $11 \mathrm{in}$. concrete slab above the steel deck. The WT sections were designed to act as a horizontal truss within the plane of the floor between the perimeter and core columns (see Fig. 2-23). Floor 6 had two openings on the floor to form a double-height mechanical space, one at the east side and the other at the southeast corner. Floor 7 had 5 in. normal weight concrete on top of 3 in., 18 gauge metal deck, which made a total thickness of 8 in. The slab was reinforced with \#5 reinforcing bars spaced at 6 in. on center in both directions.

\section{Columns}

Core columns were primarily rolled wide-flange shapes of grade 36 or 50 steel. As the loads increased toward the base of the building, many of these column sizes were increased through the use of built-up shapes. These built-up columns had a W14x730 core with cover plates welded to the flanges (to form a box) or web plates welded between the flanges as shown in Fig. 2-24. The reinforcing plate welds were specified to be continuous $0.5 \mathrm{in}$. fillet welds at the cover plates and $0.313 \mathrm{in}$. minimum at the web plates. Plate thickness ranged from 1.5 in to 8 in. Steel used for reinforcing plates were specified as follows:

Plate thickness $\mathrm{t}$ (in.):

$\begin{array}{ll}2<\mathrm{t}<4 & \text { ASTM A } 588 \text { Grade } 50 \\ 4<\mathrm{t}<6 & \text { ASTM A } 572 \text { Grade } 42 \\ \mathrm{t}>6 & \text { ASTM A } 588 \text { Grade } 42\end{array}$

Typical core column splices were specified to be milled. The splice plates were welded or bolted to the outsides of the column web and flanges. Built-up columns were also milled at their bearing ends, but the splice plates were fillet welded to the cover plates.

Perimeter columns were nominally 14 in. wide-flange shapes (W14) of ASTM A 36 steel. Perimeter column splices were similar to the core column splices.

\section{Column Transfer Trusses and Girders}

Because the layout of the substructure and Con Edison columns did not align with the column layout in the upper portion of WTC 7, a series of column transfers were constructed. These transfers occurred 
primarily between floors 5 and 7. See Fig. 2-25 for a schematic rendering of the transfer trusses and girders.

Columns 47 through 54 , at the north facade, were transferred at floor 7 by cantilever girders to bring them in line with the substation columns, offset $6 \mathrm{ft}$ to $9 \mathrm{ft}$ to the south. The back-span of these cantilevers was supported by the north side core columns. The eastern most cantilever girder was connected to truss \#1, and the western most cantilever girder was connected to truss $\# 3$.

Column 76 was supported at floor 7 by truss \#1. The west side of truss \#1 was supported by column 73, while the east side was supported by a transfer girder running north-south which was, in turn, supported by columns E3 and E4 at floor 5 .

Columns 58, 59, and 78 were transferred by simply supported girders at floor 7 . Column 78 was supported at floor 7 by a transfer girder that was supported at its north end by truss \#2. Column 77 was also supported by truss \#2. Truss \#2 was supported by column 74 at its west end and by column 80 at its east end.

Column 61 was supported by truss \#3. Truss \#3 runs north-south and was supported by columns 62 and $61 \mathrm{~A}$. Truss \#3 has a $10 \mathrm{ft}$ cantilever span between column 61 and column $61 \mathrm{~A}$ and an $18 \mathrm{ft}$ back-span to column 62. 


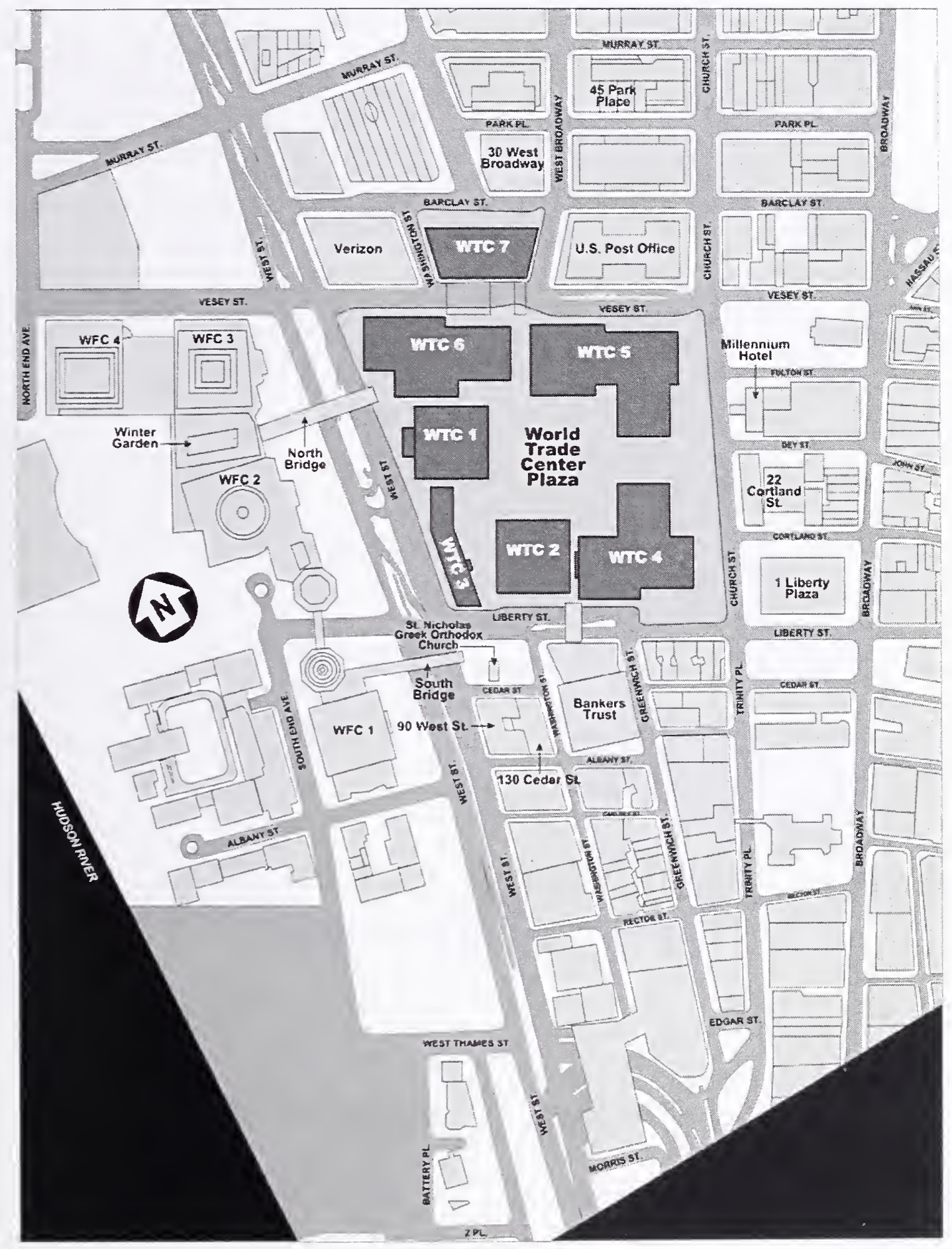

Figure 2-1. WTC site plan. 

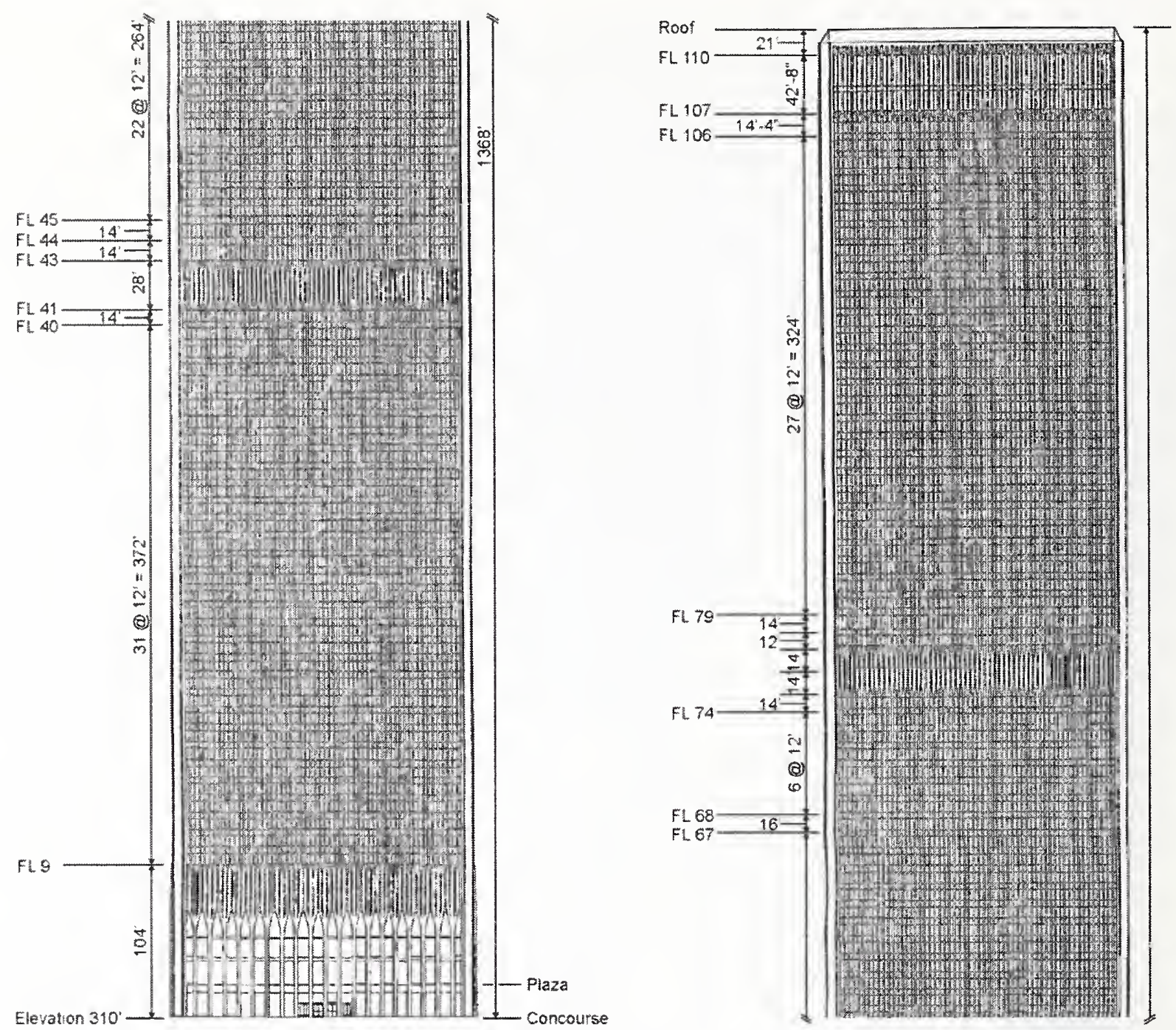

Figure 2-2. West elevation of WTC 1. 


$$
6-11^{n}
$$

$58 @ 3^{\circ}-4^{\prime \prime}=193^{\circ}-4^{\circ}$

1

Floor 9

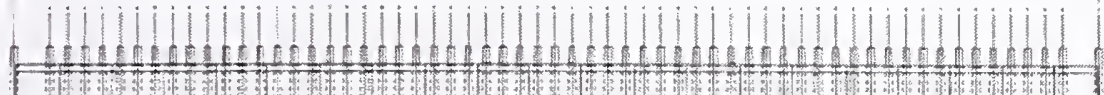

Floor 7

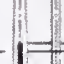

M 5
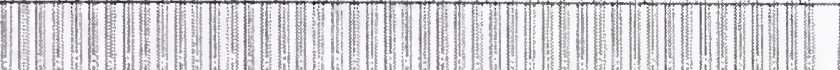

LUแ

EL. $363^{\circ}$

EL. $350^{\circ}-3^{\circ}$

Floor 2

EL. $332^{\circ}$

Floor 1

EL. $310^{\circ}$

EL. $294^{\circ}$

EL. $242^{\circ}$
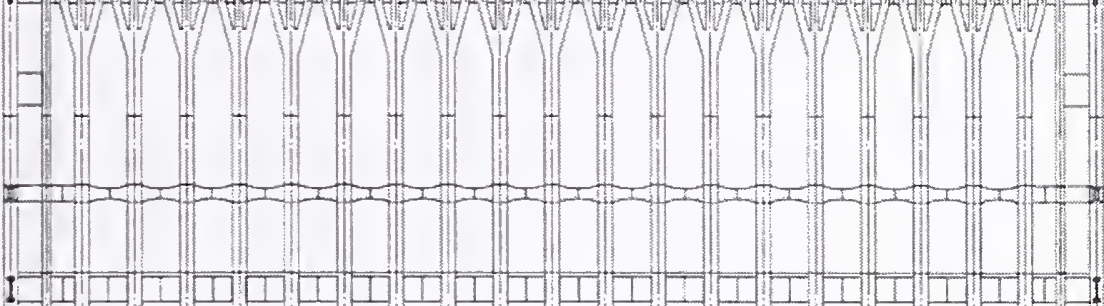


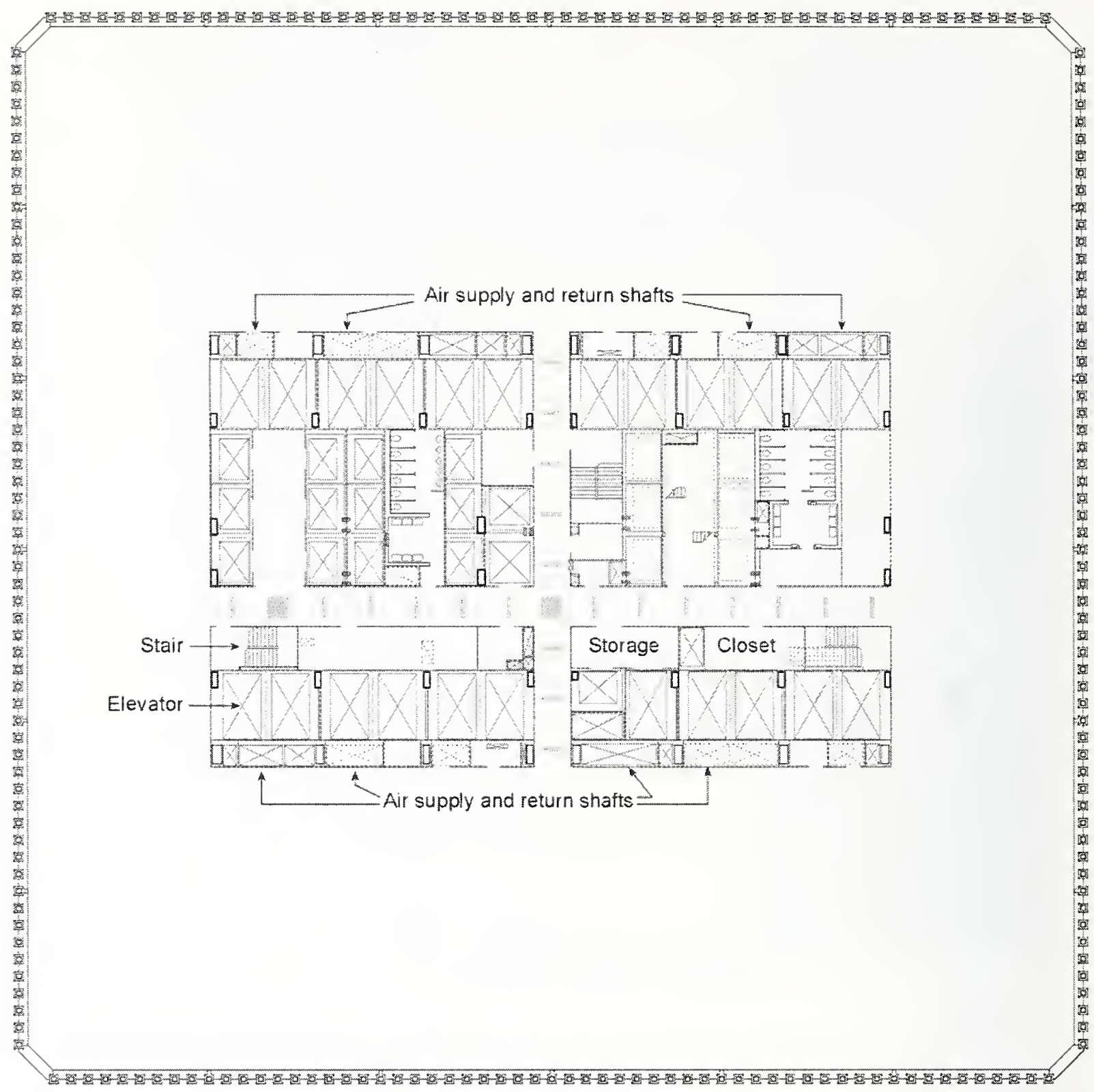

Figure 2-4. Typical WTC tower architectural floor plan. 


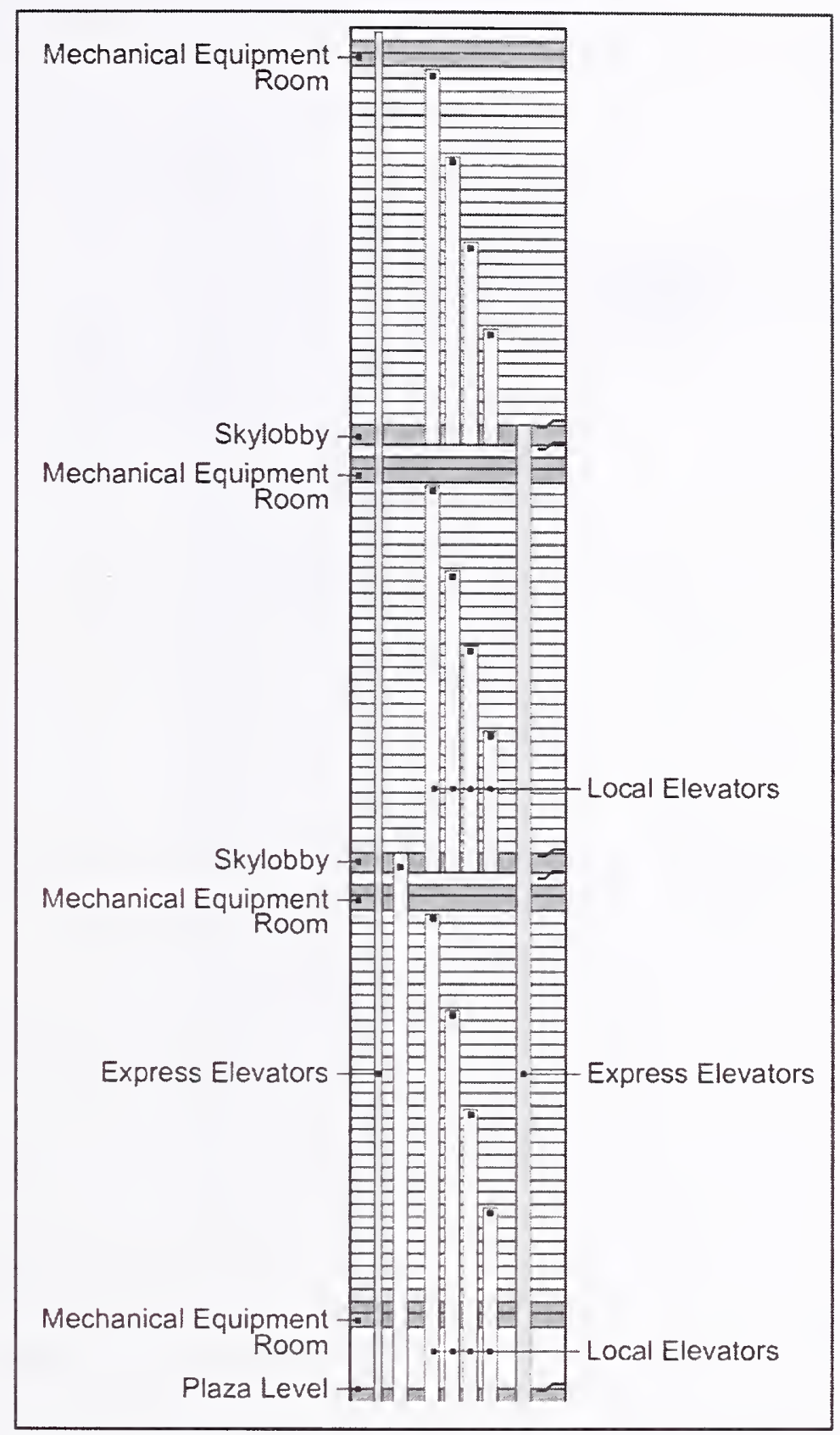

Figure 2-5. Arrangement of express and local elevators. 

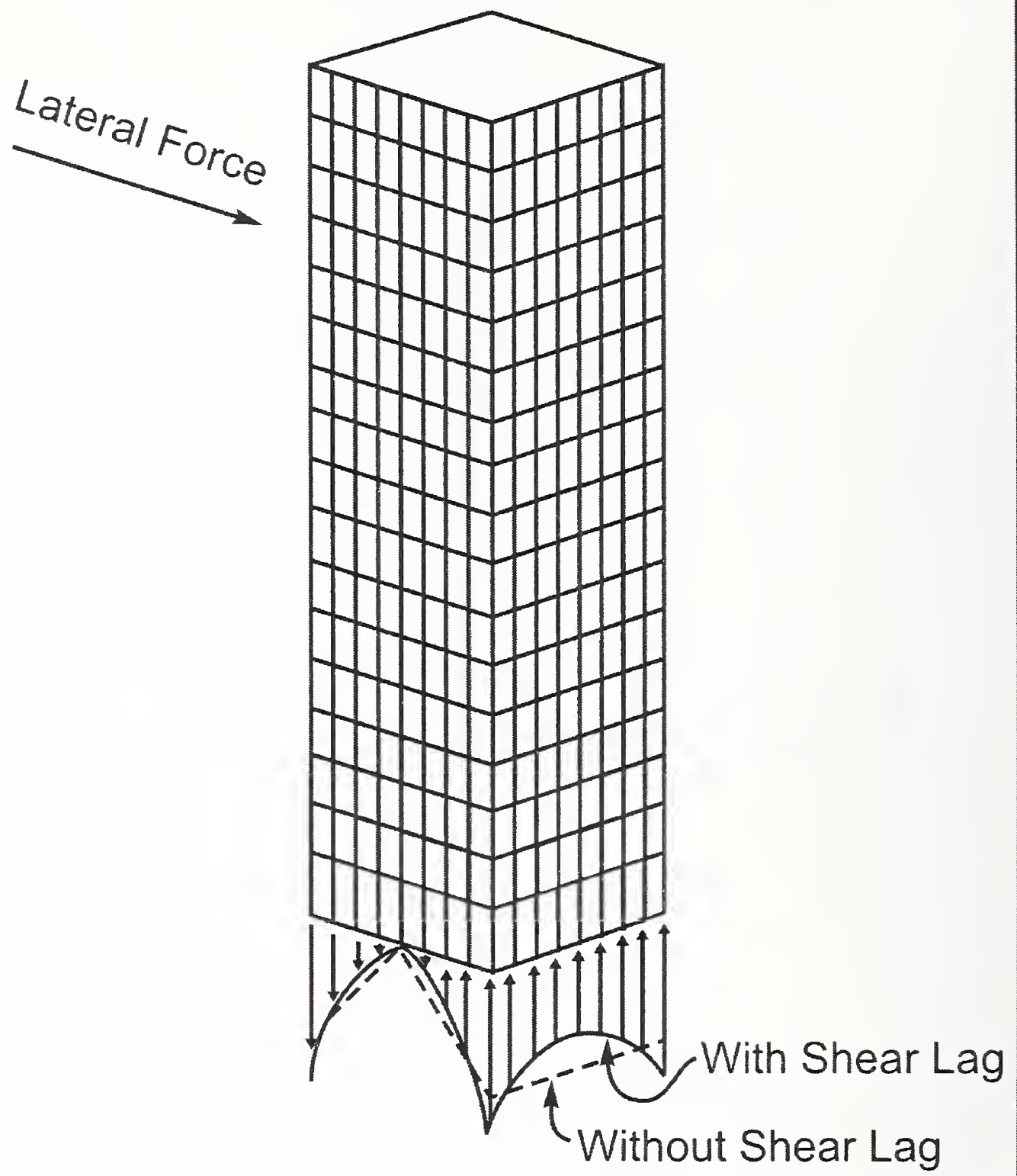

Source: Robertson and See 1987.

Figure 2-6. Framed tube system. 


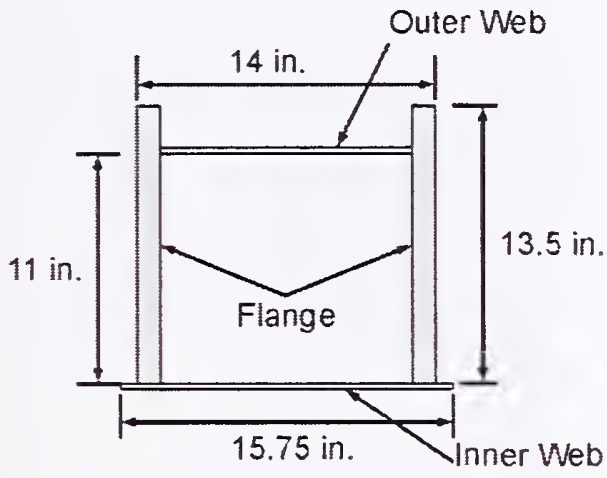

Section at Individual Column

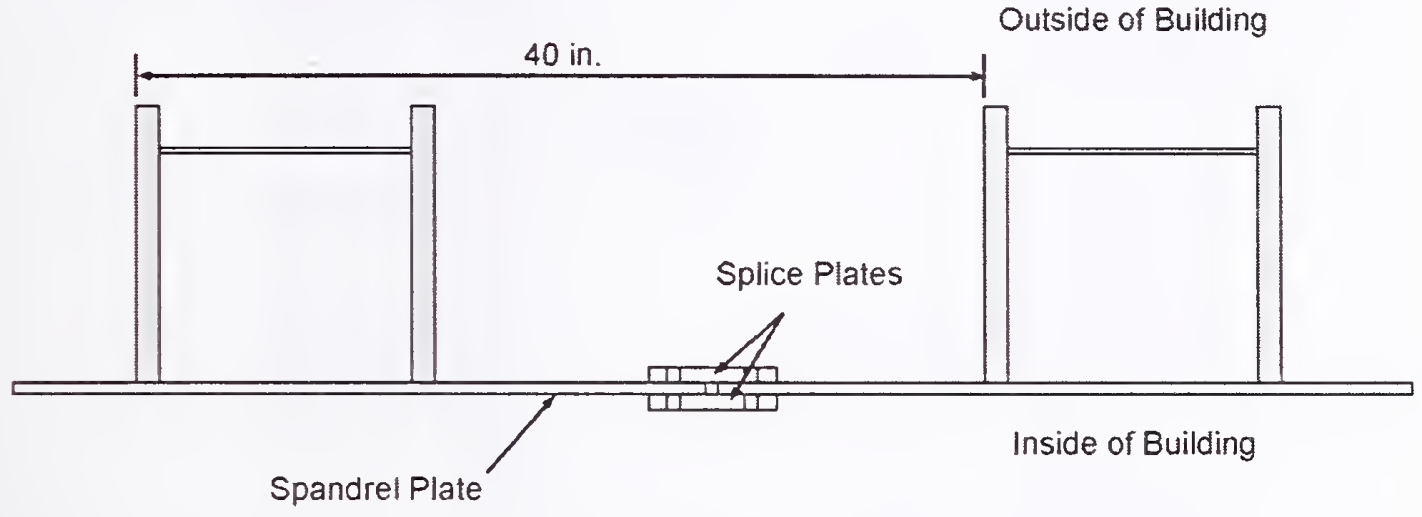

Section at Spandrel

Figure 2-7. Cross section of perimeter columns. 


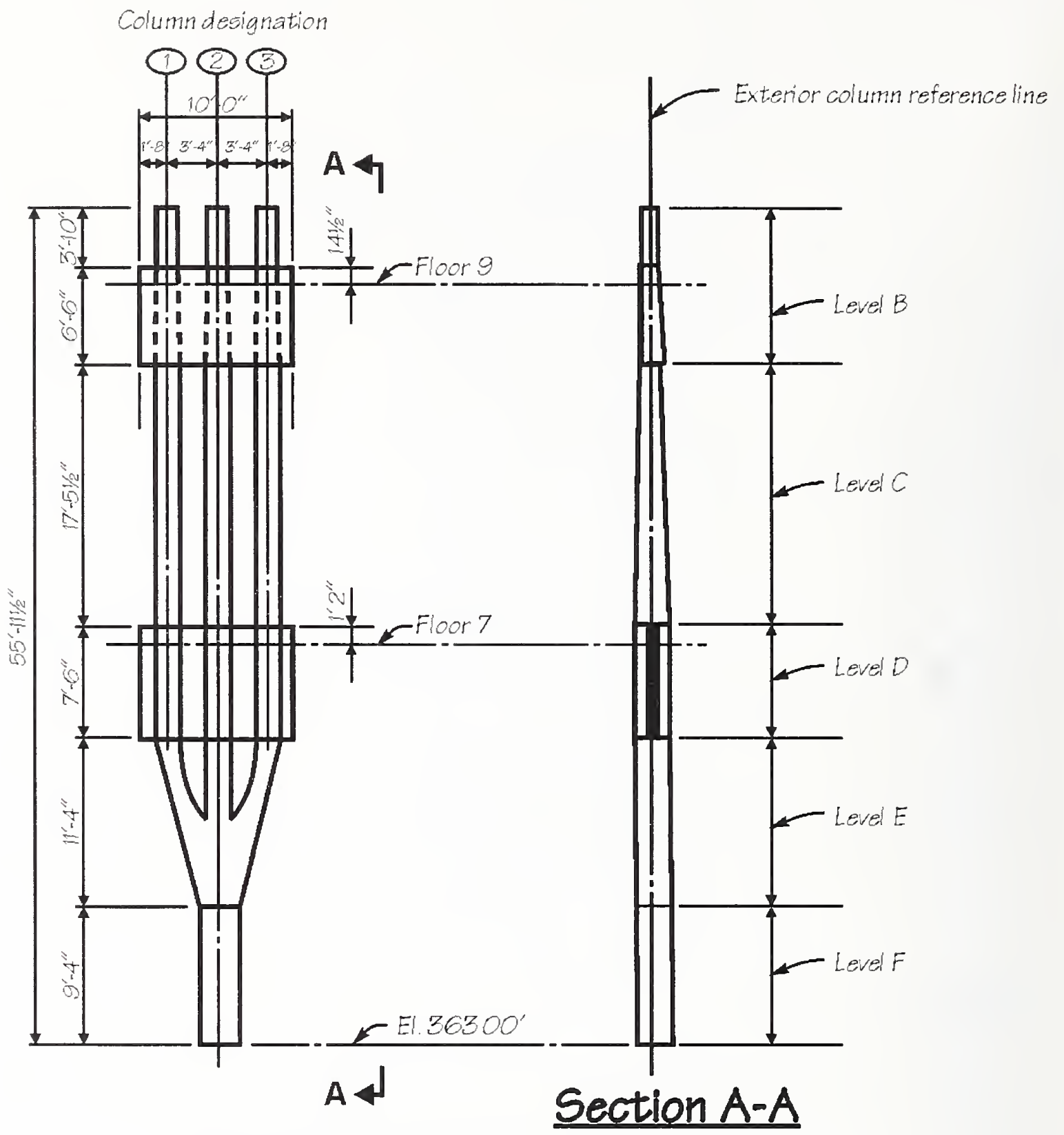

Figure 2-8. Typical WTC tower exterior wall tree panel. 


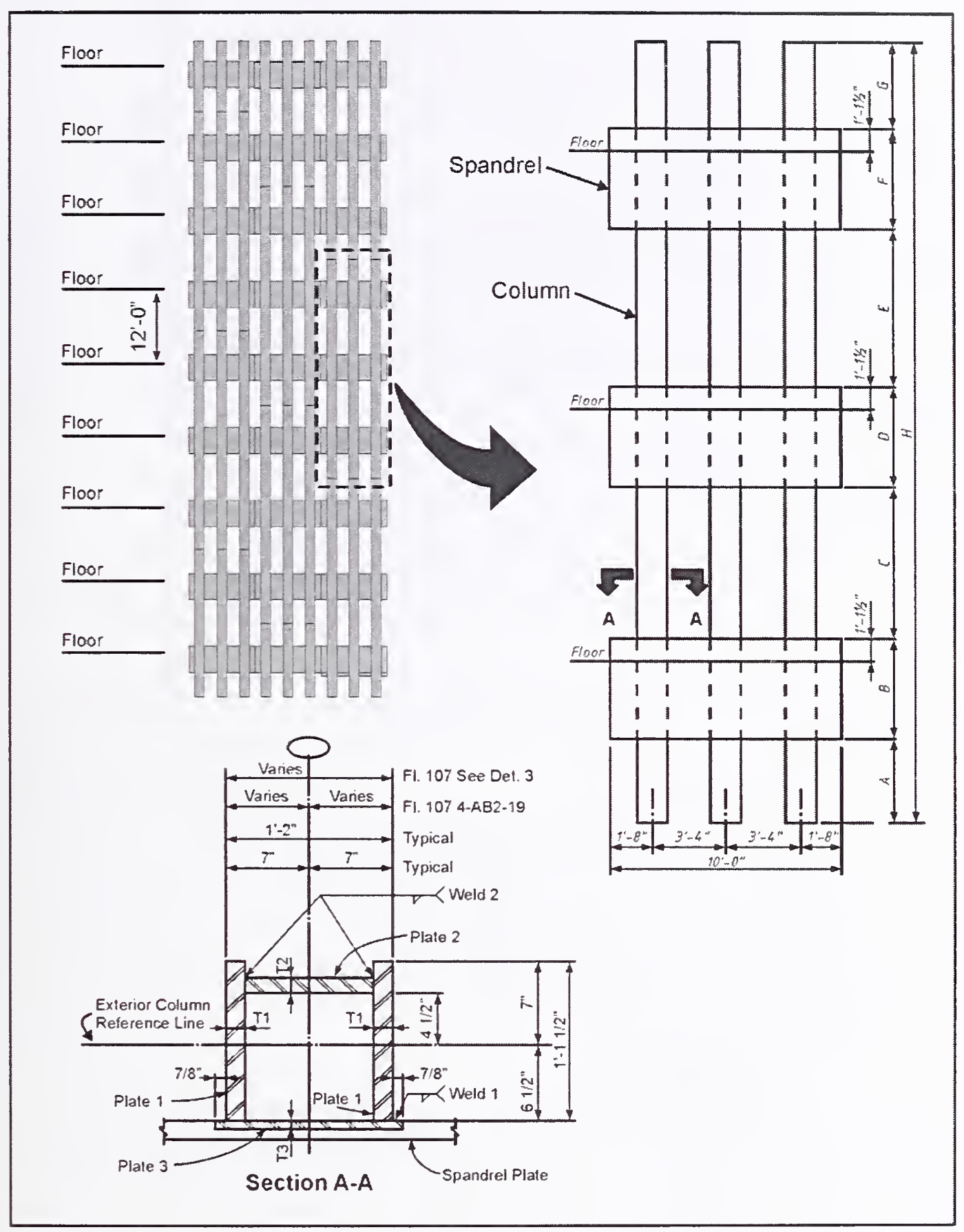

Figure 2-9. Typical WTC tower exterior wall panel. 


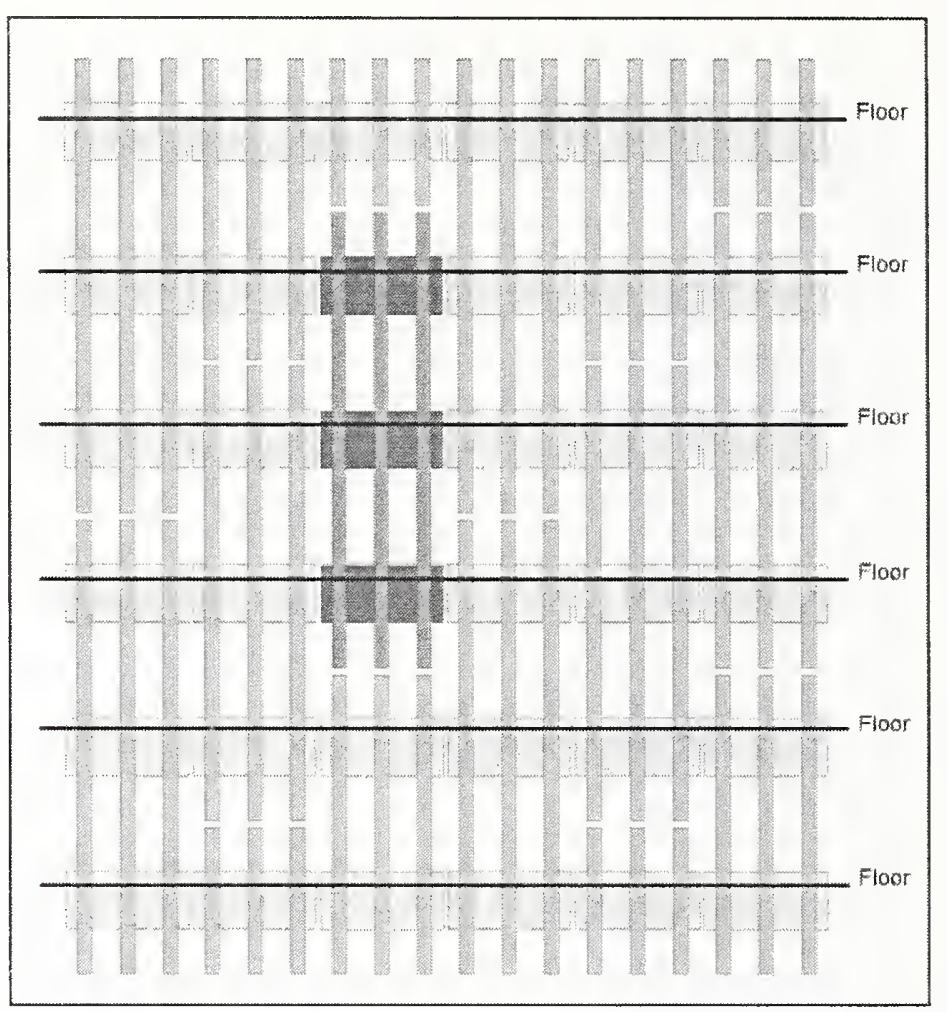

Figure 2-10. Elevation of exterior wall frame illustrating staggered panel construction.
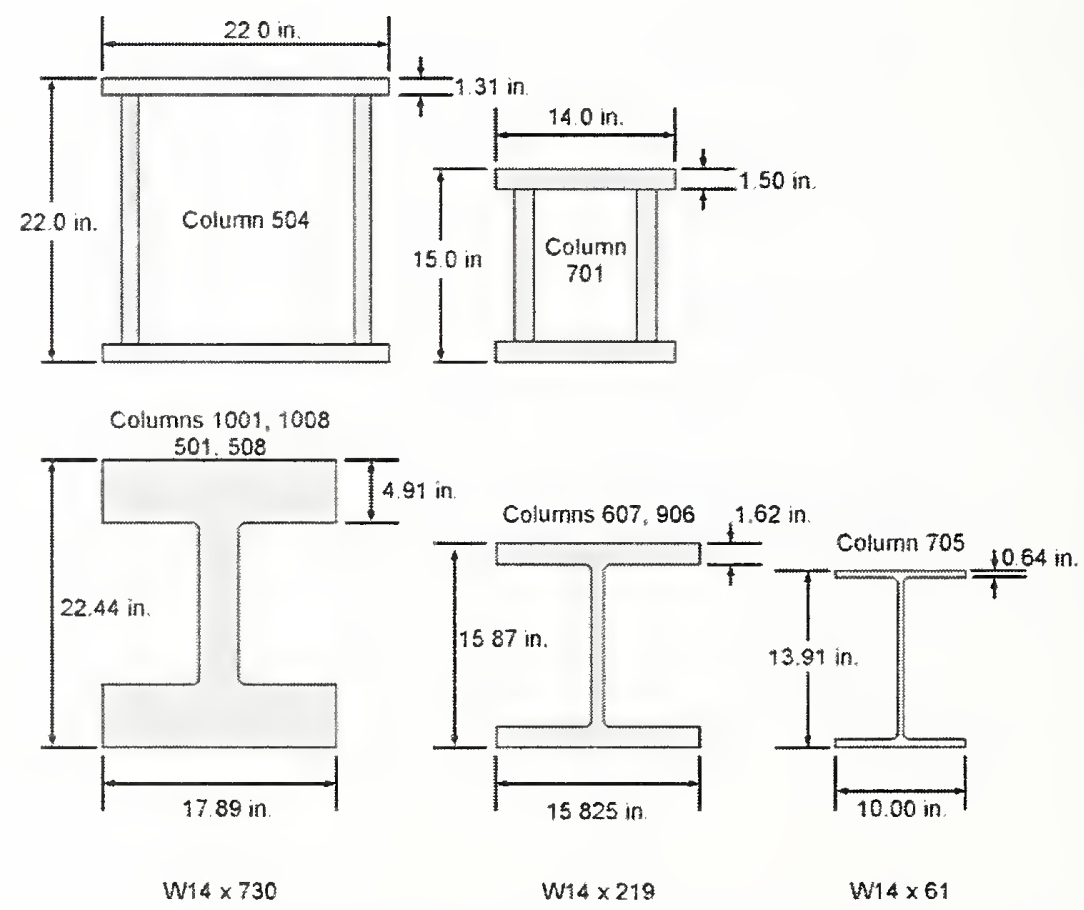

Figure 2-11. Typical welded box members and rolled shapes between floor 83 and floor 86 . 


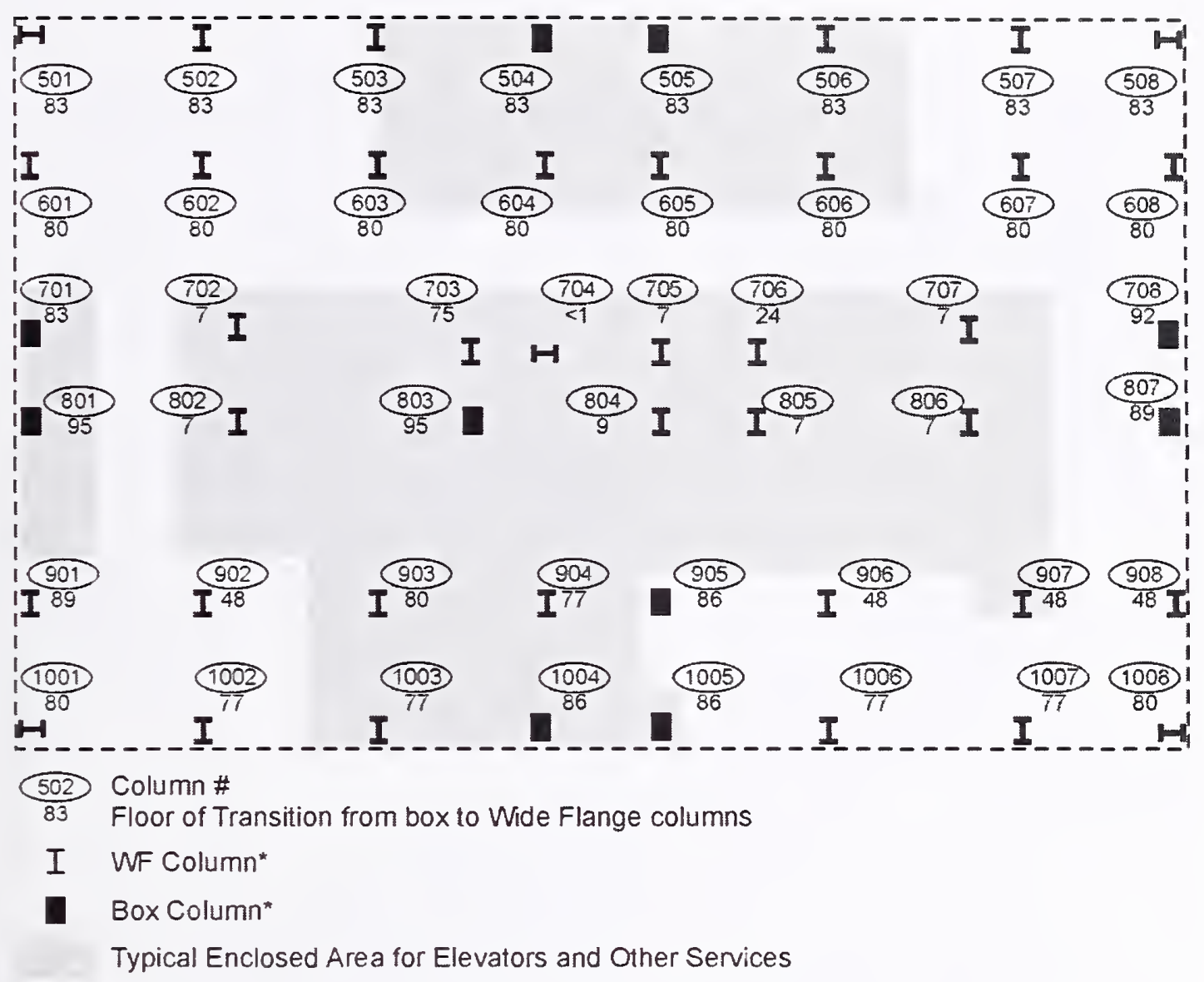

"Shape of Column at the 84th Floor

Figure 2-12. Core column layout in WTC towers. 


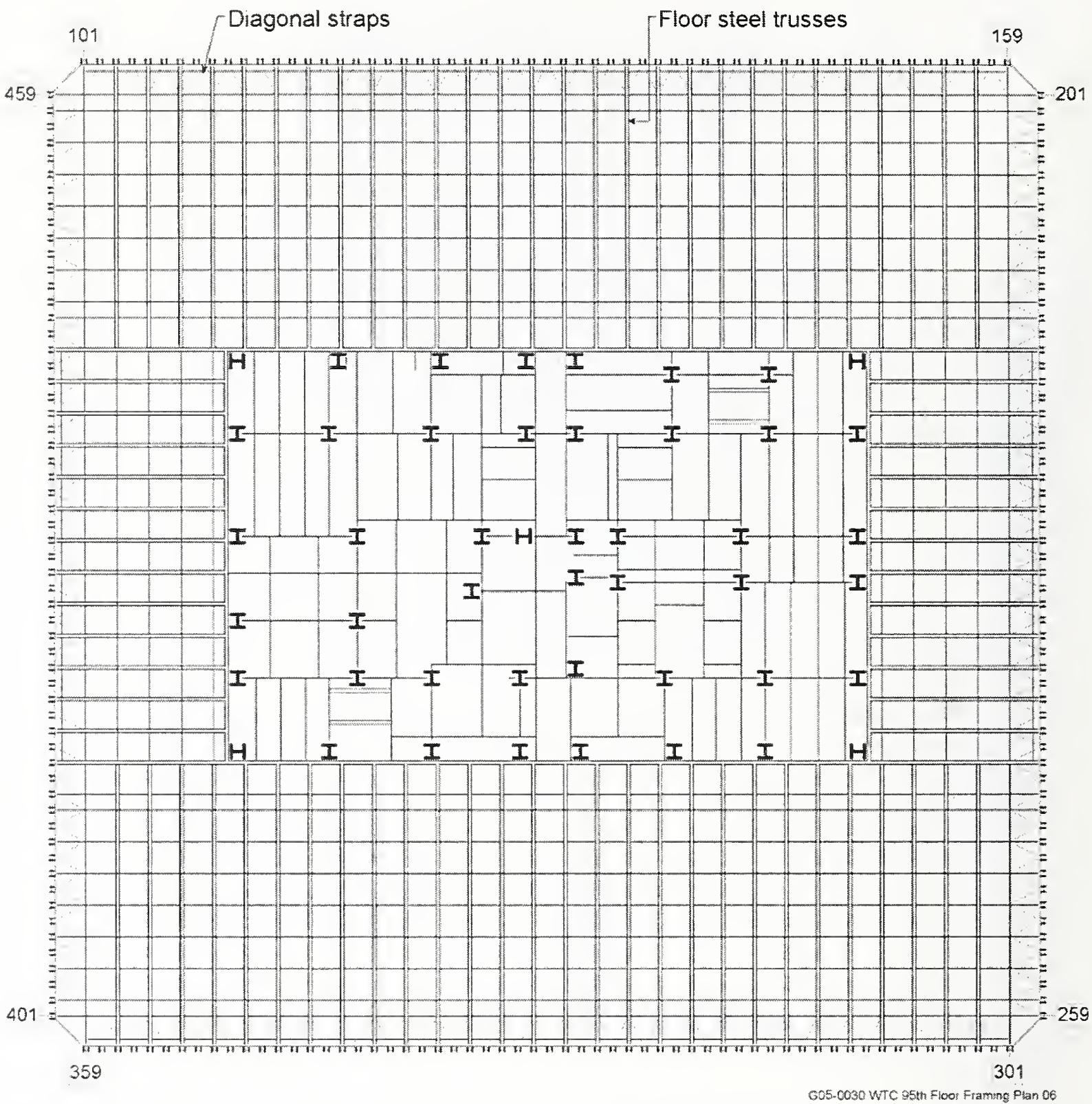

Figure 2-13. Typical floor-framing plan. 


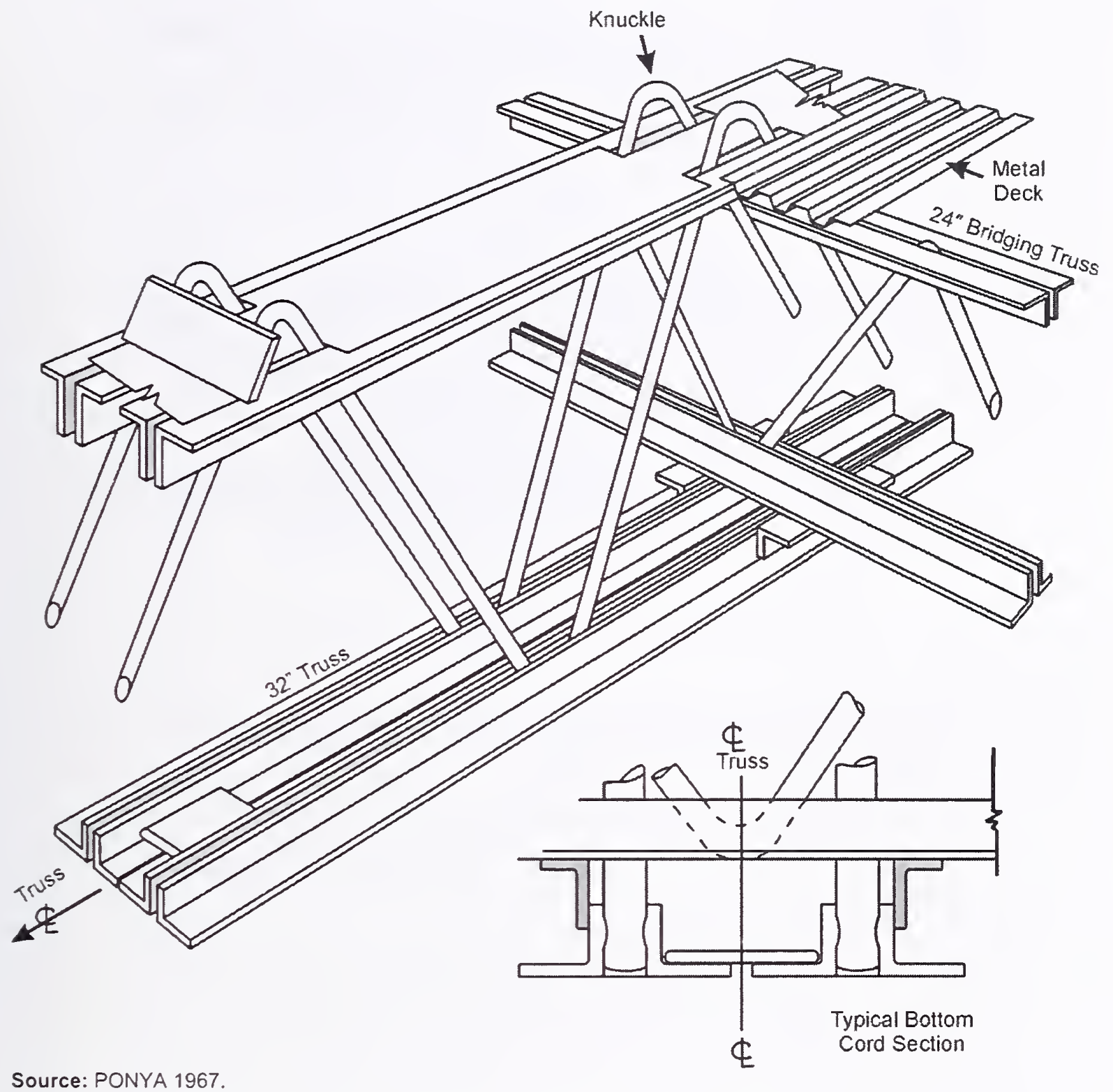

Figure 2-14. Prefabricated floor panel used in WTC 1 and WTC 2. 


\section{Column}

Reference Line

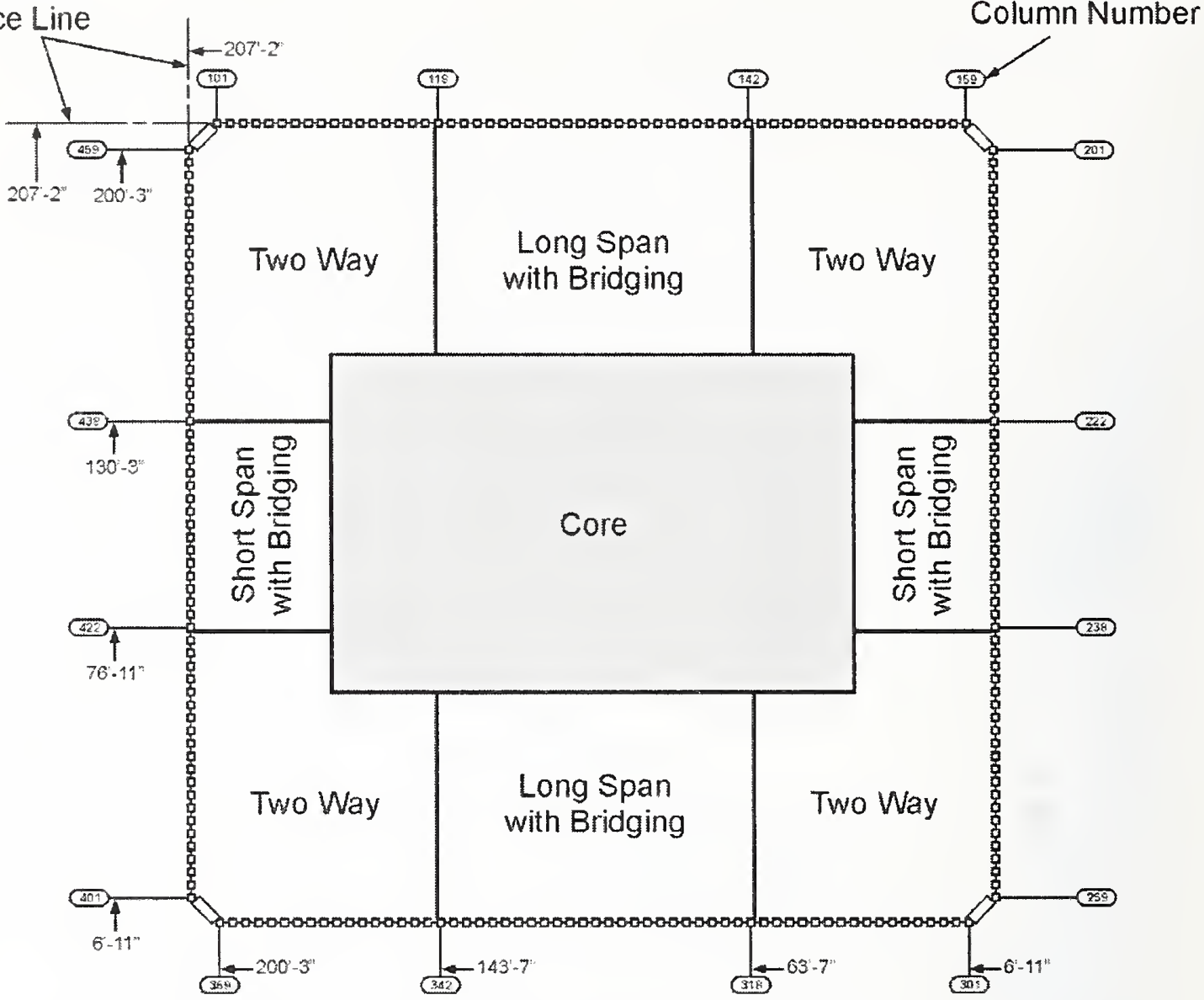

Figure 2-15. Typical WTC floor truss framing zone. 


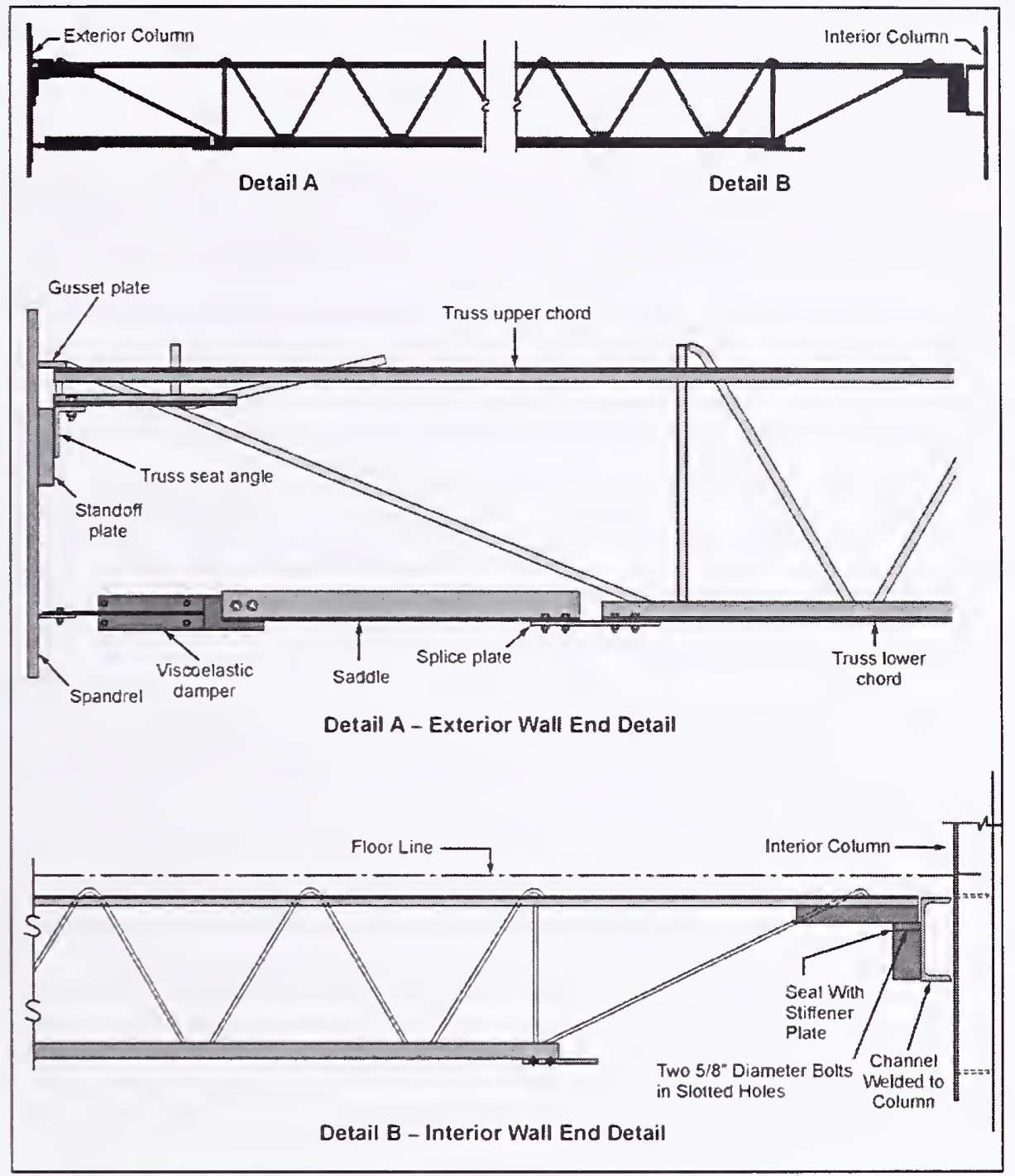

Figure 2-16. Position of viscoelastic damper. 


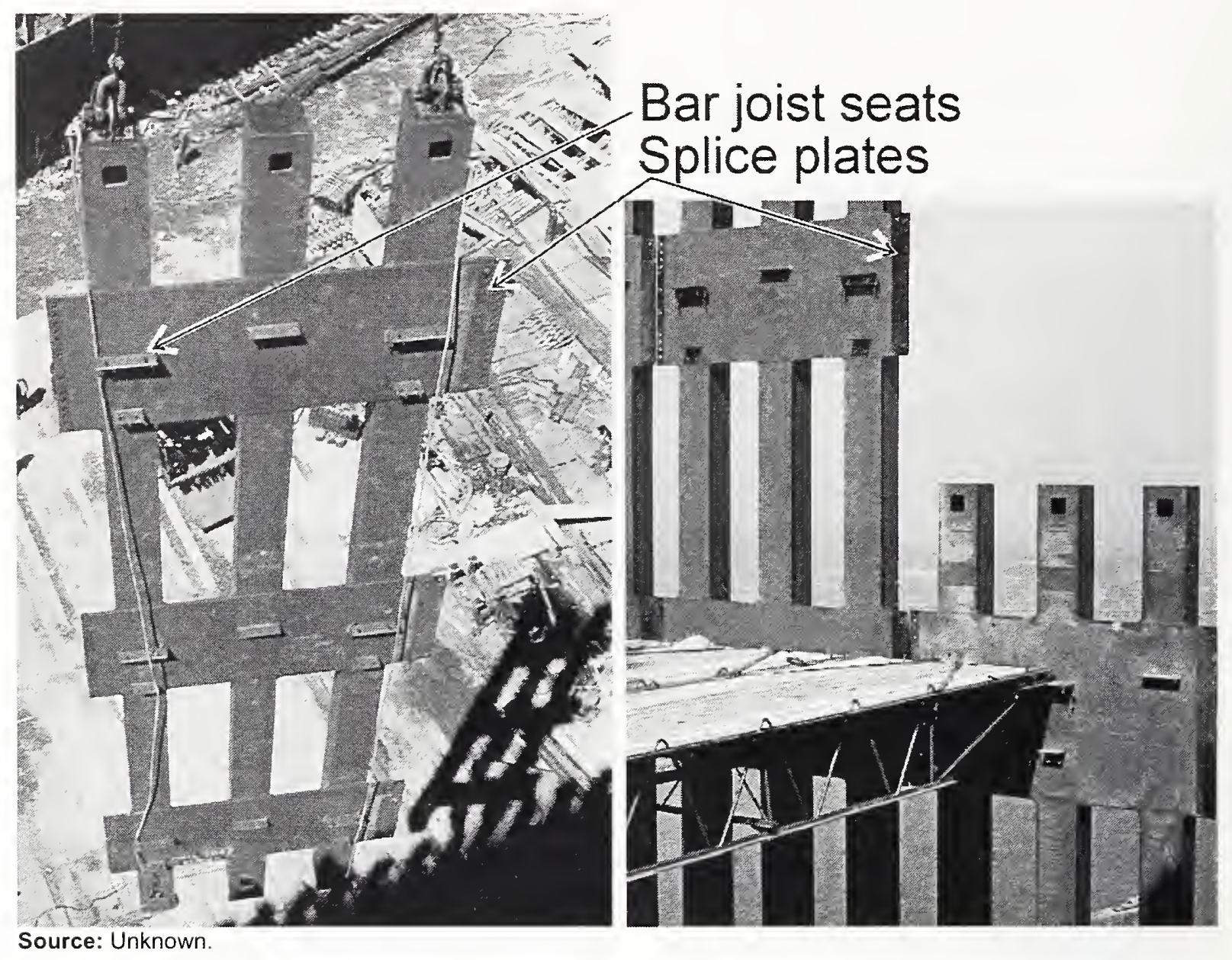

Figure 2-17. Perimeter column wall panel and steel truss floor modules. 


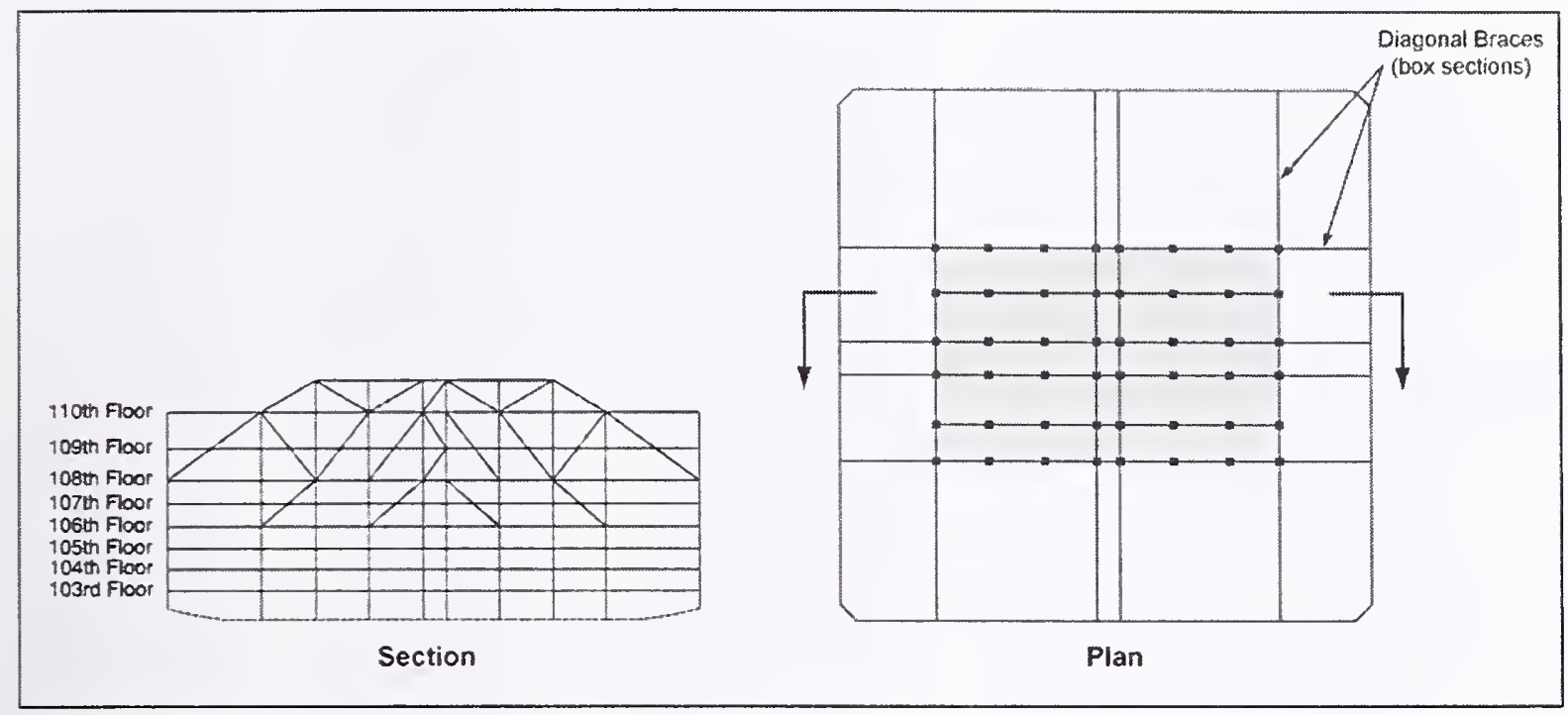

Figure 2-18. Hat truss.

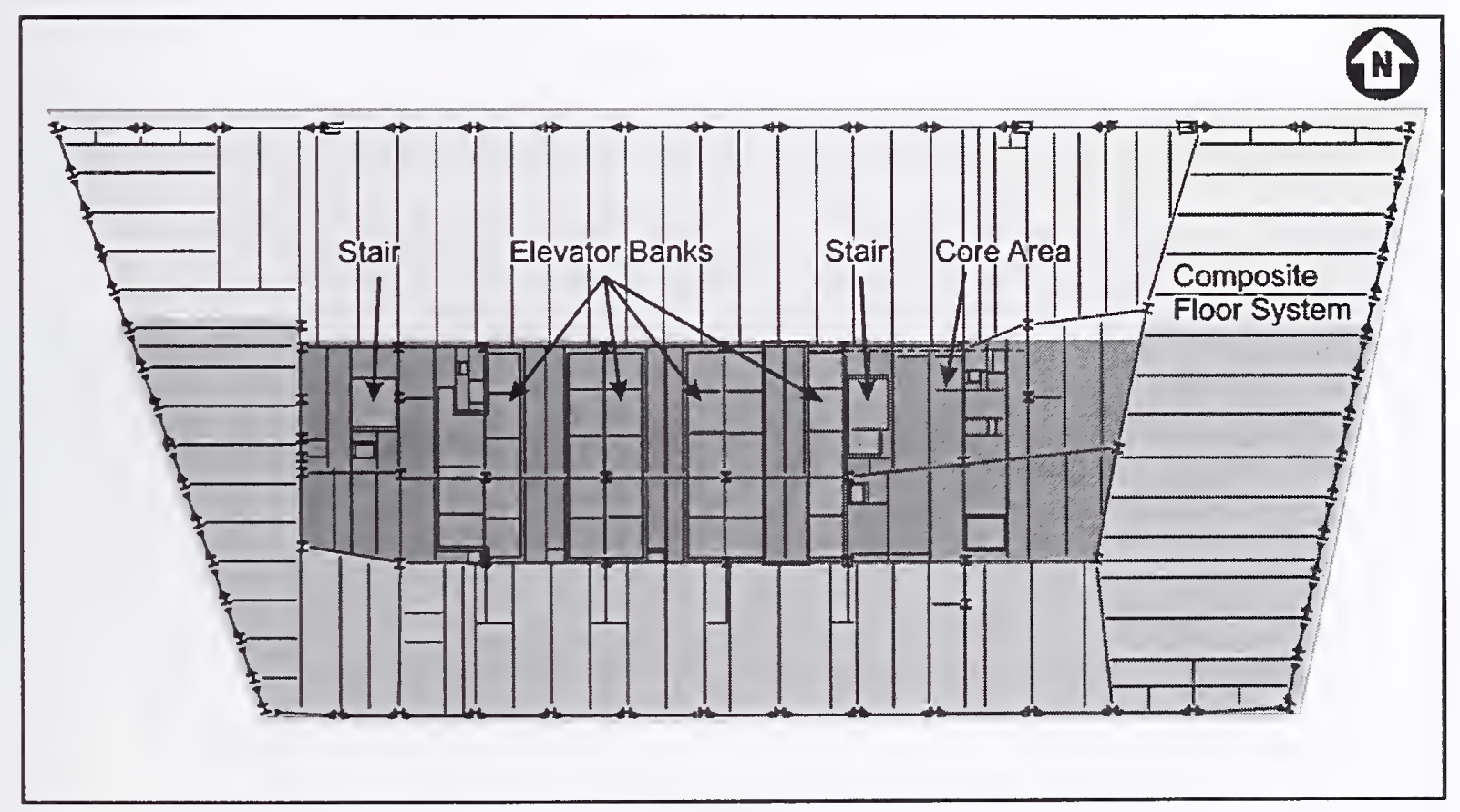

Figure 2-19. Typical floor plan above floor 7. 


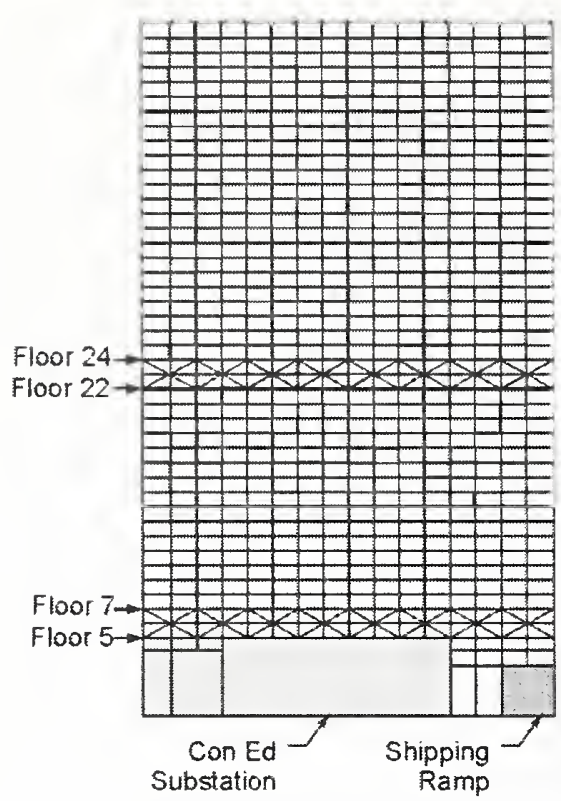

NORTH

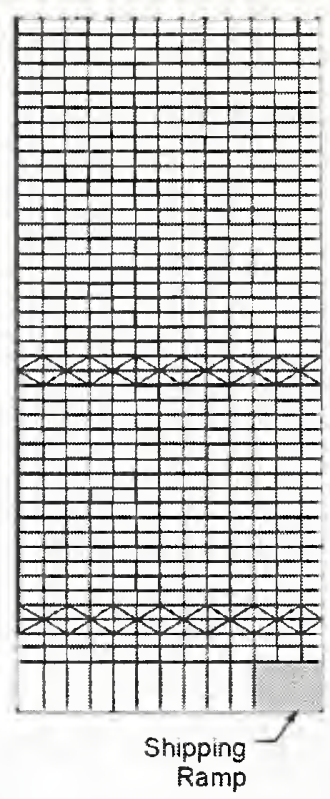

SOUTH

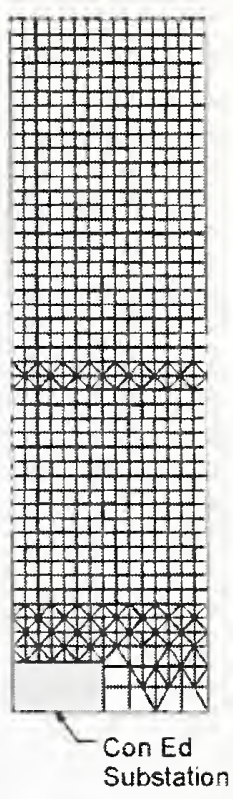

WEST

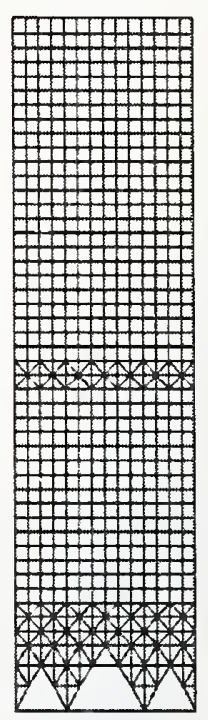

EAST

Figure 2-20. Perimeter elevations of WTC 7.

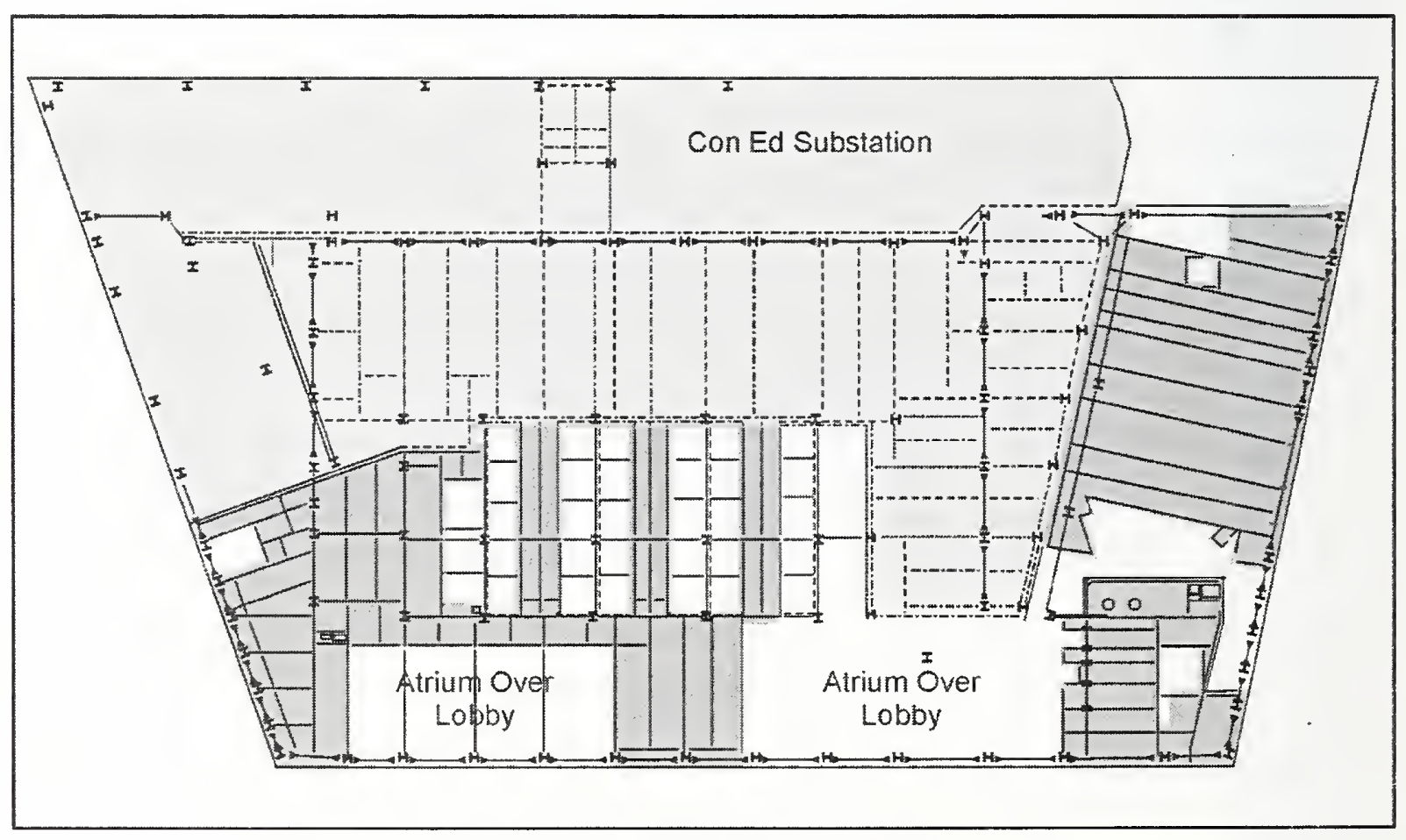

Figure 2-21. Floor 1 plan of WTC 7. 


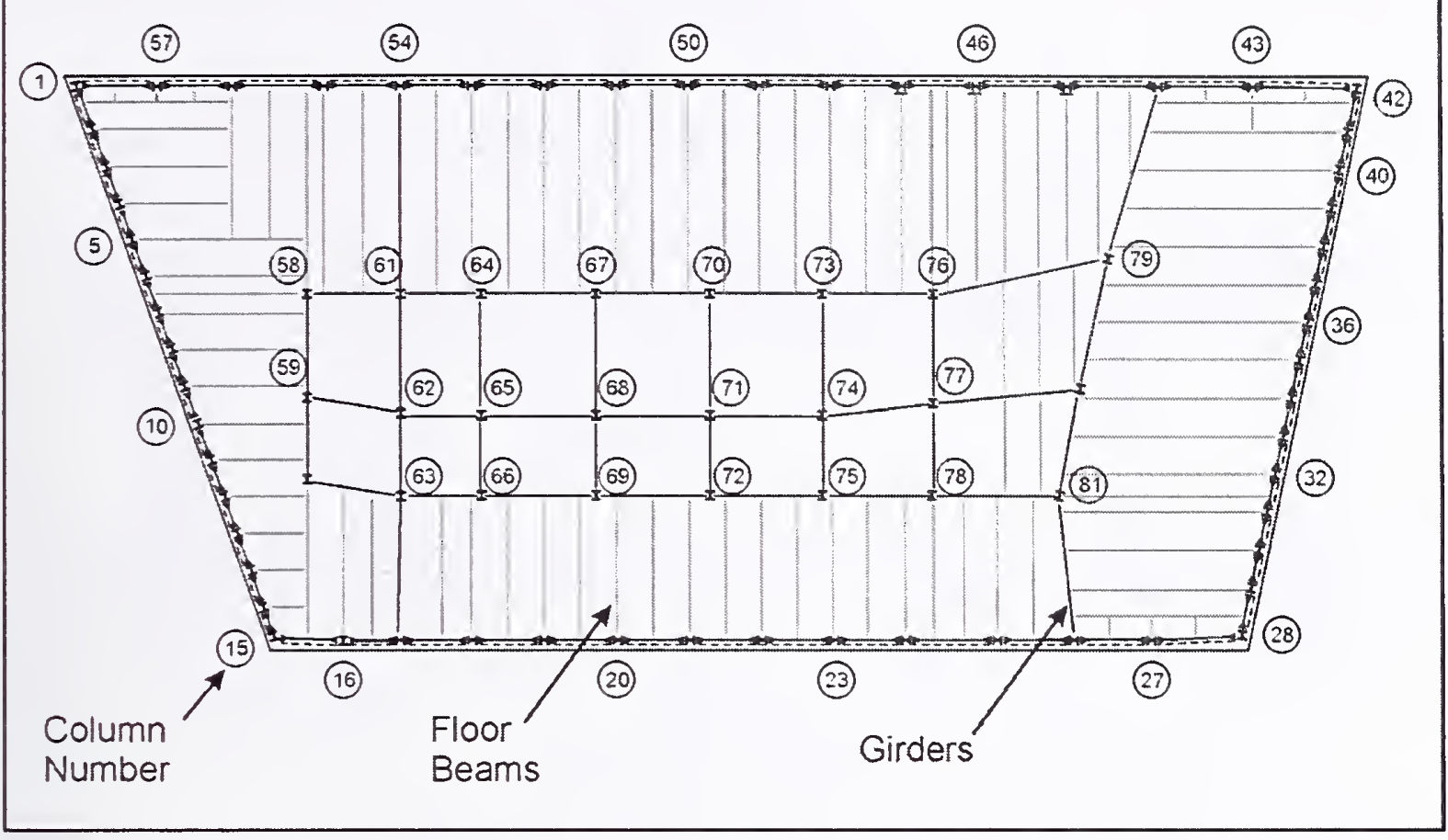

Figure 2-22. Framing plan for floor 8 through floor 45 .

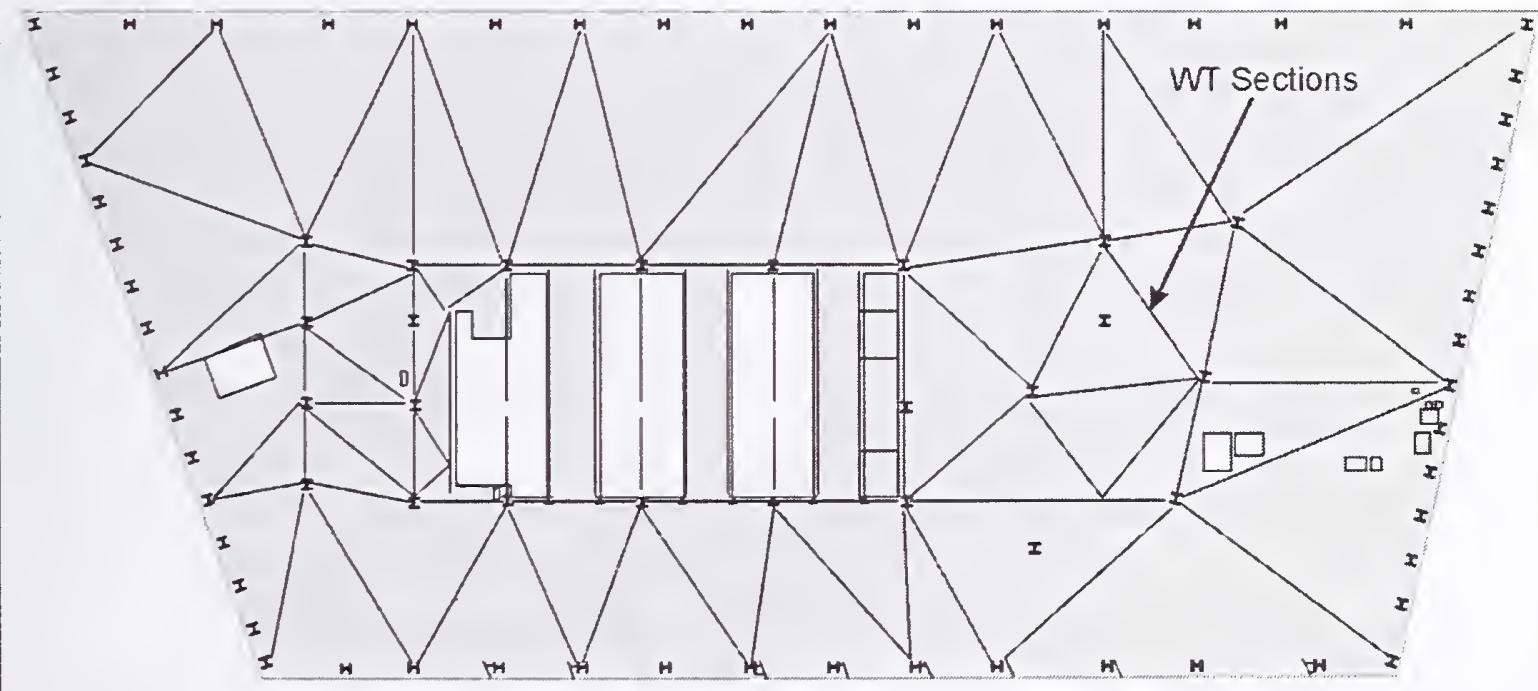

Figure 2-23. Floor 5 diaphragm plan. 

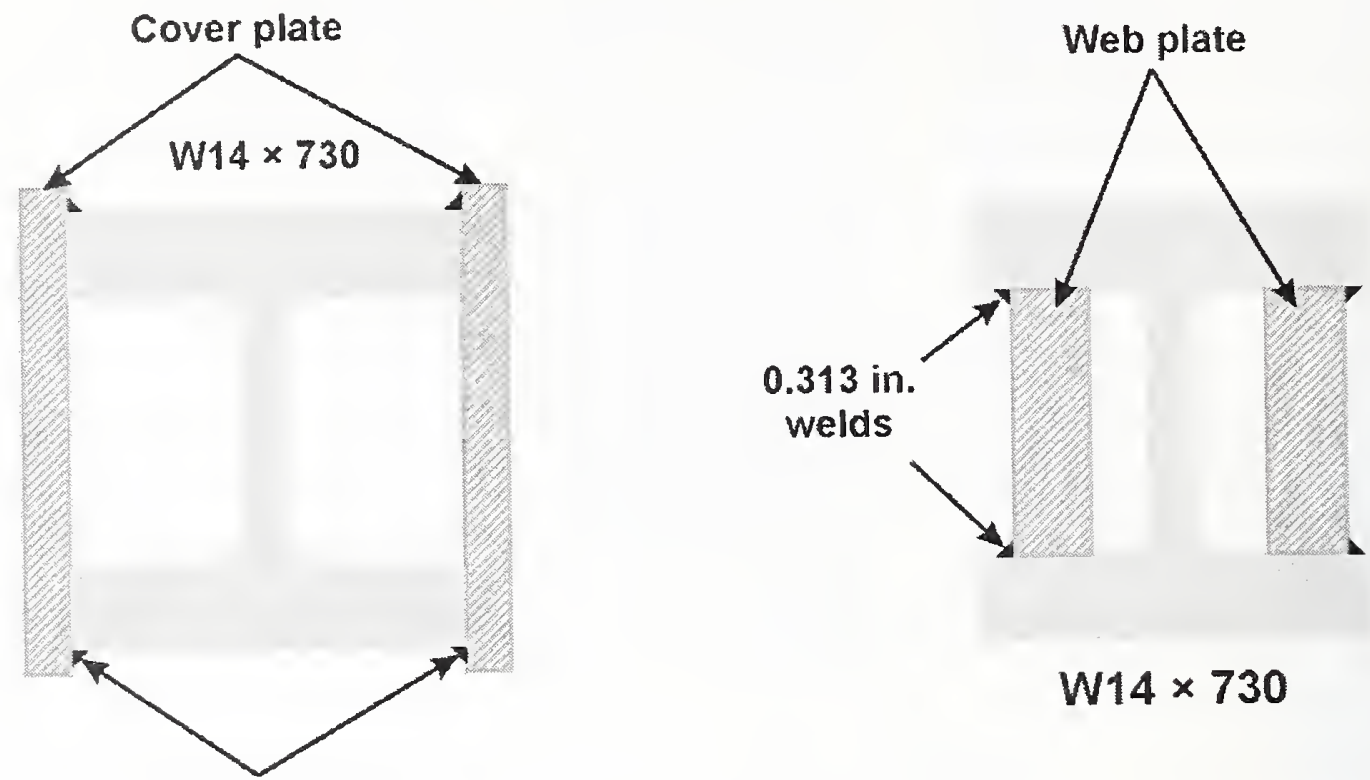

$0.5 \mathrm{in.}$ welds

Figure 2-24. Typical built-up column details.

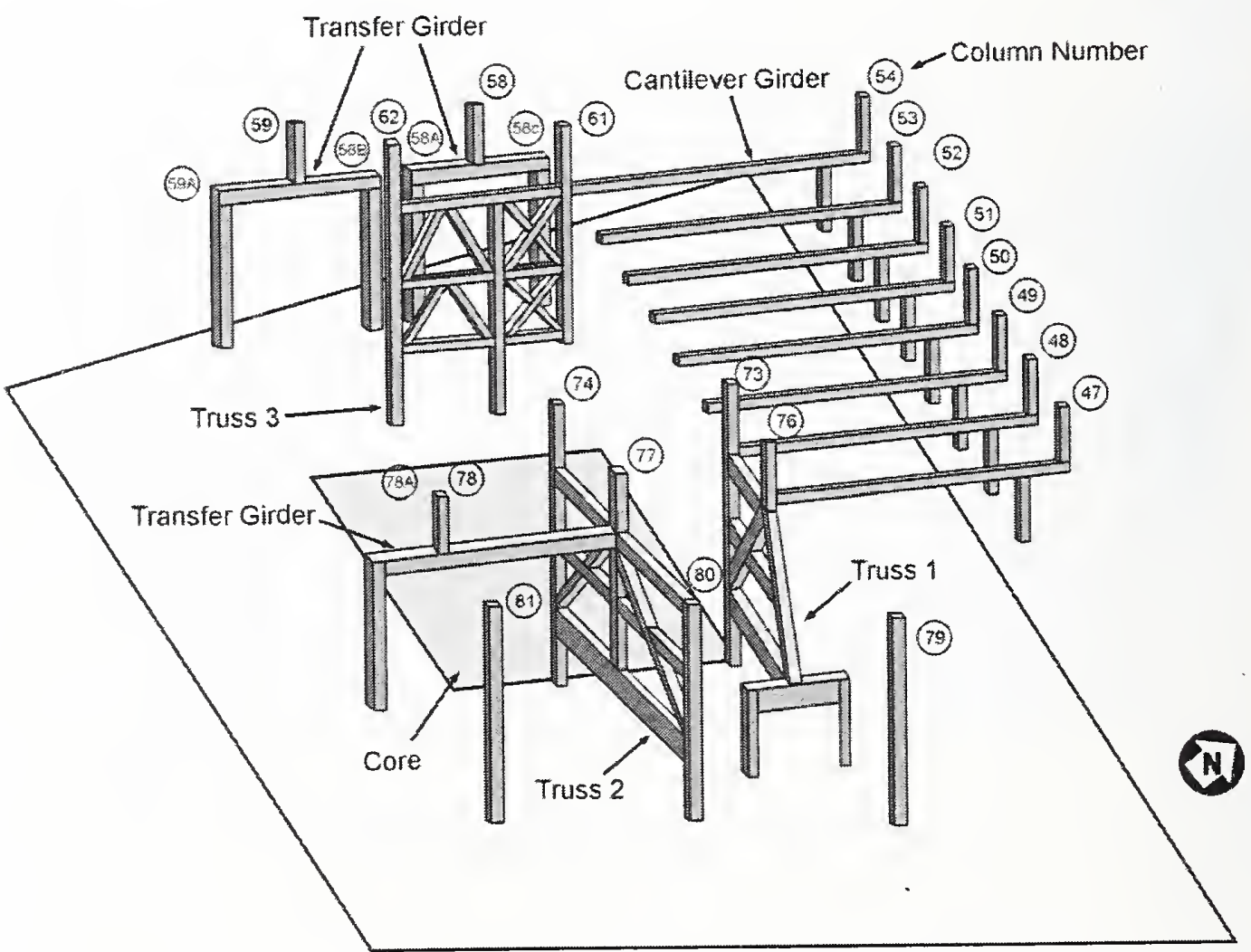

Figure 2-25. Schematic view of transfer trusses and girders between floors 5 and 7 . 


\section{Chapter 3 \\ DEVELOPMENT OF BUILDING CODES}

Since World Trade Center (WTC) 1, 2, and 7 were designed according to the New York City (NYC) Building Code, it is important to understand the evolution of this building code. This chapter presents the historical background of the development of the NYC Building Code. This chapter also summarizes the Port Authority policies for design and construction of its buildings.

\subsection{BUILDING CODE DEVELOPMENT IN THE UNITED STATES}

In the United States, building codes were introduced to minimize losses from fire. Following large fires in major cities such as Boston, New York, Chicago, and Baltimore in the late 1800s, the first model building code was developed by the fire insurance industry. The National Board of Fire Underwriters (predecessor of the American Insurance Association) published the National Building Code in 1905. Subsequently, the Pacific Coast Building Officials Conference (predecessor of the International Conference of Building Officials) issued the Uniform Building Code (UBC) in 1927, the Southern Building Code Congress International Inc. (SBCCI) published its Southern Standard Building Code in 1946, and the Building Officials and Code Administrators, Inc. (BOCA) published the Basic Building Code in 1950. In the mid1980s, the Basic Building Code was changed to the BOCA National Building Code (NBC). The three model building codes, namely the BOCA National Building Code, the Southern Standard Building Code, and the Uniform Building Code, were revised annually to incorporate developments in new materials, construction methods, and practices, and new editions were published every three years.

Before the issuance of the International Building Code (IBC) in 2000 , which was published by the International Code Council (consolidation of the three model code organizations), most local and state jurisdictions in the United States adopted one of the three model building codes. The model codes were sometimes adopted by these jurisdictions in their entirety and other times with significant modifications. The version adopted is law in that jurisdiction. In early 1900s the National Fire Protection Association (NFPA) initiated the development of a "life safety code" for safety of building occupants. This code, while not a building code, is frequently used as a supplement to the building codes. In 2002, NFPA also published a model building code known as the NFPA Building Construction and Safety Code (NFPA 5000). A number of major cities in the United States have developed their own building codes to meet their specific needs, such as San Francisco for earthquake resistant design and New York City for highrise buildings. At the present time, 44 states have adopted $1 \mathrm{BC}$ with some modifications, ${ }^{10}$ and it is being considered for adoption by New York City.

These model building codes establish minimum requirements to safeguard life, health, property, and public welfare through provisions pertaining to the design, construction, and quality of materials, use and occupancy, and maintenance of buildings. When buildings are designed, constructed, and maintained according to building code requirements, they are considered to have met minimum requirements. While

\footnotetext{
${ }^{10}$ The International Code Council updates the number of local jurisdictions that have adopted IBC (www.iccsafe.org).
} 
building code regulations address a number of objectives demanded by society, the primary objectives of building codes are structural stability and fire safety.

\subsection{NEW YORK CITY BUILDING CODE}

The New York City (NYC) Building Code is part of the Administrative Code of New York City. ${ }^{11}$ Although New York City had laws governing construction as early as 1674, after a tenement fire in 1860 took 20 lives, New York City modified and strengthened building safety laws extensively. New York City building laws are amended from time to time by Local Laws to improve safety requirements or to incorporate technological advances.

Local Laws are enacted by the NYC Council. Any member can introduce a bill to the Council for the purpose of amending the Building Code rcquirements. When passed by the Council and approved by the Mayor, the bill becomes a Local Law. The current Building Code was enacted on December 6, 1968. Through 2002, 79 Local Laws were adopted that modified the 1968 Building Code.

To aid the implementation of and to clarify Building Code requirements, New York City issues "rules." Typically these rules are initiated by City Government offices such as the Department of Buildings and the Department of Environment, and issued by the Building Commissioner. The rules do not require enactment by the City Council, and new rules issued by the Building Commissioner can be put into effect expeditiously. The rules, although are not part of the Building code, are required to be complied with for design, construction, and maintenance of buildings.

The 1968 NYC Building Code includes "Reference Standards," including standard test methods published by the American Society for Testing and Materials (ASTM), and design standards published by other organizations such as the American Concrete Institute and the American Institute of Steel Construction. These reference standards may include modifications to the provisions in the published standards, or they may be stand-alone requirements developed by New York City.

At the time the WTC project was begun (early 1960s), the 1938 NYC Building Code, which was first adopted on January 1, 1938, was in effect and enforced throughout the five boroughs. In the late 1950s, it was noted that "great changes have occurred in all facets of thc building industry" and that "As a result of these developments, and the failure in many instances, of the Code to keep pace, there had been a growing dissatisfaction with it" (Schaffner 1964). Thus, in 1960, the Building Commissioner requested the New York Building Congress to form a working committee to study the problem. The committee recommended that the Code should not be rewritten by a group of volunteers and that a local educational institution should conduct a study to develop an approach to solve the problem. The Polytechnic Institute of Brooklyn conducted the study, and in July 1961, the Institute made the following recommendations (Schaffner 1964):

1. The NYC Building Code should be completely rewritten. The new Codc should provide for frequent periodic revision through a committee or board appointed solely for this purpose.

\footnotetext{
${ }^{11}$ The historical information about the development the New York City Building Code may be found at the New York City/the Buildings Department web site (www.nyc.gov).
} 
2. The new Code should be a combination of performance and specification types with heavy emphasis on performance, wherever possible, and with liberal reference to accepted national standards.

3. The BOCA Basic Building Code should be used as a guide for the development of the NYC Building Code.

4. The Code should be rewritten by a private professional group such as an engineering company, architectural firm, educational institution, or any combination of the three. Those rewriting the Code should work closely with the NYC Building Department. They should be supported, for review purposes, by volunteer committees composed of representatives of professional, trade, and industry associations.

In April 1962, New York City signed an agreement with the Polytechnic Institute of Brooklyn for the writing of a new Code to be completed in 3 years. The first draft was completed in 1964. A public relations document highlighted the "major advantages to be gained from recommendations in the proposed new Building Code" (Bell and Stanton 1964). One of these related to "area and height limitations." and it was stated that:

Area and height limitations will be liberalized and present unrealistically high construction requirements for fire protection in structures of low combustible content such as auditoriums, halls, schools, institutions and residences will be significantly reduced and considerable economy will result.

On December 6, 1968, Local Law 76 repealed the 1938 code and replaced it with the 1968 Code, which itself has been subsequently amended by Local Law's. As is the general custom with changes to building codes, the new provisions generally are not applied to existing buildings (those approved under the prior code) provided they do not represent a danger to public safety and welfare.

Between 1969 and 2002, there were 79 Local Laws adopted that modified the 1968 code. Of particular importance with regard to fire protection and life safety are Local Law 5, adopted in 1973, and Local Law 16, adopted in 1984 (see NIST NCSTAR 1-1D). Local Law 5, among other things, added requirements on compartmentation of large floor areas, and Local Law 16 added requirements for sprinklers in high-rise buildings (greater than $100 \mathrm{ft}$ ). Local Law 5 is particularly significant because its provisions, which are reviewed in Sec. 11.1. applied retroactively to existing office buildings taller than $100 \mathrm{ft}$ in height. Local Law 84, which was passed in 1979, revised the compliance dates of Local Law 5 so that full compliance was required by February 7, 1988. 


\subsection{PORT AUTHORITY POLICIES FOR DESIGN AND MODIFICATIONS TO BUILDINGS}

\subsubsection{Procedures for PANYNJ Owned Projects}

Established in 1921, the Port of New York Authority (PONYA) ${ }^{12}$ was a self-supporting, public interstate agency and is not subject to the local laws of jurisdictions where its properties are constructed. This means that for the construction of the WTC buildings, the PONYA was not bound by the NYC Building Code or any regulations requiring inspection or approval of the building construction or operation. The PONYA could establish its own requirements, conduct its own inspections, and enforce its own rules without independent oversight.

The PONYA established an office to act as the Authority Having Jurisdiction for their facilities generally, and there was a special office for the towers. The PONYA staff reviewed and approved plans, monitored construction, and developed specifications. They developed a series of manuals that described the building infrastructure (sprinkler systems, fire alarm systems, smoke control systems) and how tenants would interface systems in their space to the building. Large tenants were generally permitted to contract for their own systems as long as they were compatible and complied with the manuals. Smaller tenants could use the PONYA office for this purpose. In either case approvals and inspections were performed by the PONYA and did not involve the City services (Department of Buildings or Fire Department).

To reaffirm and formally state the Port Authority's "long standing policy" that its facilities meet or exceed New York Building Code requirements, a memorandum of understanding between the Port Authority and the New York City Department of Buildings was established in 1993. ${ }^{13}$ Specific commitments were made by the Port Authority to the Department of that would ensure that any building construction project undertaken by the Port Authority or by any of its tenants at the buildings owned and operated by the Port Authority that were located within the Department of Buildings' jurisdiction conform to the NYC Building Code.

A summary of the 1993 agreement follows:

- The Port Authority was to thoroughly review and examine all plans for conformance with the requirements of the then current NYC Building Code. Such reviews were to be conducted by New York State licensed professional engineers or architects retained or employed by the Port Authority. Plans for projects undertaken by Port Authority tenants were to be prepared and sealed by a New York State licensed professional engineer or architect retained or employed by the tenant. Similarly, for projects undertaken by the Port Authority, plans were to be prepared and sealed by a New York State licensed professional engineer or architect retained or employed by the Port Authority.

- The Port Authority was to maintain a file containing the most recent drawings, plans, and other documents required in connection with the review of the project for code conformance.

\footnotetext{
12 In 1972, PONYA.s name was changed to the Port Authority of New York and New Jersey (PANYNJ).

${ }^{13}$ Memorandum of Understanding between the New York City Department of Buildings and PANYNJ, 1993 (WTCI-160-P, see Appendix A).
} 
- The Port Authority was required to obtain the certification of a New York State licensed professional engineer or architect that any tenant projects undertaken at any of its facilities was constructed in accordance with the approved plans and specifications for the project. Such certification was to be kept in the project file described in item 2 above.

- The Port Authority was required to provide copies of any project files to the Department of Buildings at any time.

- The Port Authority was to promptly advise the Department of Buildings of any deviations from code requirements that were proposed on a project. In cases where the Department of Buildings believed that such deviations were unacceptable, further review by the Port Authority Board of Commissioners was required.

- The Port Authority was required to perform building inspections and structural integrity inspections on a cyclical basis for all of its structures located in New York City.

- The Port Authority was responsible for life safety in buildings at its facilities. The Department of Buildings was not responsible for any type of inspection or review.

- Personnel from the Port Authority and the Department of Buildings were not to be held personally responsible under any provision of this agreement.

A supplement to the 1993 agreement was executed in $1995 .^{14}$ The supplement added that the design professional responsible for performing the review and certification of plans for WTC tenants must not be the same design professional providing certification that the project had been constructed in accordance with the plans and specifications. But the plans were to be approved by the Port Authority and held for possible inspection by the City if the Port Authority so chose.

\subsubsection{Review of Tower Plans by New York City Department of Buildings}

While the Port Authority facilities, including the WTC buildings, were not required to undergo review or approval by the NYC Department of Buildings, a letter dated February 18, 1975, from Joseph Solomon of Emory Roth \& Sons (the architect of record for the towers) to Malcolm Levy, General Manager, World Trade Center Operations states, "The Building Department reviewed the tower drawings in 1968 and made six comments concerning the plans in relation to the old code. Specific answers noting how the drawings conformed to the new code with regard to these points were submitted to the Port Authority on March 21, 1968."

NIST has attempted to locate the March 21, 1968, letter without success. NIST hoped to gain information about the six points and the level of review provided by the NYC Department of Buildings because they were under no obligation to conduct any review. However, NIST located a letter dated January 25, 1968, from Mr. Solomon to Mr. Levy that appears to list the six items questioned in the NYC Department of Buildings' review (note that the letter states five points and contains five numbered paragraphs, which are

${ }^{14}$ Supplement to Memorandum of Understanding between the New York City Department of Buildings and PANYNJ (1995) (WTCI-113-P; see Appendix A). 
followed by an additional point in an unnumbered paragraph). ${ }^{15}$ The copy of this letter providcd by PANYNJ is illegible. Both the original and the NIST reconstructed copies are shown in Appendix B.

It is interesting to note that all six points raised deal with egress issues. They do not address innovative features of the building, and egress from Windows on the World is not mentioned even though the restaurant was a part of the design from the beginning.

\subsubsection{Procedures for Tenant Alteration Projects}

To maintain structural integrity and fire safety, the Port Authority developed a tenant alteration process for any modifications to leased spaces in WTC 1 and WTC 2 for tenants who would adapt their spaces to their own needs. In 1971, shortly after the first tenants occupied WTC 1 in December 1970 and before initial occupancy of WTC 2 in 1972, the Port Authority issued the first edition of a set of requirements the Tenant Construction Review Manual. The manual contained the technical criteria to be used in planning alterations (architectural, structural, mechanical, electrical, fire protection, and others). Applicable standards to be used by tenants and their agents and review criteria to be used by the Engineering Department of the Port Authority were included. Registered design professionals were to complete alteration design, and at the completion of the work, as-built drawings were to be submitted to the Port Authority. The manual referenced the 1968 NYC Building Code, and specific code provisions were referenced in various checklists. The review manual was updated in 1979, 1984, 1990, and 1997, at which times changes that had been made to the NYC Building Code were incorporated. In 1998, the manual was replaced by the Architectural and Structural Design Guidelines, Specifications, and Standard Details, which dealt specifically with alterations to WTC 1 and WTC 2.

Since WTC 7 was built as a "tenant alteration project," its design and construction followed the requirements of the 1984 edition of the Tenant Construction Review Manual. Any modifications to the building after initial occupancy were carried out in accordance with the Manual.

${ }^{15}$ Letter dated January 25, 1968 from Joseph H. Solomon (Emery Roth \& Son) to Malcolm P. Levy (General Manager, World Trade Center Operations) (see Appendix B). 


\section{Chapter 4 \\ Code Provisions for Structural Design}

This chapter presents a summary of the provisions for structural design in the 1968 edition of the New York City (NYC) Building Code, and comparison of structural provisions of this code with similar provisions of other contemporaneous codes. As previously noted in Chapter 1, the design of the World Trade Center (WTC) towers was based on the 1968 Code, and so was the design for WTC 7. The contemporaneous codes compared include the 1964 New York State Building Construction Code (NYSBC 1964), the 1965 Building Officials and Code Administrators (BOCA) model building code (Basic Building Code [BBC]), and the 1967 Municipal Code of Chicago (MCC 1967). A comparison was also made between the 1968 NYC Building Code and the current (2001) NYC Building Code. The current NYC Building Code (NYCBC 2001) consists of the code adopted in 1968 with modifications made over the years by adoption of Local Laws.

This chapter also provides a summary of the criteria used for the design of WTC 1, 2, and 7. Only those provisions that relate to the design of WTC 1, 2, and 7 are discussed here. Unless otherwise noted, referenced article and section numbers are from the 1968 edition of the NYC Building Code.

\subsection{CONTEMPORANEOUS CODES}

Three contemporaneous codes were selected for code comparison. The 1964 New York State Building Construction Code was selected, as it would have been a governing building code outside the New York City limits. The 1965 BOCA Basic Building Code was selected as it was typically adopted by local jurisdictions in the northeastern region of the United States. The 1968 NYC Building Code is compared with the 1967 Municipal Code of Chicago to note any substantial differences in the structural and fire safety requirements of the two codes. In the late 1960s and early 1970s, several tall buildings were built in Chicago including the Sears Tower (110 stories) and the John Hancock Tower (100 stories). In addition, the 2001 edition of the NYC Building Code is compared with the 1968 version to examine the extent to which Local Laws have modified the code provisions, and in most cases, is only addressed in areas where changes have occurred between the two versions.

A provision by provision comparison was made between the 1968 NYC Building Code and these four codes and documented in NIST NCSTAR 1-1B, Comparison of Building Regulatory and Code Requirements for WTC 1,2 and 7. The only code provisions compared were the requirements related to structural stability. This chapter presents a summary of substantial differences noted in the comparison. This summary focuses on the following topics:

- Loads to be considered in the design of buildings.

- Requirements for materials, design, and construction.

With respect to structural stability, no Local Law other than Local Law 17 (seismic provisions for new construction) has been adopted that modified the structural requirements of the 1968 NYC Building Code. 
Hence, comparison between the structural requirements of the 1968 and 2001 NYC Building Code is not discussed here, with the exception of earthquake loads.

\subsection{LOADS}

A key aspect of any structural design is the loading that the structure is intended to support. Building codes provide minimum values for the different types of loads that are considered in typical building designs. The designer is permitted to use larger values for these loads but is not permitted to use smaller values without approval by the building official. This section compares the specified loads in the selected codes. Similarities and differences are noted.

\subsubsection{Dead Loads}

Dead loads refer to loads that are permanently present in a building. They include, for example, the wcight of the structural components, the weights of permanent partitions, the weights of floor and wall finishes, and the weights of service equipment that is part of the building (elevator equipment, plumbing, electrical, heating, air conditioning, and ventilation systems). Weights of the structural components are computed from the sizes of the members and the densities of the materials, and codes typically provide default density values for different materials. The dead loads of partitions and walls are typically prescribed in terms of weight per unit area of wall, and the weight per unit length of wall or partition is determined from these prescribed values and the heights of the partitions or walls. Floor finishes and ceilings are typically specified in terms of a uniform load per unit area of floor or ceiling. Table 4-1 gives examples of the minimum values of dead load prescribed in Reference Standard RS 9-1 in the 1968 New York City (NYC) Building Code and in Appendix J of the 1965 BOCA Basic Building Code. There are no corresponding provisions in the 1964 New York State Building Construction Code or the 1967 Municipal Code of Chicago. All building codes permit the designer to use weights based on available data that are greater than the specified minimum values in the code, but the designer is not permitted to use lower values without approval of the Code Official.

According to the 1968 NYC Building Code, weights from service equipment (plumbing stacks, piping, heating, ventilating, and air conditioning [HVAC], etc.) are to be included in the dead load (C26-901.2). ${ }^{16}$ The weight of equipment that is part of the occupancy of a given area is to be considered as live load (see next section). The 1964 New York State Building Construction Code and the 1967 Municipal Code of Chicago do not have a provision in this regard. The 1965 BOCA Basic Building Code has a similar provision but does not cite specific types of service equipment as the NYC Building Code.

The 1968 NYC Building Code requires that weights of partitions be considered in two ways: (1) using line loads at locations shown on plans or (2) using the equivalent uniform load given in Reference Standard RS 9-1. The stipulated equivalent uniform load depends on the partition weight, for example, if a partition weighs 201 plf to 350 plf, it may be taken into account by designing for a uniform load of 20 psf. The uniform loading approach, however, is not permitted in certain situations for which actual partition weights must be used. Equivalent uniform loads must be used in areas where the locations of partitions are not shown on plans, or in arcas where partitions can be relocated. The 1964 New York

\footnotetext{
${ }^{16}$ Refers to section number in the 1968 New York City Building Code.
} 
Table 4-1. Examples of dead loads given in NYC Building Code and BOCA Code.

\begin{tabular}{|c|c|c|}
\hline & NYC & BOCA \\
\hline \multicolumn{3}{|c|}{ Walls and Partitions } \\
\hline Hollow concrete block -8 in. thick & $53 \mathrm{psf}$ & $50 \mathrm{psf}$ \\
\hline Clay tile, nonload bearing -8 in. thick & $34 \mathrm{psf}$ & $36 \mathrm{psf}$ \\
\hline Plaster partition. metal studs and lath, gypsum plaster both sides & 18 psf & $18 \mathrm{psf}$ \\
\hline \multicolumn{3}{|l|}{ Floor Finishes } \\
\hline Resilient flooring & $2 \mathrm{psf}$ & 2 psf \\
\hline Hardwood flooring $7 / 8$ in. thick ( 1 in. for BOCA) & $4 \mathrm{psf}$ & 4 psf \\
\hline Cement. 1 in. thick & $12 \mathrm{psf}$ & $12 \mathrm{psf}$ \\
\hline \multicolumn{3}{|l|}{ Ceilings } \\
\hline Suspended acoustical tile & $2 \mathrm{psf}$ & - \\
\hline Suspended metal lath and gypsum plaster & $9 \mathrm{psf}$ & $10 \mathrm{psf}$ \\
\hline \multicolumn{3}{|c|}{ Miscellaneous Materials } \\
\hline Marble & $168 \mathrm{pcf}^{\mathrm{a}}$ & $168 \mathrm{pcf}$ \\
\hline Concrete (normal density stone or gravel) & $144 \mathrm{pcf}$ & $144 \mathrm{pcf}$ \\
\hline Reinforced concrete (normal density) & $150 \mathrm{pcf}$ & $150 \mathrm{pcf}$ \\
\hline
\end{tabular}

a. Note that the units in the 1968 NYC Building Code are given incorrectly as "psf."

State Building Construction Code does not have a specific provision in this regard. The 1967 Municipal Code of Chicago prescribes a minimum partition load of 20 psf. The BOCA Basic Building Code requires consideration of the actual weight of the partitions or an equivalent uniform load of at least 20 psf.

\subsubsection{Live Loads}

Live loads are those resulting from the use and occupancy of the building, and include loads such as weights of occupants, furniture, filing cabinets, safes, mechanical equipment, and other items that the structure is called upon to support. Live loads are specified in terms of weight per unit of floor (or roof) area or in terms of concentrated loads. The values specified in codes are based largely on load survey data, experience, and judgment.

\section{Floor Live Loads}

In general, values of minimum uniformly distributed live loads specified in codes are organized on the basis of use or occupancy of spaces, and there is no consistency in the names of these use categories. Thus, comparison between codes is not straightforward. Table 4-2 gives some examples of minimum uniformly distributed live loads for floors. It is seen that there is general agreement in the values of these selected minimum uniform live loads specified by the four codes. 
Table 4-2. Comparison of uniform live load values. Examples of minimum uniformly distributed live loads.

\begin{tabular}{|l|c|c|c|c|}
\hline & 1968 NYC & 1964 NYS & 1967 Chicago & 1965 BOCA \\
\hline Office space & $50 \mathrm{psf}$ & $50 \mathrm{psf}$ & $50 \mathrm{psf}$ & $50 \mathrm{psf}$ \\
\hline Restaurant & $100 \mathrm{psf}$ & $100 \mathrm{psf}$ & - & $100 \mathrm{psf}$ \\
\hline Lobbies & $100 \mathrm{psf}$ & $100 \mathrm{psf}$ & $100 \mathrm{psf}$ & $100 \mathrm{psf}$ \\
\hline Stairways & $100 \mathrm{psf}$ & $100 \mathrm{psf}$ & $75-100 \mathrm{psf}^{\text {a }}$ & $100 \mathrm{psf}$ \\
\hline Rest rooms & $40 \mathrm{psf}$ & $60 \mathrm{psf}$ & - & - \\
\hline Hospital operating room & $60 \mathrm{psf}$ & $60 \mathrm{psf}$ & $40 \mathrm{psf}$ & $60 \mathrm{psf}$ \\
\hline School classroom & $40 \mathrm{psf}$ & $60 \mathrm{psf}$ & $40 \mathrm{psf}$ & - \\
\hline
\end{tabular}

a. Depends on occupancy, for example, 75 psf for business, $100 \mathrm{psf}$ for schools.

The codes also specify concentrated live loads placed so as to result in maximum stresses.

\section{Live-Load Reduction}

There is a low likelihood that the full design floor live loads will be present on all floors of a building at the same time. In addition, the likelihood that the complete area any one floor is loaded with the design live load decreases as the floor area increases. To account for these factors, building codes permit "liveload reductions" in calculating the design loads for primary members (columns and girders) that support the roof and floors. The codes use several methods for live-load reduction (CTB\&UH 1980):

1. Percentage Method - In this method, the live-load reduction increases by a certain percentage with increasing numbers of floors, with a limit on the maximum value of reduction (typically 50 percent).

2. Tributary Area Method-The live load is reduced as the accumulated tributary area that a member supports is increased. The limiting value depends on the ratio of live load to dead load. The type of occupancy affects whether a reduction is permitted.

3. Live Load to Dead Load Ratio-The permitted reduction depends on the ratio of live load to dead load, provided that the dead load is greater than the live load.

The 1968 NYC Building Code uses the tributary area method and permits the percentage method as an alternative for columns, piers, and walls. The 1964 New York State Building Construction Code and the 1967 Municipal Code of Chicago use the tributary area method for beams and girders and the percentage method for columns and walls. The 1965 BOCA Basic Building Code uses a tributary method that is similar to the New York State Code.

Figure 4-1 compares the reduced live load for columns, walls, and piers on the basis of the percentage method for three of the codes. The permitted reductions are similar with the exception of the roof and top floor, where the 1968 NYC Building Code and the 1967 Municipal Code of Chicago are more conservative (less reduction permitted) than the 1964 New York State Building Construction Code.

Table 4-3 compares the reduced live loads for beams and girders for the selected codes. For the 1968 NYC Building Code, the reduced value of live load for a given contributory area depends on the live load 
to dead load ratio, with lower values permitted for lower live load to dead load ratios. For the 1964 New York State Building Construction Code and the 1965 BOCA Basic Building Code, the values shown in the table are based on a reduction factor of 0.08 percent $/ \mathrm{ft}^{2}$. The lowest reduced value, however, is limited to 40 percent or

$$
100 \% \frac{3.33 \frac{L}{D}-1}{4.33 \frac{L}{D}}
$$

whichever is larger, where $L / D$ is the live load to dead load ratio. As the ratio of live load to dead load increases, less live-load reduction is permitted. A comparison of the values in Table 4-3 shows that the 1967 Municipal Code of Chicago did not permit as large a reduction in live load for the same contributory area as the other codes.

\subsubsection{Wind Load}

The effect of wind on buildings is accounted for in the building codes by specifying a uniform pressure to be applied horizontally to a building. These pressures are to be applied in any direction so as to obtain the most critical loading condition.

The pressure due to wind varies with the square of the wind speed, and wind speed increases with height. Thus building codes specify minimum design wind pressures that increase with elevation. The variations of pressure with height, however, are not the same among the building codes compared. Figure 4-2 compares the specified wind pressure versus height relationships for the four selected codes. Several observations are noted:

- For buildings up to $600 \mathrm{ft}$ in height, the 1964 New York State Building Construction Code prescribes the largest wind pressures.

- The 1967 Municipal Code of Chicago prescribes the lowest wind pressures for buildings up to $900 \mathrm{ft}$ in height.

- The 1968 NYC Building Code and the 1965 BOCA Basic Building Code provide similar wind pressures for buildings up to $700 \mathrm{ft}$ in height; for taller buildings the BOCA Code specifies larger pressures.

For a building height of 1,370 ft (the approximate heights of WTC 1 and WTC 2), the wind pressure distribution specified by the 1965 BOCA Basic Building Code would result in the largest shear force and overturning moment at the base of the building. 
Table 4-3. Reduced live load for beams and girders.

\begin{tabular}{|c|c|c|c|}
\hline $\begin{array}{c}\text { Contributary Area } \\
\left(\mathbf{f t}^{2}\right)\end{array}$ & $\begin{array}{c}\text { 1968 NYC } \\
\text { Building Code (\%) }\end{array}$ & $\begin{array}{c}\text { 1967 Chicago } \\
\text { Municipal Code (\%) }\end{array}$ & $\begin{array}{c}\text { 1956 NY State and } \\
\mathbf{1 9 6 5} \text { BOCA Codes (\%) }\end{array}$ \\
\hline 100 or less & 100 & 100 & 100 \\
\hline $100-149$ & 100 & 95 & 100 \\
\hline $150-199$ & 80 to $85^{\mathrm{a}}$ & 95 & 84 to $88^{\mathrm{b}}$ \\
\hline $200-299$ & 80 to $85^{\mathrm{a}}$ & 90 & 76 to $84^{\mathrm{b}}$ \\
\hline $300-449$ & 60 to $75^{\mathrm{a}}$ & 85 & 64 to $76^{\mathrm{b}}$ \\
\hline $450-599$ & 50 to $70^{\mathrm{a}}$ & 85 & 52 to $64^{\mathrm{b}}$ \\
\hline 600 and more & 40 to $65^{\mathrm{a}}$ & 85 & 40 to $52^{\mathrm{b}}$ \\
\hline
\end{tabular}

a. Permitted value depends on live load to dead load ratio; less reduction permitted with higher ratio.

b. The lowest value is limited to 40 percent, or 100 percent of $(3.33 \mathrm{~L} / \mathrm{D}-1) /(4.33 \mathrm{~L} / \mathrm{D})$, whichever is greater.

Assuming wind is blowing in the direction perpendicular to the face of the tower, a comparison using the specified wind pressures from the aforementioned codes reveals that the largest shear force at the base of a building the height of the WTC towers is obtained from the BOCA Basic Building Code. Similarly, the largest overturning moment at the base of a building the height of the WTC towers is also obtained from the BOCA Basic Building Code. The lowest base shear and moment are obtained from the 1968 and 2001 New York City Codes. The base shear from the New York City Codes is approximately 8 percent less than that from the BOCA code, while the base moment is approximately 11 percent less (see Table 4-4).

Table 4-4. Base shears and overturning moments from reviewed codes for a building the height of WTC towers $(1,368 \mathrm{ft})$.

\begin{tabular}{|c|c|c|c|c|c|}
\hline & $\begin{array}{c}1968 \\
\text { NYC Building } \\
\text { Code }\end{array}$ & $\begin{array}{c}\mathbf{2 0 0 1} \\
\text { NYC Building } \\
\text { Code }\end{array}$ & $\begin{array}{c}\mathbf{1 9 6 4} \text { NY State } \\
\text { Code }\end{array}$ & $\begin{array}{c}\mathbf{1 9 6 7} \text { Chicago } \\
\text { Municipal } \\
\text { Code }\end{array}$ & $\begin{array}{c}\mathbf{1 9 6 5} \\
\text { BOCA/BBC }\end{array}$ \\
\hline Base Shear (kip) & 9,250 & 9,250 & 9,460 & 8,610 & 9,970 \\
\hline $\begin{array}{c}\text { Overturning } \\
\text { Moment } \\
\text { (ft kip } \times 10^{3} \text { at } \\
\text { footing) }\end{array}$ & 7,621 & 7,621 & 7,572 & 7,446 & 8,470 \\
\hline
\end{tabular}

The 1968 NYC Building Code permits the designer to use wind pressure values, other than specified minimums, on the basis of wind tunnel tests and with approval of the building official. ${ }^{17}$ The following wording is provided in Sec. 6 of Reference Standard RS 9-5, "Minimum Design Wind Pressures."

In lieu of the design wind pressures established in sections 1 and 2 of this reference standard, and subject to review and approval of the commissioner, design wind pressures may be approximated from suitably conducted model tests. The tests shall be predicated on a basic wind velocity of $80 \mathrm{mph}$ at the $30 \mathrm{ft}$ level, and shall simulate and include all factors involved in considerations of wind pressure, including pressure and suction effects, shape factors, functional effects, gusts, and internal pressures and suctions.

\footnotetext{
${ }^{17}$ See Sub-article 904.0, the 1968 New York City Building Code.
} 
The other three contemporaneous codes do not have a similar provision for conducting model tests to determine the design wind pressure.

Thus the 1968 NYC Building Code presumes a wind with a speed of $80 \mathrm{mph}$ measured $30 \mathrm{ft}$ above the ground. The 1964 New York State Building Construction Code, on the other hand, states that the prescribed wind loads "are based on a design wind speed of $75 \mathrm{mph}$ at a height of $30 \mathrm{ft}$ above grade level." Both the 1965 BOCA Basic Building Code and the 1967 Municipal Code of Chicago do not specify the design wind speed.

\subsubsection{Earthquake Load}

The 1968 NYC Building Code did not have provisions for earthquake loads. Among the selected contemporaneous codes, only the 1965 BOCA Basic Building Code had earthquake load provisions. These are contained in Appendix K-11 of that Code and were adapted from the 1962 edition of the Uniform Building Code.

The 2001 edition of the NYC Building Code contains seismic design provisions from the 1988 edition of the Uniform Building Code (UBC 1988), including the 1990 Accumulative Supplement. These provisions were put into effect in 1996 as a result of Local Law 17 (1995). Significant modifications to the 1988 Uniform Building Code were made, and described in Reference Standard RS 9-6.

For example, the paragraph on "Minimum Seismic Design," is modified to read:

The following types of construction shall, at a minimum, be designed and constructed to resist the effects of seismic ground motions as provided in this section:

new structures on new foundations;

new structures on existing foundations; and

enlargements in and of themselves on new foundations.

Buildings classified in New York City occupancy group J-3 and not more than three stories in height need not conform to the provisions of this section. The Commissioner may require that the following types of construction be designed and constructed to incorporate safety measures as necessary to provide safety against the effects of seismic ground motions at least equivalent to that provided in a structure to which the provisions of the section are applicable:

new buildings classified in occupancy group J-3 and which are three stories or less in height; and

enlargements in and of themselves where the costs of such enlargement exceeds sixty percent of the value of the building.

In the subdivision on "Criteria Selection" the following paragraph was added:

Seismic Zone. The seismic zone factor, Z, for buildings, structures and portions thereof in New York City shall be 0.15 . The seismic zone factor is the effective zero period acceleration for $S_{1}$ type rock. 
Another significant amendment is the addition of consideration of soil liquefaction that was not found in the Uniform Building Code.

\subsubsection{Other Loads}

\section{Temperature and Shrinkage}

The 1968 NYC Building Code included provisions dealing with types of loadings not considered in the other codes that were compared. Two examples are "thermal forces" and "shrinkage."

Section C26-905.7 deals with thermal forces and includes the following requirement:

...For exterior exposed frames, arches, or shells regardless of plan dimensions, the design shall provide for the forces and/or movements resulting from an assumed expansion and contraction corresponding to an increase or decrease in temperature of forty degrees $\mathrm{F}$ for concrete or masonry construction and sixty degrees F for metal construction...

Section C26-905.8 on shrinkage includes the following requirement:

The design of reinforced concrete components shall provide for the forces and/or movements resulting from shrinkage of the concrete in the amount of 0.0002 times the length between contraction joints for standard weight concrete, and 0.0003 times the length between contraction joints for lightweight concrete....

\section{Abnormal loads (Progressive collapse consideration)}

The 1968 NYC Building Code did not have provisions for design against progressive collapse of buildings due to abnormal loads. Abnormal loads would include explosions resulting from ignition of gas or industrial liquids, vehicle impacts, gross construction errors, and the like. In response to the collapse of a concrete panel building in Ronant Point, England in 1968, the NYC Building Code by rule ${ }^{18}$ adopted the progressive collapse provisions in August 2, 1973. However, on August 7, 1973, the Department of Buildings issued a memorandum to clarify the type of structures to which the new progressive collapse provisions apply. These include structures with connections that rely on friction due to gravity loads to transfer tension, compression and shear forces in the structural members. Thus, for cast-in-place concrete construction having adequate joint reinforcement, the new progressive collapse provisions would not apply. Similarly, for structural steel construction with bolted, riveted or welded connections to transfer tension, compression and shear forces, the provisions would not apply. In practical sense, the new provisions would apply to precast construction wherein joint forces are transferred by friction developed by gravity loads.

\footnotetext{
${ }^{18}$ The rules intrepret the code to clarify the intent of the code.
} 


\subsubsection{Distribution of Loads}

Another topic that is addressed only in the 1968 (and 2001) NYC Building Code is the distribution of loads, which is covered in Article 7 of Sub-chapter 9. Section C26-906.1 deals with vertical loads and states:

Distribution of vertical loads to supporting members shall be determined on the basis of a recognized method of elastic analysis or system of coefficients of approximation. Elastic or inelastic displacements of supports shall be considered and, for the distribution of dead loads, the modulus of elasticity of concrete or composition [composite] sections shall be reduced to consider plastic flow. Secondary effects due to warping of the floors shall be considered.

Section C26-906.2 deals with distribution of horizontal forces. Because this section provides important information in the design assumptions to be used in the design of high-rise buildings, several key sections are repeated here:

The following provisions shall apply to superstructure framing only, and shall not apply to structures wherein horizontal loads are transmitted to the foundation by staycables, arches, non-rectangular frames, or by frames, trusses, or shear walls not oriented in vertical planes.

(a) Distribution of horizontal loads to vertical frames, trusses and shear walls. - Horizontal loads on the superstructure shall be assumed to be distributed to vertical frames, trusses, and shear walls by floor and roof systems acting as horizontal diaphragms. The proportion of the total horizontal load to be resisted by any given vertical frame, truss, or shear wall shall be determined on the basis of relative rigidity, considering the eccentricity of the applied load with respect to the center of resistance of the frames, trusses, or shear walls. For vertical trusses, web deformations shall be considered in evaluating the rigidity.

\section{(b) Distribution of horizontal loads within rigid frames of tier buildings. -}

(1) ASSUMPTIONS. - The distribution of horizontal loads within rigid frames of tier buildings may be determined on the basis of a recognized method of elastic analysis or, subject to limitations in paragraph two of this subdivision, may be predicated on one or more of the following simplifying assumptions:

a. Points of inflection in beams or columns are at their midspan and midheight, respectively. The story shear is distributed to the columns in proportion to their stiffnesses.

b. The change in length of columns due to axial effects of the horizontal loads may be neglected.

c. Vertical column loads due to horizontal forces are taken by the exterior columns only, or are resisted by the columns in proportion to the column distances from the neutral axis of the bent. 


\section{(2) LIMITATIONS. -}

a. For buildings over $300 \mathrm{ft}$ in height, the change in length of the columns, due to the effects of the horizontal loads, shall be evaluated or the framing proportioned to produce regular movements of the successive joints at each floor so that warping of the floor system may be neglected.

b. Simplifying assumptions used in design shall be subject to approval by the commissioner for any of the following conditions or circumstances:

1. For buildings over $300 \mathrm{ft}$ in height or for buildings with a heightwidth ratio greater than five.

2. At two-story entrances or intermediate floors.

3. Where offsets in the building occur.

4. Where transfer columns occur.

5. In any similar circumstances of irregularities or discontinuities in the framing.

\subsection{DESIGN STANDARDS}

Article 10 of the 1968 NYC Building Code is entitled "Structural Work," and it provides minimum requirements for materials, design, and construction of all structural elements in buildings. Section 4.3.1 compares design standards in the selected building codes. Section 4.3.2 discusses design load combinations that were specified in the selected building codes.

\subsubsection{Design Standards}

Design standards are those documents that are used to proportion the structural elements and their connections. The principal structural materials in the WTC buildings were concrete and steel, and the design standards were those produced by the American Concrete Institute ( $\mathrm{ACI}$ ) and the American Institute of Steel Construction (AISC). The ACI produced the standard known as ACI 318, Building Code Requirements for Reinforced Concrete, ${ }^{19}$ and the AISC produced the following:

- Specification for the Design, Fabrication and Erection of Structural Steel for Buildings (AISC 1963)

- Specifications for Structural Steel Buildings-ASD and Plastic Design (AISC 1989)

- Load and Resistance Factor Design Specifications for Structural Steel Buildings (AISC 1993)

\footnotetext{
${ }^{19}$ In 1999, the title was changed to Building Code Requirements for Structural Concrete.
} 
Table 4-5 summarizes the concrete and steel design standards adopted by the codes that were compared. The 1964 New York State Building Construction Code was a performance standard and did not adopt design standards by reference. Thus, at the time the WTC towers were being designed, the other two codes (Chicago and BOCA) referenced the same concrete and steel design standards as the New York City code.

Table 4-5. Design standards for concrete and steel.

\begin{tabular}{|l|c|c|c|c|}
\hline Naterial & 1968 NYC Code & 2001 NYC Code & $\begin{array}{c}\text { 1967 Chicago } \\
\text { Code }\end{array}$ & $\begin{array}{c}\text { 1965 BOCA } \\
\text { Code }\end{array}$ \\
\hline Concrete & ACI 318-63 & ACI 318-89 & ACI 318-63 & ACI 318-63 \\
\hline Steel & AISC 1963 & $\begin{array}{c}\text { AISC } 1989 \\
\text { AISC } 1993\end{array}$ & AISC 1963 & AISC 1963 \\
\hline
\end{tabular}

The 1963 edition of ACI 318 permits reinforced concrete members to be designed by either the working stress (or allowable stress) method or by the ultimate strength method. The 1963 AISC specification, on the other hand, is based on allowable stress design. The design method affects the loads used in the design calculations.

\subsubsection{Load Combinations}

The loads prescribed by the codes are used in different combinations to assess the governing design condition. The codes distinguish between sustained loads and loads of short duration or infrequent occurrence. For allowable stress design, two approaches are used for dealing with these two categories of loads, as will be discussed. For ultimate strength design, the prescribed loads are multiplied by specified load factors. In either case, the designer considers all applicable load combinations and determines the most critical condition, which becomes the design basis for a particular element.

\section{Allowable Stress Design}

The 1968 NYC Building Code defines two categories of loads:

- Basic loads, which include dead load, live load, and reduced live load where applicable; and

- Loads of infrequent occurrence, which include wind load, thermally induced load, shrinkage induced load, and unreduced live load where live load reduction is permitted.

Under the 1968 NYC Building Code, stresses in structural elements may not excecd the allowable values specified in the referenced design standards under the following load combinations ${ }^{20}$ :

- The sum of the basic loads multiplied by a factor equal to 1 .

- The factored sum of one or more basic loads and one load of infrequent occurrence, where the load factor equals 0.75 .

\footnotetext{
${ }^{20}$ See Section C26-1001.4 of the 1968 NYC Building Code.
} 
- The factored sum of one or more basic loads plus two or more loads of infrequent occurrence, where the load factor equals 0.6 .

The 2001 NYC Building Code is similar with the exception that it includes earthquake load as another load of infrequent occurrence.

The other Codes that were compared use a different approach for dealing with loads of infrequent occurrence. The 1964 New York State Building Construction Code states that stress due to wind load may be ignored if it is less than one-third of the stress due to dead load plus imposed load excluding wind load. If the stress due to wind load exceeds this limit, the allowable stress for the material is permitted to be increased by $1 / 3$.

The 1967 Municipal Code of Chicago uses a similar approach and states: "For combined stresses due to dead, live, and wind load, the allowable stresses in materials may be increased $1 / 3$, provided the section thus determined is at least as strong as that required for dead and live load alone. Snow load shall be considered a live load."

The 1965 BOCA Basic Building Code is similar except that wind load or earthquake load is considered along with dead load and live load (including snow load). The same $1 / 3$ increase in allowable stress is permitted under wind or earthquake load. The BOCA Code also explicitly states that wind load is permitted to be neglected if it results in stress less than one-third the stress due to dead load plus live load.

\section{Ultimate Strength Design}

In the 1960s, ultimate strength design was standardized only for reinforced concrete. As shown in Table 4-5, the three codes from the 1960s referenced ACI 318-63, which includes the following load combinations to establish the design loads (U) for structural members:

1. For structures where wind and earthquake loads may be neglected, $\mathrm{U}=1.5 \mathrm{D}+1.8 \mathrm{~L}$.

2. For structures where wind load must be included, $U=1.25(\mathrm{D}+\mathrm{L})$ or $\mathrm{U}=0.9 \mathrm{D}+1.1 \mathrm{~W}$, whichever produces the most unfavorable condition for the member.

3. For structures where earthquake loading is included, $\mathrm{E}$ shall be substituted for $\mathrm{W}$ in condition 2.

4. In structures where effects of shrinkage and temperature are included, the effects of such items shall be considered on the same basis as the effects of dead load.

The 2001 NYC Building Code refers to ACI 318-99, which includes many more load combinations to be considered. These are as follows:

1. For all structures, $\mathrm{U}=1.4 \mathrm{D}+1.7 \mathrm{~L}$.

2. For structures where wind load must be included, $U=0.75[1.4 \mathrm{D}+1.7 \mathrm{~L}+1.7 \mathrm{~W})]$ or $\mathrm{U}=0.9 \mathrm{D}+1.3 \mathrm{~W}$, whichever produces the most unfavorable condition for the member. 
3. For structures where resistance to earthquakes must be included, the load combinations of condition 2 are used with 1.1 E substituted for W.

4. For structures where resistance to earth pressure $(\mathrm{H})$ must be included, $\mathrm{U}=1.4 \mathrm{D}+1.7 \mathrm{~L}+1.7 \mathrm{H}$ or $0.9 \mathrm{D}+1.7 \mathrm{H}$, whichever produces the most unfavorable condition.

5. For structures where resistance to fluid pressure $(F)$ must be included, $\mathrm{U}=1.4 \mathrm{D}+1.7 \mathrm{~L}+1.4 \mathrm{~F}$ or $0.9 \mathrm{D}+1.7 \mathrm{~F}$, whichever produces the most unfavorable condition.

6. For structures where resistance shrinkage and temperature (T) must be included, $\mathrm{U}=0.75(1.4 \mathrm{D}+1.4 \mathrm{~T}+1.7 \mathrm{~L})>1.4(\mathrm{D}+\mathrm{T})$.

7. For structures where resistance to impact must be taken into account, such effects shall be included with live load L.

\subsection{ALTERATION OF EXISTING BUILDINGS}

The compared codes have provisions to address code compliance when existing buildings are altered. The provisions of all codes, other than the 1964 New York State Building Construction Code, are broadly similar. In general, whether the altered building or only the alternations need to comply with code requirements depends on the ratio of alterations to the total building expressed either in terms of cost or dimensions. When the ratio is low, even the alterations may not have to be in compliance with the code, provided stipulated conditions are met. The 1964 New York State Building Construction Code, however, requires that any addition or alteration, regardless of building value, shall be made in conformity with that code. It is silent as to the structure being altered. Table 4-6 summarizes code provisions related to alterations.

Table 4-6. Compliance requirements for alterations.

\begin{tabular}{|l|l|}
\hline \multicolumn{1}{|c|}{ Code } & \multicolumn{1}{c|}{ Provisions } \\
\hline Building Code & $\begin{array}{l}\text { Alterations exceeding } 60 \text { percent of building value (in any } 12 \text { month period): The } \\
\text { entire building shall be made to comply with the requirement of the code. } \\
\text { Alterations between } \mathbf{3 0} \text { percent and } \mathbf{6 0} \text { percent of building value (in any } \mathbf{1 2} \text { month } \\
\text { period): Only those portions of the building altered shall be made to comply with the } \\
\text { requirements of the code. } \\
\text { Alteration under 30 percent of building value (in any 12 month period): Those } \\
\text { portions altered may, at the option of the owner, be altered in accordance with the } \\
\text { requirement of the code. or altered in compliance with their previously required } \\
\text { condition and with the same or equivalent materials and equipment, provided the } \\
\text { general safety and public welfare are not thereby endangered. }\end{array}$ \\
\hline $\begin{array}{l}\text { 2001 New York City } \\
\text { Building Code }\end{array}$ & $\begin{array}{l}\text { Same as 1968 Code, except that wording for alterations less than 30 percent of } \\
\text { building values was changed to: "those portions of the building altered may, at the } \\
\text { option of the owner, be altered in accordance with the requirements of this code, or } \\
\text { altered in compliance with the applicable laws in existence prior to December sixth, } \\
\text { nineteen hundred sixty-eight, provided the general safety and public welfare are not } \\
\text { thereby endangered." } \\
\text { In addition. certain alterations are required to conform to the code regardless of }\end{array}$ \\
\hline
\end{tabular}




\begin{tabular}{|l|l|}
\hline \multicolumn{1}{|c|}{ Code } & \multicolumn{1}{c|}{ Provisions } \\
\hline & $\begin{array}{l}\text { magnitude or cost. These include, among others: } \\
\text { Alterations to standpipes, sprinklers, or interior fire alarm and signal systems; } \\
\text { Alterations to equipment for heating or storing water; } \\
\text { Sprinkler, alarm protection, and emergency lighting requirements for places of } \\
\text { assembly. }\end{array}$ \\
\hline $\begin{array}{l}\text { 1964 New York State } \\
\text { Building Construction }\end{array}$ & $\begin{array}{l}\text { Addition or alteration: Any addition or alteration, regardless of cost, made to a } \\
\text { building shall be made in conformity with applicable regulations of the code. }\end{array}$ \\
\hline of Chicago & $\begin{array}{l}\text { More than 50 percent: Such buildings and structures shall be made to conform to all } \\
\text { requirements of the code that are applicable to new buildings and structures. } \\
\text { 25 percent to 50 percent: All new constructions shall conform to the requirements of } \\
\text { the code for new buildings or structures of like area, height and occupancy. } \\
\text { 25 percent or less: Certain exceptions can be made that allow the use of materials that } \\
\text { conform to the strength and fire resistance for the materials with which the building is } \\
\text { constructed. Otherwise, all new construction shall conform to the requirements of this } \\
\text { code for a new building. }\end{array}$ \\
\hline $\begin{array}{l}\text { 1965 BOCA Basic } \\
\text { Building Code }\end{array}$ & $\begin{array}{l}\text { "In the reconstruction, repair, extension or alteration of existing buildings, the } \\
\text { allowable working stresses used in design shall be as follows: } \\
\text { 1. Building extended: If altered by an extension in height or area, all existing } \\
\text { structural parts affected by the addition shall be strengthened where necessary and all } \\
\text { new structural parts shall be designed to meet the requirements for buildings hereafter } \\
\text { erected. } \\
\text { 2. Building repaired: When the uncovered structural parts are found unsound, such } \\
\text { parts shall be made to conform to the requirements for buildings hereafter erected. } \\
\text { 3. Existing live load: When an existing building heretofore approved is altered or } \\
\text { repaired within the limitation prescribed in Sec. 106.3 (alteration under 50 percent) and } \\
\text { 106.4 (alteration under 25 percent), the structure may be designed for the loads and } \\
\text { stresses applicable at the time of erection, provided that public safety is not } \\
\text { endangered. } \\
\text { 4. Posted live load: May be posted for original approved live loads." }\end{array}$ \\
\hline
\end{tabular}

\subsection{MATERIALS AND METHODS OF CONSTRUCTION}

The compared codes have requirements for the materials and construction methods. Each code makes distinctions in materials and methods that depend on the nature of inspection and conformance with standards.

The 1968 NYC Building Code prescribes testing and inspection requirements for all materials, assemblies, forms, and methods of construction. A distinction is made between materials and methods subject to "controlled inspection" and those that are not subject to controlled inspection. Materials and methods subject to controlled inspections "shall be inspected and/or tested to verify compliance with code requirements." In general, activities related to controlled inspections "shall be made and witnessed by or under the direct supervision of an architect or engineer retained by or on behalf of the owner or lessee, who shall be, or shall be acceptable to, the architect or engineer who prepared or supervised the preparation of the plans." On the other hand, materials and methods not designated for controlled inspection "shall be inspected and/or tested to verify compliance with code requirements by the person superintending the use of the material or its incorporation into the work..." 
The 1968 NYC Building Code provides tables to indicate which materials and methods are subject to controlled inspections and which are not. Table 4-7 includes excerpts from the requirements for inspection of materials and assemblies. A footnote to the table in the code states that "All structural materials and assemblies subject to controlled inspection shall be tested and/or inspected at their place of manufacture and evidence of compliance with the provisions of this subchapter shall be provided as stipulated in sub-articles 1003.0 through 1011.0." Table 4-8 is an excerpt of the inspection requirements for methods of construction. A footnote to the companion table in the code states that "All construction operations designated for controlled inspection shall be inspected by the architect or engineer designated for controlled inspection during the performance of such operation."

Table 4-7. Excerpts of inspection requirements for materials and assemblies in Article 10 of 1968 NYC Building Code.

\begin{tabular}{|l|l|l|}
\hline Material & Elements Subject to Controlled Inspection & \multicolumn{1}{c|}{$\begin{array}{c}\text { Elements Not Subject to Controlled } \\
\text { Inspection }\end{array}$} \\
\hline Steel & None & All structural elements and connections \\
\hline Concrete & $\begin{array}{l}\text { Materials for all structural elements } \\
\text { proportioned on the basis of calculated } \\
\text { stresses 70 percent or greater, of basic } \\
\text { allowable stresses. See Sec. 1004.0 for } \\
\text { specific requirements relating to "quality } \\
\text { control of materials and batching." }\end{array}$ & $\begin{array}{l}\text { (1) All materials for all structural elements } \\
\text { proportioned on the basis of calculated stresses } \\
\text { less than 70 percent or greater of basic allowable } \\
\text { values. } \\
\text { (2) Concrete materials for: } \\
\text { (a) Short span floor and roof construction } \\
\text { proportioned as per Sec. 1004.8. } \\
\text { (b) Walls and footings for buildings in } \\
\text { Occupancy Group J-3. }\end{array}$ \\
\hline
\end{tabular}

The 1968 NYC Building Code required that the installation of "sprayed-on fire protection" of structural members (except those encased in concrete) be subjected to controlled inspection requirements, as defined above. There were, however, no specific provisions on what testing was required.

The 1964 New York State Building Construction Code and the 1965 BOCA BBC make distinctions between "controlled" and "ordinary" materials in reference to establishing allowable stresses. For example BOCA defines "controlled materials" as those that are "certified by an accredited authoritative agency as meeting accepted engineering standards for quality." Ordinary materials are thosc that do not conform to the requirements for controlled materials.

The 1967 Municipal Code of Chicago specifies that all materials and methods uscd in the design and construction of buildings shall be classified as "controlled materials" or "ordinary materials." According to the Chicago Code, "controlled materials" means a building, structure, or part thereof, which has been designed or constructed under the following conditions: (a) All controlled materials must be selected or tested to meet the special strength, durability and fire resistance rcquirements upon which the design is based. (b) The design, preparation of working drawings, including details and connections, the checking and approval of all shop and field details and the inspection of the work during construction shall be under the supervision of a registered architect or structural engineer (Sec. 69-3.1). 
Table 4-8. Excerpts of inspection requirements for methods of construction in Article 10 of 1968 NYC Building Code.

\begin{tabular}{|l|l|l|}
\hline Material & \multicolumn{1}{|c|}{$\begin{array}{c}\text { Operations Subject to Controlled } \\
\text { Inspection }\end{array}$} & \multicolumn{1}{c|}{$\begin{array}{c}\text { Operations Not Subject to Controlled } \\
\text { Inspection }\end{array}$} \\
\hline Steel & $\begin{array}{l}\text { (1) Welding operations and the tensioning of } \\
\text { high strength bolts in connections where the } \\
\text { calculated stresses in the welds or bolts are 50 } \\
\text { percent or more of basic allowable values. } \\
\text { (2) Connection of fittings to wire cables for } \\
\text { suspended structures, except where cables } \\
\text { together with their attached fittings are proof- } \\
\text { loaded to not less than 50 percent of ultimate } \\
\text { capacity. }\end{array}$ & $\begin{array}{l}\text { (1) Welding operations and the tensioning of } \\
\text { high strength bolts in connections where the } \\
\text { calculated stresses in the welds or bolts are less } \\
\text { than 50 percent of basic allowable values. } \\
\text { (2) All other fabrication and erection operations } \\
\text { not designated for controlled inspection. }\end{array}$ \\
\hline $\begin{array}{l}\text { Cxcept for those operations specifically } \\
\text { designated in this table as not subject to } \\
\text { controlled inspection, for all concrete, the } \\
\text { operations described in Sec. 1004.5(a) shall be } \\
\text { subject to controlled inspection." }\end{array}$ & $\begin{array}{l}\text { (1) All operations relating to the constriction of } \\
\text { members and assemblies (other than prestressed } \\
\text { concrete) which involve the placement of a total } \\
\text { of less than 50 cubic yards of concrete and } \\
\text { wherein said concrete is used at levels of } \\
\text { calculated stress 70 percent or less of basic } \\
\text { allowable values. } \\
\text { (2) placing and curing of concrete for all: } \\
\text { (a) short span floor and roof construction as } \\
\text { per Sec. 1004.8. } \\
\text { (b) Walls and footings for buildings in } \\
\text { Occupancy Group J-3. }\end{array}$ \\
$\begin{array}{ll}\text { (3) Size and location of reinforcement for walls } \\
\text { and footings in Occupancy Group J-3. } \\
\text { (4) All other operations not described in } \\
\text { Secs. C26-1004.5(a). }\end{array}$ \\
\hline
\end{tabular}

The 1968 and 2001 NYC Building Codes are the only codes of those compared that include provisions for stability, bracing, and secondary stresses. The provisions are the same in the two editions of the code. Stability, in this case, refers to resistance to sliding or overturning of the building on its foundation. The NYC Building Code requires a factor of safety of 1.5 against failure by sliding or overturning. The required stability is to be provided solely by the dead load plus any permanent anchorage that is provided. Bracing refers to lateral support to prevent buckling of compression members (columns and walls). The NYC Building Code requires that the bracing be proportioned to resist a load of at least 2 percent of the total design compression load in the braced member plus any transverse shear load on the bracing member. Secondary stresses refer to stresses associated with transverse deflection of a member. In trusses, for example, secondary stresses arise because joints are not true pins, and some bending is introduced, which results in transverse displacements of the individual elements. The NYC Building Code requires that secondary stresses in trusses be considered in designing the size of the individual elements. 


\subsection{DEFLECTION LIMITATIONS}

All five codes contain limits on vertical deflections of floor and roof assemblies. Except for the NYC Building Codes (both the 1968 and 2001 versions), the deflection limits relate to crack formation of plastered building components. The deflection is limited to $1 / 360$ of the span for plastered members and $1 / 240$ of the span for non-plastered members. The NYC Building Codes refer to the reference standards for deflection limits in addition to the $1 / 360$ of the span limit. For concrete members, ACl 318-63 specifies limits for both short- and long-term deflections of beams and one-way slabs. For steel members, the 1963 AISC Specification specifies deflection limits to avoid damage to plastered ceilings and to limit deflections of flat roofs.

\subsection{LOAD TESTS}

Building codes generally allow load tests to ascertain the adequacy of load carrying capacity of structural members. Specifically, building codes allow load tests or tests of in-place materials:

- To verify adequacy of structural design for a member or an assembly;

- To verify adequacy of partially completed construction;

- To prequalify structural members or assemblies before used in service;

- To verify adequacy of questionable completed structure; and

- To determine concrete strength by means of core tests.

The NYC Building Codes have provisions to cover all five categories. The New York State Code had provisions for (1) and (4). The Chicago Municipal Code had provisions for (1), (4) and (5). The BOCA/Basic Building Code had provisions for (1) and (2). 


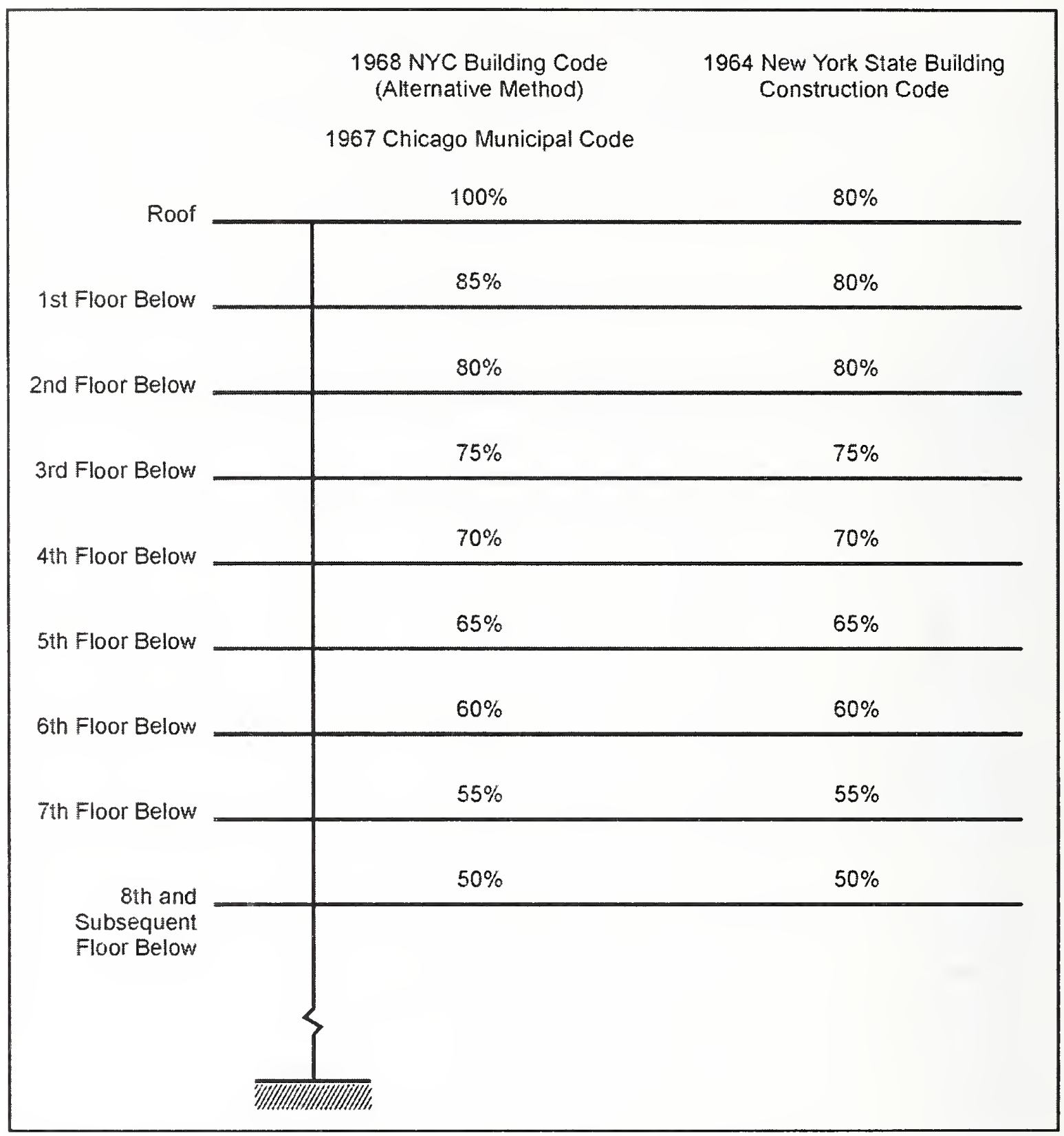

Figure 4-1. Reduced live load as a function of floor location based on the percentage method (for columns, walls, and piers). 


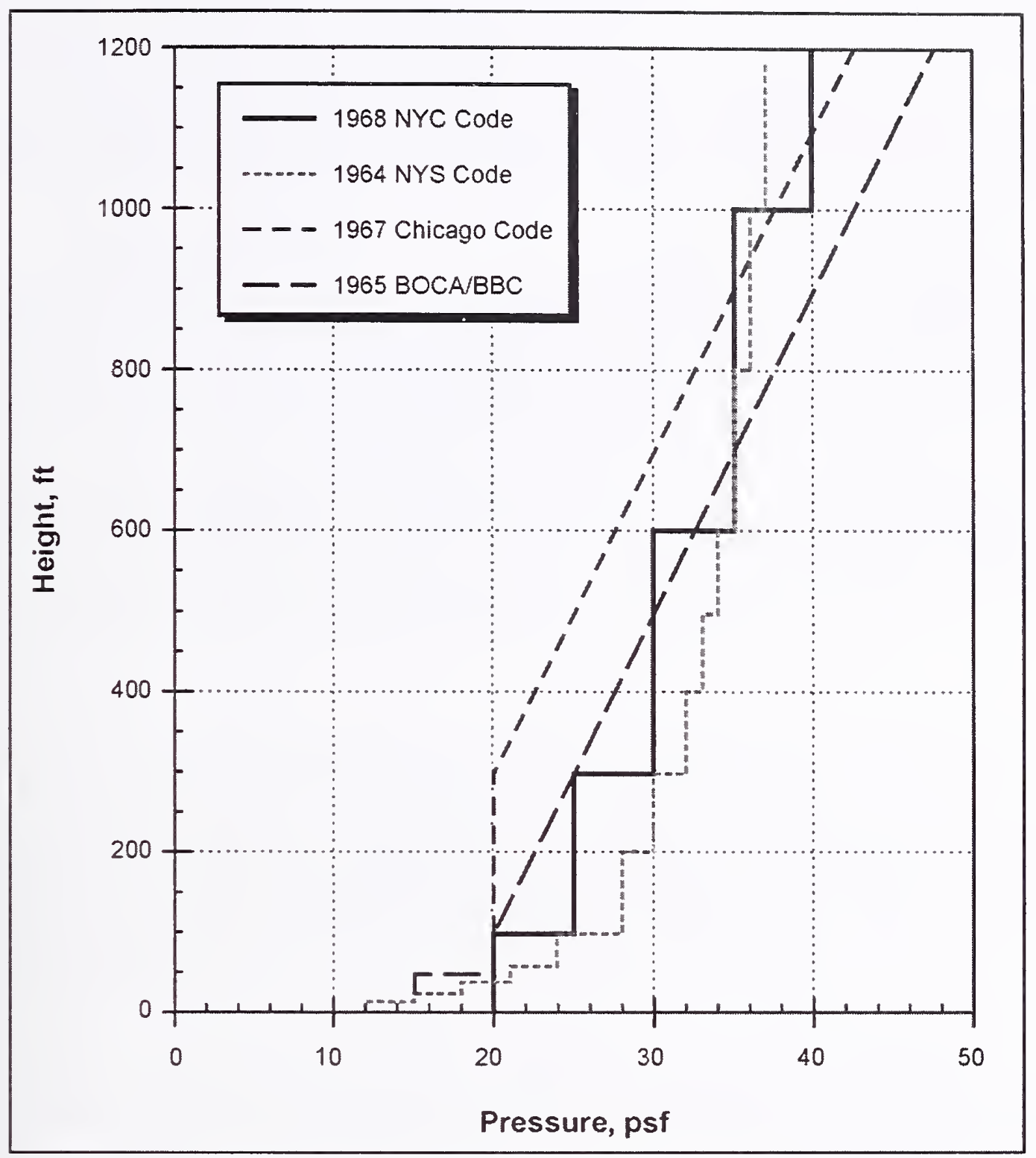

Figure 4-2. Wind load pressure versus elevation. 
This page intentionally left blank. 


\section{Chapter 5 \\ STRUCTURAL DESIGN OF WTC 1, 2, AND 7}

\subsection{DESIGN CRITERIA}

As stated in Sec. 1.1, the design of World Trade Center (WTC) 1 and WTC 2 was governed by the second and third drafts of the 1968 New York City (NYC) Building Code. The 1968 Code also governed the design of WTC 7. However, different design values were allowed by the Building Code if they were more conservative than minimum design requirements specified in the Building Code.

In a number of cases, the design of the WTC 1 and WTC 2 were based on values that were more conservative than those specified in the 1968 NYC Building Code, such as live loads for the tenant spaces outside the central core area and wind loads for the towers. These will be presented in further detail below. No design calculations are available for review of the actual design criteria used for the design of WTC 7. The materials presented in this chapter pertain mainly to WTC 1 and WTC 2.

\subsubsection{Loads}

As presented in Chapter 4, the building codes specify minimum design values for vertical and lateral loads. In the NYC Building Code, Chapter 26, Article 9 prescribes the minimum loads to be used in the design of buildings and their parts. Section C26-900.2, Standards, refers to Reference Standard RS-9 for the minimum dead, live, and wind loads, which are incorporated by reference into Article 9 . In no case does the Code allow for the loads used in design to be less than the minimum values contained in that article. In this section, actual design loads used for design are presented and compared with the New York City Code requirements.

\section{Dead Loads}

The unit dead loads specified for the various structural members are contained in the Design Criteria for WTC 1 and WTC 2 (WSHJ 1965a). Different criteria were established for members located inside the core and outside the core.

\section{Floor Inside of Core}

The core area in a representative upper floor of WTC 1 and WTC 2 is illustrated in Fig. 2-13. Unit design dead loads for the beams, columns, and slabs within the core area of the towers are summarized in Fig. 5-1..$^{21}$ In all cases, the dead loads in the design criteria were greater than or equal to the corresponding dead loads prescribed in the Code. Examples of design dead loads in the $1968 \mathrm{NYC}$ Building Code are listed in Table 4-1. A comprehensive list of the dead loads prescribed in the Code is given in Annex A1 of the report entitled Comparison of Building Code Structural Requirements (NIST NCSTAR 1-1B). For equivalent uniform loads for partitions (according to C26-901.3(b) of the NYC

${ }^{21}$ In Fig. 5-1, "contact" fireproofing is listed. This is a type of fireproofing that is sprayed on to steel members. 
Building Code), the equivalent uniform partition loads in Reference Standard RS 9-1 may be used in lieu of actual partition weights when partitions are not shown on the plans. The actual values for design are given in the design criteria shown in Fig. 5-2. As allowed by the Code, the actual partition loads, which were less than specified 20 psf in the Code for a partition of 201 plf to 350 plf, were used in the design of WTC 1 and WTC 2.

\section{Floor Outside of Core}

Unit dead loads for areas outside of the core are specified in the design criteria for the following structural members: one-way long-span floor trusses, one-way short-span floor trusses, two-way floor trusses, bcams on framed floors, bridging, columns, steel deck, and reinforced concrete slabs. The design criteria vary depending upon the floor level. Figure 5-3 contains sample design criteria for the long-span floor trusses at typical floor levels. For a further description of dead loads used in design, see NIST NCSTAR 1-2. The dead loads in the design criteria for all of the structural members were greatcr than or equal to the corresponding dead loads prescribed in the Code.

\section{Design Criteria for WTC 7}

Design load criteria for WTC 7 are summarized in Fig. 5-4. These criteria appear on Sheet S-24, Typical Superstructure Sections and Details, in the structural drawings (The Office of Irwin G. Cantor 1983). Because the actual materials used for the partitions, flooring, and ductwork were not specified, the reasonableness of these design values cannot be ascertained.

\section{Live Loads}

\section{Design Criteria for WTC 1 and WTC 2}

Specified live loads are given in the Design Criteria for WTC 1 and WTC 2 (WSHJ 1965a). As in the case of dead loads, different live-load criteria were established for members located inside the core and outside the core.

- Floor inside of core. Live loads to be used in the design of the beams and columns within the core area are summarized in Fig. 5-5, Fig. 5-6, and Fig. 5-7. As can be seen from the figures, except for floor 109 and areas occupied by equipment, the design live load varied from $40 \mathrm{psf}$ to $100 \mathrm{psf}$. For all occupancies or use of spaces common to the design criteria and the Code, the live loads in the design criteria were equal to the corresponding live loads prescribed in the Code (which are given in Annex Al of NIST NCSTAR 1-1B/Comparison of Building Code Structural Requirements).

- Floor outside of core. Like the unit dead loads, design live loads outside of the core area varied with the floor level. At most floor levels, a design live load of $100 \mathrm{psf}$ was specified for the slabs (see Fig. 5-8 from the Design Criteria). At mechanical floors 7, 41, 75, and 108, a 75 psf live load was used. Figure 5-9 shows sample design criteria for the columns at the floor levels noted in the figure. Live loads specified in the design criteria were equal to or greater than the corresponding live loads prescribed in the Code. It should be noted that the 100 psf live load used is twice the design live load specified in the NYC Building Code. 
Table 5-1 compares live loads used for the design of floors with corresponding values specified in the 1968 NYC Building Code. In most cases, they are the same. Major differences are noted for the design live loads for corridors within the core, tenant spaces outside of the core, and passenger elevator lobbies on the tenant floors. Note that the design live load for the tenant spaces are twice the code specified value.

Table 5-1. Live loads used in design of WTC 1 and WTC 2.

\begin{tabular}{|l|c|c|}
\hline \multicolumn{1}{|c|}{ Use of Spaces } & $\begin{array}{c}\mathbf{1 9 6 8} \\
\text { NYC Code } \\
\text { (psf) }\end{array}$ & $\begin{array}{c}\text { WTC Design } \\
\text { Criteria } \\
\text { (psf) }\end{array}$ \\
\hline Cafeteria & 100 & 100 \\
\hline Closets (tenant floors) & 100 & 100 \\
\hline Concourse & 100 & 100 \\
\hline $\begin{array}{l}\text { Corridors within core (mechanical equipment } \\
\text { floor) }\end{array}$ & $\mathbf{7 5}$ & $\mathbf{1 0 0}$ \\
\hline Corridors within core (skylobby floor) & 100 & 100 \\
\hline Corridors within core (typical office floor) & 75 & 75 \\
\hline Duct offset space & 75 & 75 \\
\hline Electric closet & 75 & 75 \\
\hline Electric substation \& transformer room & 75 & 75 \\
\hline Expansion tank room & 75 & 75 \\
\hline Janitor's closets & 100 & 100 \\
\hline Kitchen & 100 & 100 \\
\hline Local passenger elevator lobbies (skylobby floors) & 100 & 100 \\
\hline Main shuttle elevator lobbies (skylobby floors) & 100 & 100 \\
\hline Mechanical equipment rooms & 75 & 75 \\
\hline Men's toilets & 40 & 40 \\
\hline Observation lobby & 100 & 100 \\
\hline Tenant space outside core & $\mathbf{5 0}$ & $\mathbf{1 0 0}$ \\
\hline Passenger elevator lobbies (tenant floors) & $\mathbf{1 0 0}$ & $\mathbf{7 5}$ \\
\hline Powder rooms & 40 & 40 \\
\hline Restaurant & 100 & 100 \\
\hline Roof & 30 & 40 \\
\hline Secondary motor rooms & 75 & 75 \\
\hline Service room (mechanical equipment floor) & 75 & 100 \\
\hline Service room (tenant floor) & 75 & 100 \\
\hline Sprinkler tank room & 75 & 75 \\
\hline Stairs & 70 & 100 \\
\hline Telephone closets & 70 \\
\hline Tenant spaces within core & & 56 \\
\hline Woman's toilets & & \\
\hline
\end{tabular}




\section{Design Criteria for WTC 7}

As noted previously, design criteria for WTC 7 are summarized in Fig. 5-4. These criteria appear on Sheet S-24, Typical Superstructure Sections and Details, in the structural drawings (The Office of Irwin G. Cantor 1983). For the floor levels where the type of occupancy was noted on Sheet S-24, the live loads in the design criteria were equal to those given in the Code.

\subsubsection{Live Load Reduction}

\section{Code Requirements}

Provisions for live-load reduction in the 1968 NYC Building Code are contained in Sub-article 903.0, Live Load Reduction. According to C26-903.1, live load reduction is not permitted on roofs. The allowable reduced live load for floor members is determined by multiplying the basic live load value from Reference Standard RS 9-2 (see above) by the percentages given in Table 9-1 of the Code, which is reproduced in Table 5-2. These percentages are a function of the contributory floor area, which is defined in C26-903.3, and the ratio of live load to dead load.

Table 5-2. Percentage of live load per the 1968 NYC Building Code.

\begin{tabular}{|l|c|c|c|}
\hline \multirow{2}{*}{$\begin{array}{c}\text { Contributory } \\
\text { Area }\left(\mathbf{f t}^{\mathbf{2}}\right)\end{array}$} & \multicolumn{3}{|c|}{ Ratio of Live Load to Dead Load } \\
\cline { 2 - 4 } & $\mathbf{0 . 6 2 5}$ or less & $\mathbf{1}$ & 2 or more \\
\hline 149 or less & 100 & 100 & 100 \\
\hline $150-299$ & 80 & 85 & 85 \\
\hline $300-449$ & 60 & 70 & 75 \\
\hline $450-599$ & 50 & 60 & 70 \\
\hline 600 or more & 40 & 55 & 65 \\
\hline
\end{tabular}

a. For intermediate values of live load/dead load, the applicable percentages of live load may be interpolated.

Contributory floor areas are computed as follows (C26-903.3):

- For one-way and two-way slabs: product of the shorter span length and a width equal to onehalf the shorter span length. Ribbed slabs shall be considered as though the slabs were solid.

- For flat plate or flat slab construction: one-half the area of the panel.

- For columns, girders, or trusses framing into columns: the loaded area directly supported by the column, girder, or truss. For columns supporting more than one floor, the loaded area shall be the cumulative total area of all the floors that are supported.

- For joists and similar multiple members framing into girders or trusses, or minor framing around openings: twice the loaded area directly supported but not more than the area of the panel in which the framing occurs. 
No live load reduction is permitted (C26-903.2(b)) for members and connections (other than columns, piers, and walls) supporting:

- Floor areas used for storage (including warehouses, library stacks, and record storage);

- Areas for parking of vehicles;

- Areas for places of assembly, for manufacturing; and

- Areas for retail or wholesale sales.

The maximum live load reduction is 20 percent for columns, piers, and walls supporting such areas.

Live-load reduction is also not permitted for calculating shear stresses at the heads of columns in flat slab or flat plate construction (C26-903.2).

As an alternative procedure, live load reduction for columns. piers. and walls may be taken as 15 percent on the top floor, increased successively at the rate of 5 percent on each successive lower floor, with a maximum reduction of 50 percent. For girders supporting $200 \mathrm{ft}^{2}$ or more of floor area, the live-load reduction is 15 percent.

\section{Design Criteria for WTC 1 and WTC 2}

Live-load reduction criteria from the Design Criteria for WTC 1 and WTC 2 are given in Fig. 5-9 (WSHJ 1965a). The figure shows the percentage of design live load from the Design Criteria that was used in the design of structural members. For floor members, these percentages were the same as those from the 1968 Code, except in the case where the live load to dead load ratio was 2 or more and the loaded area tributary to the floor member was between $150 \mathrm{ft}^{2}$ and $299 \mathrm{ft}^{2}$; in this case, the codeprescribed percentage is 85 percent, while the value in the Design Criteria was 90 percent, which is more stringent than the code requirement (see Fig. 5-10).

Figure 5-11 shows the design live loads from the Design Criteria for the tenant areas inside of the core. The solid line represents the reduced live load that was used in the design of the beams; these values were computed in accordance with the live-load reduction provisions in the Design Criteria (see Fig. 5-10). The unreduced live load specified in the Design Criteria for tenant spaces inside the core was $100 \mathrm{psf}$, which matches the design live load shown in Fig. 5-12 for tributary areas up to $200 \mathrm{ft}^{2}$. Also included in this figure are two other sets of data points: one set represents the reduced live load computed in accordance with the 1968 Code provisions with a live load to dead load ratio equal to one and the other set is the Code equivalent uniform load for partitions, which is a constant 6 psf for partition weights up to 100 plf. The Code requires a $50 \mathrm{psf}$ live load in tenant areas (office areas without storage) per Reference Standard RS 9-2. The $50 \mathrm{psf}$ live load plus the $6 \mathrm{psf}$ partition load is shown in the figure for tributary areas up to $150 \mathrm{ft}^{2}$. Figure 5-12 clearly shows that the design live loads specified in the Design Criteria, including live load reduction, were greater than those required by the Code for office areas without storage.

Figure 5-13 contains the design criteria for live load reduction for the floor areas outside of the core for the floor levels that are noted in the figure. These criteria are the same as those for the tenant space inside 
of the core (see Fig. 5-12). Similar criteria were also provided in the Design Criteria for other floor levels.

\subsubsection{Wind Load}

In lieu of using its prescribed pressures, the 1968 NYC Building Code allows "suitably conducted model tests" to establish design wind pressures, subject to review and approval of the Building Commissioner (Item 6 in Reference Standard RS 9-5). The tests are to be based on a basic (fastest-mile) wind velocity of $80 \mathrm{mph}$ at $30 \mathrm{ft}$ above ground and are to simulate and include all factors involved in consideration of wind pressure, including pressure and suction effects, shape factors, functional effects, gusts, and internal pressures and suctions.

\section{Design Criteria for WTC 1 and WTC 2}

Design wind forces on the towers were determined based on a series of wind tunnel tests that were conducted at the Colorado State University (CSU) and the National Physical Laboratory (NPL) in the United Kingdom. Specific details on these tests can be found in NIST NCSTAR 1-1A.

The design wind loadings of the exterior walls of WTC 1 and WTC 2 consisted of shear forces and overturning moments that were computed at each floor level in the two principal directions of the towers due to the equivalent design wind velocity of $98 \mathrm{mph}$ from 24 wind directions equally spaced at 15 degrees intervals around the tower. The equivalent design wind velocity was defined as the mean wind velocity averaged over a $20 \mathrm{~min}$ period at a height of $1,500 \mathrm{ft}$ above the ground and was based on a 50 year return period.

The shear forces $S$ and overturning moments $M$ at each floor level were comprised of static and dynamic components:

$$
\begin{aligned}
& S=\bar{S} \pm S^{\prime} \\
& M=\bar{M} \pm M^{\prime}
\end{aligned}
$$

where the first and second terms indicate, respectively, the mean or steady-state components and the dynamic components. The static components of the shear and moments were calculated from the following equations.

$$
\begin{aligned}
& \bar{S}(z)=\frac{1}{2} \rho \bar{V}_{o}^{2} D H C_{S}(z) \\
& \bar{M}(z)=\frac{1}{2} \rho \bar{V}_{o}^{2} D H^{2} C_{M}(z)
\end{aligned}
$$

where:

$$
\begin{aligned}
& \rho=\quad \text { design air density }=0.0023 \text { slugs per cubic foot } \\
& \bar{V}_{o}=\quad \begin{array}{l}
\text { mean design wind velocity }=98 \mathrm{mph} \text { averaged over } 20 \mathrm{~min} \text { at a height of } 1,500 \mathrm{ft} \text { above } \\
\text { ground }
\end{array}
\end{aligned}
$$




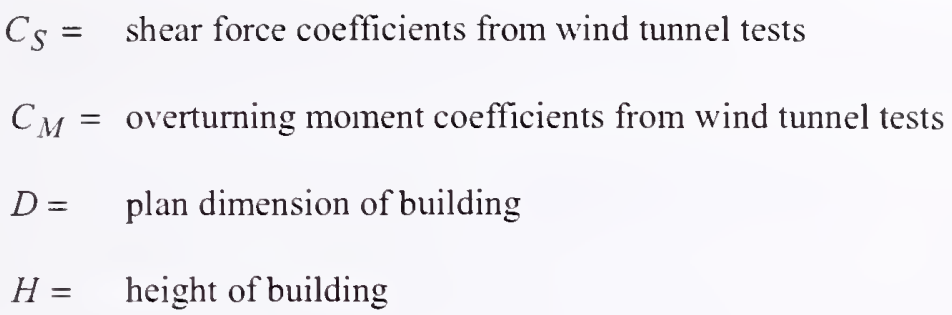

The dynamic components of the shear forces and overturning moments at any height $z$ were calculated from the following equations.

$$
\begin{aligned}
& S^{\prime}(z)=4 \pi^{2} n_{o}^{2} A \int_{z}^{H} m(z) \mu(z) d z \\
& M^{\prime}(z)=\int_{z}^{H} S^{\prime}(z) d z
\end{aligned}
$$

In the first of these equations, $n_{o}$ is the natural frequency of oscillation of the building, and $A$ is the amplitude of oscillation at the top of the tower corresponding to a mean design wind velocity. The quantity $m(z)$ is the mass per unit height of the building, and $\mu(z)$ is the mode amplitude at height $z$ for unit amplitude at the top of the building. Using sets of shear and overturning moment coefficients obtained from the wind tunnel tests (WSHJ 1966a), the shear forces and overturning moments at each floor were computed.

A comparison of the base shear and moment obtained from using the wind pressures from the 1968 NYC Building Code and the wind tunnel test results are shown in Table 5-3. The code-based values of base shear and overturning moment occur simultaneously on the same face of the tower, whereas the base shear and the overturning moment obtained from the wind tunnel tests represent the largest values related to most unfavorable wind direction, thus they may not occur simultancously on the same face of the tower. For the description used to compute the values based on the wind tunnel tests, see NIST

NCSTAR 1-2. The wind load used to design the towers are greater than that based on the code specified wind pressure values.

Table 5-3. Base shears and overturning
moments based on the 1968 NYC Building Code
and wind tunnel tests.
\begin{tabular}{|c|c|c|}
\hline & $\begin{array}{c}1968 \\
\text { NYC Building Code }\end{array}$ & $\begin{array}{c}\text { Wind } \\
\text { Tunnel Tests }\end{array}$ \\
\hline $\begin{array}{c}\text { Base Shear } \\
\text { (kip) }\end{array}$ & 9,250 & 13,100 \\
\hline $\begin{array}{c}\text { Overturning } \\
\text { Moment } \\
\left(10^{3} \mathrm{ft} \mathrm{kip)}\right.\end{array}$ & 7,621 & 12,600 \\
\hline
\end{tabular}

For external cladding and glazing, design wind pressures were specified in the WTC Design Criteria. Outward (negative) pressure acting normal to the surface varied from $65 \mathrm{psf}$ below the 7 th floor to $125 \mathrm{psf}$ at the 109th floor. Inward (positive) pressures varied from $45 \mathrm{psf}$ below the 7 th floor to $55 \mathrm{psf}$ at 
the 108th floor. These pressures are based on the results of a series of wind tunnel tests that were performed specifically for this purpose (WSHJ 1967a).

Dcsign criteria were also established for the antenna mast located on top of WTC 1 (WSHJ 1973). The antenna and its components were to be designed for the following conditions:

- A mean wind speed of $140 \mathrm{mph}$ in any direction and no ice coating;

- A mean wind speed of $110 \mathrm{mph}$ in any direction with an ice coating of $1 / 2$ in. over all exposed unheated metallic surfaces with a minimum air temperature of $20^{\circ} \mathrm{F}$;

- A mean wind speed of $110 \mathrm{mph}$ in any direction and no ice coating under a range of air temperatures from $10^{\circ} \mathrm{F}$ to $90^{\circ} \mathrm{F}$;

- A mean wind speed of $40 \mathrm{mph}$ in any direction and no ice coating under a range of air temperatures from $-15^{\circ} \mathrm{F}$ to $105^{\circ} \mathrm{F}$; and

- Dynamic effects of wind associated with the mean wind speeds specified above (dynamic effects of wind gusts were obtained by multiplying the mean wind forces by a factor of 5).

The requirement of a $1 / 2$ in. thick coating of ice is consistent with the requirement in C26-905.6 of the 1968 NYC Building Code for the design of open-framed or guyed towers. Also, the NYC Code requires that exterior exposed frames, arches, or shells be designed for the forces and/or movements resulting from an increase or decrease in temperatures of $60^{\circ} \mathrm{F}$ for metal construction (C26-905.7). These requirements are less stringent than those contained in the design criteria. The design criteria contain a section on how the wind forces were computed based on these velocities.

\section{Design Criteria for WTC 7}

No design criteria or calculations were available for WTC 7 with respect to wind loads. However, a wind tunnel study of WTC 7 was carried out in 1983 by the University of Western Ontario at the request of the structural engineer of record, Irwin G. Cantor, Consulting Engineers (Isyumov 1983). No document is available to show whether the wind tunnel test results were used in design of WTC 7.

\subsubsection{Aircraft Impact}

No building code in the United States has specific design requirements for impact of an aircraft, and thus, buildings are not specifically designed to withstand the impact of fuel-laden commercial aircraft. However, since the collision of a B-25 bomber into the Empire State Building in 1945, designers of highrise buildings have become aware of the potential of the crash of aircrafts into buildings. A three-page document from the Port Authority of New York and New Jersey (PANYNJ or Port Authority) indicates that the impact of a Boeing 707 aircraft flying at $600 \mathrm{mph}$ was analyzed during the design stage of the WTC towers in February/March 1964. ${ }^{22}$

\footnotetext{
22 Letter with an attachment dated November 13, 2003 from John R. Dragonette (Retired Project Administrator, Physical Facilities Division, World Trade Department) to Saroj Bhol (Design and Engineering Department, PANYNJ).
} 
No documents on the aircraft impact analysis are available to review the criteria and method used in the impact analysis of a Boeing 707 aircraft on the WTC tower and to verify the assertion in the three-page document that "... such collision would result in only local damage which could not cause collapse or substantial damage to the building and would not endanger the lives and safety of occupants not in the immediate area of impact." Without the original calculations of the aircraft impact analysis, any comment on the document would be a speculation. In March 1964, a calculation was made by the Port Authority to determine the period of vibration of the tower due to an aircraft impact at the 80th floor. ${ }^{23}$ Although no conclusion was stated on the calculation sheet, it clearly indicates that the Port Authority recognized during the design stage the possibility of an aircraft impact on the tower.

\section{$5.2 \quad$ STRUCTURAL DESIGN REQUIREMENTS}

According to sub-article 1002.0 of the NYC Building Code (Adequacy of the Structural Design), the design of structural members was to conform to the applicable material standards mentioned in subarticles 1003.0 through 1011.0 (C26-1002.1). If such computations as prescribed in these standards cannot be executed due to "practical difficulties," the structural design can be deemed adequate if the member or assembly performs satisfactorily when subjected to load tests in accordance with 1002.4(a). Provisions to determine the adequacy of completed or partially completed structures are also provided. Prequalifying load tests (C26-1002.4(a)) can be used to establish the strength of a member or assembly prior to having such members or assemblies incorporated into a structure. The test specimens are to be a true representation of the actual members or assemblies in all aspects, including the type and grade of material used. Support conditions for the members or assemblies being tested are to simulate the conditions of support in the building, except that conditions of partial fixity might be approximated by conditions of full or zero restraint, whichever produces a more severe stress condition in the mcmber being tested. In regard to strength requirements, the member or asscmbly must bc capable of supporting the following (note: no specific reference to a particular type of building material is given in this section of the Code):

1. Without visible damage (other than hairline cracks) its own weight plus a test load equal to 150 percent of the design live load plus 150 percent of any dead load that will be added at the site, and

2. Without collapse its own weight plus a test load equal to 50 percent of its own weight plus 250 percent of the design live load plus 250 percent of any dead load that will be added at the site.

The latter loading is to remain in place for a minimum period of one week, and all loading conditions in Article 9 of the Code are to be considered. Exceptions to the above load conditions are also given in this section.

The member or assembly is also subject to the following deflection requirements: the recovery of the deflection caused by the superimposed loads listed in item 1 above must be at least 75 percent. Also, the deflection under the design live load is limited to the values prescribed in C26-1001.5.

\footnotetext{
23 A three-page calculation dated March 2, 1964 by E. Liu (Structural Engineer, the Port of New York Authority)
} (WTCl-408-LERA). 
The Code also gives requirements for tests on models less than full size. The similitude, scaling, and validity of the analysis are to be attested to by an officer or principal of the firm or corporation making the analysis. The firm or corporation is to be approved by the Building Commissioner.

\subsubsection{Concrete Requirements}

According to sub-article 1004.0, design of reinforced concrete structural members was to conform to the requirements in that section and Reference Standard RS 10-3, which is the 1963 edition of Building Code Requirements for Reinforced Concrete (ACI 1963) with modifications, which was applicable to the design of WTC 1 and WTC 2. These modifications include the replacement of the requirements of ACI 318 Secs. 902 (Design loads) and 903 (Resistance to wind, earthquake, and other forces) with the following: "Building code requirements for loads and infrequent stress conditions shall apply." "Infrequent stress conditions" refer to such conditions as wind and earthquake. In other words, all loads are to be determined in accordance with the 1968 Code. In case of concrete structures designed by the ultimate strength design method, design (factored) loads are to be determined in accordance with Sec. 1506 of ACI 318-63.

According to the specifications for WTC 7 (WTC 7 Projeet Specifications 1984), the 1983 edition of ACI 318 was applicable (ACI 1983).

\subsubsection{Steel Requirements}

Design of steel structural members was to conform to the requirements in sub-article 1005.0 and Reference Standard RS 10-5, which is the 1963 edition of Specification for the Design, Fabrication, and Erection of Structural Steel for Buildings (AISC 1963b) with modifications, which was applicable to the design of WTC 1 and WTC 2. Similar to the design of reinforced concrete members, the NYC Building Code replaced the provisions of Sec. 1.3 (Loads and Forces) of the AISC Specification with a statement: "The provisions of the building code for loads shall apply." Other notable modifications to the AISC Specification are:

- The following paragraph is added to the definition of composite construction in Sec. 1.11.1: "Concrete materials shall meet the applicable requirements of the building code. Where concrete having a unit weight less than $130 \mathrm{pcf}$ is used, the capacity of the shear connectors to resist applied load under the proposed conditions of use shall be investigated..."

- Sec. 1.25.5 on field connections during erection is deleted and replaced with the following: "... No holes, copes or cuts of any type shall be made to facilitate erection unless specifically shown on the shop drawings or authorized in writing by the party or parties designated for inspection of such work."

The 1968 NYC Building Code requires that Reference Standards RS 10-6 and 10-7 be used for light gauge cold formed steel and open web steel joists, respectively (see Comparison of Building Regulatory and Code Requirements for WTC 1, 2, and 7 [NIST NCSTAR 1-1B]).

According to the specifications for WTC 7 (WTC 7 Project Specifications 1984), the 1978 edition of the AISC Specification was applicable (AISC 1978). 


\subsubsection{Methods Used to Proportion Structural Members}

The general methods that were used to proportion the structural members and components of the buildings are given in detail in Sec. 2.3 of NIST NCSTAR 1-1A. Since the 1968 NYC Building Code adopted the 1963 AISC Specification and the 1963 ACI 318, all steel members were designed following the allowable stress design procedure, and the concrete sections were proportioned following the ultimate strength design procedure (see Sec. 4.3.1). 


\begin{tabular}{|c|c|c|c|c|c|}
\hline \multirow[t]{2}{*}{$\begin{array}{l}\text { PORTHIN GTON, SKILLINGG } \\
\text { HELLE S JACHSON }\end{array}$} & THE WORLD TR & $\begin{array}{l}\text { NE POAT OT } \\
\text { EW YOSH AUTHORITY }\end{array}$ & $3 / 3 / 66$ & shoot & \\
\hline & \multirow{2}{*}{ MENONU YAMASAX: O ASSOS. } & \multirow{2}{*}{ EMERY ROTH SONS } & PREPAREE GY JN & $\ln ^{2}$ & \multirow{2}{*}{7} \\
\hline Civil \& Struetural Enginoors & & & APFROVEO & & \\
\hline
\end{tabular}

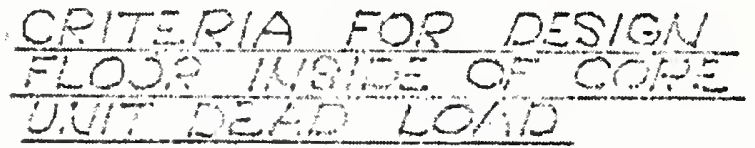

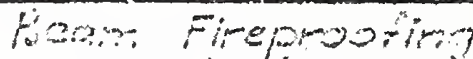

"unted (12pen) 1"

Cuinditious (24 pot) "

Gyosur- piaster w/metol lath ("B")

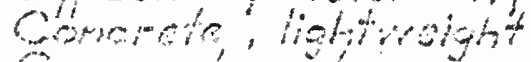

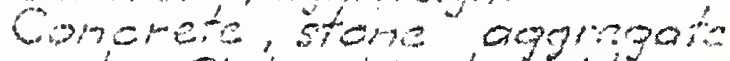

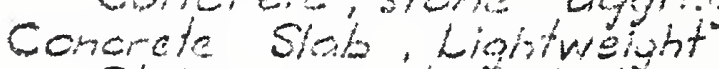

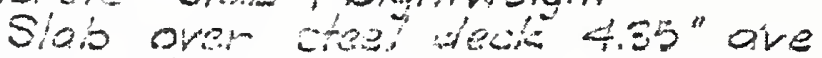

俏" síán

5. siak

El?" slob

conmone Siab, Stonk Concrete

Coilimas

Subunates aluminum par.

Suspended acoustic fibme

Suspendivet metal lath to gypsum

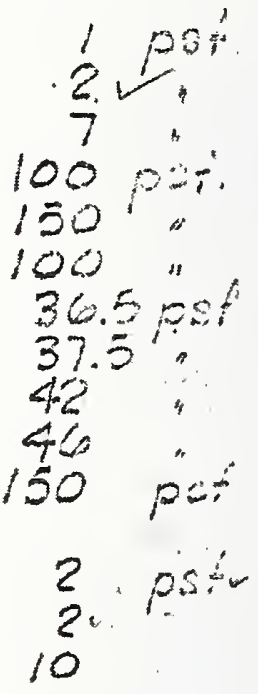

Floor Finisin

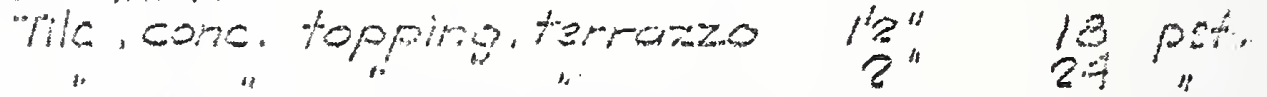

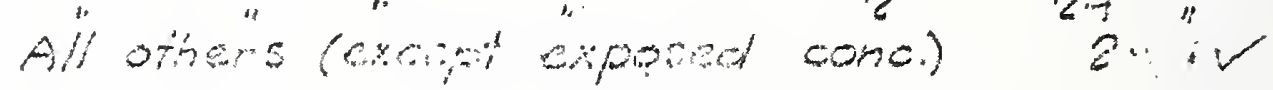

Woi: Findsh

Cename Tie (8'men ony)

15 psi.

Vigi:

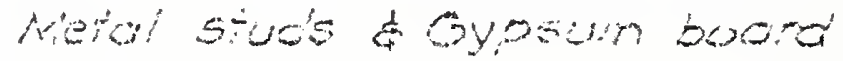

5 pisfor.

Source: Reproduced with permission of The Port Authority of New York and New Jersey.

Figure 5-1. Design dead load criteria for WTC 1 and WTC 2: floor inside of core. 


\begin{tabular}{|c|c|c|c|c|c|}
\hline \multirow[t]{3}{*}{ 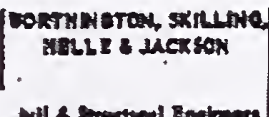 } & THE WORLD 'TR & 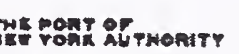 & ante $3 / 3 / 6 G$ & 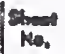 & \\
\hline & HEOH YAMALAKI ALSOC, & TMEnY nOTH \& SONS & PREPARED or I & 156 & 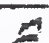 \\
\hline & 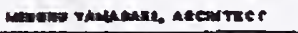 & 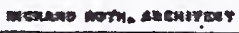 & APPAOVED & & $c$ \\
\hline
\end{tabular}

CPITERIA: "FOOFIEESIG/W FLOOR MUSINE OF COPE PARTITION WELG:TT

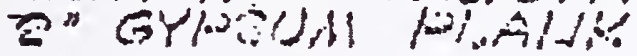
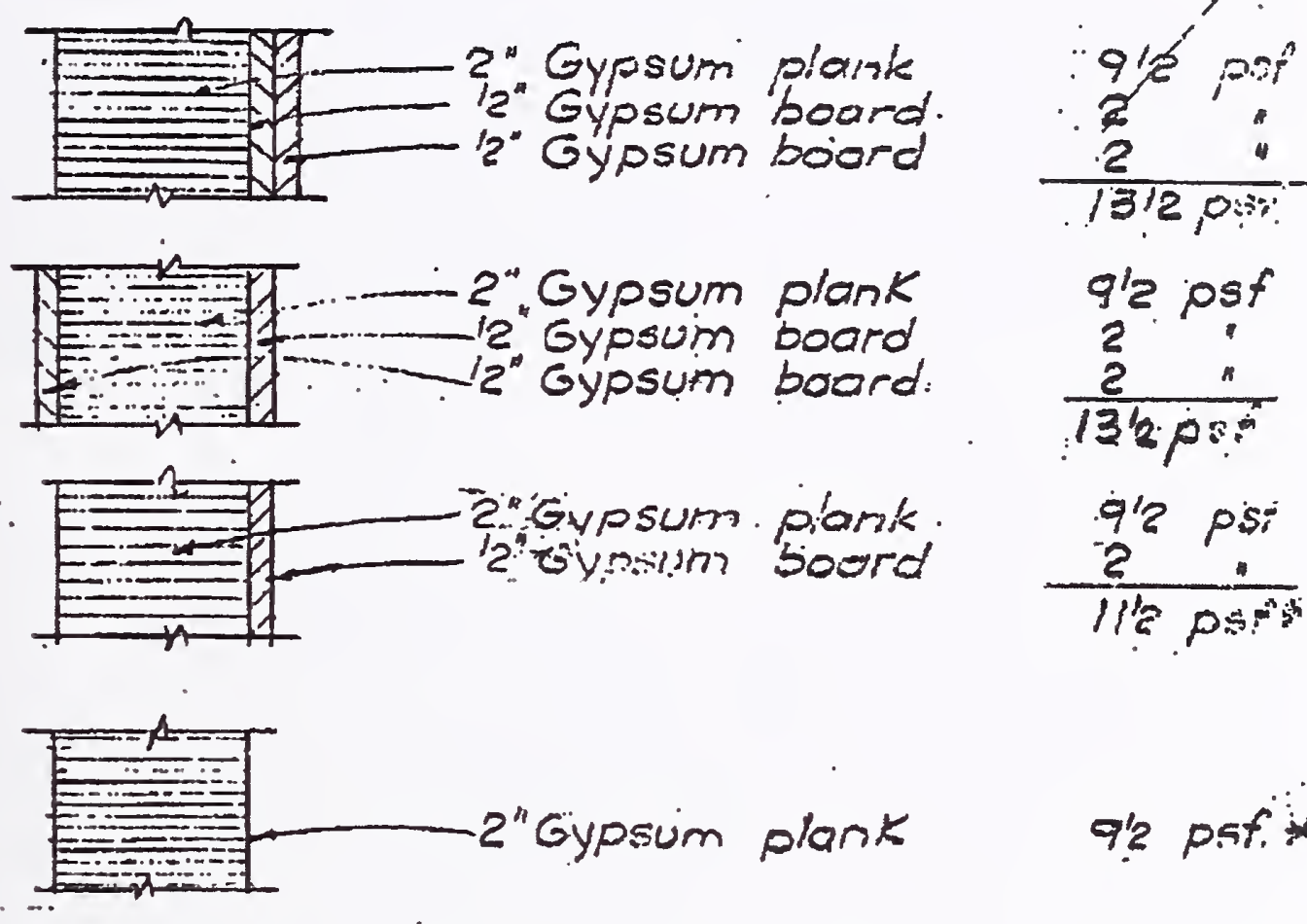

9'2 psti
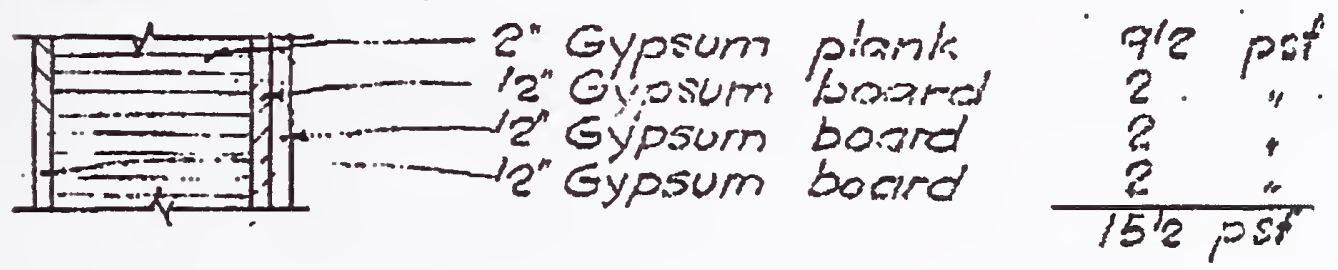

$\because$ forsol. Firián

Ceramic $7:=$ (3ition on/y) 15,05,

Source: Reproduced with permission of The Port Authority of New York and New Jersey.

Figure 5-2. Design partition load criteria for WTC 1 and WTC 2: floor inside of core. 


\begin{tabular}{|c|c|c|c|c|}
\hline \multirow{3}{*}{$\begin{array}{l}\text { VERTHINCTON, SKILLIMG } \\
\text { THELLE OA JACKSON } \\
\text { Civil \& Strwetura! Enginoess }\end{array}$} & \multicolumn{2}{|c|}{ 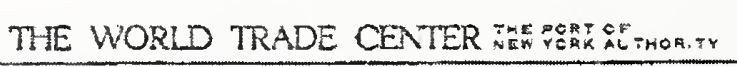 } & Dors 2,$0 ; 0$ & \begin{tabular}{|l|l|} 
Shoor \\
No.
\end{tabular} \\
\hline & MINORI YAMASAKI ASSOE. & ENERY ROTH I SONS & BREFAAEC \&Y $1 / 2 R$ & TFi \\
\hline & & & APPROVEO & \\
\hline
\end{tabular}

CRTERIA FOR DESIGN DESIGN LOAD FLORS OUTSTOE DF COPE

LONGSPAA TRUSGES- ONE WAY

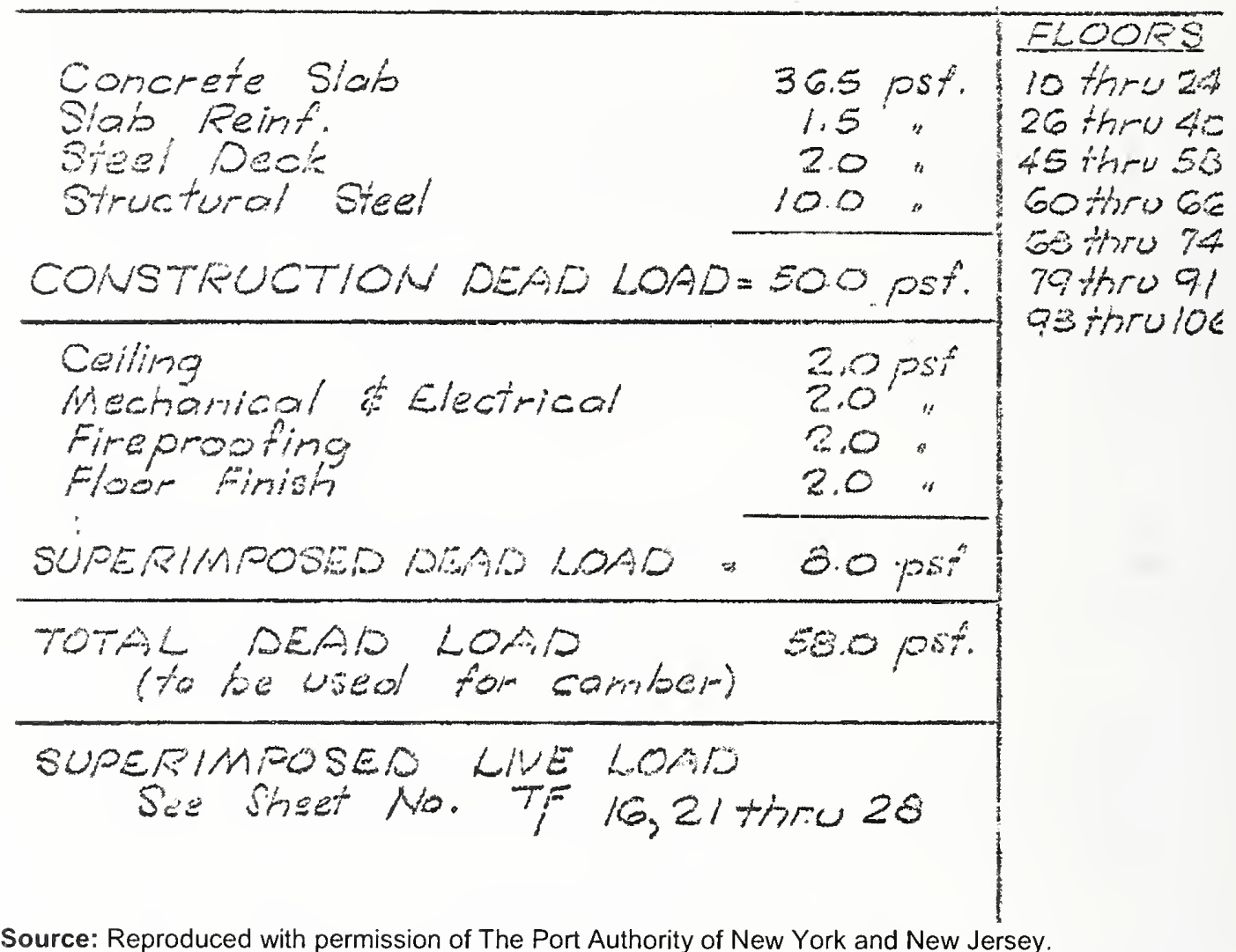

Figure 5-3. Design dead load criteria for WTC 1 and WTC 2: floor outside of core. 


\begin{tabular}{|c|c|c|c|c|c|c|c|c|c|}
\hline \multicolumn{10}{|c|}{ LOAOING SCHEOULE } \\
\hline AREA & $\underset{36 A B}{C O A C R E C}$ & RISISA & $\begin{array}{l}\text { cersent } \\
\text { outhoset }\end{array}$ & antritions & PLOORINO & 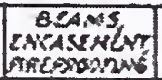 & $\begin{array}{l}7098 \mathrm{C} \\
0640 \\
2010\end{array}$ & TOA & $\begin{array}{l}\text { rogis } \\
\cos 0\end{array}$ \\
\hline 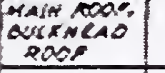 & 50 & 10 & 8. & & & 7 & 75 & 30 & 105 \\
\hline 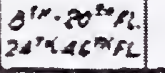 & 50 & & 5 & 12 & & $s$ & 75 & 50 & 125 \\
\hline $23^{13} \cdot 23^{28} \pi$ & 50 & & 9 & 12 & 15 & 8 & $\infty$ & 75 & $i 65$ \\
\hline 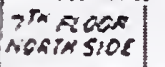 & $8:$ & & 5 & 12 & & 93 & 198 & 50 & 200 \\
\hline 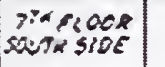 & 80 & 38 & 8 & 12 & & $2 ?$ & 165 & 50 & 215 \\
\hline 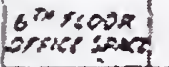 & 56 & & 3 & 12 & & $T$ & 80 & 50 & 130 \\
\hline 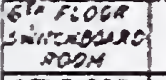 & 68 & 38 & & & & 55 & 155 & 100 & 255 \\
\hline 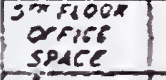 & 150 & j8 & 5 & & & 17 & 210 & so & 260 \\
\hline 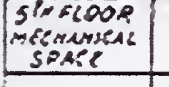 & 150 & 38 & $s$ & & & $\therefore 7$ & 210 & 150 & 360 \\
\hline$s^{2} r: 028$ & 56 & 75 & 5 & & & 10 & 186 & 100 & 246 \\
\hline 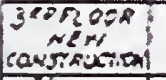 & 56 & 75 & 8 & & & 10 & 196 & 100 & 246 \\
\hline Ores gand & & & & & & & 240 & 100 & 340 \\
\hline 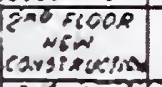 & 56 & 60 & 5 & & & 10 & +31 & 150 & $28:$ \\
\hline 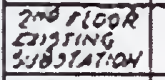 & & & & & & & 240 & 150 & 390 \\
\hline \begin{tabular}{|l|}
58,81001 \\
$: 0801$
\end{tabular} & 175 & 90 & & & & 50 & 315 & 100 & $4: 5$ \\
\hline 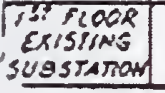 & & & & & & & 300 & 225 & 525 \\
\hline
\end{tabular}

\section{NeTE:}

All SPECIAL EOUIPMENT LOAOS SHALC

O! 10010 SipaeArstY TO AOVI LOAOWG

Source: Reproduced with permission of The Port Authority of New York and New Jersey.

Figure 5-4. Design load criteria for WTC 7. 


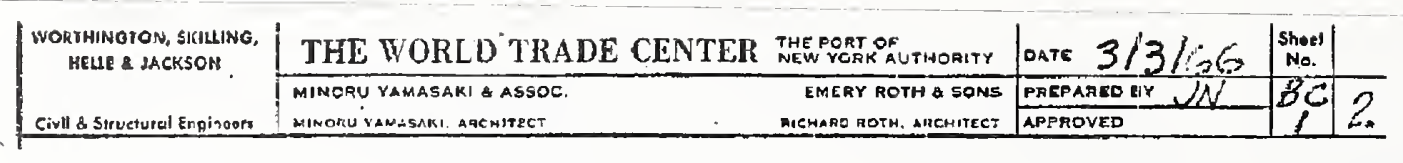

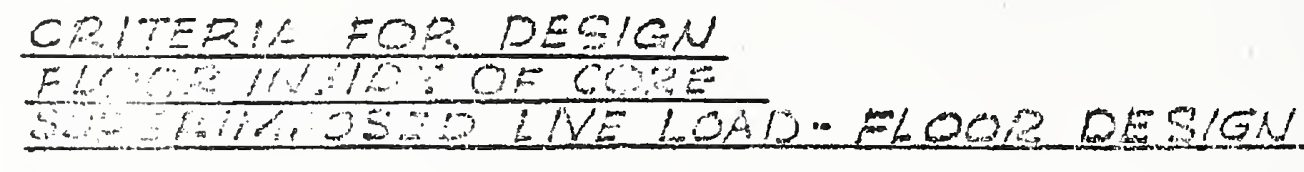

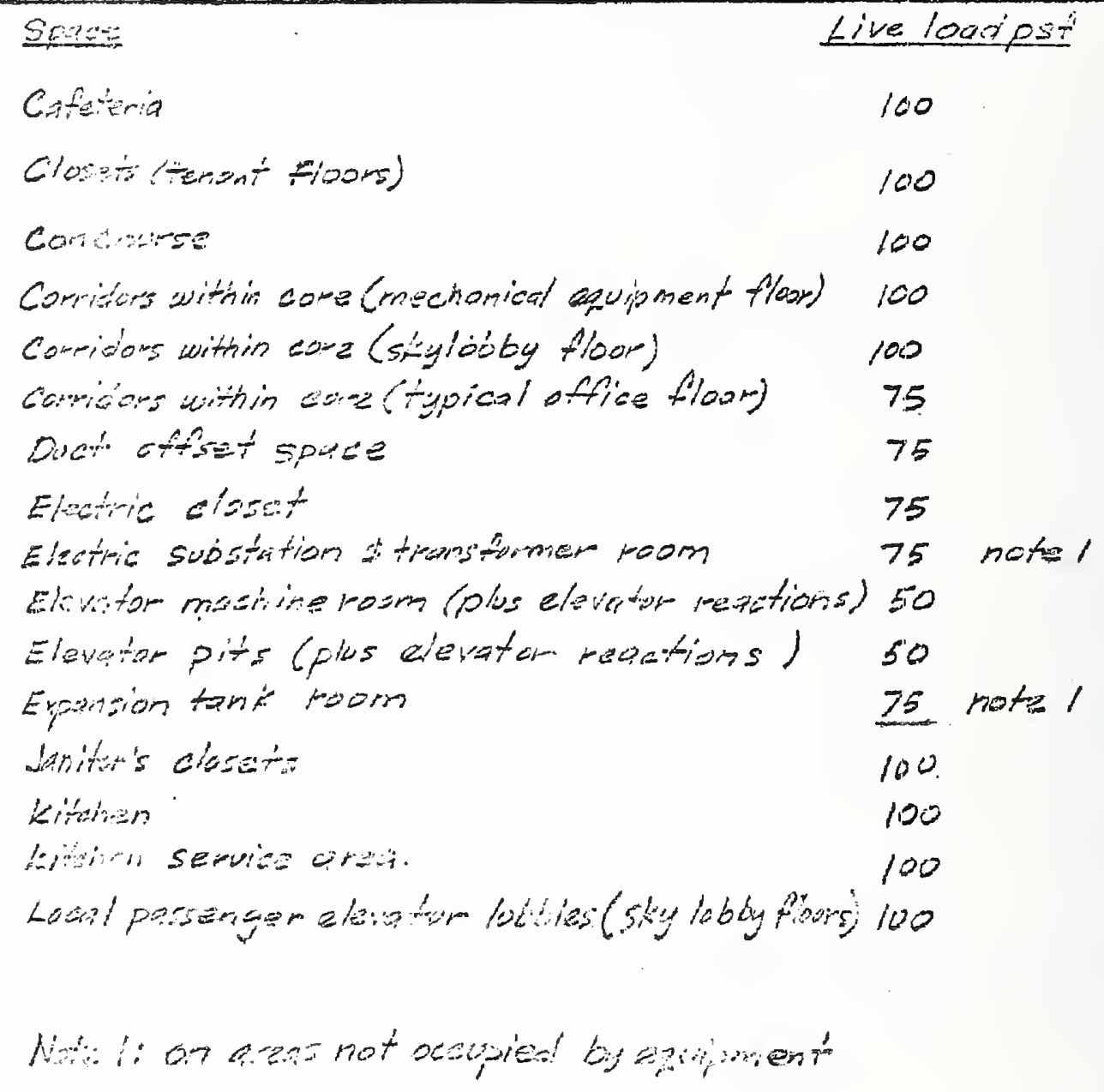

Source: Reproduced with permission of The Port Authority of New York and New Jersey.

Figure 5-5. Design live-load criteria for WTC 1 and WTC 2: floor inside of core. 
Structural Design of WTC 1, 2, and 7

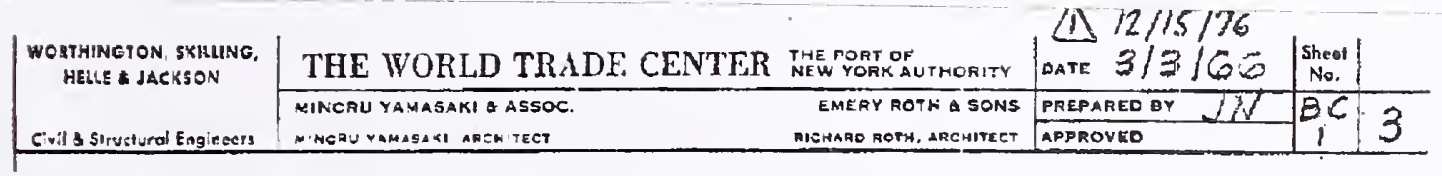

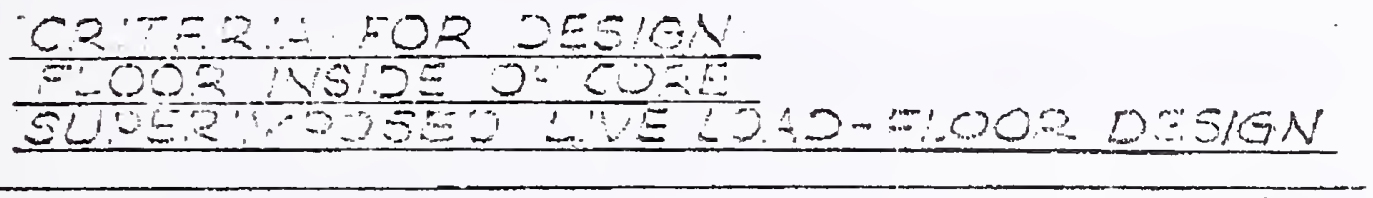

Spos

Live lont pst

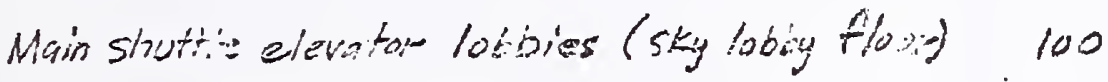

Mechariali equipuent roon(plus michequip. Note2) 75 hotel

Men's toilets

40

Observation lobisy

100

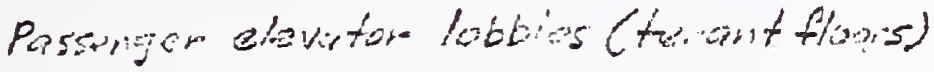

75

Poitier rooirs

40

Restivingt

100

Roof

40

Scesindarg motor room

75 hosi

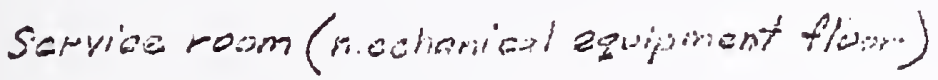

100

Service rion (temant flosio)

100

Sprinklar tamk risern

75 notel

stail-s.

Teleinone clongis

106

75

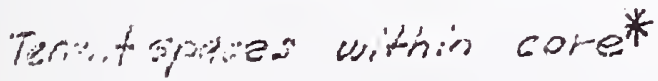

100

Worien's toinizisis

40

1 Flos: 109 (entire floor)

150

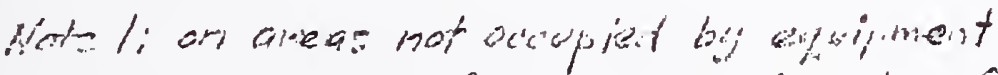

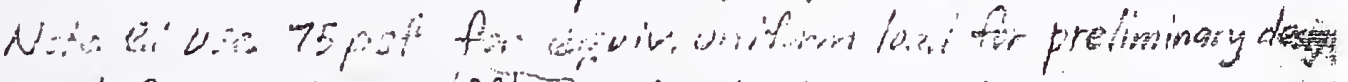

* See next page BC 3 A dated 29 vur 89

Source: Reproduced with permission of The Port Authority of New York and New Jersey.

Figure 5-6. Design live-load criteria for WTC 1 and WTC 2: floor inside of core.

NIST NCSTAR 1-1, WTC Investigation

79 


\begin{tabular}{|c|c|c|c|c|c|}
\hline 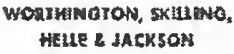 & THE WORLD TRADE CENTER & $\begin{array}{l}\text { THE POAT OF } \\
\text { NEW YORK AUTHORITY }\end{array}$ & Date $3 / 3 / 66$ & $\begin{array}{l}\text { Sheot } \\
\text { No. }\end{array}$ & \\
\hline & MINORU YAMASAKI ASSOC. & EMEAY MOTH A SONE & PREPARED BY NN & $E E$ & \\
\hline Chtol s Structurd Enginsers & MINORU YAMARAKI. ARCHITECT & MESHASP MOYM, ARCHITECT & APPAOVEA & & $\Sigma$ \\
\hline
\end{tabular}

CRITERIA FOR DESIGN
FLOOR WISIOE OE CORE
LIVELOAO FOL COLUVN DESIGN

Space.

Livelogesp

Cafeteria

100

closets (temsint Plocis)

100

Conoourse

100

Corridors within comb (methanieat ejuipmant fland 100

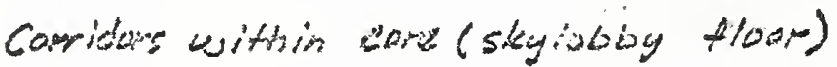

100

Corridere within cama (tupiest sffice floon)

75

Duct offiset spoce

75

Eleutric closiet

75

Elactric sibstation fransfarmer poom

75 notw।

Elevator machine poom

50

Elevatow pits

50

Expansion tank room

75 notal

Janitors closets

100

kitchen

100

kittien saivice area

100

Local parsenger elevator lobby (Skylabsy flost) 100

Note' 1 i On area not decipied by epuiphant

Source: Reproduced with permission of The Port Authority of New York and New Jersey.

Figure 5-7. Design live-load criteria for WTC 1 and WTC 2: column inside of core. 


\begin{tabular}{|c|c|c|c|c|c|}
\hline \multirow[t]{3}{*}{$\begin{array}{l}\text { YOATANAETOA, SKILLING, } \\
\text { HELLE \& JACXSON }\end{array}$} & THE WORLD TRA & 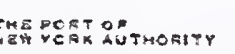 & Date $3 / 3 / 66^{\circ}$ & Shoos & \\
\hline & MINORE YANASAKI a AESOC. & EMERY FOTH O SONS & PAEPAAEE EY & 160 & 3 \\
\hline & 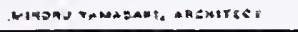 & MESWADE SETH, AREMISECS & APPAOVEO & & \\
\hline
\end{tabular}

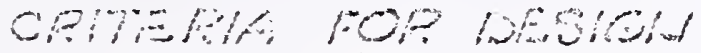 \\ DOUIOA LOADE-OFFICE FLOOR SLAB

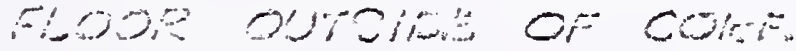

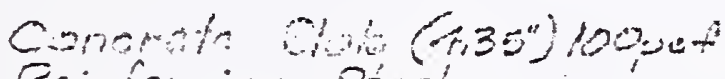
Reinforcina oreel

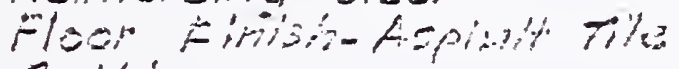
ceiling

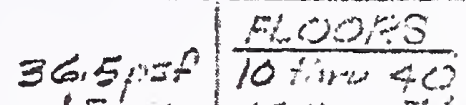

$$
\begin{aligned}
& 1.5 \text { " } 45 \text { inin } 74 \\
& 2.0 \cdots 79 \text { thelot } \\
& 2.0 \text { " } \\
& 42.0904 \\
& \frac{100.0}{1.00 .0+2}
\end{aligned}
$$$$
\text { DASD LOAD }
$$$$
\text { LIVE LOAD }
$$$$
\text { TOTA: LOAD }
$$

Source: Reproduced with permission of The Port Authority of New York and New Jersey.

Figure 5-8. Design live-load criteria for WTC 1 and WTC 2: floor outside of core. 


\begin{tabular}{|c|c|c|c|c|c|}
\hline \multirow[t]{3}{*}{\begin{tabular}{|} 
WORTAINGTON, SKILLING, \\
MELLE SACKSON
\end{tabular}} & \multicolumn{2}{|c|}{ THE WORLD TRADE CENTER THE PORY OF } & \multicolumn{3}{|c|}{$6\left[\begin{array}{l}\text { Shaor } \\
\text { Ho. }\end{array}\right]$} \\
\hline & MANORU YAMABAKI A ASSOC. & EMERY ROTH O SONS & PREPAREO BY & mins & \\
\hline & 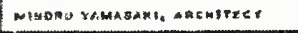 & 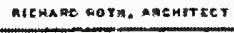 & APPROVED & & \\
\hline
\end{tabular}

CRITEDAA FOP DESHON

FLOOR OUTOIDE OF COPE

LWE SOAD FOP COLUMU DESION

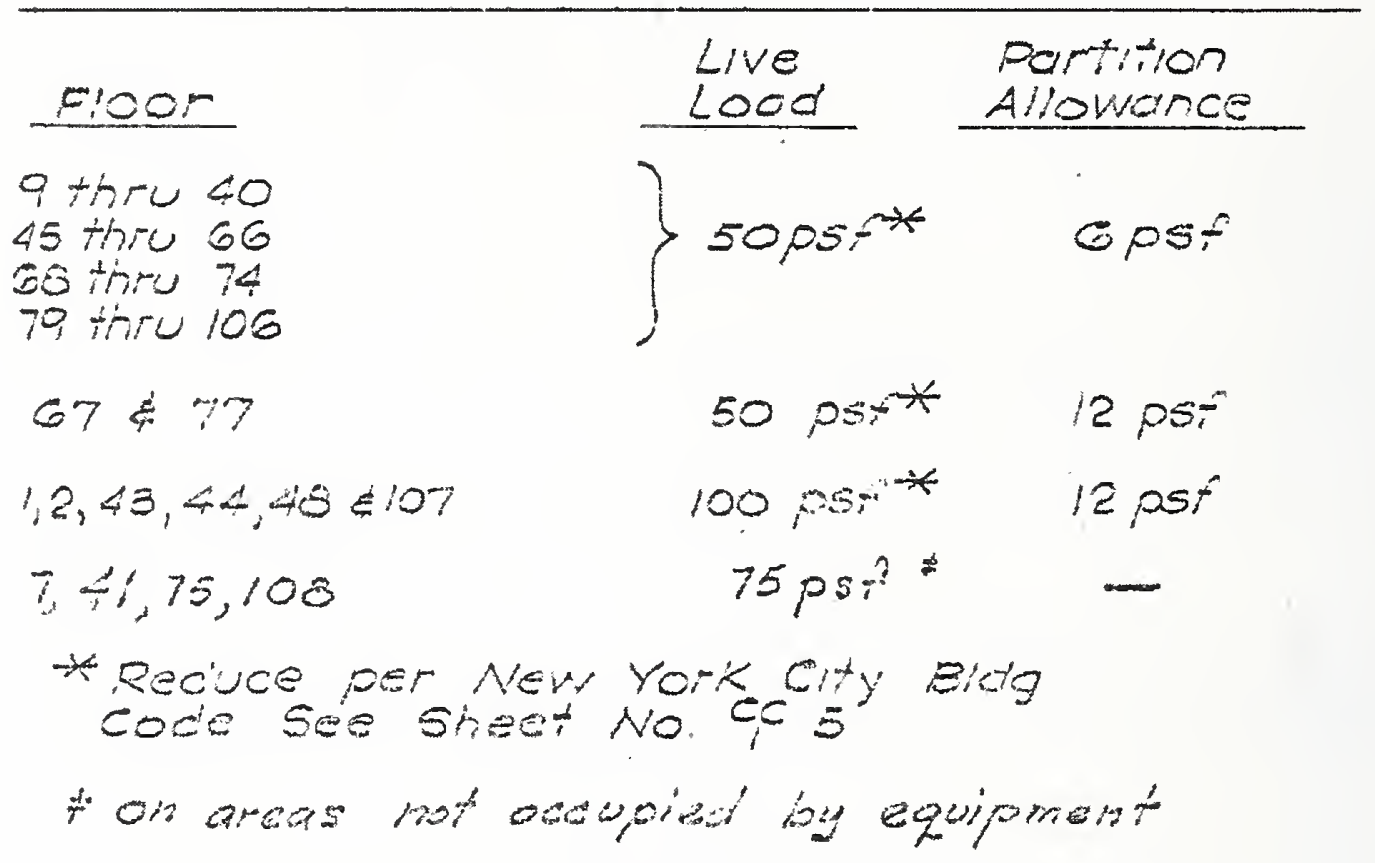

Source: Reproduced with permission of The Port Authority of New York and New Jersey.

Figure 5-9. Design live-load criteria for WTC 1 and WTC 2: column outside of core. 


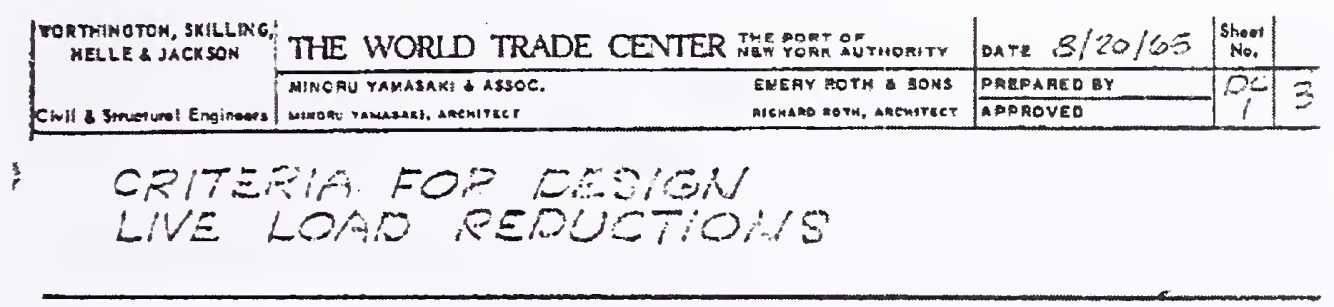

Live load reductions shall be taken in accordance with the requitement of the New York Bu1lifing Code, Section C26-348.0 modifled as follows:

a) Colunas: In structures intended for storage purposes all colums, piers or walls and fourdations aball be designed for $85 \%$ of the full assuned Ilve load. In structires Intended for other uses the sssumed live loak used in designing all colums, plers or valls and foundations shall be as follows:

$$
\begin{aligned}
& 100 \% \text { of live lood on roof } \\
& 85 \% \text { of l1ve load on top f } 100: \\
& 80 \% \text { of l1ve load on next to top fluor } \\
& 75 \% \text { of } 19 \text { ve load on next floor below }
\end{aligned}
$$

On each successtve lower floor, there shall be a $5 \%$ decrease in the percentage sith a winicur of $50 \%$ of the live loat provided for any floor. The live loacs used as the basis for colurn live load reductions are the "Code isve Loads" for the appropriate occupancy, and are not the reduced live zoods used for bear or truss design.

b) Girder nembers, except at rcofs, which have a tributary area of 200 s.f. or greater sball be designed using a reciuced live lond in accordance ut th the design criteria sheets 4 and 5.

c) In designing erusses and girders which supfort colunas and in deteraining the aree of footings, use the total caad load plus the cotal live load (reduced as showa above in item a).

Source: Reproduced with permission of The Port Authority of New York and New Jersey.

Figure 5-10. Live-load reduction criteria for WTC 1 and WTC 2. 


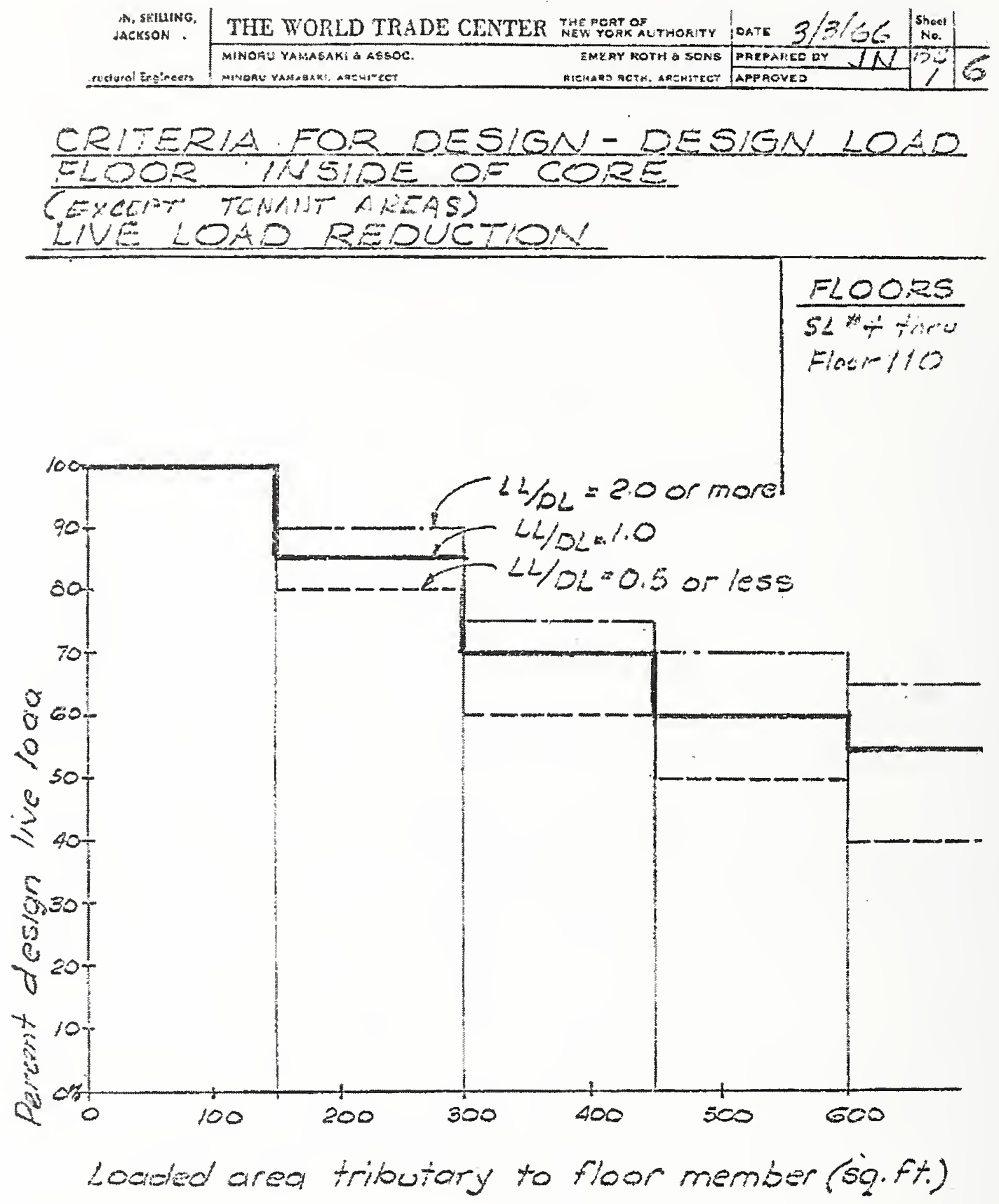

Source: Reproduced with permission of The Port Authority of New York and New Jersey.

Figure 5-11. Live-load reduction criteria for floors inside of core, except for tenant areas. 


\begin{tabular}{|c|c|c|c|c|}
\hline \multirow{2}{*}{$\begin{array}{c}\text { WORTHINGTON, SXILLING, } \\
\text { HELLE \& JACXSON } \\
\text { EWII Stquetwal ENgInGers }\end{array}$} & THE WORLD-TRADE & CENTER NEW YOAK AUTTOAMYY & oate $3 / B / 66$ & \begin{tabular}{|l} 
Shoont \\
no.
\end{tabular} \\
\hline & MINOAL YAMASA KI \& ASSOC. & 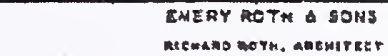 & 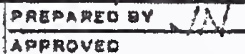 & 8 \\
\hline
\end{tabular}

\section{CRITERIA FOR DESIGN-DESIGN LOAD FLOOR INSIDE OF CORE TENANT SPACE \\ LIVE LOAD REDUCTION}

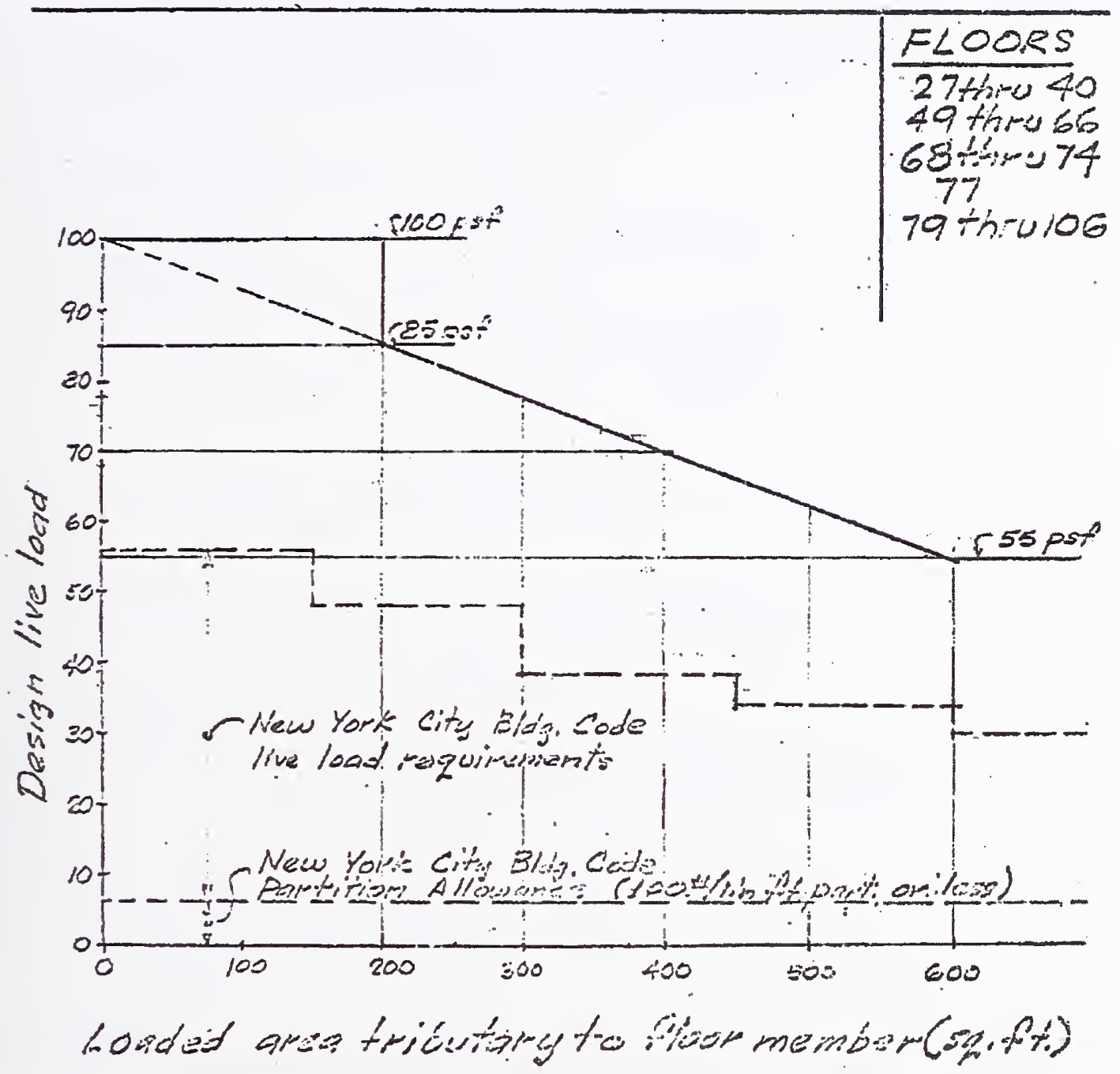

Source: Reproduced with permission of The Port Authority of New York and New Jersey.

Figure 5-12. Live-load reduction criteria for floors inside of core, tenant areas. 


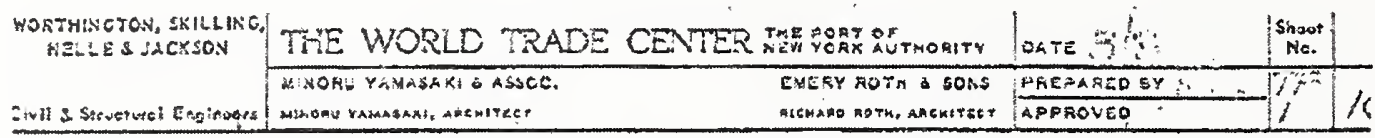

L

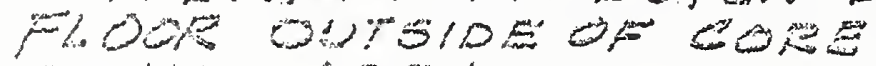

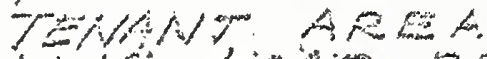

LUE

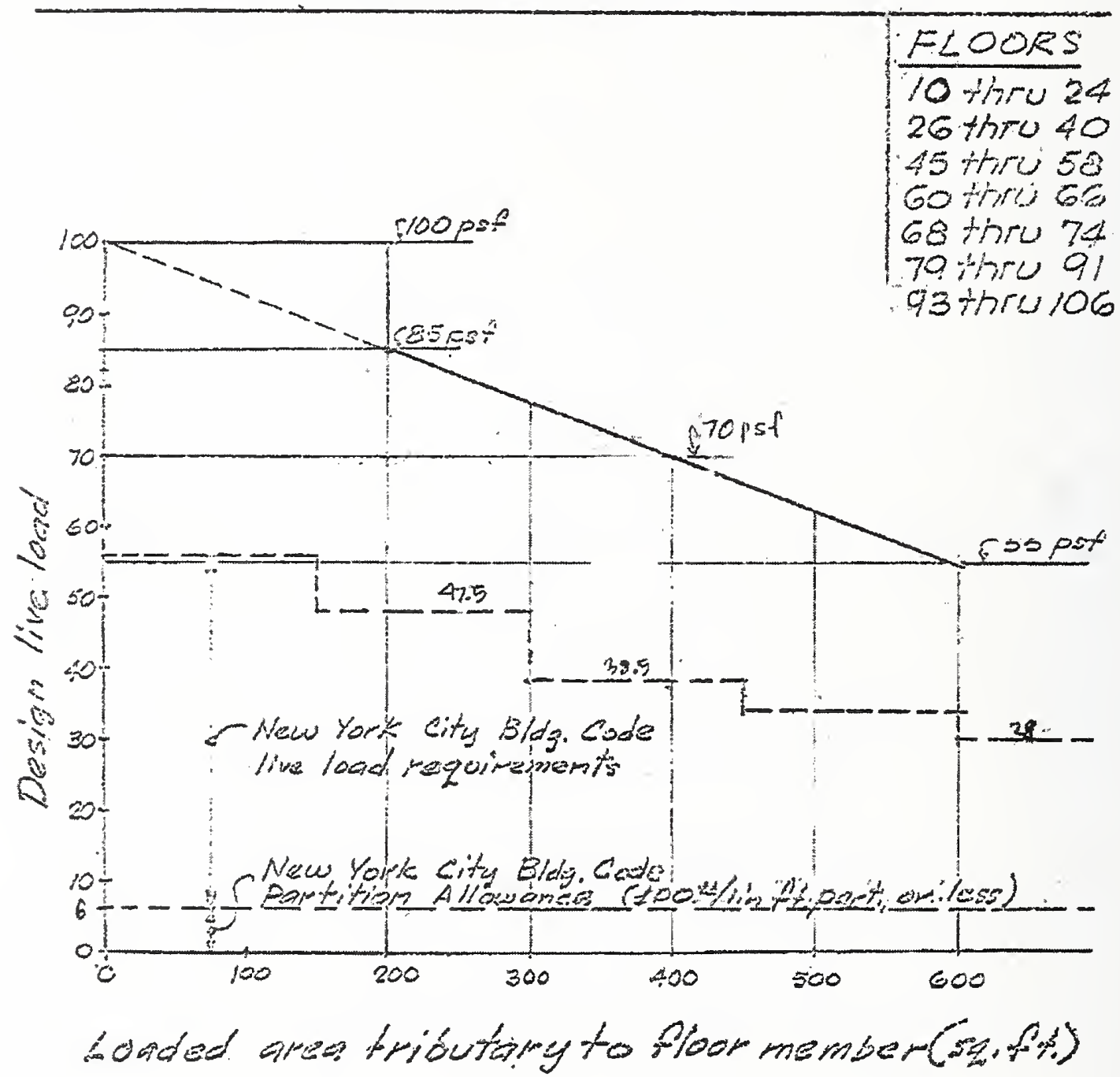

Source: Reproduced with permission of The Port Authority of New York and New Jersey.

Figure 5-13. Live-load reduction criteria for floors outside of core. 


\section{Chapter 6 \\ INNOVATIVE FEATURES INCORPORATED IN STRUCTURAL DESIGN}

\subsection{INNOVATIVE FEATURES}

A number of innovative features, which were applied to the design of a super high-rise steel building for the first time, were incorporated in the structural design of World Trade Center (WTC) 1 and WTC 2. They were incorporated in both the lateral-load-resisting system and the gravity-load-carrying system.

These features include the following:

- Application of the framed-tube system to resist lateral loads.

- Uniform exterior column geometry (14 in. by 14 in. cross-section) was maintained over most of the height of the 110-story buildings by using 12 different grades of steel.

- Use of deep spandrel plates as beam elements connecting perimeter columns.

- Use of long-span composite steel trusses for the floor system to develop diaphragm action in super tall buildings and to develop composite action by extending truss diagonals into the concrete slab.

- Application of sprayed fire-resistive materials on open-web steel trusses for fire protection.

- Application of viscoelastic dampers connecting the floor trusses to the perimeter framed tube system to control dynamic response.

- Use of wind tunnel test data to establish the wind loads used in the design of the towers.

Several prominent features are described below in detail.

\subsection{LATERAL-LOAD-RESISTING SYSTEM}

The structural design of high-rise buildings (over 40 stories) is usually controlled by lateral loads. It is well known that for high-rise buildings, the most efficient way to resist lateral loads is by mobilizing the exterior framing system. As described in Sec. 2.2.2, the lateral-load-resisting system of WTC 1 and WTC 2 used the framed-tube concept wherein the lateral loads are resisted by the exterior frames. A framed-tube system does not depend on shear walls or other bracing systems to resist lateral loads. Typically, the exterior wall is comprised of moment resisting frames with closely spaced columns and deep spandrel beams to form a Vierendeel-truss-type structural form.

In the United States, the first application of a framed-tube system was the 43-story DeWitt-Chestnut apartment building (later renamed The Plaza on DeWitt) in Chicago, which was completed in 1965. This building used reinforced concrete for the structural framing system. Since then, many variations of this 
structural system have been used in a number of buildings. WTC 1 and WTC 2 were the first super highrise steel buildings that were designed using the framed-tube concept.

The framed-tube system of WTC 1 and WTC 2 was comprised of closely spaced steel columns that were connected by deep spandrel plates. To assess the stiffness characteristics of the wall panel, a series of model tests using one-quarter scale models made of thermoplastics were carried out prior to final design of the frame-tube system (Gardner 1966). The model tests allowed the evaluation of changes in the overall stiffness of the wall panels as the sizes of the members that made up the wall panels varied, which included columns, spandrels, and stiffeners. The results of the model tests guided the design of the wall panels. Detailed descriptions of the tests are given in NIST NCSTAR 1-1A.

The columns and spandrels were shop-assembled and welded into $36 \mathrm{ft}$ high by $10 \mathrm{ft}$ wide panels, which consisted of three columns and three spandrels as shown in Fig. 2-9. These panels were erccted on site by bolting the base plate of an upper column to a cap plate of a lower column (see Fig. 2-10). Such splices were staggered so that only one-third of the panels were spliced at each story level, except at the base of the building and at the mechanical floors where all of the panels were spliced at the same level. In such cases, supplemental welds were employed to improve connection capacity. Spandrels were connected at midspan with high-strength bolted shear connections.

\subsection{COMPOSITE FLOOR SYSTEM}

As described in Sec. 2.2.2, outside of the central core area, floor construction of WTC 1 and WTC 2 typically consisted of $4 \mathrm{in}$. of lightweight concrete on fluted metal deck supported by a series of composite floor trusses that spanned between the core and the exterior walls. The floor trusses consisted of double angles that were used for the top and bottom chords and round bars that were used for the diagonals. What made the floor system in WTC 1 and WTC 2 innovative was that (1) use of the lightweight composite floor system, comprised of lightweight concrete slab on long-span open-web steel trusses, to provide lateral stability of columns and diaphragm action in super tall buildings,

(2) development of composite action by extending truss diagonals into the concrete slab (see Fig. 2-14), and (3) application of sprayed fire-resistive materials on open-web steel trusses for fire protection (for detailed description, see NIST NCSTAR 1-6B).

The first recorded tests on composite open-web steel joists were conducted under a project jointly sponsored by Granco Steel Products and Laclede Steel Company (who manufactured the trusses for WTC 1 and WTC 2) in September 1964. ${ }^{24}$ In this study, the overall performance of non-composite joists was compared with composite joists. The joists were manufactured with their webs projecting above the top chord. The tests revealed that the composite joists had greater moment capacities and smaller deflections than the non-composite joists.

Since composite action was achieved by the "knuckle" functioning as a shear connector, a test program was carried out by Laclede Steel Company to determine the failure loads of the shear knuckles. The shear knuckle tests are described in detail in NIST NCSTAR 1-1 A. The test results indicated that shear strengths of the knuckles were found to be well over the allowable values used in the design of the composite trusses.

\footnotetext{
${ }^{24}$ See Sec. 1.1 of Sen and Galambos (1968).
} 
Additional tests on open-web joists were performed at Washington University (Tide and Galambos 1968). The findings, which were reported in February of 1968, were similar to those reported from the previous tests. In particular, the specimens with extended web diagonals into the concrete slab serving as shcar connectors were shown to be strong and stiff, and failure was due to crushing of the concrete near the connectors. Further tests conducted at Washington University are reported in Sen and Galambos (1968). In summary, the findings from this study confirmed those obtained from earlier research programs.

The composite floor trusses used in the WTC towers were similar to those that were tested only in the sense that the webs were used as shear connectors. Other than that, they were different in all other aspects, including member sizes and overall lengths. It may have been the first time that this type of floor construction was used in a high-rise building, especially of this size.

\subsection{VISCOELASTIC DAMPING UNITS}

Viscoelastic damping units were used in the structural system of WTC 1 and WTC 2 to supplement the tubular steel frame in limiting wind-induced building oscillations. According to Mahmoodi (1987), "The selection, quantity, shape. and location of the dampers was based on the dynamic analysis of the towers (computer modeling, wind tunnel, etc.) and of the damping required to achieve performance standards." This may have been the first application of damping units for this purpose in tall building structures, and would certainly qualify it as an innovative system at that time.

The damping units were uniformly distributed throughout both of the buildings. One hundred four (104) dampers were used on each floor from the 7 th to the 107 th floor. The planned locations of damping units on the various floors of the buildings are contained in structural drawings D-AB1-2 through D-AB1-14.2 (WSHJ 1967). As the buildings oscillated from the wind, part of the energy of oscillation was dissipated by shear deformations in the viscoelastic part of the damping units.

Two testing programs were carried out to test the effectiveness and efficiency of the damping units in controlling building motion due to wind. The Minnesota Mining and Manufacturing Company (3M) conducted the first set of tests in May of $1967 .{ }^{25}$ The Massachusetts Institute of Technology (MIT) conducted the second test program during 1968 and $1969 .{ }^{26}$ These tests included variations in (1) amplitude and frequency of the applied cyclic axial deformation, (2) ambient tempcrature, and (3) a static preload superimposed on the simple harmonic loading. In general, it was found that "...the energy absorbing capabilities of the elements are generally adequate to provide the expected damping under design conditions and that the elements do perform satisfactorily under limited variations of loading conditions, speed of oscillation, duration of oscillation, and ambient temperaturc." Dctailed descriptions of these tests are given in NIST NCSTAR 1-1A.

Two different types of damping units were used in WTC 1 and WTC 2. Type A damping units were used on floors with trusses spanning between the core and the outside wall, and were located bctween the bottom chords of the floor trusses and the columns of the outside wall (Fig. 2-16). Typc B damping units were used on floors that had wide-flange beams spanning between the core and the outside walls (i.e.,

\footnotetext{
${ }^{25}$ Letter dated June 22, 1967 and enclosure from Don Caldwell of 3M to Peter Chen of SHCR (WTCI-501-L;see Appendix B of NIST NCSTAR 1-1A without appendixes that are contained in WTCI-501-L).

26 "Test Program for World Trade Center Viscoelastic Damping Units," by Stephen H. Crandall of MIT, May 20, 1968 (WTCI501-L, see Appendix B of NIST NCSTAR 1-1A).
} 
floors $7,9,41,43,75,77$, and 107). This type of damping unit was located between the bottom flanges of the floor beams and the outside wall, as shown in Fig. 6-1. The use of dampers increased significantly the critical damping ratio of the towers. The reduction of oscillation during strong winds was estimated to be about 12 percent of the amplitudes without dampers. Expected time period during which building oscillation might be perceived by the occupants was estimated to be reduced by about 34 percent (SHCR 1967).

Type B damping units were slightly longer than Type A damping units. Also, the connections between Type A damping units and the floor trusses were different than those between Type B damping units and the wide-flange beams. Sheet DA-3 in the structural drawings shows specific details for each type of damping unit (WSHJ 1967).

Worthington, Skilling, Helle \& Jackson (WSHJ) initially inquired about different types of viscoelastic damping materials in a letter to $3 \mathrm{M}$ in $1964 .{ }^{27} \mathrm{~A}$ follow-up letter from them to $3 \mathrm{M}$ contained the physical and mechanical properties required for the viscoelastic material, based on calculations they had performed. $^{28}$ Additional correspondence on various aspects of the damping units, including the results of tests that were run at $3 \mathrm{M}$ that measured the properties of the damper material and the strength of an assembled damping unit prototype, was exchanged subsequent to these letters. In particular, it was noted that testing of an assembled truss damping unit by $3 \mathrm{M}$ was completed and that the results agreed with the theoretical predictions. ${ }^{29}$

\subsection{WIND TUNNEL TESTS}

Wind tunnel tests were part of an overall wind program that was developed by WSHJ for the design of the WTC (WSHJ 1964). Details of the wind program are given in NIST NCSTAR 1-1A. Briefly; the program consisted of four parts:

- Meteorological Program was to determine the mean wind speeds, the return periods, the magnitude of wind shear and gradient, the directional characteristics of the wind, and the energy spectra of wind gusts that were expected at the site of the WTC.

- Wind Tunnel Program was to (a) develop a physical model of lower Manhattan and subject the model to wind velocities obtained from the meteorological program, (b) obtain static and dynamic responses of the WTC towers, (c) study construction problems, and (d) study the effect of the structural parameters on the integrity of the towers.

- Structure Damping Program was to determine the critical damping ratio of the structural system and to determine ways of increasing this ratio.

\footnotetext{
${ }^{27}$ Letter dated July 16, 1964 from Alan G. Davenport of WSHJ to Carl A. Dahtquist of 3M (WTCI-450-L; see NIST NCSTAR 1-1A, Appendix D).

28 Letter dated November 23, 1964 from Richard D. Steyert of WSHJ to Carl A. Dahlquist of 3M (WTCI-450-L; see NIST NCSTAR 1-1A, Appendix D).

${ }^{29}$ Internal correspondence dated February 1966 by Richard D. Steyert of WSHJ (WTCI-450-L; see NIST NCSTAR 1-1A, Appendix D).
} 
- Physiological Program was to determine acceptable levels of response to wind-induced excitations as measured by perception levels of a cross-section of the population.

Wind tunnel tests were conducted at Colorado State University (CSU) and the National Physical Laboratory (NPL), located in Teddington, Middlesex, United Kingdom (WSHJ 1964). Tests were conducted on single-tower and twin-tower configurations subject to uniform and turbulent flow conditions.

\subsubsection{Tests Conducted at CSU}

Over 2,000 tests were conducted at the CSU Microclimatological Wind Tunnel to study the behavior of static and aeroelastic models (WSHJ 1964). One of the most important requirements in the modeling process was to achieve correct simulation of the wind velocity profile (considering both surface roughness and its influence on wind velocity with respect to height) as it approached the model of lower Manhattan. From the southeast direction, wind traveled across Brooklyn to the site of the WTC, which was a relatively rough urban area. From the southwest, wind traveled mainly across open water.

Aside from wind velocity, the principal variables in the wind tunnel tests were the following:

- Spacing of towers

- Number of towers

- Damping

- Wind direction

- Boundary layer characteristics

- Relative stiffnesses of the models

It was found that the models oscillated in the wind due to vortex shedding, gust buffeting, and wake buffeting under certain combinations of the variables listed above.

Two hundred tests were run at CSU to study the effect of tower spacing on the response of the buildings. It was concluded that the "as planned" spacing was satisfactory.

Aeroelastic tests and measurements of steady pressure for single-tower and twin-tower configurations in uniform flow provided a comparison between the performance of the models at CSU and at the NPL. The CSU report concluded that the aeroelastic tests at the two locations were in good qualitative and quantitative agreement (WSHJ 1965c). Models used for the pressure tests at the CSU were constructed of clear acrylic plastic at a scale of $1 / 500$, the same scale used in the aeroelastic tests

The aeroelastic tests were designed to determine the predominant sway motion (i.e., deflections or amplitudes) of the towers and to provide a check of the steady-state component of the overturning moment at the base. To determine the pressure distribution on the towers, tests were conducted using models with pressure points along a regular grid. From these tests, shear forces and overturning moments were obtained along the height of the towers. 
The tests also indicated that large lateral deflections at the top of the building occurred for wind velocities in the range of $125 \mathrm{mph}$ to $130 \mathrm{mph}$ for angles of incidence within approximately 10 degrees of normal (see Fig. 6-2). The results are plotted in Figs. 19 and 20 in WSHJ (1965c). The deflections showed a consistent dependence on the degree of damping and were shown to be inversely proportional to the damping ratio.

Tests were also conducted at CSU using the southeast and southwest models of lower Manhattan subjected to turbulent flow conditions (WSHJ 1966c). ${ }^{30}$ Both single-tower and twin-tower configurations were considered. Definition of the grid system and tower configurations used in the tests is illustrated in Fig. 6-3. Also shown in the figure are the experimentally determined fundamental frequencies of the towers in the two principal directions in cycles per second (cps). Included in these tests were measurements of the maximum deflections at the tops of the towers (aeroelastic tests; wood models) and pressures along the height of the towers (thermoplastic models).

Similar to the other tests described above, test results for the single-tower model indicated that the most severe oscillations were transverse to the wind and occurred with the wind blowing within a small range of angles on either side of the normal to a face. The results also showed that an increase in turbulence, which was characteristic of the southeast model of lower Manhattan, appeared to suppress vortex shedding but gave rise to turbulence excitation with increased wind speed. Finally, it was observed that greater levels of damping reduced the dynamic response of the single tower in all cases, more so in uniform flow conditions than in turbulent conditions.

Based on the results obtained from the twin-tower wind tunnel tests, it was concluded that the response of the WTC towers was governed by three aerodynamic factors: (1) Magnitude of the effective turbulence forces induced by the wind flow, (2) Magnitude of the effective forces induced by vortex shedding and turbulence in the structure's own wake, and (3) Effective aerodynamic damping and coupling forces generated by the motion of the tower through the airflow. It was also noted that the effective mass, the effective stiffness, the mode of vibration, and the mcchanical damping of the towers influenced these factors (WSHJ 1966).

A theoretical method was derived and was used to predict the dynamic behavior of the towers (WSHJ 1966 c). Results from the theoretical models were compared to the results from the wind tunnel tests. A comprehensive discussion on this comparison can be found in WSHJ (1966c).

The results from the wind tunnel tests were used in the design of the exterior columns and spandrels, which is discussed in Sec. 2.3.2 of this report.

The extensive wind tunnel testing that was performed to establish the lateral wind loads used in the design of WTC 1 and WTC 2 was state-of-the-art at that time.

\footnotetext{
${ }^{30}$ The meteorological program found that winds were stronger from westerly and northerly quadrants. Wind from the southeast direction was chosen in the wind tunnel program not because the velocity from this direction was the greatest, but because winds from this direction were the most turbulent (wind in this direction traveled over Brooklyn, which is a relatively rough urban terrain). Turbulence plays an important part in the dynamic excitation of structures, especially tall, slender structures. A fundamental discussion on turbulence and resulting aeroelastic phenomena can be found in Simiu and Scanlon (1996).
} 


\subsubsection{Tests Conducted at NPL}

Tests were performed on single-tower and twin-tower models at NPL to measure deflections at the tops of the towers in both smooth (uniform) flow and turbulent flow conditions (Whitbread and Scruton 1965). The models were constructed of light timber framework supported on diaphragms at 6 in. intervals from a central 2 in. diameter aluminum tube. The models had an external covering of plywood.

Principal differences between the CSU and NPL models were (WSHJ 1965c): (1) the model scale was $1 / 400$ at the NPL compared to 1/500 at the CSU, (2) displacements were determined from output of accelerometers mounted near the tops of the models at NPL compared with strain gauges at CSU, and (3) displacements were recorded on a resetting digital voltmeter at the NPL compared with chart records at CSU. In the NPL tests, a grid of tubes in a plane normal to the wind stream was used to provide the required velocity profile over the height of the model. According to Whitbread and Scruton (1965), the velocity profile achieved in this manner was similar to that observed in the tests carried out at CSU on the model of lower Manhattan.

As noted previously, WSHJ reported that the overall results obtained from the tests conducted at NPL were in good qualitative and quantitative agreement with those obtained from the tests performed at CSU. 


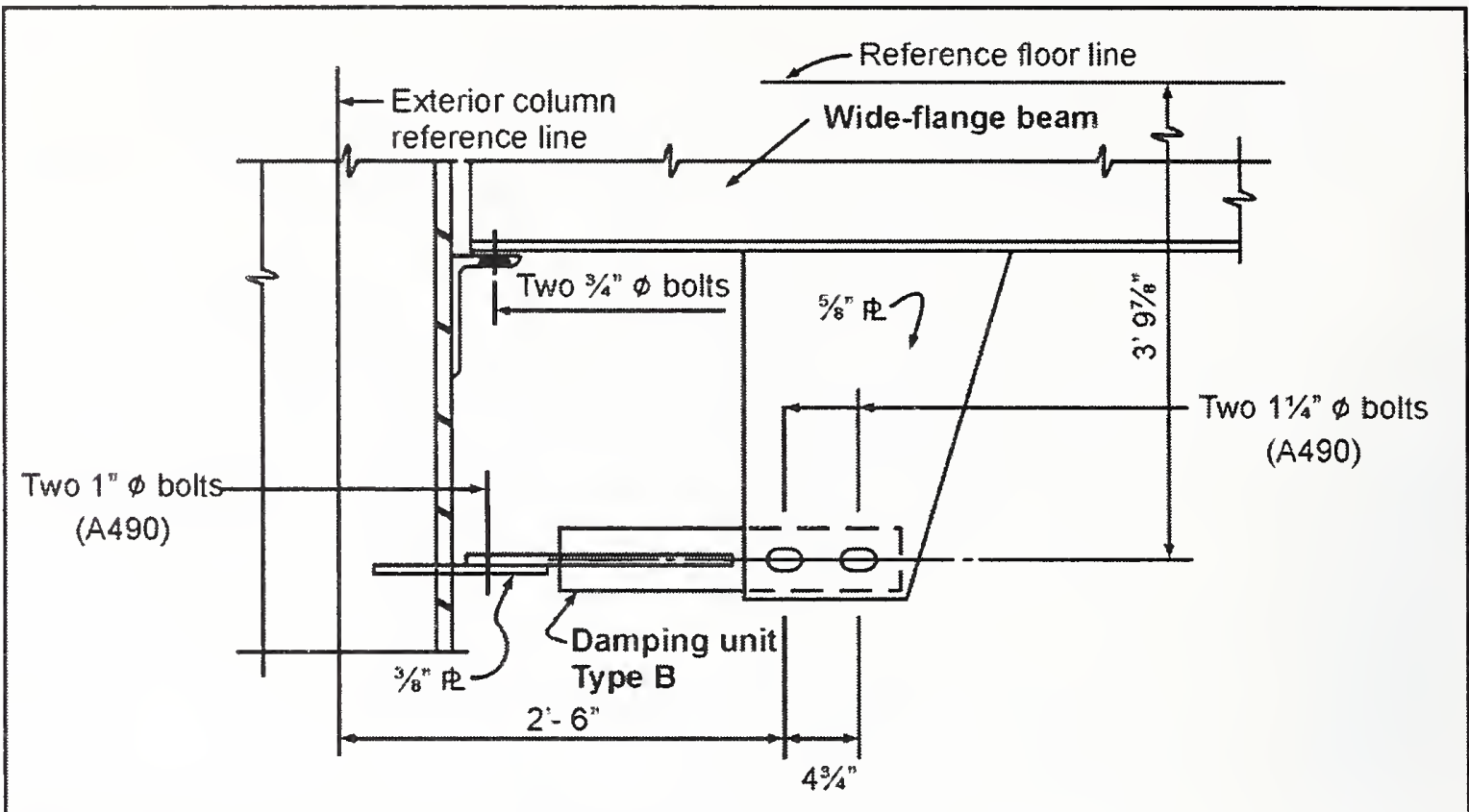

Source: Reproduced with permission of The Port Authority of New York and New Jersey.

Figure 6-1. Wide-flange beam member with Type B damping unit.

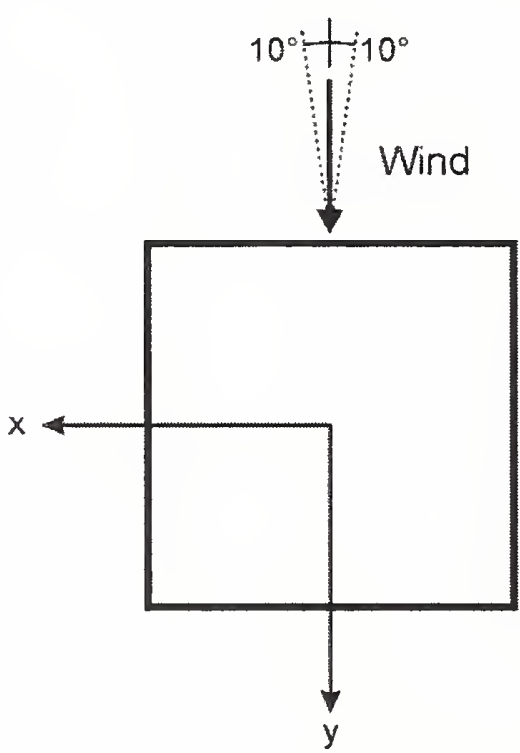

Produced largest displacement in $x$-direction

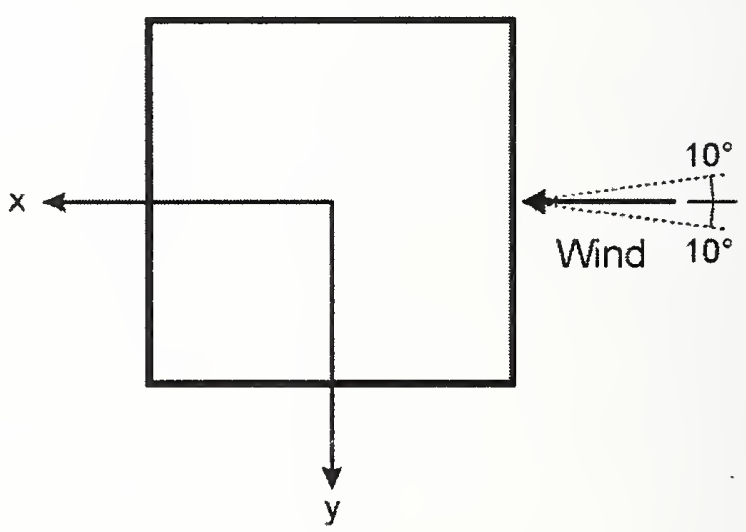

Produced largest displacement in $y$-direction

Source: WSHJ 1965c. Reproduced with permission of The Port Authority of New York and New Jersey.

Figure 6-2. Wind directions that produced the greatest displacements at the top of the tower during the wind tunnel tests. 


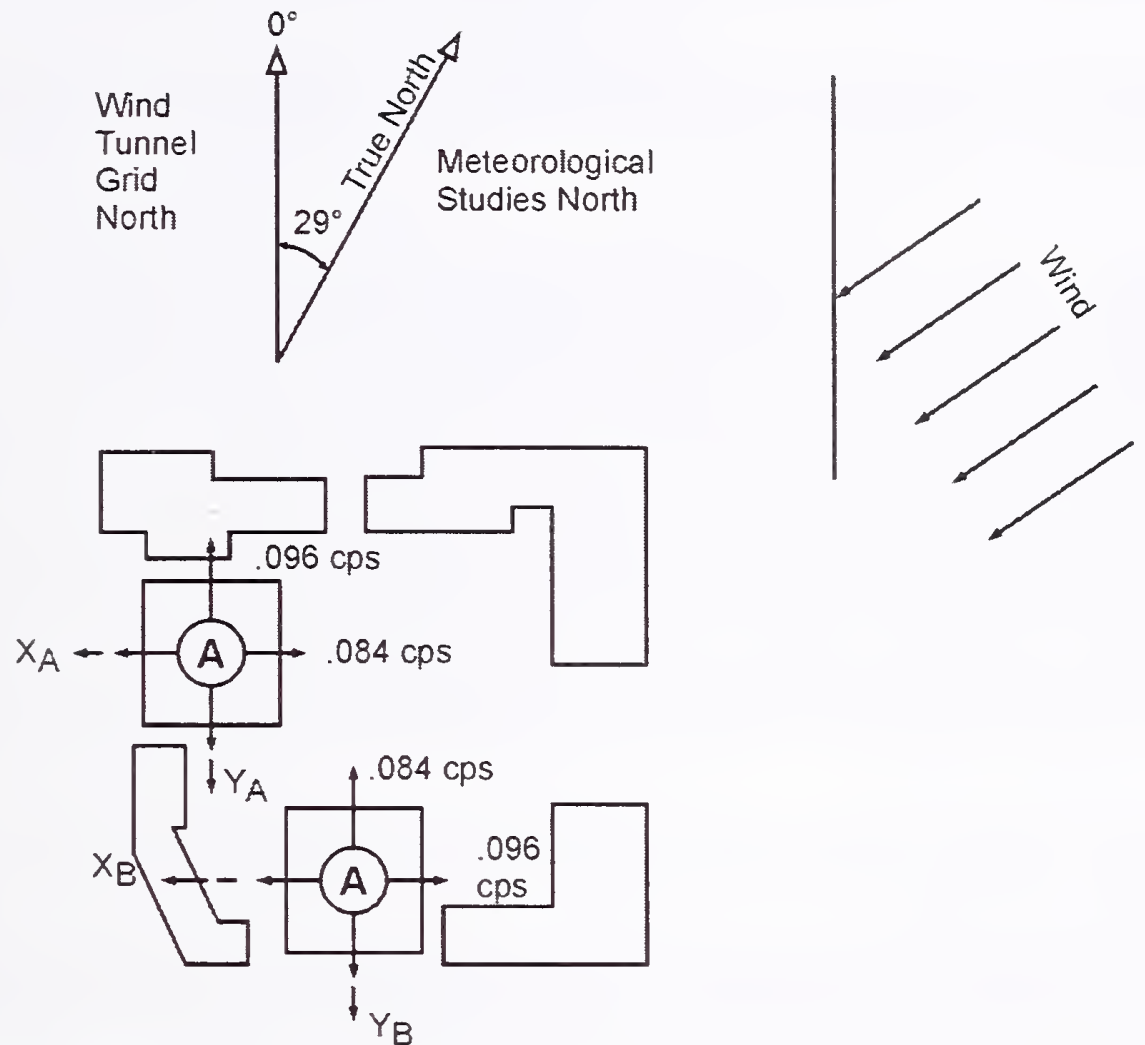

Source: WSHJ 1966c. Reproduced with permission of The Port Authority of New York and New Jersey.

Figure 6-3. Definition of grid system and tower configurations for wind tunnel tests at Colorado State University. 
This page intentionally left blank. 


\section{Chapter 7 \\ FABRICATION AND CONSTRUCTION INSPECTIONS AND DEVIATIONS}

\section{$7.1 \quad$ INTRODUCTION}

The contract documents for World Trade Center (WTC) 1 and WTC 2 between Port Authority of New York and New Jersey (PANYNJ or Port Authority) and the steel fabricators and erector, and the construction contract specifications for WTC 7, indicate that inspection programs were instituted at the steel fabrication sites. For WTC 1 and WTC 2, the documents reviewed revealed that the inspection requirements were part of the contract. For WTC 7, the project specifications list inspection requirements. The records of inspections for both the WTC 1 and WTC 2 and the WTC 7 projects were not available to the investigation. According to PANYNJ, the records for WTC 1 and WTC 2, which were kept in WTC 1, were destroyed, and the records for WTC 7 were discarded by the general contractor after retaining them for 7 years. In this section, the inspection requirements for WTC 1 and WTC 2 and for WTC 7 are described briefly. NIST NCSTAR 1-1A provides more detailed description of the inspection requirements.

\subsection{FABRICATION INSPECTION REQUIREMENTS FOR WTC 1 AND WTC 2}

As described in Sec. 1.3, the Port of New York Authority (PONYA) instructed the consultants to comply with the second and third drafts of the 1968 New York City (NYC) Building Code for their designs of WTC 1 and WTC 2. The Code contains provisions that govern the fabrication and inspection of materials used in buildings. Thus, in general, the requirements in the specifications of the contracts with various steel fabricators were equivalent to those in the Code at a minimum. However, in a number of cases, the contract specifications were more comprehensive and stringent than the corresponding provisions in the Code. Section C26-1000.7, Material and Methods for Construction, of the Code refers to the requirements in Reference Standard RS 10-5, which is the 1963 American Institute of Steel Construction (AISC) Specification for the Design, Fabrication, and Erection of Structural Steel for Buildings (AISC 1963). The AlSC Specification, Sec. 1.23 contained minimum fabrication requirements for the following:

- Straightening of materials

- Gas cutting

- Planing of edges

- Riveted and bolted construction - holes

- Riveted and high strength bolted construction - assembling

- Welded construction 
- Finishing

- Tolerances

Specific inspection requirements during fabrication of various structural members were covered in the contract documents between PONYA and individual fabricators. The individual contract documents which contain the inspection requirements during fabrication are found in appendixes of NIST NCSTAR 1-1A.

Some salient features of the fabrication inspection requirements for different structural framing systems are presented below.

\subsubsection{Floor Trusses}

The contract between the PONYA and the Laclede Steel Company, the manufacture of the floor trusses, contained the specifications for fabrication, including welding of structural steel, and also a quality control and inspection program (see Appendix E of NIST NCSTAR 1-1A). In addition to the quality control requirements for steel fabrication in the AISC Specification (AISC 1963), Chapter three of the contract included a list of specific requirements for inspection during fabrication, including: continual visual inspection and surveillance of the fabrication process of steel trusses by qualified contractor's supervisory personnel; physical and nondestructive testing welding of truss panel points; and full-scale testing of completely fabricated steel truss components.

\subsubsection{Box Core Columns and Built-Up Beams}

The contract between the PONYA and the Stanray Pacific Corporation contained the specifications for the box core columns and built-up beams from the 9th story to the roof. The requirements for fabrication, including welding of structural steel, inspection, and quality control, were in the contract specification. Appendix E of NIST NCSTAR 1-1A addresses the applicable sections of the contract specifications and other quality control requirements in detail.

In addition to the inspection requirements in the contract, special requirements were added for inspection, testing, coordination, and supervision by an independent testing agency at the fabrication plant before structural components left the fabrication yard. These additional requirements were necessary because a major portion of the steel used for the core structural members was to be produced in Japan and England. ${ }^{31}$ The description of a comprehensive program for "supervision, coordination, inspection, and testing based on the use of the personnel and facilities of a local independent testing agency supervised by a resident engineer (a professional engineer employed full time by the structural engineer Skilling, Helle, Christiansen, \& Robertson [SHCR])" was attached to the letter sent from Leslie Robertson of SHCR to Malcolm P. Levy of PONYA (see footnote 31). The scope of this program was two-fold:

- To provide the Port Authority assurance through adequate documentation that fabricated steel conformed to the contract documents and to ensure on-time delivery of fabricated steel.

\footnotetext{
${ }^{31}$ Letter dated June 5, 1967, from Leslie E. Robertson of SHCR to Malcolm P. Levy of PONYA (WTCI-491-L; see NIST NCSTAR 1-1A, Appendix E).
} 
- To provide detailed inspection by checklist and by non-destructive testing prior to final acceptance of the members.

The responsibilities of the resident engineer included the following items:

- Prior to fabrication, performing a complete study of the fabricator's quality eontrol procedures, proposed fabrication procedures, provisions for storage of incoming material, and provisions for loading and shipping of completed building components.

- Ensuring proper interpretation of the contract drawings and specifications.

- Directing the work performed by the independent testing agency and its inspectors.

- Performing surveillance of the quality of work on a continuous basis.

The structural engineer (SHCR) also recommended that an independent testing agency be hired for mill inspection of Japanese steel. ${ }^{32}$ The main responsibility of the testing agency was to verify the accuracy of the certified mill testing reports by witnessing tests at the manufacturing mill. Procedures were established for witnessing the tests at both Stanray Pacific and Pacific Car \& Foundry in the United States. The Port Authority subsequently contracted with Superintendence Inc., an international inspection agency, who provided the mill inspections in both countries. ${ }^{33}$

The Port Authority set forth requirements for the independent testing portion of the mill inspection program. ${ }^{34}$ The requirements, which were part of PONYA's overall quality control program on fabricated steel for the WTC, depended on whether the steel was from a domestic source or from a foreign source. For steel obtained from domestic sources, the independent testing portion of the mill inspection program consisted of the following:

- For steel with yield points less than $50,000 \mathrm{psi}$, one tensile test and one check analysis on samples selected at random from 1 out of 10 heats.

- For steel with yield points of 50,000 psi and higher, one tensile test, one bend test, and a check analysis on samples selected at random from 1 out of 10 heats.

For steel obtained from foreign sources:

- For steel with yield points less than 50,000 psi, one tensile test and one check analysis on samples selected at random from 1 out of 10 heats to be performed abroad. In addition, one sample suitable for a tensile test from 1 out of 4 heats was to be shipped by the inspection agency to a laboratory in the United States for tensile testing and check analysis.

${ }^{32}$ Letter dated April 5, 1967 from Leslie E. Robertson of SHCR to Malcolm P. Levy of PONYA (WTCI-489-L; see NIST NCSTAR 1-1A, Appendix E).

${ }^{33}$ Letter dated September 21. 1967 from R. M. Monti of PONYA to R. E. Morris of the Stanray Pacific Corporation (WTCI-490-L: see NIST NCSTAR 1-1A, Appendix E).

${ }^{34}$ Letter dated November 13, 1967 from R. M. Monti of PONYA to R. E. Morris of Stanray Pacific Corp. (WTCI-498-L; see NIST NCSTAR 1-1A, Appendix E). 
- For steel with yield points of 50,000 psi and higher, one tensile test, one bend test, and a check analysis on samples selected at random from 1 out of 10 heats to be performed abroad. In addition, one set of samples suitable for machining into a tensile specimen and a bending specimen was to be selected at random from 1 out of 4 heats and shipped by the inspection agency to a laboratory in the United States for testing.

The Port Authority paid special attention to the quality control of structural steel members fabricated using steels produced in Japan and England.

\subsubsection{Exterior Columns from Elevation $363 \mathrm{ft}$ to the 9th Floor Splice}

The Pittsburgh-Des Moines Steel Company (PDM) fabricated the column trees, as depicted in Fig 2-8, from elevation $363 \mathrm{ft}$ to the 9 th floor splice. Per the contract specifications, PDM developed the procedures for quality control and welding (see Appendix E of NIST NCSTAR 1-1A). The final draft of the quality control program was submitted to the PONYA on September 28, 1967, and was subsequently approved by SHCR.

Different specifications were written by PDM for the different types of welds that were to be used in the manufacture of the column trees. These specifications were reviewed and approved by SHCR, and subsequently approved by the PONYA.

The PONYA hired the Pittsburg Testing Laboratory, an independent inspection company, in 1967, for mill inspection at PDM's suppliers' plants and for fabrication inspection at PDM's shop.

\subsubsection{Exterior Columns Above the 9th floor Splice}

The contract between the PONYA and the Pacific Car \& Foundry Co. (PCF) contains the specifications for the exterior walls (box columns and spandrel plates as shown in Figs. 2-9 and 2-11) from the 9th story splice to the roof. Requirements for fabrication and welding of structural steel are in the specification, and inspection and quality control requirements are in Sec. 105 of the contract. These requirements can be found in Appendix E of NIST NCSTAR 1-1A.

The quality control and welding procedures were prepared by PCF, and subsequently reviewed by SHCR and approved the PONYA, subject to the following conditions:

- The first three full penetration spandrel butt welds performed by each new welding machine operator or welder was to be subjected to ultrasonic testing.

- Where a spandrel weld was rejected, all welds made by the same welder or welding machine were to be tested by the ultrasonic testing technique for the spandrel in question, as well as for the spandrels produced immediately before and after the subject spandrel.

- Approval of the Pacific Car \& Foundry Co. quality control and testing program did not include approval of any welding process or procedure subject to American Welding Society qualification tests. 
- Visual inspection was to be carried out by certified Pacific Car \& Foundry Co. inspection personnel on 100 percent of all types of welds included in the work.

Weekly inspection reports were submitted by the SHCR resident engineer at the Pacific Car \& Foundry plant in Seattle, WA, to the SHCR home office in New York. ${ }^{35}$ These reports reference a test jig that was built by Pacific Car \& Foundry. Fabricated wall panels were checked for compliance with required tolerances on the jig before they were approved for shipment.

\subsubsection{Rolled Columns and Beams}

The contract between the PONYA and the Montague-Betts Company, Inc. contains the specifications for the rolled core columns, interior columns, louver wall struts, and rolled beams that were used in both towers. Requirements for fabrication and welding of structural steel are in the specifications, and inspection and quality control requirements are in the contract. These requirements can be found in Appendix E of NIST NCSTAR 1-1A.

The quality control and testing program was part of the contract. In particular, the following specific points were to be included in the quality control program:

- Material received should be checked against the certified mill test reports for size, grade, heat number, and color code. One copy of each certified mill report should be submitted to PONYA and SHCR.

- Overhangs, gross laminations, excessive slag inclusions, and similar defects should be defined and repair procedures for these defects should be outlined.

- Certification papers for each welder and welding machine operator should be submitted to PONYA and SHCR. Welding procedures must be prepared and the fabricator must perform qualification tests where applicable. All welds should receive 100 percent visual inspection. Non-destructive testing of welds needs to be described.

- The amount of periodic inspection of work in progress and the persons performing this inspection should be described. The inspection of finished work should be documented in reports submitted to PONYA and SHCR.

\subsubsection{Other Requirements}

Where problems arose in the fabrication yards, particularly when it came to fabrication tolerances, specific requirements that addressed the specific problems were adopted. The typical method used to remedy a problem was for the fabricator to submit a procedure for correction to the PONYA. The procedure was subsequently accepted or rejected by SHCR, and final approval by the PONYA was contingent upon the fabricator satisfying the requirements set forth by SHCR. These deviations from the original specifications are presented in Chapter 8 of this report.

\footnotetext{
${ }^{35}$ Weekly inspection reports contained in WTCI-749-L.
} 


\subsection{FABRICATION INSPECTION REQUIREMENTS FOR WTC 7}

No contract documents were available to rcview for the inspection requirements during fabrication of structural members for WTC 7. However, WTC 7 project specifications for structural steel referred to the following codes and standards for fabrication:

- New York City (NYC) Building Code (1968)

- Specification for the Design, Fabrication, and Erection of Structural Steel for Buildings, AISC

- Specifications for Structural Joints using ASTM International (ASTM) High Strength Bolts, ASTM A 141 Rivets, and ASTM A 307 Unfinished Bolts, Research Council on Riveted and Bolted Structural Joints

- Spccifications for Structural Joints using ASTM A 325 or A 490 Bolts, AISC

- Code of Standard Practice, AISC (cxcept that the first sentence of Sec. 4, paragraph d shall not apply)

- Code of Arc and Gas Welding in Building Construction, AWS Standard Code D1.1, American Welding Society

- Steel Structures Painting Manual, Vols. 1 and 2, Steel Structures Painting Council (SSPC)

- Handbook of Bolts, Nut and Rivet Standards, Industrial Fasteners Institute

Structural steel was to be fabricated and assembled in the shop to the "greatest extent possible" according to these codes and standards.

The project specification called for a separate contract for testing and inspection of fabrication including welding. This contract was not available to the NIST investigation, and implementation of this contract could not be ascertained.

\subsection{INSPECTION DURING CONSTRUCTION}

Construction of WTC 1 and WTC 2 was overseen and managed by the Tishman Realty \& Construction Company (TRCC), acting as the construction manager. In that role, TRCC as the general contractor coordinated the scheduling of the various activities required on the project, including the day-to-day construction activities at the site. The Port Authority required that all correspondence pertaining to administration of a prime contractor's contract, including contract changes, matters pertaining to field problems, job progress, and schedule be submitted to TRCC. ${ }^{36}$ Karl Koch Erecting Co. (KKE) performed structural steel erection (see NIST NCSTAR 1-1A). As pointed out in Sec. 7.1, the record of construction and inspection were not available to the investigation. However, construction inspection identified a number of problems during the erection of WTC 1 and WTC 2, such as material defects, damaged

\footnotetext{
${ }^{36}$ General instructions from Malcolm P. Levy of PONYA to prime contractors for WTC contracts [WTCI-239-P; see Appendix F of NIST NCSTAR 1-1A].
} 
structural members, fabrication errors, and fabricated and field welding defects. In a number of cases, the Port Authority granted construction deviation and repair requests by the fabricators and the erector, and they are presented in Sec. 7.5.

Although WTC 7 project specifications have general erection requirements for fasteners, anchor bolts, column bases, installation, and bracing, no inspection requirements during construction are given in the specifications. Further, the records of construction and inspection documents were not available to the investigation.

\subsubsection{Erection Marks and Marking System WTC 1 and WTC 2}

To facilitate steel erection, a marking system for structural steel in WTC 1 and WTC 2 was developed by the Port of New York Authority and Nassau Bridge Detailers. The marking system was devised to identify following structural members:

- Exterior wall columns - below the first story splice

- Exterior wall columns - above the first story splice

- Core columns

- Louver wall struts

- Vertical bracings at exterior wall columns

- Vertical bracings at core columns

- Interior pipe posts and hangers

- Floor beams

- Horizontal bracings at exterior walls

- Prefabricated floor units

- Loose deck and loose power/telephone cells for beam-framed areas

- Anchor bars and anchor plates

- Shear studs

- Viscoelastic damping units

- Grillages, column base plates and anchor bolts

This system was used by the fabricators to properly identify the different steel members/pieces that were used in the tower construction. For detailed description of the marking system, see Appendix F of NIST NCSTAR 1-1A. 


\subsubsection{Quality Control and Inspection Program for WTC 1 and WTC 2}

A quality control and inspection program was developed by Karl Koch Erecting Co., who performed structural steel erection work, submitted to the Port Authority for approval. The quality control and inspection program included information on the following:

- Survey control

- Control of construction and erection loads

- Field welding

- Bolting of structural steel

- Control of stud welding operations

- Erection procedures

- Control of workmanship

- Control of erection tolerances

- As-built drawings

- Safety programs

For detailed description of the inspection program, see Appendix F of NIST NCSTAR 1-1A. Section 7.5 cites a number of construction errors identified during construction inspection.

\subsection{DEVIATIONS GRANTED}

The WTC towers were very complex steel frame buildings. The structural frames of the towers incorporated many beams, columns and trusses that were formed by welding steel plates. During fabrication and erection of structural members, errors were noted by the steel fabricators and the erector. Such errors included mainly dimensional deviations of structural members from the design and fabrication drawings. The PONYA was requested by the fabricators and the erector to approve deviations to contract drawings and specifications.

For deviation requests, the following procedure was established by the PONYA. All deviations resulting from difficulties encountered in complying with the contractual requirements for fabrication or erection were submitted by the fabricators or erector to the Office of the Construction Manager of PONYA. Deviations were also requested when, in the opinion of a fabricator or erector, an alternative detail or procedure was warranted. For expediency, such requests were usually submitted at the same time to the SHCR.

Typically, the Office of the Construction Manager approved a deviation after SHCR reviewed the details of the deviation and recommended its approval. In many cases, SHCR submitted alternative methods, which were incorporated into the deviation. 
The deviations that were granted may be categorized into the following groups:

- Fabrication/erection tolerances

- Defective (cracked, laminated, misfit) components

- Fabricator/erector-preferred procedure

- Material substitutions

- Frequency/rate of weld inspections

Listed below are types of deviations granted by PONYA for each of the above categories. NIST NCSTAR 1-1A gives a detailed listing of fabrication and erection related deviation requests by fabricators and the erector.

\subsubsection{Deviations Relating to Fabrication and Erection Tolerances}

The following is a list of approved deviation requests for fabrication and erection of box beams, box columns, and floor trusses.

- Flange offset of $3 / 16$ in. instead of $1 / 8$ in. from the web for box-column sections fabricated by Stanray Pacific Corporation.

- Out-of-square tolerances of box beams and a maximum twist of box columns by Mosher Steel Company.

- Greater depth of the floor truss end bearing of 20 trusses (4.5 in. vs. specified 4 in.) by Laclede Steel Company.

- Field modification procedures for vertical struts of floor trusses to meet erection tolerances by Karl Koch Erecting Company.

- Change of fabrication tolerances of floor trusses by Laclede Steel Company.

- Fabrication modifications of floor trusses to avoid erection difficulties to Laclede Stecl Company by the PONYA.

\subsubsection{Deviations Relating to Defective Components}

The following is a list of specific requests relating to deviations for defective components of column trees and floor trusses.

- Fabrication error for truss connectors that were $1 / 4$ in. narrower than the required width by Laclede Steel Company. 
- Fabrication errors of placing filler plate at incorrect locations at the bearing end of floor trusses by Laclede Steel Company. These errors were approved by the inspection company Pittsburgh Testing Laboratory subject to approval by SHCR.

- Repair procedures to correct fabrication errors by Laclede Steel Company.

- Repair procedure to correct laminations in column trees by Pittsburgh-Des Moines Steel Company.

- Repair procedure to correct cracks that developed in a number of column trees by PittsburghDes Moines Steel Company.

- Repair procedure to correct fabrication errors by adding back up plates by Pittsburgh-Des Moines Steel Company.

- Repair procedure for butt welds in column trees by Pittsburgh-Des Moines Steel Company.

\subsubsection{Deviations Relating to Alternate Fabrication and Erection Procedures}

The following is a list of specific requests relating to deviations for alternate fabrication and erection procedures of core columns, floor trusses, exterior wall columns, and beam seats.

- Deviation of weld splice location of core columns from the contract drawings by Stanray Pacific Corporation.

- Use of Hobart automatic arc welding equipment to expedite welding process by Laclede Steel Company.

- Elimination of clipped corners of stiffener plates in the exterior wall columns by Pacific Car \& Foundry.

- Substitution of different beam seat angles of ( 8 by 6 by $7 / 8)$ in. with ( 8 by 6 by 1$)$ in. angles by Pacific Car \& Foundry.

\subsubsection{Deviations Relating to Product Substitutions}

The following is a list of specific requests relating to deviations for product substitutions in the exterior wall.

- Substitution of different steel plates with yield strengths ranging from $42 \mathrm{ksi}$ to $100 \mathrm{ksi}$ for specific plates that were originally specified for use in the exterior wall by Pacific Car \& Foundry.

- Substitution of $3 / 4$ in. thick plates for $5 / 8$ in. and $1 / 2$ in. thick plates by Pittsburgh-Des Moines Steel Company.

- Substitution of ASTM A36 steel with ASTM A 441 modified steel by Pittsburgh-Des Moines Steel Company. 


\subsubsection{Deviations Relating to Inspection Practice}

The following is a list of specific requests relating to deviations in inspection practice for the exterior wall and welds.

- Modifications to radiographic inspection procedures for butt-weld joints by Pittsburgh-Des Moines Steel Company was not approved. Instead, SHCR suggested an alternate program to be followed.

- Revision to the quality control program with respect to the minimum inspection rate for welds by Stanray Pacific Corporation. 
This page intentionally left blank. 


\section{Chapter 8 \\ StRuctural MaintenanCE AND Modifications DURING OCCUPANCY}

\section{$8.1 \quad$ INTRODUCTION}

Both architectural and structural modifications were made to meet the occupancy needs of individual tenants throughout the history of occupancy of the World Trade Center (WTC) 1, 2, and 7. ${ }^{37}$ Examples of modifications include openings cut in existing floors to construct new stairways linking two or more floors, and reinforcement of floor framing members to accommodate heavy loads imposed by tenants. All modifications were reviewed by the Port of New York Authority (PONYA), later called the Port Authority of New York and New Jersey (PANYNJ), to maintain structural integrity of the buildings and to ensure that modifications were compatible with existing building conditions. In order to guide tenants in their modification process, the PONYA issued Tenant Alteration Review Manual (PONYA 1971). This manual was first issued in 1971 soon after the first tenant occupied WTC 1 in December 1970, and subsequently updated periodically through 1997.

In anticipation of structural degradation, in 1986, the PANYNJ issued the Standard for Structural Integrity Inspection of the World Trade Center Towers A \& B (PANYNJ 1986) to guide periodical inspection of structural members. Deteriorated and damaged members were identified for repair. The standard was used by consultants who were retained by PANYNJ for systematic examination of WTC 1 and WTC 2.

In 1998, the PANYNJ issued the Standards for Architectural and Structural Design (PANYNJ 1998) for modification works. The standards included not only the design guide, but also included specifications and standard details to be used in modification works. Tenants proposing any modifications were required to follow the requirement specified in the standards.

In this chapter, the documents described above are presented, and significant modification and repairs to the structural systems of WTC 1, 2, and 7 are summarized. NIST NCSTAR 1-1C provides more detailed description of structural maintenance and modification during occupancy of WTC 1, 2, and 7.

\subsection{TENANT CONSTRUCTION REVIEW MANUALS}

PONYA issued the first edition of the Tenant Construction Review Manual in 1971, shortly after the first tenants occupied WTC 1 in December 1970 and prior to initial occupancy of WTC 2 in January 1972. Subsequent editions were issued in 1979, 1984, 1990, and 1997.

\footnotetext{
${ }^{37}$ The manual and standards mentioned below and the records on structural modifications, inspection and maintenance presented in this chapter were made available to the NIST investigation by PANYNJ. The Tenanat Alteration Review Mamual, the Standard for Structural Integrity Inspection of the World Trade Center Towers A \& B, and the Standard for Structural Integrity Inspection of the World Trade Center Towers $A \& B$ are given in Appendices A through F of NIST NCSTAR 1-1C.
} 
The purpose of these manuals was to present the technical criteria, standards, and requirements that were to be followed by tenants that were planning construction work in any PONYA facility. The manuals included the criteria that werc used by the Engineering Department of the Port Authority when reviewing proposcd construction or alterations. Requirements were given for alterations and modifications to architectural, structural, geotechnical, civil, mechanical, plumbing, and fire protection systems.

The General Requirements section of the manual required that all tenants submit an application form to the Port Authority outlining the scope of work, the design criteria, and the plans prior to construction. The design was to be performed by a registered architect or licensed professional engineer. Contractors were required to comply with all applicable provisions of federal, state, municipal, local, and departmental laws, ordinances, rules, regulations, and orders, except where stricter requirements were contained in the project specifications.

\subsubsection{Edition}

The 1971 edition of the Tenant Construction Review Manual (see footnote 37) requires that all structural modifications conform to the provisions of the 1968 New York City (NYC) Building Code. Registered design professional were to submit structural calculations for review by PONYA. The PONYA structural reviewer was responsible for the structural integrity of all walls and partitions. Building frames were checked for stability and sidesway, including the effects of these on the columns.

A comprehensive inspection program was implemented for all construction. Inspection was required during various phases of construction and was mainly to be performed in accordance with the 1968 NYC Building Code Sec. C26-106.3 (Materials, Assemblies, Forms and Methods of Construction; Inspection Requirements) and Sec. C26-107.3 (Service Equipment; Inspection Requirements). The architect, engineer, or other person who supervised the work was required by PONYA to be present at final inspection.

\subsubsection{Edition}

In the 1979 edition of the Tenant Construction Review Manual (see footnote 37), structural requirements were modified and expanded. Significant differences between the 1971 and 1979 editions were based on updates of the Structural Chapter of the 1968 NYC Building Code. These include:

- Rules and regulations relating to resistance to progressive collapse under extreme local loads.

- Rules and regulations for the design of composite construction with metal decks or lightweight concrete.

- Rules related to structural design based on electronic computer computations.

- Rules for application and protection of sprayed fire-resistive material (BSA Cal. \#118-68-GR). ${ }^{38}$

\footnotetext{
${ }^{38}$ Denotes number of the New York City Board of Standards and Appeals (BSA) document.
} 
- Rules for arc and gas welding and oxygen cutting of steel covering the specifications for design, fabrication, and inspection of arc and gas welded steel structures and the qualification of welders and supervisors (BSA Cal. \#1-38-SR).

Significant updates to controlled inspection of materials, operations, and equipment include:

- Inspection requirements for proper use of admixtures for concrete.

- Deletion of the requirement for checking welders' licenses or qualifications as this item was covered in the new rules and regulations relating to structural items.

- Acceptance of mill, manufacturers', and suppliers' inspection and test reports as evidence of compliance with the provisions of the Code for all structural materials and assemblies.

- Inspection of sprayed fire-resistive material since such inspection was added for the first time in C26-502.2(f) of the 1968 NYC Building Code in 1976 (Local Law 55). This new section of the code required that the installation of all sprayed fire-resistive material on structural members, except those encased in concrete, be subject to the controlled inspection requirements of C26-106.3, which requires all materials designated for controlled inspection were to be inspected and/or tested to verify compliance with code requirements. All required inspections and tests were to be made and witnessed by or under the direct supervision of an architect or engineer who the owner retained and who was acceptable to the architect or engineer who prepared the plans. The architect or engineer was to file with the NYC Building Department signed copies of all inspection and test reports, together with a signed statement that the material and its use or incorporation into the building complied with code requirements.

\subsubsection{Edition, Revised 1990}

Except for some editorial changes, the requirements of the 1984 edition of the Tenant Construction Review Manual remained virtually the same as those of the 1979 edition. In the revised March 1990 edition, requirements were added concerning the role of consultants working on the project who were not the architect or engineer of record.

The scope of structural review of the alterations and/or modifications consisted of compliance with the applicable codes, standards, and design criteria given in the Structural Review section of the manual. In particular, the provisions of the then applicable New York City (NYC) Building Code were to be satisfied for work performed in New York City.

The revised March 1990 edition (see footnote 37) of the manual included a requirement that all structures were to be designed for earthquake zone 2 forces in accordance with the BOCA (Building Officials Code Administrators, Inc.) code. Local laws that contained seismic provisions more stringent than those in the BOCA code were to take precedence. Also, reference was made to ASTM International (ASTM) E 580, Standard Practice for Application of Ceiling Suspension Systems for Acoustical Tile and Lay-in Panels in Areas Requiring Moderate Seismic Restraint for lightweight ceilings to resist seismic forces. 
The Controlled Inspection section of the manual contained a comprehensive inspection program that was to be implemented for all construction. Controlled inspection requirements were abstractcd from the NYC Building Code Secs. C26-106.3 and 107.3. All materials, equipment, and construction designated by the Code for controlled inspection were required to be inspected and/or tested to verify compliance with the Code. Controllcd inspection was required to be made and witncssed by or under the direct supervision of a registered architect or professional engineer retaincd by the tenant and acceptable to the architect or engineer responsible for the plans.

The inspection requirements were significantly reorganized and modified in the revised March 1990 edition of the manual. Requirements for approval/acceptance of materials and controlled inspections were abstracted from the applicable sections of the NYC Building Code.

\subsubsection{Edition}

The requirements of the 1997 edition of the Tenant Construction Review Manual are essentially the same as those in previous editions of the manual. The most notable change was related to earthquake design. The manual added horizontal force factors for overhead signs, anchorage for suspended ceilings weighing more than 4 psf, elevator and counterweight guardrails and supports, sprinkler piping, gas and high hazard piping, other piping, and heating, ventilation, and air conditioning (HVAC) ducts, along with new notes pertaining to sprinkler piping, other piping, and HVAC ducts. These requirements were added to the manual to ensure that potential overhead hazards would not fall on building occupants during a seismic event.

No significant changes were made to the inspection requirements from the 1990 edition of the manual.

\subsection{STANDARDS FOR STRUCTURAL INTEGRITY INSPECTION OF THE WTC TOWERS}

To guide the PANYNJ in the evaluation of the structural integrity of the WTC towers, the Engineering Department of PANYNJ issued Standards for Structural Integrity Inspection of the World Trade Center Towers $A$ \& $B$ (PANYNJ 1986) ${ }^{39}$ in 1986. These standards were used to identify structural degradation, and to repair damaged structural members.

Three methods were used to evaluate the structural integrity of the towers: (1) statistical inspections, (2) review of maintenance and tenant complaint reports, and (3) building movement and deformation measurements.

In the first method, periodic visual inspection of selected structural components in "higher-potential trouble areas" was to be made initially by qualified outside consultants. The periodic inspections were to be supplemented by occasional visual inspcctions when the structure was exposed during tenant remodeling or general maintenance work.

In the second method, various reports were to be examined by the Engineering Department of PANYNJ, which could possibly shed light on underlying structural problems. Maintenance reports of non-structural

\footnotetext{
${ }^{39}$ See Appendix E of NIST NCSTAR 1-1C for the complete document.
} 
repairs, water leakage, and tenant complaints about unusual building movements, vibration, or noise are examples of such reports.

In the third method, the performance of systems within the buildings was to be evaluated by the Engineering Department through measurement of movement or deformation using appropriate tests and instruments. Measurements were to be performed on individual components in the towers as well as on the entire towers themselves.

\subsubsection{Visual Inspections}

Since the visual inspection of the entire structure, or even a major portion of WTC 1 or WTC 2, was not practical, a statistical inspection program was implemented. This approach involved sampling those components and systems that were important to structural integrity at locations with "a relatively higher potential for occurrence of defects or problems."

Visual inspection was to be supplemented by the use of simple hand tools, measurements, and recording techniques, as required. Loose, cracked, or rust-stained sprayed fire-resistive materials and concrete or masonry encasement covering structural steel members and connections was to be removed prior to examining the steel. After inspection, any removed fireproofing had to be properly replaced. Also, whcre it was necessary to drill a hole through a structural steel element to provide access for a borescope or any other device for inspection, the access hole was to be sealed with weld metal, body putty, or caulking, as appropriate.

Periodic inspection of WTC 1 and WTC 2 was to be carried out on the following components at various time intervals:

1. TV antenna mast on the top of WTC 1. This program consisted of four parts:

(a) inspection of the structural steel elements in the antenna, (b) inspection of the high tensile bolts and studs, (c) inspection of the weatherproof enclosure, and (d) inspection of the radomes. Inspection of these components was to be performed on a "continuing basis," as weather and operational restrictions permitted. A complete inspection of the mast structure within the weatherproof enclosure was to be performed at least once a year; the other components were to be inspected at least once every 3 years.

2. Exterior roof and wall elements. Every year, the exterior roof and wall elements were to be inspected for signs of water intrusion. Roof leakage was to be ascertained from an examination of the spaces immediately below the roof areas. Wall leakage was to be determined from signs of water staining on interior finishes.

3. Room occupancies. An inspection of room occupancies and uses throughout both towers was to be performed on an annual basis to verify that design live load was not exceeded.

4. Accessible column envelopes, including fireproofing. Every 2 nd year, accessible columns were to be inspected for bowing or deviation from plumb. Also, fireproofing was to be examined for signs of rust or cracking. Inspection for lateral displacement or rotation of columns in elevator shafts, where the columns were braced on only one axis by connecting beams or concrete slabs, was required. 


\section{Fireproofing and masonry partitions on diagonal bracing and transfer trusses.}

Fireproofing and masonry partitions enclosing the diagonal bracing on exterior column lines in both towers below the Service Level Floor and the transfer trusses below floor 1 in WTC 2 under exterior and core columns were to be inspected every 2 nd year for cracking, stains, and other possible signs of structural distress.

6. Hat truss members. Every 2 nd year, the hat truss members between floor 107 and the roof in the core area were to be inspected.

7. Exterior box columns and spandrel plates. Exterior box columns and spandrel plates under column trees below floor 7 were to be inspected every 4 th year. Exterior aluminum covers and sprayed fire-resistive material were to be removed to gain access to the exterior surfaces of the box columns and spandrel plates. Both the columns and plates were to be visually inspected for bowing or distortion, cracking, and corrosion. Visual inspection was also required for accessible welds. Ultrasonic testing of full or partial penetration welds and adjacent base metal was to be performed where base metal thickness exceeded $1.5 \mathrm{in}$.

The interior of the box columns was to be examined by a borescope for the presence of water and the existence of rust on the interior plate surface. This was to be accomplished by drilling an access hole in the column or the spandrel plate.

The "tree" junction where the three superstructure columns merged was also to be inspected. The top surface of the horizontal diaphragm plate that capped the tapered box column just below the point where the three separate columns merged was to be examined, as was the exterior column plate between this location and the column splice at elevation $+372 \mathrm{ft} 4 \mathrm{in}$.

8. Steel floor framing over mechanical spaces. Every 4th year, the steel floor framing over mechanical spaces and other areas without suspended ceilings was to be inspected.

9. Concrete slabs, partitions, and finishes. Concrete slabs, partitions, and finishes were to be inspected every 4 th year for signs of distress, which could indicate excessive structural deformation.

Occasional inspections were also to be made of the structural steel framing, connections, and concrete slabs when general repairs or remodeling was done that involved removing ceilings, partitions, finishes, or other coverings. In particular, the top of the concrete slab was to be examined for cracking, spalling, and exposed or corroded top reinforcement. Where reinforcing bars were corroded and where concrete had spalled, repairs were to be made as tenant relocation permitted.

\subsubsection{Review of Reports}

General maintenance reports and complaints from tenants were to be used to search for possible problems related to underlying structural defects. Water damage caused by leaks at the roof level or at the exterior walls, broken plumbing, and cracks in partitions or the concrete floor slab were to be reviewed to determine whether such events were caused by structural deformations. Records were to be kept of tenant complaints of building sway, floor vibration, sagging ceilings, unusual noise, and other items. Visual inspection of the appropriate area of the building was to be performed where a reasonable assessment of 
the data in the reports or logs was tied to a specific structural element or system. Reports and log data were to be correlated with testing and measurements.

\subsubsection{Periodic Measurements}

Periodic measurements of various types of deformation and vibration were to be made by the Engineering Department of PANYNJ for the purposes of monitoring changes in certain important characteristics of the buildings. Adverse changes in such measurements were assumed to reflect possible structural deterioration.

Measurements of the following items were to be performed on a periodic basis:

1. Natural frequency of the towers. Accelerometers were to be used to measure natural frequencies of the towers on a monthly basis. Wind speed and direction were also to be recorded at that time.

Accelerometers were installed only in WTC 1.

2. Natural frequency of the TV mast on WTC 1. Accelerometers and amplifiers were to be installed within the heated enclosure of the TV mast on the top of WTC 1 at a level of about $2 / 3$ of the height of the mast above its base. One accelerometer was to be oriented to measure $\mathrm{N}-\mathrm{S}$ displacements, and one was to be oriented to measure E-W displacements. Displacement measurements, as well as wind speed and direction, were to be recorded once a month.

There is no evidence that accelerometers were installed on the TV mast.

3. Natural frequency of the floor construction. The natural frequency of the floor construction was to be measured when floor space had been emptied due to tenant change or remodeling. The natural frequency and damping values of the floor structure were to be measured by performing a "heel drop" test. In such tests, vibrations induced in the floor structure by a vertical impact were recorded using an accelerometer attached to the floor. Vibration measurements were also taken for an impact load of $100 \mathrm{lb}$ dropped from approximately 6 in. above the floor slab on to a 1 in. thick neoprene pad.

4. Viscoelastic dampers. This program consisted of continuously measuring and recording the movements of WTC 1. Wind speed and direction were also to be measured. It was anticipated that such measurements would continue until the end of 1985 or longer, depending on available funds.

Twelve viscoelastic damping units (four units from each of three floors) were to be removed from WTC 1 annually and were to be tested by the Minnesota Mining and Manufacturing Company (3M), who were the manufacturers of the damping units. Temperature effects and shear strength were to be tested.

5. Plumbness and level. Building plumbness and floor level checks were to be performed semiannually for each tower, preferably in the early morning hours in August when wind velocity was low and outside air temperatures were moderate. 
Building plumbness was to be determined by measuring the offsets from a vertical laser beam, which was to be projected up from the bottom of freight elevator shaft 50 , to the shaft walls. Offset measurements were to be taken at 20 -story intervals.

Floor levelness was to be determined by measuring the relative elevation of 16 benchmarks on the floor slab at floor 70 of each tower.

\subsubsection{Recordkeeping}

Standards for-Structural Integrity Inspection lists the defects and signs of distress that were to be noted and recorded during inspection of the structural steel and the reinforced concrete. Detailed descriptions of the defects and signs of distress are given in NIST NCSTAR 1-1C.

In general, a description was to be made of the defect or indication of distress. Measurements, sketches, and photographs were to be provided in thosc cases where a written description was not adequate. The use of a tape recorder was also permitted.

If defects that appeared to require more than routine attention were uncovered, a separate report of such findings was to be submitted to the Engineering Department, PANYNJ. For conditions of a serious nature, immediate notification was to be made to the Engineering Department in person.

Three categories of urgency were established for repairs. Repairs falling into the "immediate" category included possible closure of the area and/or structure affected until interim remedial action (such as shoring or removal of a potentially unsafe element or structure) could be implemented. Such action was to be undertaken immediately after discovery, and a description of the action taken and recommendations for permanent repair were to be included in the inspection report.

The "priority" category was for those conditions where no immediate action was required, or for which immediate action had been completed, but for which further investigation, design, and implementation of interim or long-term repairs should be undertaken on a priority basis (i.e., taking precedence over all other scheduled work).

Repairs falling into the "routine" or "non-priority" category could be undertaken as part of a scheduled major work program or other scheduled project, or when routine facility maintenance was to be performed, depending on the type of repair that was required.

Standards for Structural Integrity Inspection outline the various measurements and test data that were to be recorded during the inspection process. Also given are the criteria that determine whether a possible problem may exist, based on the recorded measurements. 


\subsection{STANDARDS FOR ARCHITECTURAL AND STRUCTURAL DESIGN}

Standards for Architectural and Structural Design was issued on February 27, 1998, by PANYNJ and contained architectural and structural design requirements, specifications and standard details for tenant alterations that were to be made specifically at WTC 1 and WTC $2{ }^{40}$

Prior to any design work, the tenant's consultants were required to perform a field inspection of all areas that would be affected by the alterations so that the latest information was available for all structural elements, including, but not limited to truss reinforcement, stair openings in slabs, and core-hole locations.

Tenants are required to submit calculations and construction drawings to PANYNJ for review and approval. All construction documents were required to be signed and sealed by a professional engineer or registered architect licensed to practice in the state of New York.

Minimum loads to be used in the calculations were also specified. Calculations to compare the proposed loading with the allowable loads were required to conform to the latest edition of the NYC Building Code. Both allowable stress design and load-and-resistance-factor design were acceptable design methods.

All work was required to conform to the latest edition of the NYC Building Code, including any revisions. Provisions in the latest editions of the following codes took precedence over those in the NYC Building Code whenever they were more stringent:

- American Institute of Steel Construction, Specification for the Design, Fabrication and Erection of Structural Steel for Buildings. Supplement 1 is specifically excluded.

- American Concrete Institute, Standard Building Code Requirements for Reinforced Concrete, ACI 318.

- American Welding Society, Structural Welding Code - Structural Steel (AWS D1.1) and Reinforcing Steel (AWS D1.4).

Any steel plates that were added to reinforce existing framing or for other reasons were required to conform to ASTM A36, and any reinforcing bars that were added were required to conform to ASTM A 615 Grade 60.

Welding materials for structural steel and reinforcing steel were required to be E7018 conforming to American Welding Society (AWS) A5.1 Specifications for Covered Carbon Steel Arc Welding Electrodes. Specifications for non-shrink grout were also specified.

\subsection{STRUCTURAL INSPECTION PROGRAMS}

Beginning in 1990, the Port Authority of New York and New Jersey implemented a systematic facility condition survey program of WTC 1 and WTC 2 using Standards for Structural Integrity Inspection,

\footnotetext{
The complete document is in Appendix F of NIST NCSTAR 1-1C.
} 
which was developed in 1986. WTC 7, which was not owned by PANYNJ, was also inspected based on the criteria in Standards for Structural Integrity Inspection. Prior to 1990, both WTC 1 and WTC 2 were inspected occasionally by the Engineering Department of PANYNJ.

The survey program included:

1. Condition survey of WTC 2 in 1990 by the Engineering Quality Assurance Division of PANYNJ.

2. Condition survey of WTC 1 in 1991 by the Office of Irwin G. Cantor, Consulting Engineers, for the Engineering Quality Assurance Division of PANYNJ.

3. Condition survey of WTC 7 in 1997 by Ammann \& Whitney for the Engineering Quality Assurance Division of PANYNJ.

4. Due diligence physical condition survey of WTC 1 and WTC 2 in 2000 by Merrit and Harris for PANYNJ prior to entering into a long-term leasing contract for the WTC buildings with Silverstein Properties.

In addition to these four separate condition surveys, Leslie E. Robertson Associates (LERA) and other engineering firms conducted periodic inspections of the towers under the WTC Structural Integrity Inspection (SII) Program, which was based on the proposal originally submitted to PANYNJ by LERA in 1990 .

This section summarizes the findings of these condition surveys. Detailed descriptions of the condition survey programs and findings are given in NIST NCSTAR 1-1C.

\subsubsection{Facility Condition Survey of WTC 2}

The scope of work, which was designed to minimize impact on tenant and facility operations, included inspection of (1) the exterior wall system (columns, spandrel plates, and splices), (2) core columns (including column splices and lateral bracing below the 7 th floor), (3) the space frame (hat trusses), (4) floor systems (floor slabs and decks, trusses, rolled beams, bridging, and connections), and (5) the damping system. Thirty floors throughout WTC 2 were selected for inspection, including all four of the two-story mechanical equipment rooms.

\section{Inspection Procedures and Methodology}

To assess the condition of the structural system in the tower, both visual inspection and nondestructive testing methods were performed. The thickness of steel members was checked using an ultrasonic thickness gauge. Fillet welds were tested for cracks and discontinuities using magnetic particle or dye penetration test methods, and groove welds were tested using the ultrasonic method.

\section{Exterior Walls (Columns and Spandrels)}

Exterior columns and spandrels were inspected at (1) column field splice connections, (2) spandrel field splice connections, and (3) the inside of the spandrel plate face at the column/floor truss seat connections. 
A total of 59 column splices were inspected and all were found to be in good condition. On two of the floor levels, the columns had only three bolts at the splice location, although the design called for four. According to the report, this had no effect on structural integrity.

Spandrel plates, splice plates, and spandrel bolted connections were also found to be in good condition. Scattered rust stains were observed on the spandrel fireproofing as well as on the inside of some of the steel box columns.

No priority recommendations were made in the report. The report recommended that a long-term maintenance program be developed and implemented to clean and paint the inside surfaces of the exterior box columns to prevent further corrosion of the structural steel.

\section{Core Columns}

Core columns were inspected from elevator shafts and from office area floors. Twenty-five elevator shafts were randomly selected for inspection, and the elevator core framing was primarily inspected with fireproofing materials in place. In general, some defects were found in the fireproofing. In most of the shafts, several small regions and a few large areas of fireproofing were found to missing from core framing members. In the worst case, 100 percent of the fireproofing was found to be missing from the south face of column 908 between floors 27 and 29 in elevator shaft number 1. Exposed steel members exhibited only isolated locations of light surface corrosion.

Gypsum wallboards surrounding the elevator shafts were also found to be in good condition, although isolated holes were detected at various locations.

Inspection of column splices and eccentric-braced column connections with fireproofing removed showed that all bolts, welds, and structural steel were in good condition.

No priority recommendations for repair were made in the 1990 report. The report recommended that the fireproofing that was missing from the framing members in the elevator shaft be replaced, including those regions where the fireproofing was removed for inspection. It also recommended that the holes in the gypsum wallboards surrounding the elevators be repaired.

\section{Space Frame (Hat Trusses)}

From floor 107 to floor 110, a steel space frame system, also known as "hat trusses" was interconnected with columns in the core and the exterior walls. The hat trusses were constructed of rolled wide-flange and welded-box sections, and were designed to support a future antenna. Thirty three locations were inspected visually from the floor below. Visual inspections of truss connections were made closely at six locations after removing the fire resistant material ("fireproofing"). The space frame system was found to be in good condition. The exposed areas exhibited light surface corrosion. Both bolted and welded connections were found to be in good condition with no significant deterioration. 


\section{Floor Framing}

In the main lobby, beams and connections that were inspected within the core area were found to be in good condition. Fireproofing was missing at various locations, exposing light surface corrosion on these elements.

On floors 9 through 41 , the floor framing that was inspected was also found to be in good condition. Light corrosion was observed on all core beams and beam connections, and on floor truss connections. The most significant deficiencies were found at the damping units, where a number of such units were missing from 1 to 4 fasteners in the connections to the framing members.

Floor framing on floors 43 through 75 were found to be in good condition. The most significant deficiencies were found on floors 64 and 75. A deformed bottom chord was found on the main truss along column 343 on floor 64 ; no signs of distress were observed. On the 75th floor, untightened bolts were found at truss seat connections at several locations, which, according to the report, had no significant affect on the structural integrity of the framing, since they served for erection purposes.

The floor framing on floors 77 through 107 was found to be in good condition with light surface corrosion observed on all core framing beams and connections. The most significant deficiencies were concrete slabs that had separated from the metal deck at floors 93 and 108. According to the report, structural integrity was not comprised, since the metal deck served as only formwork for the concrete.

The floor framing and slabs were found to be in good condition except where hairline cracks were found in concrete beam encasement at various locations on all four mechanical equipment room levels.

No priority recommendations for repair were made in the report. All of the deficiencies noted above were considered to have no significant effect on structural integrity.

\section{Damping System}

Visual inspection of damping units noted missing non-structural fasteners. Of 30 floors examined, at least 1 damping unit on each of 4 floors $(18,29,37$ and 38) had missing fasteners, ranging from 1 to 4 . No priority recommendations for repair were made in the report.

\section{Mechanical Equipment Rooms (Floors 7-8, 41-42, 75-76, 108-109)}

The floor framing and slab inspected on the Mechanical Equipment Room (MER) floors were found to be in good condition. On all MER floors, most of the structural framing was inaccessible due to HVAC ducts, fans, electrical equipment, or plumbing.

Hairline cracks were found in concrete beam encasement at various locations on all four MER floors. Exposed steel exhibited light surface corrosion, and no deterioration was found at the underside of floor slabs.

The report recommended no priority repair. As mentioned above, all the deficiencies found were considered to have no significant effect on structural integrity. The report recommended that utility supports found to be bowed or vibrating be replaced as part of the facility's regular maintenance program. 


\section{Roof}

Roof framing, which consisted of rolled steel wide flange beams supporting a structural concrete slab, was found to be in good condition. Hairline cracks in the fireproofing and in the underside of the concrete slab were found at various locations.

No priority recommendations for repair were made in the report. The report recommended repairs that were none structural in nature.

\subsubsection{Facility Condition Survey of WTC 1}

The scope of the survey was based on experience gained from the survey of WTC 2 in 1990. As in the case of the WTC 2 survey, the scope of work was designed to minimize impact on tenant and facility operations. The exterior wall system, core columns, floor framing, damping system, space frame (hat truss), mechanical equipment rooms, and roof were inspected.

\section{Exterior Walls (Columns and Spandrels)}

A total of 28 exterior column splices were inspected throughout 14 office floors on floors 9 through 106. Nondestructive testing was performed on the plate splice welds, and ultrasonic testing was performed to verify plate thickness at 26 of these locations. All inspected columns splices were found to be in good condition.

The inside faces of the steel box column plates exhibited scattered areas of light to moderate corrosion and peeling paint. Ultrasonic thickness testing on the outer column plates above and below the splice location indicated no cross-section loss.

Spandrel plates, splice plates, and bolted connections were also found to be in good condition. Scattered rust stains were observed on the spandrel fireproofing.

On the floors above 106 , only the joints at floor 108 were inspected. No structurally significant deterioration was found.

No priority recommendations for repair were made in the report. The report noted that missing fireproofing should be replaced on the spandrel plates and splices.

\section{Core Columns}

Core columns were inspected in 13 elevator shafts with fireproofing left in place. Corner core column splices were inspected on two office area floors. Core floor beam to column connections were also inspected at 25 of 56 locations on 14 floors.

The exterior wall column splices were found to be in good condition. Results from nondestructive testing of the splice plate welds were acceptable, and results from ultrasonic thickness testing showed no significant loss in member thickness. 
Several small areas and a few large areas of fireproofing were missing from some of the steel beams and columns in the express elevator shafts. According to the report, the probable cause of missing fireproofing on the columns was due to the high speed of the elevators moving up and down the shafts. All exposed steel was found to be in good condition with light to medium surface rust.

Gypsum wallboards were found to be in good condition, except for two isolated holes in two elevator shafts at the 58 th and 69 th floors.

Similar to the case of the express elevator shafts, fireproofing was found to be missing on some of the steel columns and beams, and some isolated holes were found in some of the gypsum wallboards in the local elevator shafts.

Inspection of core corner column splices and floor beam to column connections showed all of the elements to be in good condition.

No priority recommendations were made in the report. The report recommended that missing fireproofing from the framing members in the elevator shafts be replaced, including those regions where the fireproofing was removed for inspection during the condition survey. It also recommended that the holes in the gypsum wallboards be repaired.

\section{Floor Framing}

Fourteen office floors $(11,13,22,30,35,52,54,61,65,78,84,86,90$, and 93) were selected for inspection. Inspection of the structural elements at these levels followed the following sequence:

1. Six long-span trusses and two short-span trusses were selected from the plans for even, random distribution of inspection locations throughout the floor area.

2. Floor framing, damping unit, utility supports, steel decking, inside faces of steel spandrel plates, spandrel splices, and core concrete or rolled steel members were visually inspected. Structural steel members were examincd for signs of deformation or corrosion with fireproofing still in place.

3. Fireproofing was removed to inspect the condition of steel framing members at the following locations: (a) six truss locations, (b) one core floor beam, (c) two spandrel plate splices, and (d) two exterior columns (plaster removal). Visual inspections wcre made using lights, scrapers, wire brushes, and mirrors for signs of cracking, deformation, or corrosion.

4. Nondestructive testing was performed on column splice welds and welded floor framing connections. Testing was performed by the Port Authority's Materials and Research Division.

On 2 of the 14 floors inspected, column splices on 7 core columns were inspected after removal of the gypsum board firewalls. Top sides of exposed concrete floor slabs were also inspected where carpeting or floor tiles had previously been removed.

Two typical conditions were observed during inspection of the floor trusses: (1) small areas of fireproofing were missing at scattered locations throughout the floor framing, and (2) the underside of the floor trusses exhibited light rust. Welds were tested at various connections and were found to be in good 
condition. In some cases, the connection of the truss to the exterior spandrel plate had one bolt and a weld instead of the typical two-bolt connection. These field welds were also tested and were found to be in good condition.

The metal deck and concrete slabs that were inspected were also found to be in good condition, except for the slab in the southeast corner of the 60th floor where cracks were found on the top surface.

The report made no priority recommendations for repair for any of the floor framing members. Routine recommendations were made as follow's: (1) patch elastomeric sealer at the construction joint south of columns 504 and 505 under the 13th floor, (2) even though the modifications made to the bridging trusses at the 10 th and 61 st floors did not meet the original design, no further modifications were needed, (3) patch spalls that were created in concrete slabs when partition rails were removed, and (4) patch cracks on the 60 th floor with elastomeric sealer

\section{Damping System}

At all of the locations that were inspected, the damping units did not have fireproofing covering them. Light rust was observed on the surfaces of the units. A non-structural bolt was missing on one of the damping units under the 30 th floor.

\section{Space Frames (Hat Trusses)}

A total of 199 members were inspected in the space frame (hat truss). Light rust was found on diagonal braces, beams, and connections where fireproofing was missing. No priority recommendations were made in the report. Routine recommendations were made to replace missing fireproofing.

\section{Mechanical Equipment Rooms and Space Frame}

All four mechanical equipment room floor levels (floors 7-8, 41-42, 75-76, and 108-109) were inspected. Floor slabs at these levels were found to be in good condition with scattered cracks found on the slab surfaces. Scattered patches of fireproofing were found missing from the underside of the metal decks outside the core area.

A concrete encased beam on the 110 th floor was subjected to steam from a leaking steam valve. Moderate rusting was found on the member, but no significant section loss was found.

Hangers supporting ducts and piping were visually inspected, and some were found to be subject to excessive vibration. Loose hanger rods and fatigue of pipe supports were also found at various locations. Beams that supported the duct hangers had fireproofing missing where the hangers were mounted.

The report included a priority recommendation to replace the leaking valve under the 110 th floor that caused the floor beam to corrode. Routine recommendations were made to repair cracks in the concrete slabs and to repair hangers that were found to be vibrating, bowed, sagged, and/or deformed. 


\section{Roof}

No significant structural deficiencies were found at the roof level. Cracking and spalling of the concrete slab was found in localized areas of the roof.

No priority recommendations were made in the report. Routine recommendations included removing and replacing existing patches in the roof slab and patching spalled areas in the concrete slabs.

\subsubsection{Facility Condition Survey of WTC 7}

The scope of work was designed to minimize impact on tenant and facility operations and was limited to unoccupied floors and floors that had vacant space. The column splices, wind bracing system, interior beam connections, floor slabs, and the Consolidated Edison (Con Edison) Substation were all inspected.

According to the report, no problems or deterioration were found on the column splices, wind bracing, or the interior beam connections at any of the locations that were inspected. Rust buildup was found between the flanges of members that rested on top of one another at the main roof level where the steel framing was exposed. The report recommended that the steel be cleaned and painted to prevent further deterioration, even though this was not considered to be a structural problem.

Fireproofing was found to be missing from the steel framing at various locations where utility supports were installed on all of the floors that were inspected. It was most prominent on the fifth floor framing above the main lobby and the second floor framing above the loading dock area. It was recommended in the report that the fireproofing be replaced.

Loose concrete was found on the north face of column 51 on the 46th floor of the cooling tower area. Silverstein Properties personnel immediately removed the loose concrete.

Floor slabs were found to be in good condition. No deficiencies were found, except for some shrinkage cracks on the top of some of the exposed slabs and some damage to the metal deck.

The Con Edison station was found to be in very good condition, and no action was required at that time.

\subsubsection{Due Diligence Condition Survey of WTC 1 and WTC 2}

This section discusses the findings of the condition survey of WTC 1 and WTC 2, which was performed by Merritt \& Harris, Inc. in 2000 for PANYNJ (Merritt \& Harris 2000). On-site evaluations were performed to assess the general physical condition of the property, as it existed at that time. In particular, WTC 1, WTC 2, WTC 4, WTC 5, the retail mall and plaza, central services, and the subgrade were . inspected. The following discussion focuses on the findings for WTC 1 and WTC 2.

\section{Inspection Procedures and Methodology}

Observations were limited to those portions of the project that were visible during walk-through. In many areas, building finishes concealed structural components from view. 


\section{Findings of Inspection}

Merritt \& Harris reported the following findings and recommendations for both WTC 1 and WTC 2.

According to the report, the building structure appeared to be in good overall condition, based on observations of portions of the structure that were not concealed by building finishes. No apparent movement or settlement of foundations was observed, and interior slabs were reported to be in good condition.

The report noted that LERA and other engineering firms had performed, on a regular basis, SII of various structural systems and that those studies had indicated the following deficiencies: (1) rusting of steel columns in the elevator shafts, (2) missing fireproofing, and (3) floor coring damage. ${ }^{41}$ The due diligence condition survey report went on to note that the most recent SII recommended repairs were underway at the time the report was written.

Damping units had been tested every 5 years, most recently in 1996. The report noted that approximately two-dozen damping units were kept in stock for replacement. The report also stated that LERA strongly recommended that the analysis of wind acceleration measurements be continued.

The report noted that an ongoing program of re-fireproofing structural steel members was in place at the time of the inspection. Re-fireproofing the structural steel was supposed to provide a $2 \mathrm{~h}$ fire rating for those members. Such work was performed on an entire floor when the space was being built-out for new occupancy. At the time of inspection by Merritt \& Harris, Inc., approximately 30 floors had been completed in the two towers.

\subsubsection{Structural Integrity Inspection Program}

In 1986, PANYNJ implemented an inspection program to detect, record, and correct any signs of distress, deterioration, or deformation that could signal structural problems. This structural integrity inspection program, which was based on an inspection and testing plan prepared by LERA, contained detailed guidelines on inspection, record-keeping, and follow-up procedures.

Inspection findings under this program were to be categorized as "Immediate," "Priority," or "Routine." Repairs falling into the "immediate" category included possible closure of the area and/or structure affected until interim remedial action (such as shoring or removal of a potentially unsafe element or structure) could be implemented. Such action was to be undertaken immediately after discovery, and a description of the action taken and recommendations for permanent repair were to be included in the inspection report. The "priority" category was for those conditions where no immediate action was required, or for which immediate action had been completed, but for which further investigation, design, and implementation of interim or long-term repairs should be undertaken on a priority basis (i.e., taking precedence over all other scheduled work). Repairs falling into the "routine" or "non-priority" category could be undertaken as part of a scheduled major work program or other scheduled project, or when routine facility maintenance was to be performed, depending on the type of repair that was required. An important requirement in the inspection program was that where inspection procedures involved the removal of fireproofing, such fireproofing was to be properly replaced on completion of inspection.

${ }^{41}$ Detailed findings of the Structural Integrity Inspections are given in NIST NCSTAR 1-1C. 
A summary of the findings from the SII can be found in NIST NCSTAR 1-1C.

LERA's proposed plan to monitor the structural integrity of the World Trade Center Complex included WTC 1, WTC 2, WTC 4, WTC 5, WTC 6, the Vista Hotel, and the subgrade. ${ }^{42}$ The plan called for inspection/monitoring of the following items in WTC 1 and WTC 2:

- TV mast (WTC 1 only)

- Roof water tightness and curtain wall

- Space usage

- Accessible columns, including exterior box columns at locations of spandrel intersections and “tree' junctions below floor 7 and above floor 1 (Plaza Level)

- Bracing at exterior column line below elevation $294 \mathrm{ft} 0$ in., and in WTC 2 only, the transfer trusses below floor 1 under exterior columns

- Hat truss between floor 107 and the roof

- Floor framing for mechanical spaces

- Floor framing for tenant areas

- Concrete slabs, partitions, and finishes

- Steel framing, slabs, and the like where exposed for general repairs or tenant remodeling

- Measurement of natural frequency of tower and TV mast

- Floor natural frequency

- Damping units

- Plaster ceilings in main lobby

- Marble wall panel supports

- Review of maintenance reports

- Fire stairs

Inspection and monitoring of these items were to occur at regular intervals. A summary of the structural integrity inspections conducted and their corresponding dates is given in Table 8-1.

\footnotetext{
42 Letter dated January 12, 1990, from Saw-Teen See of Leslie E. Robertson Associates to Suren Batra of the Port Authority of New York and New Jersey (WTCI-123-P).
} 
Table 8-1. Summary of Structural Integrity Inspections Completed for WTC 1 and WTC 2.

\begin{tabular}{|l|l|}
\hline \multicolumn{1}{|c|}{ Inspection Program } & \multicolumn{1}{|c|}{ Date(s) of Inspection Reports } \\
\hline Space Usage Survey & $1995,1996,1997,1998,1999$ \\
\hline Accessible Columns & $1993,1995,1996,1997,1998$ \\
\hline Plaza Level Box Columns & 1998 \\
\hline Bracing Below Elevation 294 ft 0 in. & 1991,1995 \\
\hline Hat Trusses & 1992,1995 \\
\hline Floor Framing Over Mechanical Areas & $1992,1996,1999$ \\
\hline Floor Framing Over Tenant Areas & $1992,1995,1997,1999$ \\
\hline Natural Frequency Measurements & $1993,1995,2000$ \\
\hline Natural Frequencies of Floors & 1995 \\
\hline Viscoelastic Damping Units & 1996 \\
\hline
\end{tabular}

\section{Space Usage Surveys}

The purpose of the space usage surveys was to identify possible structural overloading of the slabs and floor framing due to changes in occupancies and uses and/or due to additions of heavy equipment or furniture. Surveys were conducted annually over a 5-year period starting in 1995, with two surveys conducted in 1996. The only priority recommendation was made in the 1995 report, which advised PANYNJ to distribute the load of the granite slabs on floor 106 of WTC 1 over a larger area.

\section{Accessible Columns}

Surveys of the accessible columns (columns in the core area that are not enclosed by an architectural finish, which can be visually inspected) in the elevator shafts of WTC 1 and WTC 2 were performed to:

- Ascertain the condition of the accessible columns with respect to rusting, cracking, bowing, and deviation from plumb;

- Identify specific locations of structural distress or damage;

- Identify locations of damage to the fireproofing;

- Identify lateral displacement or rotation of the column about a vertical axis where the column is directly braced on only one axis by connecting beams or concrete slabs; and

- Identify deformations of the slabs-on-ground surrounding each column at the sublevel.

Accessible column surveys were performed approximately every two years, starting in 1993 and ending in 1998. Priority recommendations were made in the 1996 report and also in the 1998 report. The later report recommended that missing fireproofing be repaired as part of a scheduled work program on columns at various locations in WTC 1 and WTC 2. 


\section{Plaza Level Box Columns}

The purpose of the inspection of the Plaza Level box columns was to assess their overall structural integrity, including the condition of the fireproofing. The proposed inspection interval was four years. One such inspection was conducted in April of 1998. The east face of WTC 1 and the north face of WTC 2 were visually inspected between the Concourse Level ceiling and the underside of the Plaza Level slab. The columns between the Concourse floor level and ceiling level were inaccessible due to their enclosures.

The report recommended no immediate and priority repairs. However, it noted that fireproofing was missing from approximately 2 percent to 3 percent of the Plaza Level box columns and seated beam connections in WTC 1 and about 1 percent to 2 percent in WTC 2. The report recommended that PANYNJ to clean all exposed steel on Plaza Level columns 236, 242, and 248 in WTC 1 and repair damaged fireproofing on columns and seated beam connections in both towers.

\section{Bracing Below Elevation $294 \mathrm{ft} 0$ in.}

Below Elevation $294 \mathrm{ft} 0$ in. (Sublevel 1) in both WTC 1 and WTC 2, diagonal bracing was used in place of deep spandrels between the exterior columns to resist lateral loads from the tower above.

The purpose of the inspection of the bracing system below elevation $294 \mathrm{ft} 0 \mathrm{in}$. in the perimeter walls of the towers was to:

- Assess the overall performance and structural integrity of the bracing (and, in 1991 only, the transfer trusses below elevation $310 \mathrm{ft} 0 \mathrm{in.} \mathrm{in} \mathrm{WTC} \mathrm{2);}$

- Identify specific locations of structural distress or damage;

- Identify locations of damage to the structural fireproofing systems; and

- Provide recommendations for remedial work for both structural and fireproofing damage.

Bracing surveys were performed in 1991 and 1995. No immediate and priority recommendations were made in these reports. Routine recommendations were made to repair damaged fireproofing at several locations. These included PANYNJ to clean, repair, and reinstall fireproofing on structural members at Level B6 in the Mechanical Equipment Rooms of both towers. PANYNJ to repair all sprayed fireresistive material on the braces in WTC 1 and 2 and the transfer truss in WTC 2 between columns 242 and 248 .

\section{Hat Trusses}

The purpose of the inspection of the hat trusses between floor 107 and the roof was to:

- Assess the overall performance and structural integrity of the hat trusses;

- Identify specific locations of structural distress or damage; 
- Identify locations of damage to the structural fireproofing systems; and

- Provide recommendations for remedial work for both structural and fireproofing damage.

Hat truss surveys were performed in 1992 and 1995. Although no immediate and priority recommendations were made in the SII reports, routine recommendations were made to repair fireproofing and gypsum wallboard at various locations in WTC 1 and WTC 2. No follow-up actions were stated in the report. Fireproofing that was removed during the Facility Condition Survey inspections performed by the PANYNJ in 1990 and 1991 for WTC1 and WTC 2, respectively, was found not to be repaired.

\section{Floor Framing for Mechanical Areas}

The inspection program for the floor framing supporting the mechanical equipment rooms (MER) consisted of the following:

- Assess the overall performance and structural integrity of the steel and concrete framing

- Identify locations of defects and signs of distress in slabs, partitions, column enclosures, and concrete supports for mechanical equipment;

- Identify locations of damaged fireproofing;

- Compare the findings with those of previous inspections; and

- Provide recommendations and procedures for remedial work for both structural and fireproofing damages and/or inadequacies.

Surveys were conducted in 1992, 1996, and 1999. No immediate repair recommendation was reported in the 1992, 1996 and 1999 reports. Priority recommendations were made in the 1996 and 1999 reports. The 1996 priority recommendation called for reapplication of fireproofing at various locations in WTC 1 and WTC 2. The 1999 priority recommendation called for repair of a water leak in an overhead pipe on floor 75 of WTC 1. The report included routine recommendations for repair of cracked and spalled concrete slabs in the 1996 and 1999 reports.

The reports indicated that damaged concrete masonry unit (CMU) walls in Level B6 of WTC 1 and WTC 2 still existed in 1996. These damages were found initially during the structural integrity inspection of the diagonal bracing in 1991 and again in 1995. Similarly, damaged fireproofing on the perimeter diagonal bracing members at this level in WTC 1 and WTC 2, which was initially found in 1991 and 1995, still existed in 1999.

\section{Floor Framing for Tenant Areas}

The inspection program for the floor framing supporting the tenant areas consisted of the following:

- Assess the overall performance and integrity of the steel and concrete framing; 
- Identify locations and signs of distress in slabs, partitions, column enclosures, and steel framing;

- Identify locations of inadequate fireproofing; and

- Provide recommendations and procedures for remedial work for both structural and fireproofing damage and/or inadequacies.

Surveys for floor framing supporting tenant areas were conducted in 1992, 1995, 1997, and 1999. No immediate recommendation was made in the 1992, 1995, 1997 and 1999 reports. Priority recommendations were made in the 1999 report concerning restoration of fireproofing on a truss on floor 89 in WTC 2, repair of spalled concrete on floor 89 of WTC 2 and floors 33 and 91 in WTC 1, and repair of damaged reinforcement on floor 91 of WTC 1. In the 1992, 1995 and 1997 reports, PANYNJ was directed to replace or repair damaged fireproofing on steel members.

\section{Natural Frequency Measurements}

The purpose of this inspection program was to determine the natural frequencies of oscillation of WTC 1 due to wind excitation. Only WTC 1 was instrumented with accelerometers at six locations on floor 108, which measured the accelerations in both principal directions of the building with respect to time due to wind. These natural frequencies were to be compared with corresponding values that had been determined in the past. A significant change in the tower's dynamic behavior was considered to be a possible indication of diminishing structural integrity. According to the reports, characteristics that may have been observed or inferred by revicw of the recorded acceleration data were:

- Integrity of the lateral-load-resisting system;

- Condition of the viscoelastic damping system;

- Condition of other sources of inherent structural damping; and

- Other changes that affect fundamental characteristics of the lateral-load-resisting system.

Reports were prepared by LERA in 1993, 1995, and 2000. ${ }^{43}$ The 1993 and 1995 reports compared the available measured first mode natural frequencies of WTC 1 to those determined by the structural engineer in 1966, which were $0.084 \mathrm{~Hz}$ in the north-south direction and 0.096 in the east-west direction (WSHJ 1966). A summary of the measured first mode natural frequencies from the 1995 report, which contained the most current data, is shown in Table 8-2. No recordings were reported for the period between 1981 and 1991.

${ }^{43}$ These reports were prepared by Leslie E. Robertson Associates [WTCI 4073/66-L, 4056/66-L, 4094/66-L]. 
Table 8-2. Measured first mode natural frequencies for WTC 1.

\begin{tabular}{|c|c|c|c|}
\hline \multirow{2}{*}{ Date } & \multirow{2}{*}{$\begin{array}{c}\text { Wind Speed (mph) and } \\
\text { Direction }\end{array}$} & \multicolumn{2}{|c|}{ Measured Frequency $(\mathbf{H z})$} \\
\cline { 3 - 4 } & $11.5, \mathrm{E} / \mathrm{SE}$ & 0.098 & 0.105 \\
\hline $10 / 11 / 78$ & $33.0 . \mathrm{E} / \mathrm{SE}$ & 0.089 & 0.093 \\
\hline $01 / 24 / 79$ & $41.0 . \mathrm{E} / \mathrm{SE}$ & 0.085 & 0.092 \\
\hline $03 / 21 / 80$ & $49.0^{2}$ & 0.087 & 0.092 \\
\hline $12 / 11 / 92$ & $20.0 . \mathrm{NW}$ & 0.085 & 0.095 \\
\hline $02 / 02 / 93$ & $32.0, \mathrm{NW}$ & 0.085 & 0.094 \\
\hline $03 / 13 / 93$ & $14.0, \mathrm{~W}$ & 0.094 & 0.094 \\
\hline $03 / 10 / 94$ & $37.0, \mathrm{~W}$ & 0.081 & 0.091 \\
\hline $12 / 25 / 94$ & & & \\
\hline
\end{tabular}

a. No direction was given in the report.

Both the 1993 and 1995 reports concluded that the measured and computed first mode frequencies compared well, especially for the greater wind speeds. The 1995 report also concluded that the February 1993 bombing had no permanent measurable effect on the dynamic response of WTC 1 . Both reports recommended that WTC 2 be instrumented similarly to WTC 1.

The 2000 SlI report pointed out that PANYNJ had not been able to analyze the data acquired from the instrumentation of WTC 1 since 1998 because the PANYNJ laboratory that contained playback and analytical equipment necessary to assess the recorded data was dismantled in the fall of 1998. The report recommended that the capability to assess and analyze the accelerometer data be re-established as soon as possible. The report further recommended that WTC 1 be additionally instrumented at a mid-level floor, and that WTC 2 be instrumented at its top floor and at a mid-level floor.

\section{Natural Frequencies of Floors}

The purpose of this inspection program was to determine the natural frequencies of the floor systems in WTC 1 and WTC 2 and to compare them with corresponding values that had been determined in the past. A significant change in the vibration characteristics of the floor system was considered to be a possible indication of diminishing structural integrity.

For purposes of determining the natural frequencies of the floor construction, a typical tower floor was divided into three zones, which corresponded to the type of floor truss that was used in that zone: shortspan zone, long-span zone, and two-way zone.

Vibration characteristics of the floor systems were studied both analytically and experimentally. In 1971, Teledyne Geotronics of Long Beach, CA made field measurements of vertical vibration on floors 13, 27, and 32 of WTC 1 using seismometers. The field measurements were obtained under the direction of Skilling, Helle, Christiansen, Robertson (SHCR). SHCR also made analytical estimates of the natural frequencies of the floor systems at that time (SHCR 1971). They determined that the natural frequencies of the long-span and short-span trusses, considering viscoelastic damping, were $4.6 \mathrm{~Hz}$ and $7.9 \mathrm{~Hz}$, respectively. A summary of the natural frequency test results for WTC 1 is contained in Table 8-3. 


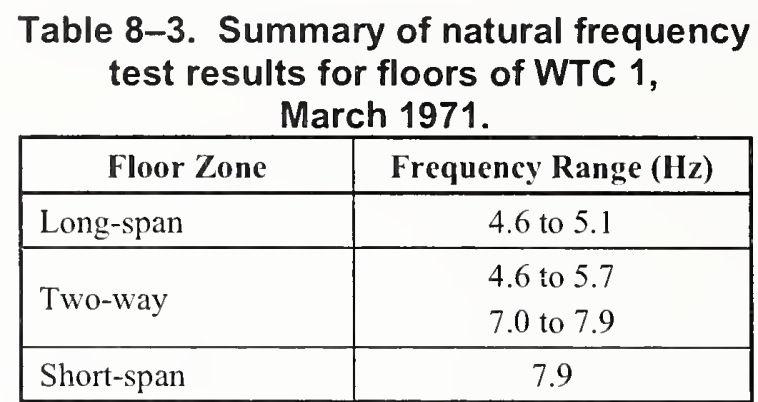

In March of 1995, Cerami and Associates, of New York, NY, made field measurements on floors 17, 22, 26, 38, and 88 of WTC 1 and floors 23, 24, an 58 of WTC 2 using the following equipment: piezo-electric accelerometer, vibration meter, peak band pass filter, and strip chart recorder (Cerami 1996). The floors were subjected to a standard heel-drop test or by jumping in place. All field work was performed under the direction of LERA. A summary of the test results for WTC 1 and WTC 2 are given in Table 8-4.

The SII report produced by LERA in April of 1995 summarized the analytical and experimental results to date (LERA 1995). Based on the available data, the report concluded that there had been no significant measurable change in the performance of the typical floor systems in WTC 1 and WTC 2.

\section{Table 8-4. Summary of natural frequency test results for floors of WTC 1 and WTC 2, March 1995.}

\begin{tabular}{|c|c|}
\hline Floor Zone & Frequency Range $(\mathrm{Hz})$ \\
\hline \multicolumn{2}{|c|}{ WTC 1} \\
\hline Long-span & 4.5 to 5.3 \\
\hline Two-way & $\begin{array}{l}4.6 \text { to } 4.9 \\
6.6 \text { to } 7.6\end{array}$ \\
\hline Short-span & 7.8 to 8.8 \\
\hline \multicolumn{2}{|c|}{ WTC 2} \\
\hline Long-span & 4.8 to 5.6 \\
\hline Two-way & $\begin{array}{l}4.9 \text { to } 5.4 \\
7.5 \text { to } 7.8\end{array}$ \\
\hline Short-span & 7.9 to 8.0 \\
\hline
\end{tabular}

\section{Viscoelastic Damping Units}

A summary of the integrity of the viscoelastic damping units in WTC 1 and WTC 2 was given in a report by LERA in 1996 (LERA 1996). Also given in the report is a historical review related to the performance of the damping units.

The report concluded that based on the then available studies, the integrity of the damping units was good, and that no action was required at that time beyond the routine testing of the damping units. 


\section{Inspections Related to Explosion of February 16, 1993}

Six different inspections were performed before and after repairs were made to WTC 1 in the aftermath of the terrorist attack in February 1993. Summaries of these inspections were reported in a series of inspection reports prepared for the PANYNJ. ${ }^{44}$ No anomalies were detected in the welds used to repair structural members.

\subsubsection{Summary of Structural Integrity Inspection Programs}

In general. the structural integrity inspections found that the structural systems of WTC 1, 2, and 7 were in good condition. The inspection consultants made numerous routine and some priority recommendations for repairs to the PANYNJ. According to the PANYNJ, all of the construction records on repairs following the inspections were lost on September 11, 2001. Thus, it cannot be determined whether all of the recommended repairs were performed. However, in 1999, the PANYNJ issued guidelines requiring that fireproofing be upgraded for steel floor trusses when full floors were undergoing alterations.

\subsubsection{Modifications and Repairs to Structural Framing Systems of WTC 1, 2, and 7}

Most of the modifications to the structural systems of WTC 1,2, and 7 were done to accommodate tenant requirements (see NIST NCSTAR 1-1C). These generally involved cutting holes in existing floor slabs to construct new stairways linking two or more floors or reconstructing the floor system over previously cut openings. In other cases floor or column members were reinforced to accommodate new floor loadings imposed by tenant requirements.

Modifications to the structural systems were to follow the Tenant Construction Review Manuals of PANYNJ, which are summarized in Sec. 8.2.

\section{Modifications and Repairs Made to WTC 1}

\section{Openings Made in Floor Slabs}

Slab openings were made in the floor slabs on the following floors during the following years:

1. Floors 93 to 95,1978 (openings were made in floors 94 and 95 between columns 901,902 , 1001 , and 1002 in core)

2. Floors 99 to 101,1979 (openings were made in floors 100 and 101 between columns 707 , 708,806 , and 807 in core, and in floor 99 between columns 701, 702, 801, and 802)

3. Floors 89 and 90, 1985 (opening was made in floor 90 between columns 901, 902, 1001, and 1002)

4. Floor 107, 1995 (opening was made in floor 107; location could not be determined)

\footnotetext{
${ }^{44}$ These reports can be found in WTCI-67-L.
} 
5. Floors 105 to roof, 1997 (opening was made in floor 105 near columns 704 and $804 \mathrm{~A}$ in the core)

6. Floors 93 to 100, 1999 (openings were made on all floors; location could not be determined)

Most openings were made to accommodate new stairs and elevators.

\section{Closing of Previously Opened Floor Slabs}

Openings that had been cut primarily for stairways were subsequently closed on the following floors during the following years:

1. Floor 95, 1972 and 1985 (new beams and floor deck were added near lines 124 and 239)

2. Floors 91 and 92, 1987 (new beams and floor deck were added between columns 901, 902, 1001 , and 1002 in the core)

3. Floors 96 and 100, 1998 (new beams and floor deck were added between columns 119 and 123 on floor 96 outside of the core and near columns 707, 708, 806, and 807 on floor 100)

\section{Structural Members that were Reinforced}

Various floor members were reinforced to accommodate floor loads that were greater than the original design loads. Members were reinforced on the following floors during the following years:

1. Floors 97 to 100,1979 (cover plates were added on existing beams on floor 98 between columns 601 and 602 and between columns 701 and 702; on floor 98, diagonals were added to existing floor trusses on the east side of the core between columns 218 and 221; on floor 99 , floor trusses along lines $309,311,313,315,317,319,321,323,325,327$, and 329 were reinforced; and, on floor 99, core perimeter columns were reinforced)

2. Floor 86, 1996 (floor trusses were reinforced in the northwest corner of the building)

3. Floor 85, 1998 (cover plates were added to existing bcams and existing floor trusses were rcinforced)

4. Floors 47 and 48, 2001 (floor trusses were reinforced)

\section{Repair Work Following the February 26, 1993, Explosion}

\section{Damage from the Explosion}

The explosion of February 26, 1993, occurred on Level B2 near the center of the south wall of WTC 1 and adjacent to WTC 3 (Vista Hotel). Structural steel columns, diagonal braces, and spandrel beams in the vicinity of the blast were damaged. Concrete floor slabs at Levels B1 and B2 and unreinforced masonry walls were also damaged over a large area. A detailed description of damage of structural members and subsequent repairs is given in NIST NCSTAR 1-1C. 
Briefly, the explosion tore out the diagonal brace between column 324 at Lcvel B2 and column 327 at Level B1 and severely bent the diagonal brace between column 324 at Level B2 and column 321 at Level B1. Spandrel beams at Level B1 from column 321 to 324 and from column 324 to 327 were also damaged by the blast. Spandrels were bowed and cracked and some had missing bolts.

The explosion caused a crack along the field splice in column 324. Ultrasonic testing determined that the crack extended across the full width of the weld on the south face of the column and at each end of the weld on the north face. A magnetic-particle testing procedure determined that the crack extended across the east face of the column and the majority of the weld on the west face as well.

The explosion also damaged floor beams framing into the tower side of column 324 at Levels B1 and B2. Concrete spandrel beams at Level B3 between columns 318 and 330 also sustained damage. Masonry walls in WTC 1 were breached over distances of approximately $50 \mathrm{ft}$ to the east and $120 \mathrm{ft}$ to the west of the blast origin.

\section{Repair Work}

The diagonal bracing members between Levels B1 and B2 that were damaged by the explosion were removed and replaced with new members.

New plates were added to the damaged spandrel beam at Level B1 between columns 324 and 327 and between columns 321 and 324. Also, the cracked weld on the south face of the spandrel beam at Level B1 near column 324 was removed and replaced.

An eight-step procedure was prescribed for repair of the crack in column 324 immediately adjacent to the field weld at the column splice above Level B2. No documentation was found to confirm that this crack was repaired according to that procedure.

Repairs were made to the floor beams framing into columns 321,324 , and 327 . Repairs were also made to connections between floor beams and columns on Levels B3 and B4. Along the south face of WTC 1, the damaged concrete spandrel beams were demolishcd and replaced.

\section{Modifications and Repairs Made to WTC 2}

\section{Openings Made in Floor Slabs}

Slab openings were made in the floor slabs on the following floors during the following years:

1. Floor 77, 1979 (openings were made at nine locations in the northeast quadrant of the building)

2. Floor 96,1987 (opening was made near columns 901 and 902 in the southeast quadrant of the building)

3. Floors 94 and 95, 1993 (opening was made betwcen columns 507, 508, 607 and 608)

4. Floors 99 to 101, 1997 (openings were made; locations could not be determined) 
5. Floor 99, 1998 (opening as made between columns 601, 602, 701, and 702 in the core on Floor 99)

6. Floors 25 and 26, 1999 (opening was made near column 901 in the core)

7. Floors 88 and 89,1999 (openings were made; locations could not be determined)

Most openings were made to accommodate new stairs.

\section{Closings of Previously Opened Floor Slabs}

Openings that had been cut were subsequently closed on the following floors during the following years:

1. Floors 37 and 38, 1997 (new framing and floor deck was added near column 608)

2. Floors 95 and 96, 2000 (new beams and floor deck were added between columns 901, 902, 1001 , and 1002)

\section{Structural Members that were Reinforced}

Members were reinforced on the following floors during the following years:

1. Floor 96, 1993 (a number of floor trusses and their connections were reinforced in the northeast quadrant of the building)

2. Floor 81, 1991 (two-way floor trusses were reinforced in area occupied by United Parcel Service)

\section{Other Modifications}

In 1994, the slab in the elevator lobby on floor 90 (bounded by columns 702, 703, 902, and 903) was repaired for Fiduciary Trust; NIST has not found evidence of the reason for this modification. The existing slab was demolished and was replaced with a 5 in. thick lightweight aggregate concrete slab.

\section{Modifications and Repairs Made to WTC 7}

\section{Modifications Made due to New Loading Requirements}

Members were reinforced primarily to accommodate floor loads that were greater than the loads for which these members were originally designed. Members were reinforced on the following floors during the following years:

1. Floor 38, 1988 (cover plates were added to existing beams along lines 30, 35, 37 and 40)

2. Floor 24, 1989 (cover plates were added to existing beam on line 45 and to two adjacent beams) 
3. Floor 47, 1989 (cover plates were added to existing beams on line 2-5 and to the existing girder on line 56)

4. Floors 11 and 12, 1990 (cover plates were added to eight existing beams and girders in the northwest corner of the building on floor 11, and to three existing beams between lines 48 and 49 and to the girder between columns 70 and 73 on floor 12)

5. Floor 19, 1991 (cover plates were added to existing beams; location could not be determined)

6. Floor 12, 1992 (cover plates were added to 11 existing beams in the northwest corner of the building, and a new beam was added between existing beams)

7. Floors 18 and 19, 1992 (cover plates were added to existing beams on lines 31, 32, and 33)

8. Floor 28, 1993 (additional shear studs were added to existing beams located in the mechanical/electrical room)

9. Floors 7 and 8, 1993 (a new beam was added between lines 7 and 8)

10. Floors 7-29, 1994 (cover plates were added to 22 existing beams between lines 5 and 25 on the south side of the building and on each floor between levels 7 and 29, and to eight existing beams on the east side of the building between lines 31 and 37)

11. Floor 20, 1995 (cover plates were added to existing beams along lines 23 and 25, and WT sections and cover plates were added to existing beams east of line 19)

12. Floor 37, 1999 (a new beam was added between two existing beams along lines 76 and 77)

13. Floor 13, 1999 (additional shear studs were added to an existing beam; location could not be determined)

14. Floor 40, 1999 (four new beams were added near column 76 and WT sections were welded to the bottom of two existing beams)

15. Floor 31, 2000 (cover plates were added to an existing beam between columns 77 and 80 )

16. Floor 38, 2000 (cover plates were added to existing beams between columns 76 and 77 and between columns 77 and 78, and to existing girders between columns 76 and 79, 77 and 80 , and 78 and 81 )

17. Floor 39, 2000 (new beams were added between columns 76 and 77)

\section{Openings Made in Floor Slabs}

The floor slabs on floors 41 and 43 were completely removed on the east side of the building to accommodate the trading floors for Salomon Brothers Inc. Columns 76, 78, 79, 80, and 81 were reinforced with plates that ran from the top of the 39 th floor to the underside of the 49 th floor due to the removal of the floor slab at the 39th floor. Similarly, column 74 was reinforced with plates that ran from 
the top of the 43rd floor to the underside of the 44th floor due to the removal of the floor slab at the 43rd floor.

Other slab openings were made in the floor slabs on the following floors during the following years:

1. Floors 3 and 4, 1989 (openings were made on the 3rd floor on the west, north, and east sides of the building; on the 4th floor, openings were made on the north side of the building)

2. Floor 3, 1989 (openings were made near columns 24 and 25)

3. Floor 11, 1990 (opening was made between columns 77, 78, 80, and 81)

4. Floor 43, 1994 (opening was made near column 71 in the core area)

\section{Modifications Made to Beam Webs and Flanges}

Modifications were made to beam webs and flanges on the following floors during the following years:

1. Floor 28, 1993 (openings were cut in the web of an existing beam; location could not be determined)

2. Floors 4 to 7, 16, 21, 29, 38, and 45, 1993 (notches were cut in the bottom flanges of various beams and plates were welded to the upper side of the bottom flanges)

3. Floor 1, 1998 (notch was cut into the top flange of an existing beam, and two plates were welded under the top flange; location could not be determined)

4. Floors 36 to 44, 1999 (openings were cut in the web of an existing beam framing into column 75 on all floor levels; the beams was reinforced with web plates and a WT section welded to its bottom flange)

5. Floors 42 and 44, 1999 (openings were cut in the webs of numerous beams along the north and east sides of the building)

\section{Other Modifications}

A list of structural modifications that were made to WTC 7 prior to April of 1997 is given in Chapter IV, Sec. A(5) of the Facility Condition Survey Report for WTC 7 (PANYNJ 1997). The following is a summary of the modifications that are noted in that report:

1. In the Convention Area on the 3rd floor between column numbers 45 and $48 \mathrm{~A}$, steel plates were installed around the perimeter of the room between the slab and the floor surface (behind the wall coverings and above the suspended ceiling). According to the PANYNJ report, these plates were installed to protect attendees of the Convention Center from the magnetic field generated from the Con Ed Substation beneath the conference rooms. No documentation was located that provides any additional details on this modification. 
2. On the north side of the 5 th floor generator room, masonry block walls were added to partition the eight transformer vaults installed for Salomon Brothers. The vaults were between columns 46 and 53 . No documentation was located that provides any additional details on this modification.

3. A penthouse was constructed on the 47th floor roof to house the chiller plant and the cooling towers for Salomon Brothers. The chiller plant was an enclosed steel-framed structure with corrugated steel walls. It was approximately $25 \mathrm{ft}$ in height and took up about one-third of the square footage of the 47 th floor roof. The cooling towers were supported on a steel frame and were enclosed by louvered walls on the north and south sides and by the chiller plant and the bulkhouse on the east and west sides, respectively. No documentation was located that provides any additional details on this modification.

The list of modifications in the PANYNJ report also included the removal of the floor slabs on floors 41 and 43 to accommodate the trading floors for Salomon Brothers, as noted above. 
This page intentionally left blank. 


\section{Chapter 9 \\ Comparison of Fire SAFETy Codes AND PRActices}

\subsection{COMPARISON OF FIRE PROVISIONS IN BUILDING CODES}

\subsubsection{Introduction}

The 1968 New York City (NYC) Building Code (NYCBC 1968) was compared with four other building codes to determine the extent to which the codes and mandatory referenced standards were utilized in the design and construction of the towers. The other codes are: the 1964 New York State Building Construction Code (NYSBC 1964); the 1965 Building Officials and Code Administrators/Basic Building Code (BOCA/BBC 1965); the 1967 Municipal Code of Chicago Relating to Buildings (MCC 1967); and the 2001 edition of the NYC Building Code (NYCBC 2001). In addition, comparisons of fire safety requirements were made to the 1966 edition of the National Fire Protection Association (NFPA 101), Code for Safety to Life in Buildings and Structures. While not a building code, National Fire Protection Association (NFPA) 101 is widely adopted for its requirements on life safety in fires.

The codes selected for comparison are nationally or regionally recognized model regulations that are the basis for laws and reflect the standards of practice of the time. The 1964 New York State Building Construction Code was the governing building code outside the New York City limits. The 1965 BOCA Basic Building Code was typically adopted by local jurisdictions in the northeastern region of the United States. The 1968 NYC Building Code is compared with the 1967 Municipal Code of Chicago (MCC) to see whether there are any substantial differences in the fire safety requirements of the two codes. In the late 1960s and early 1970s, several tall buildings were built in Chicago including the Sears Tower (110 stories) and the John Hancock Tower (100 stories), both of which were classified as business use and incorporated innovative design features. In addition, the 2001 edition of the NYC Building Code was compared with the 1968 version to examine the extent to which Local Laws modified the code provisions, and in most cases, is only addressed in areas where changes occurred between the two versions.

A provision by provision comparison was made between the 1968 NYC Building Code and these codes. The code provisions that were compared are limited to the requirements related to structural stability, active and passive fire safety, and emergency egress and are presented in the reports NIST NCSTAR 1-E and $1-\mathrm{F}$.

The NYC Building Code was regularly modified by local laws, two of which, Local Law 5 (1973) and Local Law 16 (1984), had a significant influence on the fire and life safety features of WTC 1 and WTC 2, even though the buildings were completed and occupied at the time of adoption. Normal practice is not to apply building code changes to existing buildings unless they undergo major renovation or change in primary use, although Local Laws 5 (1973) and 16 (1984) did contain some retroactive provisions. The Port Authority of New York and New Jersey (PANYNJ or Port Authority) chose to follow the revised provisions and to retrofit the buildings as required under the new provisions. The resulting changes to WTC 1 and WTC 2 are discussed primarily in the sections on modifications to the building systems and in reports NIST NCSTAR 1-G and 1-H. Local Laws 5 (1973) and 16 (1984) were in place at the time WTC 7 was designed and constructed, and the requirements of these local laws were 
reflected in that building. There were no significant revisions to the NYC Building Code that affected the fire and life safety features of WTC 7.

\subsubsection{Interrelation of Codes, Standards, and Practices}

Model codes that include minimum requirements for public health, safety, and welfare are developed in an open process by private sector organizations. The resulting model codes are traditionally organized into volumes according to the regulatory official responsible for their enforcement. These include a building code, fire code, plumbing code, mechanical code, and so forth. These model codes contain mandatory references to standards and reflect generally accepted standards of practice of the time.

These model codes and referenced standards do not become law until they are adopted legislatively or administratively by a jurisdiction empowered to enforce regulations. These jurisdictions may modify specific provisions of the model codes and referenced standards to suit local conditions and traditional practice. This adoption process is governed by general rules applicable to the adoption of laws that cover public notice and consultation, public debate, and access to the final regulation, often described by the term due-diligence. Once legally adopted, the totality of the modified model codes and standards are refered to as building regulations.

The provisions contained in building codes generally specify what is required under specific conditions. The building codes contain references to standards that provide further details on how the provisions are to be implemented to meet the intent of the code. New York City makes use of nationally recognized technical standards but adopts them with modifications to meet local needs and accepted practices. These modified standards are known as Reference Standards (RS) and are available from the city. Reference standards take on the force of law when they are included in the building regulation as mandatory references and enforced by the regulatory official. For the WTC towers, the Port Authority utilized the New York City reference standards and the source standards from NFPA and others in design guidelines, manuals, and procurement contracts associated with system upgrades.

In some cases, trade associations and professional societies develop practices that may guide how building design and construction work is done. While not strictly enforceable unless referenced in the code, such practices represent a consensus of what is reasonable or prudent. A few, relevant practices are discussed in this section.

\subsubsection{Comparison of New York City and Contemporary Building Codes}

While New York City developed its own building code, its code development committees were influenced by the same forces that bore on the model codes. Thus, there were relatively few differences between the NYC Building Code and the others. 


\section{Construction Classification}

The model building codes classify building constructions into different "Types." Although there are some variations in categories, they are reasonably consistent. ${ }^{45}$ The main categories are Type I (fire resistive), Type II (non-combustible), Type III (ordinary), Type IV (heavy timber), and Type V (combustible).

Types I and II are constructed with non-combustible exterior and interior bearing walls and columns. Fire resistance ratings (see Fire Ratings) are greatest for Type I, and Type II is any (non-combustible) construction not meeting Type I requirements. For Type III, exterior bearing walls are non-combustible and interior bearing walls and some columns may employ approved combustible materials. Type IV is known as heavy timber; which utilizes large, solid cross section wooden members such as in post and beam construction. Type $\mathrm{V}$ is all other types of construction, including traditional wood frame construction. Common non-combustible structural elements are made of steel or reinforced concrete. Combustible structural elements are usually made of solid- or engineered-wood and laminates.

Combustibility of the materials in a structural element is determined in an ASTM International (ASTM) E 136 test in which the material is placed in a furnace at $750^{\circ} \mathrm{C}\left(1,380{ }^{\circ} \mathrm{F}\right)$, which is a "typical" fire temperature. Some minor surface burning (e.g.. from paint or coatings) is allowed in the first $30 \mathrm{~s}$, but there cannot be any significant energy release as indicated by more than a $30^{\circ} \mathrm{C}\left(54^{\circ} \mathrm{F}\right)$ increase in the furnace temperature, and the test specimen cannot lose more than half its initial mass. Materials that pass are designated non-combustible, and the rest are combustible.

Within each construction type, there are several sub-categories determined by the fire resistance ratings of the columns, beams, and floor supports. In some codes, these sub-categories are identified by letters following the type (e.g., 1B or 3A) or by a set of three numbers that represent the fire resistance required (in hours) of exterior bearing walls; columns, beams, girders, trusses, or other components supporting loads from more than one floor; and floors or components supporting loads of a single floor, respectively (e.g., Type $1[3,3,2])$.

For unsprinklered office buildings, the following construction classes are permitted in the five building codes reviewed.

- Type 1A and 1B-NYCBC 1968, NYSBC 1964, BOCA/BBC 1965 (Unlimited height)

- $\quad$ Type 1A, 1B, 1C, 1D-NYCBC 2001 (Height limited to $75 \mathrm{ft}$ )

- Type 1A only-MCC 1967 (Unlimited height)

The 1938 NYC Building Code did not include Type 1B construction for office occupancies. The reasons for the inclusion of Type 1B construction for office occupancies in the 1968 NYC Building Code are not recorded (record keeping in the codes and standards development process was very poor prior to the Hydrolevel vs. ASME Supreme Court decision in 1982). The codes then and now tend to follow each other, as champions of changes to one code usually try to change all of the codes.

${ }^{45}$ Construction type definitions varied among the model codes until an effort in the 1970 s by the Board for the Coordination of the Model Codes to eliminate unnecessary differences. 
The 1950 edition of the Basic Building Code (BOCA), the regional model code used in the Northeastern United States, included a Type 1B construction class with unlimited height and area for business and low hazard storage occupancies without sprinklers. Among other model codes, the Standard Building Code (1946-47 edition, SBCCI) had a Type 2 construction similar to Type 1B for business occupancies and buildings more than $80 \mathrm{ft}$ in height; the National Building Code (1934 edition, NBFU) had a semifireproof construction similar to Type 1B for buildings above $75 \mathrm{ft}$; and the Uniform Building Code (1927 edition, ICBO) had a Type 2 construction similar to Type 1B for buildings above $75 \mathrm{ft}$. The $1968 \mathrm{NYC}$ Building Code is consistent with the 1950 BOCA in its inclusion of the Type 1B construction.

Mandatory sprinkler requirements for new high-rise buildings was first introduced in the NYC Building Code in 1984 (by Local Law 16), in BOCA in 1984, and in the Chicago Building Code (which allows a compartmentation alternative) in 1975. Before Local Law 16 was adopted, the 1968 NYC Building Code permitted Type 1A, 1B, 1C, and 1D construction for sprinklered office buildings of unlimited height. In the 2001 NYC Building Code, the minimum permitted construction classification for sprinklered office buildings of unlimited height is Type $1 \mathrm{C}$.

\section{Selection of Construction Type for WTC Towers}

The 1938 NYC Building Code recognized one construction type for buildings of unlimited height and area, namely Class 1 -Fireproof Structures, which required a $4 \mathrm{~h}$ fire rating for columns and a $3 \mathrm{~h}$ rating for floors. In the 1968 NYC Building Code, Group I (Noncombustible) construction was subdivided into "Class 1 A-4-hr protected" and "Class 1B-3-hr protected" construction. Class 1A specified similar protection as the previous Class 1 , and Class $1 \mathrm{~B}$ specified a $3 \mathrm{~h}$ rating for columns and girders supporting more than one floor and a $2 \mathrm{~h}$ rating for floors including beams. Both Class $1 \mathrm{~A}$ and Class $1 \mathrm{~B}$ construction permitted unlimited height and area for unsprinklered business occupancy.

Since building codes set minimum levels a building that qualifies for less than the highest construction class (1A) all or portions of that building can be constructed to a higher class, but where two or more classes are used in the same building, the building is classified by the lower class (see for example 7.2.1.2 in NFPA 5000). In such situations, the classification(s) selected for construction is at the discretion of the owner/architect.

\section{Fire Ratings}

The structural elements of a building are protected against failure in fire for a specified period, as determined in the ASTM E 119 test. The intent of the fire rating requirements is for the structure as a minimum to withstand design loads (including fire) without local structural collapse until occupants can escape and the fire service can complete search and rescue operations.

Fire resistance requirements in the building codes are greatest for structural members that are essential to the stability of the building as a whole. These include columns and other major gravity load carrying members that connect directly to columns such as girders and trusses. 
For various construction classes, the building codes specify different fire resistance ratings. The building codes reviewed all specify fire resistance ratings for high-rise office occupancies as follows:

- Type $1 \mathrm{~A}$

- Columns: $4 \mathrm{~h}$ (supporting more than one floor)

- Beams: 3 h (floor construction)

- Type 1B

- Columns: $3 \mathrm{~h}$ (supporting more than one floor)

- Beams: $2 \mathrm{~h}$ (floor construction).

- Type 1C (for sprinklered buildings only)

- Columns: $2 \mathrm{~h}$ (supporting more than one floor)

- Beams: 1 1 $\frac{1}{2} \mathrm{~h}$ (floor construction).

The choice among permitted construction classes for a particular building is made by the architect and/or the owner. Thus, an unsprinklered high-rise office building that was designed according to the 1968 version of the NYC Building Code could follow either Type 1A or 1B, and if designed subsequent to the passage of Local Law 16/1984, a high-rise office building would have to be sprinklered but it could follow Type $1 \mathrm{C}$ as a minimum classification. Similar reductions in the minimum required fire resistance ratings for sprinklered buildings are found in all model building codes over this period, as requirements for fire sprinklers, especially in high-rise buildings, have become common.

Type 1B, and eventually Type 1C, construction was permitted for high-rise office occupancies because this occupancy is considered low risk. Most other use groups in high-rise buildings were restricted to Type $1 \mathrm{~A}$, which is the construction type with the maximum structural fire protection defined in these codes.

\section{Practice Related to Fire Resistance Ratings}

Building codes specify fire resistance ratings for the structural members of buildings as a function of

- Building height,

- Construction type, and

- Use group (Occupancy),

with modifications for the presence of fire sprinklers. For example, the International Building Code (IBC 2003), Section 703.2 states, 
The fire-resistance ratings of building elements shall be determined in accordance with the test procedures set forth in ASTM E 119 or in Section 703.3. Where materials, systems or devices that have not been tested as part of a fire-resistance-rated assembly are incorporated into the assembly, sufficient data shall be made available to the building official to show that the required fire-resistance rating is not reduced.

This section appears to have been based on the 1981 BOCA (Sec. 1403.1.1) which required that, "The fire resistance ratings of building assemblies and structural elements shall be determined in accordance with the test procedures set forth in ASTM E 119..."

IBC Section 703.3 allows the fire resistance of a building element to be established by:

- Fire resistance designs documented in approved sources

- Prescriptive designs of fire-resistance-rated building elements prescribed in Section 720 ,

- Calculations in accordance with Section 721,

- Engineering analysis based on building elements with ratings established by ASTM E1 19, or

- Alternative protection methods permitted by IBC and approved by the building official.

These alternative methods were included in the other model building codes on which the IBC is based. For example, the 1997 Uniform Building Code contains tables of prescribed ratings for specific materials and assemblies which may be depended on as an alternate to ASTM E 119 testing. The 1994 Standard Building Code permits calculated fire resistance using specified methods or testing by ASTM E 119.

In the 1968 New York City (NYC) Building Code, Section C26-501.1 requires that,

Samples of all materials or assemblies required by this code to have a fire-resistance rating, ... shall be tested under the applicable test procedures specified herein .... The fire-resistance rating of materials and assemblies listed in reference standard RS 5-1 (which references ASTM E 119) may be used to determine conformance with the fire resistance requirements of this code.

In traditional practice, the architect (sometimes different from the design architect, called the code architect or architect of record) specifies the fire resistance ratings needed to comply with the building code. The required ratings are normally not shown on the architectural drawings (although the construction type may be); rather they are shown in the supporting material submitted to the building department for plans review.

Building codes require that an ASTM E 119 test be performed to determine the details of the assembly that would meet the requirement. In some cases the architect may choose to use an assembly that has already been tested and rated. Such assemblies are listed by testing laboratories in directories, databases accessed on test laboratory web sites, or in test reports available from manufacturers of materials used in the assemblies such as the producers of fireproofing products. These sources are very detailed and indicate the thickness of the specific product tested that is required to achieve a specific hourly rating. 
Enforcement officials are expected to verify that even the smallest details are followed or that the variations do not affect performance. Alternatively, some codes include descriptions of generic assemblies that can be assumed to achieve specified ratings, or provide calculation methods to determine the thickness of sprayed fire-resistive material needed to achieve a specific rating. These methods are often based on W/D (width to depth) ratios, which must be applied differently as a function of member geometry.

An additional variable that affects the needed thickness of fireproofing is whether the assembly is restrained. It is traditionally assumed that an assembly that is thermally restrained requires less fireproofing. Note that the NIST tests of the floor assemblies used in the towers showed the opposite. However, the definition of restrained is not trivial and needs to be specified by the structural engineer.

In some cases, it is not clear who actually determines the required thickness of fireproofing material. If the bid specifications for the fireproofing contract simply require the assemblies to be sprayed to achieve a specific hourly rating (which may be the case where a specific product is not identified to be used), then the thickness determination may be left to the fireproofing contractor.

Standards of practice for sprayed fire-resistive material are contained in the Underwriters Laboratories (UL) guide card (UL 2001) (although technically this only applies when a UL Listed assembly is used) and in manuals published by the Association of Wall and Ceiling Industries (AWCI 1997). There is also the American Institute of Architects Masterspec on Spray Applied Fireproofing (AIA 2000) that is similar to the Association of $\mathrm{W}$ all and Ceiling Industries (AWCI) manual. Additional guidance may be provided by the manufacturers of fireproofing materials that are specific to the characteristics of those products.

The UL guide information (BXUV) includes a number of limitations on the application of listed assemblies, including:

- Limits on the size (flange width and web depth, pipe outer diameter) without the use of a mechanical break such as metal lath or fastencrs,

- Use of bonding agents or conduct of a bond strength test in accordance with ASTM E 736 whenever the steel is painted (other than a paint specified in the listing)

- Conduct of thickness testing in accordancc with ASTM E 605.

The AWCI Technical Manual contains similar limitations and instructions, including the production of a test report on thickness and density, bond strength, correction of deficiencies, and patching procedures. Further, the AWCI manual describes a quality assurancc program and requires that the fireproofing contractor retain the services of the licensed engineer or architect qualified to make the dctermination of restrained and unrestrained members. The AWCI manual is not cited as a mandatory refcrence in any model code; rather it is voluntarily followed by contractors that are members of the association. The American Institute of Architects (AlA) Masterspec is similar to the AWCI manual, except that it is written to be incorporated into the fireproofing contract, which would make it enforceable against the contractor.

Some building codes require that sprayed fire-resistive material on steel structural members be subjected to inspection at the time of installation. Local Law 55 (1976) amended the 1968 NYC Building Code to 
require that all required, sprayed fire-resistive material on structural members, except those encased in concrete, be subjected to a controlled inspection, meaning that it must be conducted under the supervision of a building inspector or a licensed design professional who assumes responsibility for compliance. This provision applied to all installations after the date of enactment (November 1, 1976) and was not retroactive. The inspection was to include verification of the thickness of the material, its density, and its adhesion, each utilizing a specific ASTM test method. There are no code requirements nor general practice by which sprayed fire-resistive material is inspected over the life of the building. Most building codes contain a requirement that sprayed fire-resistive material that is installed in areas where it is subject to mechanical damage shall be protected and maintained in a serviceable condition. For a detailed discussion of the fireproofing system found in the towers, see NIST NCSTAR 1-6A.

\subsubsection{Occupancy Group}

All building codes define categories of occupancy (which may have more than one sub-class). The group designations vary in different codes. The ones presented here are those used in the 1968 NYC Building Code. These are:

- High Hazard (Group A)

- Storage (Groups B-1 and B-2)

- Mercantile (Group C)

- Industrial (Group D-1 and D-2)

- Business (Group E)

- General Assembly (Group F-1 through F-4)

- Educational (Group G)

- Institutional (Groups H-1 and H-2)

- Residential (Groups J-1 through J-3)

- Miscellaneous (Group K)

Building codes use occupancy as a surrogate for risk factors that determine the level of performance needed. For example, occupancy is determined by a combination of factors such as types and quantity of combustible contents, common ignition sources, and typical occupant characteristics. Business occupancies (which includes office buildings) are considered among the lowest risk because they typically contain grades of furniture that constitute relatively low combustible loads, few ignition sources, and a population that is predominately adult, and not sleeping. The most risky occupancies are High Hazard, in which are found highly flammable, toxic, or explosive materials, and Institutional (e.g., hospitals and prisons) in which occupants are likely to be incapable of unassisted egress.

In some codes, including the 1968 NYC Building Code, occupancy groups are subclassified with a "fire index" rating in hours. For example, "high hazard" occupancy is assigned a fire index of $4 \mathrm{~h}$, while 
"business" occupancy is assigned a fire index of $2 \mathrm{~h}$. These fire indexes are used to specify the performance of separations between spaces of different use in a mixed-use building. For example, spaces of different use with the same fire index are separated by a partition of lower rating than for uses with a different fire index. Many buildings are mixed use because they contain spaces used for different purposes as defined in the building codes.

\section{Business (Group E)}

The business use group includes all office buildings, but this can range from a construction office in a trailer temporarily located on a construction site to a high-rise office building like the World Trade Center. Business occupancies are characterized by an average occupant load, occupants who are generally physically fit and do not sleep in the space. Combustibles are average in quantity and include higher quality furniture and paper.

\section{Assembly (Group F)}

The assembly use group includes any place used for the gathering of more than 50 people for civic, social, or religious functions, recreation, food and drink, or awaiting transportation. Assembly use is characterized by the highest occupant loads, which may include families with small children and older adults. Combustibles are light in quantity and vary in character depending on specific use.

\subsubsection{Egress Systems}

The 1968 NYC Building Code contains requirements for the number and capacity of stairs and for the assumed occupant load that are similar to requirements in the other contemporaneous codes (see Appendix A). Codes of the time required that multiple stairs be located "as remote from each other as practicable." New York City permits scissor stairs, ${ }^{46}$ and the code requires the exit doors to be at least $15 \mathrm{ft}$ apart. Local Law 16 (1984) first imposed a remoteness requirement of $30 \mathrm{ft}$ or one-third the maximum travel distance of the floor (whichever is greater), which was not retroactive, so it did not apply to WTC 1 and WTC 2 but did apply to WTC 7.

The 1968 NYC Building Code also contains a requirement that, "...vertical exits should extend in a continuous enclosure to discharge directly to an exterior space or at a yard, court, exit passageway or street floor lobby ..." (C26-602.4). Similar requirements are found in the 1965 BOCA Basic Building Code and in 1966 NFPA 101, but not in the 1964 New York State Building Construction Code or the 1966 Municipal Code of Chicago. Current code language (2003 IBC, section 1003.6) defines continuous as: not " ... interrupted by any building element other than a means of egress component."

The requirement for exit stairs to discharge to a public way was the subject of ongoing discussion with respect to the A and C stairs in WTC 1 and WTC 2 terminating at the mezzanine level, which was not at street level but rather at the Plaza level. The Port Authority's position was that the Plaza was a street and the Concourse was an underground street, and that the arrangement met the intent of the Code. NIST found PANYNJ documents indicating that the NYC Department of Buildings agreed with this

\footnotetext{
${ }^{46}$ Scissor stairs refers to two separate interior stairways contained within the same enclosure and separated by a fire rated partition.
} 
interpretation (e.g., Solomon 1975), but did not find any documents from the NYC Department of Buildings confirming this. Thus, the issue continued to come up as a deviation with the Code as late as 1996 (see Section 11.4).

\subsection{SUMMARY OF DIFFERENCES BETWEEN CODES}

In Construction Classifications, NYC Building Code 1968, NYS Building Code 1964 and BOCA/BBC 1965 all recognized Class 1A or Class 1B (with the same fire resistance ratings for building elements) for most unsprinklered buildings of unlimited height while MCC 1967 recognized only Class 1A. New York City imposed a $75 \mathrm{ft}$ height limit on unsprinklered buildings with the adoption of LL 16 (1984).

At the time of construction, sprinklers were primarily for property protection and were rare even in highrise buildings (except for underground spaces). Fire alarm systems were mostly manually initiated, but there was a concern about smoke being recirculated through the heating, ventilating, and air conditioning (HVAC) systems, so smoke detectors controlled dampers at return shafts to prevent this. This is the arrangement of the fire alarms system originally installed in the towers. Voicc communication systems were a response to phased evacuation with the recognition that it was necessary to provide instructions to occupants who were relocated or held within the building at least until they were told to leave.

Requirements for voice systems first appeared in national standards in the mid-1980s (e.g., the 1985 edition of NFPA 72F), at the same time as New York City adopted LL 16-1984.

All building codes rely on referenced technical standards to provide the details of design, installation, operation, and maintenance of required systems. Most building codes reference national (consensus) standards as published, but New York City cites its own Reference Standards that are based on the national standards but are often highly modified. For example, fire alarm systems and fire sprinkler systems are addressed in RS 17, with Class E fire alarm systems (required in office occupancies) covered in RS 17-3A and general fire alarm system requirements in RS 17-5. The former is written entirely by a NYC code committee, and the latter is based on NFPA 72 (National Fire Alarm Code), but highly modified by the deletion of many sections and modification of many others. One major modification is the fact that RS 17 does not incorporate the NFPA 72 "Survivability" section for high-rise voice communication systems, which requires duplicate communication trunks so that loss on one trunk does not result in loss of communication with a floor. However the Port Authority explicitly applied these survivability requirements from NFPA 72 in the specification of the voice communication systems installed in the towers following the 1993 bombing, as evidenced by the specification of Style R communication trunks routed in duplicate in stairways $\mathrm{A}$ and $\mathrm{C}$, with interleaved speaker wiring.

Prior to 1988 all building codes determined egress capacity by the (22 in.) Units of Exit Width method, which New York City still uses. In 1988, other codes changed to a method involving an allowance'of width per person which provides credit for non-standard widths of corridors and doors, but for standard dimensioned components yields the same results. Another difference in egress design is that New York City applies the occupant load factor for business occupancies ( $100 \mathrm{ft}^{2}$ per person) to the net floor area while other codes use the gross floor area. The NYC Building Code allows doubling the allowable stair capacity with the provision of one horizontal exit or tripling of the stair capacity on floors with two or more horizontal exits, where all the other codes only allow doubling for one horizontal exit. For a discussion of how this impacted WTC 1, see Sec. 10.1.1, Egress Provisions from Windows on the World. 
There are a number of detail differences between NYC Building Code and the other building codes. The NYC Building Code has no requirements for fire extinguishers since they require occupant hose reels. The NYC Building Code in 1968 was the first code to include smoke developed ratings for finish materials in addition to flame spread. Now all of the codes have similar requirements. Most of these differences can be traced to the specific wording and citations by referring to the reports, NIST NCSTAR 1-E. 1-F, and 1-G. 
This page intentionally left blank. 


\section{Chapter 10 \\ INFLUENCE OF CODES AND STANDARDS ON THE DESIGN AND CONSTRUCTION OF WTC 1 AND WTC 2}

\subsection{EGRESS SYSTEM DESIGN}

One of the largest impacts to the design of World Trade Center (WTC) 1 and WTC 2 resulting from the decision to follow the 1968 New York City (NYC) Building Code rather than the 1938 Code was the impact on the emergency egress system. The other large impact was the use of the 1-B Construction Class introduced in the 1968 Code rather than the 1-A Class that would have been required under the 1938 Code, in Sec. 9.1.3, see "Selection of Construction Type." In 1963, the Port Authority of New York and New Jersey (PANYNJ or Port Authority) instructed the designers of the WTC to follow the then current 1938 NYC Building Code. During this time, the code was in the process of being revised, and in 1965, the Port Authority directed its designers to adopt the draft version of the new code for their final designs. Some of the advantages of the new draft code were noted to be the following (Levy 1965):

- Fire towers ${ }^{47}$ could be eliminated;

- Provisions for exit stairs were more "lenient;" and

- Criteria for partition weights were more "realistic."

It was not certain whether all the changes being proposed to the 1938 code would be incorporated into the final version of the new code. Thus in 1966, the Chief Engineer of the Port Authority suggested that the "architect/engineers prepare a listing of the elements of the design which do not conform to old code requirements, but are acceptable under the new. With this list in hand, we could initiate discussions, at top level in the Building Department, to see if we can secure agreement to go along with our design (Kyle 1966)."

A one-page document, ${ }^{48}$ dated " $2 / 15 / 67$ ", with the initials "CKP" listed the following items:

1. Fire tower corridors [sic] eliminated.

2. Number of stairs reduced from 6 to 3. (Old plans had 5 stairs at 3'-8" and 1 stair at 4 ' -8 " for a total population of 390 . New plans have 2 stairs at 3 '-8" and 1 stair at 4'-8" allowing a population of 390.)

3. The size of doors leading to the stairs are [sic] changed from 3'-8" to 3'-0"'.

\footnotetext{
${ }^{47}$ A "fire tower" is a stair tower enclosed within a $4 \mathrm{~h}$ fire rated shaft that is entered through a naturally ventilated vestibule. The 1938 Code stipulated that one of the required exits in most buildings over $75 \mathrm{ft}$ in height be a fire tower.

48 "Changes to Building to Conform to New York City Building Code," dated 2/15/67.
} 
4. All stairs exit through a lobby. Old plans had fire tower stair exiting through a fire enclosed corridor.

5. Shaft walls are changed from a 3-hour rating to a 2-hour rating.

6. Corridors are limited to a $100^{\prime}$ dead end and with a 2 -hour rating.

7. Additional [word(s) missing] changed from 20 pounds per square foot to 6 pounds per square foot (based on partition weight of 50 pounds to 100 pounds per linear foot).

Apparently, this list represcnts elements of the WTC design that would not have satisfied the 1938 code, but did satisfy the then-current draft version of the new code.

Thus, the provision of three egress stairs located within the core exactly provided the $6 \frac{1}{2}$ units of required capacity for the occupant load in the office spaces. By locating the stairs at the edges of the core it, could be argued that they wcre as far apart as practical, but on some floors the provision of transfer corridors to go around equipment and to recover tenant space from the termination of local elevator shafts brought the stairs quite close with far less than the one third the maximum travel distance of the floor requirement of the 1968 NYC Building Code. The proximity of the stairs on some floors also resulted in standpipe spacings that exceeded the maximum $140 \mathrm{ft}$ distance from any point on a floor in the $1968 \mathrm{NYC}$ Building Code, since the standpipes were located in the stairways.

\subsubsection{Egress Provisions from Windows on the World}

The 106th and 107th floors of WTC 1 contained the Windows on the World complex, consisting of the Windows on the World restaurant, the Greatest Bar on Earth, numerous banquet and function rooms, kitchens and support areas, and offices from which the operation was run. While the configuration of the space may have changed over the life of the building these functions were all present from the time the building was first occupied.

Restaurants, bars, and function rooms are classified in building codes as assembly use, which carries a significant increase in occupant load and consequent provisions for egress. The design occupant load for assembly space is $15 \mathrm{ft}^{2}$ per occupant as opposed to the $100 \mathrm{ft}^{2}$ per occupant for the office use on most of the floors. Thus, while the design number of occupants on an office floor was 390 , the design number of occupants for these floors was over 1,000 each (the exact number depends on the area of kitchens, dishwashing, and office space on the floor, all of which is at $100 \mathrm{ft}^{2}$ per occupant).

Locating assembly space high in a building poses particular challenges to egress design since the capacity of an egress component is not permitted to be decreased in the direction of travel. Thus where more or wider stairs are provided to meet capacity requirements these must be continued all the way down through the building with the associated impacts on space utilization.

Since Windows on the World first opened in April 1976 (Bhol 2005), it is unclear what conditions existed from that date to the time the agreed solution was implemented in 1995. The dates suggest that the need to provide for egress by the large occupant load of these floors was identified as a result of the Memorandum of Understandings between the Port Authority and the NYC Department of Buildings and FDNY executed in 1993 following the bombing. The Windows on the World facilities were closed 
following the bombing and reopened in 1996 after a complete refurbishment that included the egress system changes (Bhol 2005).

A letter dated January 27, 1995, from the PANYNJ to the Deputy Commissioner of the NYC Department of Buildings documents the confirmation of a meeting on December 6, 1994, at which they reached agreement on a plan to address egress requirements from the 106th and 107th floors (Fasullo 1995). The details of the agreed solution are summarized below. The Deputy Commissioner of the NYC Department of Buildings signed the letter to show concurrence with the agreed solution, as verification of meeting code requirements.

The basis for the agreed solution was to divide each floor into three areas of refuge in accordance with Section 27-372 of the (then current) NYC Building Code to provide additional capacity to the existing stairs in accordance with Section 27-367 of the (then current) NYC Building Code. Identical provisions were included in the version of the 1968 NYC Building Code in effect when the buildings were built as sections C26-604.5 and C26-603.3 respectively (the NYC Building Code was renumbered as the result of changes in New York State Laws, effective September 1, 1986).

The code provisions cited above allow for a doubling of allowed stair capacity when one area of refuge is provided on a floor and tripling the stair capacity for two or more areas of refuge on a floor. These areas of refuge must be separated by $2 \mathrm{~h}$ construction, be large enough for the expected occupant load at $3 \mathrm{ft}^{2}$ per occupant, each contain at least one stair, and have access to at least one elevator (above the 11th floor). Since three distinct areas of refuge were provided on each floor, the tripling of the capacity of the three stairs resulted in a maximum permitted occupant load of 1,170 people per floor.

Attached to (and referenced in) the letter were two plans entitled "106th Floor Egress Plan" and "107th Floor Egress Plan" that detailed the arrangement. The $2 \mathrm{~h}$ separation walls snaked across the floors and were not aligned on the two floors. Some areas that needed to remain open to free passage were protected with so-called Won-doors (accordion doors that are fire rated and are closed automatically on activation of the fire alarm system). Details of the egress system design calculations and corresponding NYC Building Code requirements are included on the plans to demonstrate that they met code requirements. Figures $10-1$ and 10-2 are the actual attachments to the letter which included both diagrams of the arrangement of the rated partitions and the calculation of occupant loads for the 106th and 107 th floors, respectively. Important details of the calculations have been enlarged by NIST.

By comparison to the (current) model building codes, the International Building Code and NFPA 5000 , permit a doubling (but not tripling except in IBC Type I-2 and I-3 institutional uses) of the stair capacity for the provision of a horizontal exit on a floor. The horizontal exit must consist of a $2 \mathrm{~h}$ fire rated separation, contain at least one stair on each side, and have sufficient space for the expected occupant load at $3 \mathrm{ft}^{2}$ per person. A horizontal exit must be continuous down through the building to grade (NFPA 11.2.4.3.1 and IBC 1021.2), unless the floor assemblies are at least $2 \mathrm{~h}$ with no unprotected openings. 


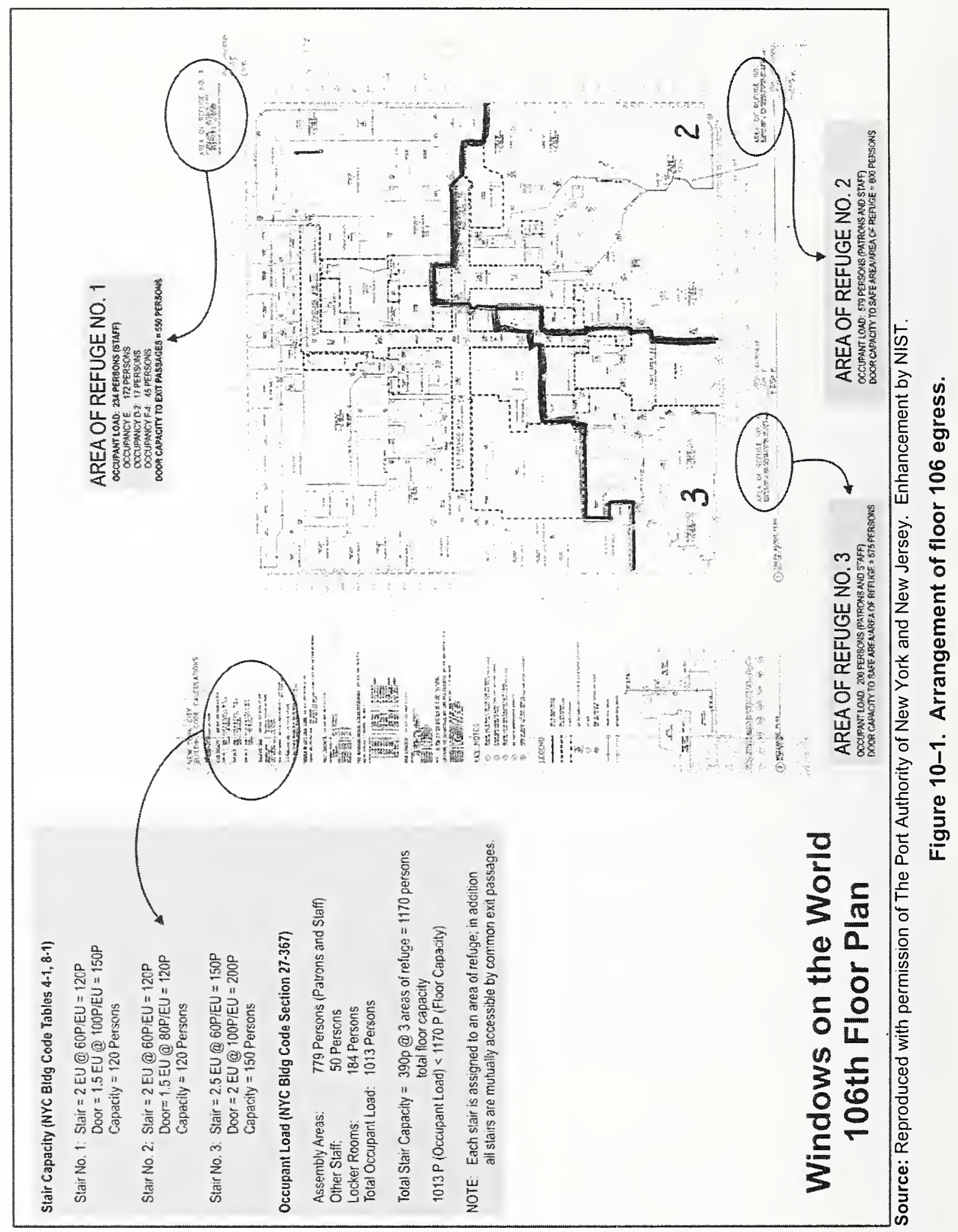




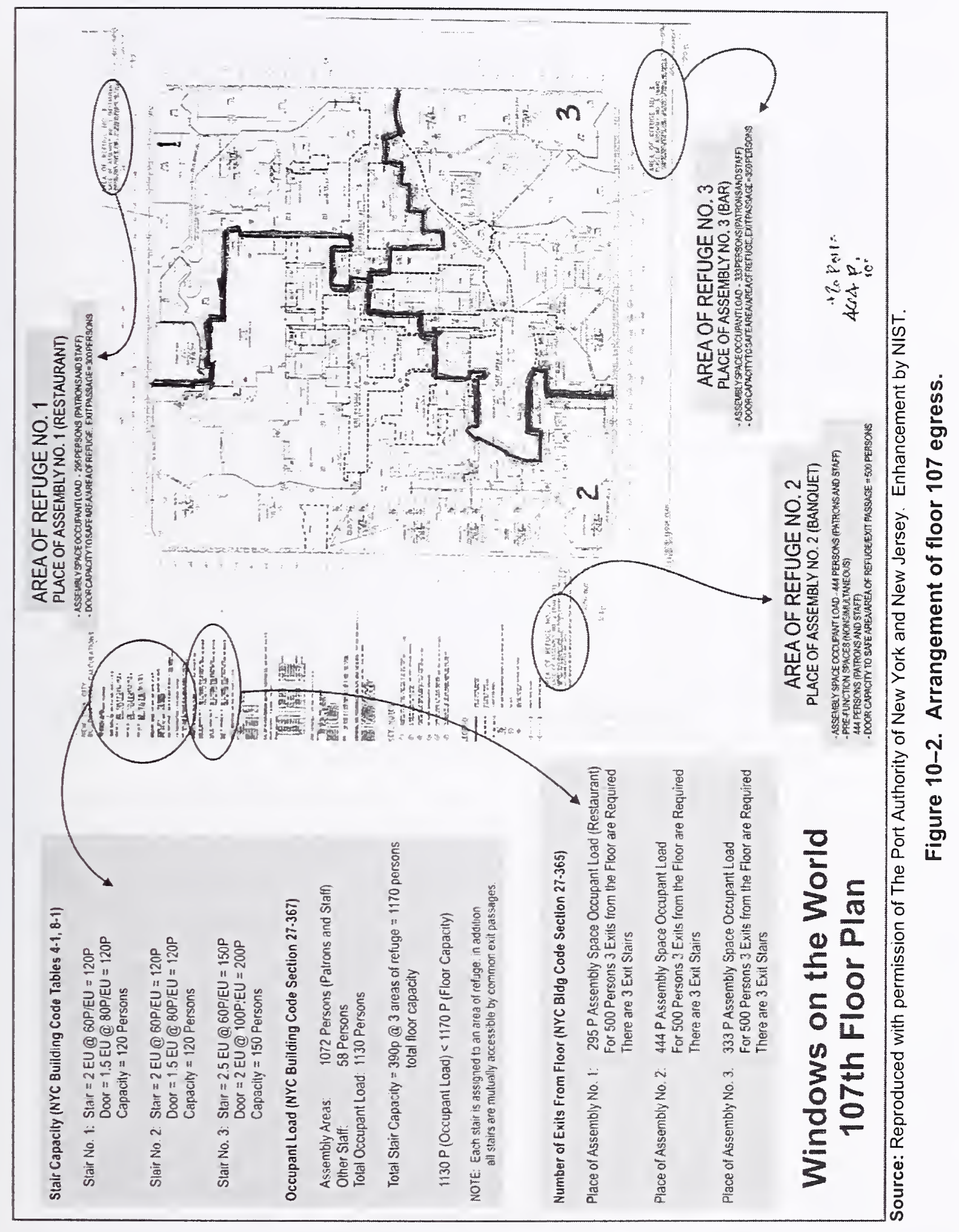


The concept of using horizontal exits to create areas of refuge was to provide a protected space in which occupants could wait to get into stairs that do not have adequate capacity for the numbers of people. In the world of post-September 11,2001, it is unclear whether people will be comfortable waiting in a large queue to enter an egress stair, and what the impact would be of such a large group of people moving down the stairs on the orderly evacuation of lower floors. The decedent analysis in NIST NCSTAR 1-7 estimates the number of people in Windows on the World at 188. The early hour of the attacks saw much fewer patrons (such as the early arrivals for a breakfast meeting) that would have been expected later in the day. The occupant load would have permitted more than 2,000 people on these two floors, from which there were no survivors.

\subsubsection{Egress Provisions from Top of the World}

Similar to the Windows on the World facilities on the 106th and 107th floors of WTC 1, there was a public observation deck on the 107th floor of WTC 2 called Top of the World. The observation deck was open to the public daily and was accessed by a dedicated, express elevator from the Concourse level after paying an entrance fee. The facilities included several shops, food vendor, a small theater showing a 6 min film of a helicopter tour of New York City, exhibits depicting life in the city, and a perimeter viewing area with telescopes and information on major landmarks visible along each face of the building. Visitors could also ascend two escalators to an open, roof-top deck which was raised to provide unobstructed views.

Observation decks are Assembly Use spaces (Group F in the NYC Building Code) like restaurants and meeting spaces. Thus, the occupant load/egress capacity issues identified for Windows on the World also existed for Top of the World. That is, the occupant load for the observation deck was calculated as the net floor area times a load factor of $10 \mathrm{ft}^{2}$ per person. This clearly far exceeded the 390 people total capacity for the three stairways. Since NIST did not find any documentation of the arrangement of the space prior to 1995 , it is unclear whether this deficiency existed from the original opening of the building until it was addressed in 1996.

NIST has correspondence between Andrew Renter (STV/Silver \& Ziskind, an Architectural/Engineering Design firm) and Victor Weisberg (Ogden Series Corporation, the tenant and operator of the facility) dated February 5, 1996, and referencing comments received from Port Authority on January 19, 1996. This letter and the drawings referenced in it (which are also in NIST's possession) detail a proposed space arrangement that parallels the solution applied to Windows on the World the year before. The letter and drawings are part of a Tenant Alteration submittal to Port Authority that was approved on January 5 , 1996. STV proposes dividing the floor into three areas of refuge, each containing an existing stairway, by $2 \mathrm{~h}$ fire rated partitions. The drawings show the existing space arrangement of the floor and calculates the occupant load for each using the load factors specified in the NYC Building Code. Their calculations reveal that the occupant load of the 107 th floor was 1,751 , which before the subdivision of the space into three areas of refuge, was $4 \frac{1}{2}$ times the maximum number of occupants permitted under the NYC Building Code.

After the proposed subdivision, the floor had an area of refuge of 5,610 $\mathrm{ft}^{2}$ net (incorporating Stairway A) with an occupant load of 935 people, a second area of 2,430 net $\mathrm{ft}^{2}$ (incorporating Stairway B) with an occupant load of 343 people, and a third area of 2,940 net $\mathrm{ft}^{2}$ (incorporating Stairway C) with an occupant load of 473 people. STV observed that the occupant load of the perimeter gallery alone is 1,267 people, 
which exceeds the stairway capacity of 1,170 after subdivision. Under Sec. 27-367 of NYC Building Code, the stair capacities are tripled with the provision of three areas of refuge, taking the capacities to 360 (Stairways A and C) and 450 (Stairway B) for a total of 1,170 people. Thus, even after the subdivision, only the area incorporating Stairway B had an occupant load less than the maximum capacity of the stair, and one area had an occupant load more than $2 \frac{1}{2}$ times the stair capacity.

These load calculations do not include the occupant load of the roof-top deck. Since these occupants were required to return to the 107 th floor to exit the facility, this load also needed to be accommodated by the stairways and the refuge space provided on that floor. This fact is simply not addressed. As to the fact that the proposed solution still does not provide sufficient egress capacity for the occupant load under the NYC Building Code, STV's position appears to be that this is an existing condition and the solution (in their opinion) meets the intent of the Code, even though the problem existed from the time the building first opened against the 1968 NYC Building Code. Taking advantage of a New York City building code provision which permits a lower basis for occupant load, the PANYNJ permitted a maximum occupant load of 1,170 on the floor, which was enforced by the lessee of the space with periodic oversight by the PANYNJ.

N1ST inquired of PANYNJ whether there was any means to limit the number of visitors to the observation deck. The following response was received: ${ }^{49}$

For controlling the number of occupants on the observation level in WTC 2, there were turnstiles on the mezzanine before the entrance to the elevators that were used to count the number of people going up, but since the patrons exited via a different route \& location, there was no way to count the number of people leaving - and thereby calculate the number actually on the deck. Since the turnstiles were not very effective, their use was discontinued later and the number of ticket sales was used for controlling the number of occupants. The length of the line waiting for the elevators to take people down were constantly observed by staff. If the crowds grew too large, ticket sales were halted until the crowd size was reduced.

Fewer than ten people who were present on the observation level perished on September 11 th. The number of people who were present and managed to evacuate is unknown.

\subsection{REQUIREMENTS FOR A FOURTH STAIRWAY}

The $107^{\text {th }}$ floor of WTC 1 contained, since it first opened in 1976, a public restaurant known as Windows on the World. At the time of the attacks this facility also included a conference center and associated catering operations on floor 106 and parts of 107 not occupied by the restaurant and the Greatest Bar in the World. Similarly, the $107^{\text {th }}$ floor of WTC 2 contained a public observation deck that opened with the building. The architectural design of these floors reflected the needs of the use as the window openings were much wider on these floors than the openings found on the office floors below. Prior to 1993, the $106^{\text {th }}$ and $107^{\text {th }}$ floors appear to have been operated with occupant access to three stairwells (two at 44 in. and one at $56 \mathrm{in}$.) and no fire-rated barriers meeting the building code requirements for areas of refuge.

\footnotetext{
${ }^{49}$ Email from Saroj Bhol, PANYNJ, to Shyam Sunder, NIST, dated March 15, 2005.
} 
However, NIST does not have records of the arrangement of these floors prior to the 1994 agreement that created the areas of refuge discussed below.

After the 1993 bombing, a review of the life safety of the towers by the New York City Department of Buildings and PANYNJ led to a redesign of the $106^{\text {th }}$ and $107^{\text {th }}$ floor egress design. Taking advantage of the capacity tripling allowance in NYCBC $\$ 27-367$, each floor was divided into three distinct areas, each separated from the others by two-hour fire rated walls, each containing one stairwell and at least one elevator, and each providing access to the other two areas with sufficient floor area to hold occupants from the other areas. Memos between the NYC DoB and PANYNJ in 1993 indicate that both parties found the arrangement met the intent of the building code requirements. In a 2005 interrogatory, PANYNJ indicated that the number of stairwells serving the $106^{\text {th }}$ and $107^{\text {th }}$ floors in WTC 1 was not discussed. Further, the due diligence study (1997) regarding life safety at WTC 1 and WTC 2 did not mention the exit capacity from Windows on the World nor Top of the World.

Drawings summarizing the egress calculations for WTC 1 floors 106 and 107 indicate a design occupant load of over 1,000 persons on each floor. The 1968 and current version of the NYCBC (and all national model codes) require four exits from areas with an occupant load of over 1,000 persons. In response to a NIST question regarding this issue, a 2005 communication from PANYNJ regarding the minimum number of required stairwells for these floors stated that:

"Based on PA's meeting on exits from the Windows on the World with the DOB on December 6,1994 , it's PA's understanding that ' $20 \%$ of the floor area' in section 27-367 is intended to be the total floor area in the building occupied by the principal use."

The 2005 PANYJ interpretation refers to an allowance for reducing the design capacity (by between $50 \%$ and $67 \%$ ) using the area of refuge arrangement referred to previously, if the public assembly space (in this case the entirety of floors 106 and 107) constituted less than $20 \%$ of the floor area occupied by the principal use. The key phrase in the interpretation of the building code language is related to the definition of principal use. The PANYNJ, according to the 2005 communication, defined the area of principal use as the entirety of WTC 1, thereby allowing the capacity reduction as the two floors in question would be less than $20 \%$ of the total floor area of the entire building.

In 2005, NIST asked for a clarification of $\$ 27-367$ from the NYC DoB regarding the definition of principal use and the applicability of the capacity reduction clause. The NYC DoB response contradicted the interpretation of PANYNJ:

"The idea behind the $20 \%$ allowance is the fact that the PA [NIST note PA refers to Public Assembly] space is used by the same tenant employees who are very familiar with the building and regularly participate in the fire drills. If we are talking about a roof top restaurant or an observation deck that is opened for the general public and tourists, the concept of exit reduction shall not be allowed."

In other words, the intent of the $20 \%$ clause is to exempt eating areas, conference rooms, or other assembly spaces which serve only occupants who would come from other places in the building. Thus, the space would not result in a net increase to the total building population. Restaurants open to the public and observation decks open to the public would not be eligible for exit reduction. 
Based upon current interpretation of Section 27 of the NYCBC, four exits would have been required for floors 106 and 107 in WTC 1 and 107 in WTC 2. Since all the codes (including BCNYC) require that the number of exits may not decrease in the direction of egress travel, all occupied above-grade floors in WTC 1 and WTC 2 should have been served by four stairwells.

\section{$10.3 \quad$ ELEVATORS}

Local Law (LL) 5 (1973) required that elevators be provided with an emergency recall system. This requirement was incorporated subsequently into the American Society of Mechanical Engineers (ASME) A17.1, Safety Code for Elevators and Escalators, that governs elevator design and operation in all building codes. The ASME Code requires that:

- All passenger elevators be marked with signs stating that they cannot be used during a fire;

- Fire detectors installed in every elevator lobby and machine room be arranged to initiate a recall of the elevators to the ground floor where the doors open and the elevator is taken out of service; and

- Fire service personnel can use a special key to operate any individual car in a manual mode as long as they feel it is safe to do so.

The elevator and building codes require that at least one elevator serving every floor be connected to emergency power. Currently, there are no U.S. building codes that permit elevators to be used as a means of occupant egress in emergencies, and ASME A17.1 (ASME 2000) requires signs at all elevators warning that they shall not be used in fires. There are some recent exceptions to this general rule, but these are limited to special cases. For example, NFPA 5000 permits protected elevators as a secondary means of egress for air traffic control towers, and the City of Las Vegas accepted elevators as a primary means of occupant egress from Stratosphere Tower based on a performance-based design (Bukowski 2003).

The United States' building codes (including New York City) require accessible elevators as part of a means of egress that may be used by the fire service to evacuate people with disabilities. These elevators must comply with the emergency operation requirements of ASME A17.1 (Phase II emergency operation by the fire service), be provided with emergency power, be accessible from an area of refuge or a horizontal exit (unless the building is fully sprinklered), and operate in a smoke protected hoistway. Phase II operation involves the use of an elevator by a firefighter for fire service access or for rescue of people with disabilities performed under manual control (with the use of a special key).

\subsection{ACTIVE FIRE PROTECTION SYSTEMS}

\subsubsection{Fire Alarm Systems}

At the time of design and construction of the WTC towers, most building codes did not require a fire alarm or required only a manual fire alarm system in buildings where occupants do not sleep. Also, concerns about smoke recirculation through heating, ventilating, and air conditioning (HVAC) systems resulted in codes being amended to require smoke detectors positioned at return air grilles to stop fans and prevent such recirculation. 
In the 1970s (shortly after the adoption of LL 5/73), discussions of phased evacuation of tall buildings led to the concept of high-rise emergency voice communications systems and fire command centers from which incident commanders would manage fire incidents. The NFPA Committee on Protective Signaling Systems developed a guide (later made a standard), NFPA 72F, for such systems that paralleled LL 5/73 requirements (see NIST NCSTAR 1-1G for a complete discussion of the requirements of LL 5/73).

\subsubsection{Fire Sprinklers}

Neither the 1968 NYC Building Code nor any of the other contemporaneous codes that were examined required sprinklers in tall buildings except for underground spaces. Thus, only the parking garage under WTC 1 and WTC 2 was originally sprinklered. Although Local Law 16, adopted in 1984, required sprinklers in new office occupancies, it was not retroactive. The incentive to retrofit for sprinklers (as explained below) was the passage of Local Law 5 in 1973, which was retroactive.

In the 1968 NYC Building Code, Class 1B construction for business occupancies had no limit on floor area. Local Law 5 required compartmentation of large floor areas in existing business occupancies over $100 \mathrm{ft}$ in height by the installation of fire rated partitions in accordance with the following:

- Compartmentation to $7,500 \mathrm{ft}^{2}$ with $1 \mathrm{~h}$ partitions; or

- Compartmentation to $10,000 \mathrm{ft}^{2}$ with $2 \mathrm{~h}$ partitions; or

- Compartmentation to $15,000 \mathrm{ft}^{2}$ with $2 \mathrm{~h}$ partitions and smoke detectors.

Compartmentation was not required, however, if "complete sprinkler protection" was provided. Compliance dates for these provisions were revised in 1979 by Local Law 84, so that one-third of the total area of buildings had to be in compliance by December 13, 1981, two-third of the total area had to comply by August 7, 1984, and full compliance was required by February 7, 1988.

Following the February 13, 1975, fire in the lower stories of WTC 1 (Powers 1975), an independent consultant was retained to review WTC life-safety provisions, including response to Local Law 5 . It is reported that the "consultant concluded that the existing structural fire retardants of the building are sufficient to make the probability of serious structural damage extremely remote and the degree of vertical compartmentation provided sufficiently limits the spread of fire in the structures but that the spread of smoke requires attention from a life safety standpoint (PONYA 1976)." The consultant reported that "...either of the two fire protcction options provided for under Local Law 5 would provide a good level of occupant life safety within the World Trade Center complex, provided that whichever is selected is supplemented by certain additional measures." The consultant provided a series of recommendations to supplement either the compartmentation option or the sprinklering option.

The Port Authority initially decided to adopt the compartmentation option in response to Local Law 5. The summary of the January 1976 report on the Fire Safety of the World Trade Center lists the following actions to be implemented to enhance the fire safety of the WTC towers (PONYA 1976):

1. The openings between floors of telephone closets, which was a source of fire spread during the February 13, 1975, fire should be 
closed. This work has been accomplished to prevent any reoccurrences of a similar condition.

2. In addition, the Port Authority will proceed with the compartmentation option of Local Law 5, including all of its requirements for fire alarm, communications, and stairway pressurization.

3. Sprinklering of all storage rooms, janitor closets, mail rooms and file rooms in the central core of each floor.

4. Building additional sprinkler capacity and provisions for extension of a sprinkler system to any area of such usage requiring it in the event of an occupancy change.

5. Equipping those doors which are normally kept open to the corridor system, such as doors at consumer service areas, with electromagnetic 'hold open' devices which would be activated by smoke detectors to close the doors.

6. Providing fail-safe automatic door closers, arranged to close upon activation by smoke detectors, for the overhead rolling fire doors separating the below-grade truck dock from the elevator lobby.

7. Developing an optimum mode of operation of the building airconditioning system to remove smoke from the central core compartments without contaminating adjacent areas.

Thus, while the Port Authority initially chose to implement the compartmentation option, it also chose to provide "for extension of sprinkler system to any area of such usage requiring it." According to the 1993 joint report written by the NYC Fire Commissioner and Commissioner of Buildings, in the 1980s the Port Authority began "a program to fully sprinkler the tower buildings (Rivera and Rinaldi 1993)." The report goes on to state that by March 1993 sprinklering was " nearly complete in tower 2 and 85 percent complete in tower 1." The report also included a table that summarized "the major system requirements of Local Laws 5/73 and 16/84 with conditions in place when the 1993 explosion occurred."

The tenant alteration guidelines issued in 1998, contained the following requirement and information (PANYNJ 1998):

All tenant spaces shall be sprinklered. Except for a few areas, most tenant floors in The World Trade Center are provided with wet-pipe sprinkler systems. New tenants normally require a new sprinkler system. For renovations of existing spaces, modifications to the existing system are normally needed to comply with any new partition configuration.

Because Local Law 16 required that business occupancies taller than $100 \mathrm{ft}$ be sprinklered, WTC 7 was sprinklered during the original construction.

Section 6 of Local Law 5 adopted by New York City in 1973, required the subdivision of unsprinklered space in new office occupancies and in existing offices over $100 \mathrm{ft}$ in height by fire rated partitions. 
Local Law 5 was challenged in the courts and was eventually upheld, although the original compliance dates were amended by Local Law 86 (1979) so that full compliance was required by February 7, 1988.

\subsubsection{Smoke Management}

New York City has historically had fewer requirements for active smoke control than many other codes and has required passive techniques such as venting of shafts and openable skylights in stairways in the local laws amending the NYC Building Code. For high-rise buildings there is a requirement for a smoke purge system to be used manually by the fire department to remove smoke after the fire is extinguished and for the ability to pressurize corridors with 100 percent fresh air (NYC Building Code Sec. 504.15(c)). Pressurized stairways are not required in sprinklered buildings. These features of WTC 1 and WTC 2 were confirmed in a March 1993 joint report from the fire and buildings departments on compliance with LL 5/73 and LL 16/84 (Rivera and Rinaldi 1993). For details of the smoke management systems see NIST NCSTAR 1-4D.

\subsection{DESIGN AND CONSTRUCTION OF FIRE SAFETY AND EGRESS SYSTEMS}

\subsubsection{Construction Classification}

No contemporaneous documentation has been found that provides the rationale for the decision to select Class 1B for the WTC towers. This decision, however, appears to have been made by the architect-ofrecord on the basis of economics. In a 1987 memorandum on the subject of fire rating of the WTC buildings, the following statement was included (Feld 1987):

For office buildings there is no [underline is in the original document] economic advantage in using Class 1A Construction, and ER\&S [Emery Roth \& Sons] used Class 1B Construction for the WTC Towers and Plaza Buildings which are Occupancy Group "E" (Business) with a fire index of 2 hours.

An interoffice memorandum between staff of the general contractor written in 1969 is the only contemporaneous document found to date that refers to the classification of the WTC towers (Bracco 1969). The following statement is included in that memorandum:

The WTC towers would be classified, by our interpretation of the code, as occupancy Group E, Business; Construction Group 1, Noncombustible; and Construction Classification 1-B (since there are no area or height limitations applicable).

\subsubsection{Occupancy Group}

As stated above, the primary occupancy group was Group E (Business) with the Windows on the World space in WTC 1 being Group F (Assembly). While there was a Port Authority cafeteria on the 44th floor, employee cafeterias not open to the public are specifically exempted from assembly classification because they do not increase occupant load and are only used intermittently. Incidental mercantile spaces such as 
news stands and coffee bars at the concourse level are also exempt from reclassification in most building codes.

\subsubsection{Compartmentation of WTC 1 and WTC 2}

Due to their innovative structural design, WTC 1 and WTC 2 featured large, open office spaces devoid of columns. Tenants could (and often did) utilize open plan office layouts that allowed impressive views of the Manhattan skyline from the perimeter windows.

The NYC Building Code and Port Authority practice required partitions to separate tenant spaces from each other and from common spaces, such as the corridors that served the elevators, stairs and other common spaces in the building core. Fire rated partitions are intended to limit fire spread on a floor and to prevent spread of fire in one tenant space to another. Partitions separating tenant space from exit access corridors were permitted to be $1 \mathrm{~h}$, although the PANYNJ specified them to be $2 \mathrm{~h}$, allowing dead ends to extend to $100 \mathrm{ft}$ (rather than $50 \mathrm{ft}$ with $1 \mathrm{~h}$ partitions), which allowed more flexibility in tenant layouts. Partitions separating tenant spaces (so-called demising walls) were required to be $1 \mathrm{~h}$ (see Sec. 9.2.5). Enclosures for vertical shafts, including stairways and transfer corridors, elevator hoistways, and mechanical or utility shafts were required to be of $2 \mathrm{~h}$ fire rated construction. Protection of vertical shafts was intended to limit the spread of fire and smoke from floor to floor.

Another influence on compartmentation of the buildings was the adoption of Local Law 5 (1973) amending the NYC Building Code. While it did not legally apply to the buildings, PANYNJ policy was to follow the NYC Building Code requirements voluntarily. Local Law 5 (1973) required compartmentation of unsprinklered spaces in existing office buildings over $100 \mathrm{ft}$ in height "having airconditioning and/or mechanical ventilation systems that serve more than the floor on which the equipment is located," to be subdivided by $1 \mathrm{~h}$ fire separations into spaces or compartments not to exceed 7,500 $\mathrm{ft}^{2}$. Floor areas could be increased up to $15,000 \mathrm{ft}^{2}$ if protected by $2 \mathrm{~h}$ fire resistive construction and smoke detectors. Regardless of the floor area, compartmentation is not required when complete sprinkler protection is provided (LL 5, Section 6)

Shortly after the adoption of LL 5 (1973), the PANYNJ began to add the required compartmentation as a part of new tenant layouts as evidenced by several tenant alteration contracts at this time. Following the 1975 fire, a fire safety consultant report recommended to the PANYNJ that the buildings be retrofit with sprinklers to address possible smoke problems, and the PANYNJ realized that this would also obviate the need for compartmentation and permit the unobstructed views for which the buildings were known. The decision to sprinkler left the arrangement again with the only required partitions being those separating tenant spaces from each other and from exit access corridors or common spaces in the core, and with shaft enclosures. 


\subsubsection{Construction of Partitions and Shaft Enclosures}

Vertical shafts surrounding stairs, mechanical shafts (carrying supply and return air), elevator hoistways, and utility shafts were all contained within the building core, and were enclosed by gypsum planking similar to fire separations commonly used today in single-family attached housing. While similar to other gypsum shaft wall systems and firewalls, this system was unique and innovative in that it eliminated the need for any framing. The gypsum planks were solid 2 in. thick $\left(2 \frac{1}{2}\right.$ in. on floors with $16 \mathrm{ft}$ ceiling heights) and $16 \mathrm{in}$. wide, with metal tongue or groove channels attached to the long sides that served as wall studs (see Fig. 10-3). Where

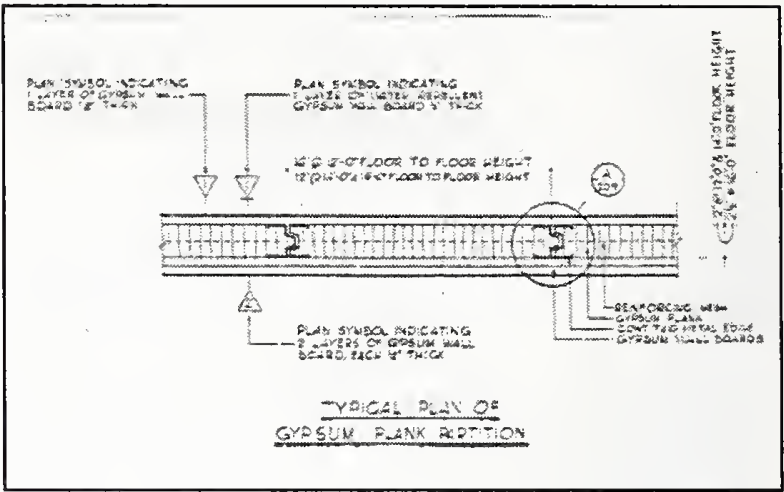

Source: WTC $1 \& 2$ drawing $A^{*} A^{*} 209$. Reproduced with permission of The Port Authority of New York and New Jersey.

Figure 10-3. Gypsum plank shaft partition. planks were cut to a narrower width, the cut edge was covered with a 2 in. by 2 in. metal $\mathrm{C}$ channel fastened with drywall screws at the top and bottom. Each plank had a mesh layer at its mid thickness and were likely custom fabricated for this job as NIST found no mention of similar products in gypsum industry literature of the time or since. Planks were provided in $12 \mathrm{ft}, 14 \mathrm{ft}$, and $16 \mathrm{ft}$ lengths to run full height. The planks were placed into metal $\mathrm{L}$ channels at the bottom and into metal top channels of various shapes depending on the construction element with which it needed to interface (see Fig. 10-4).

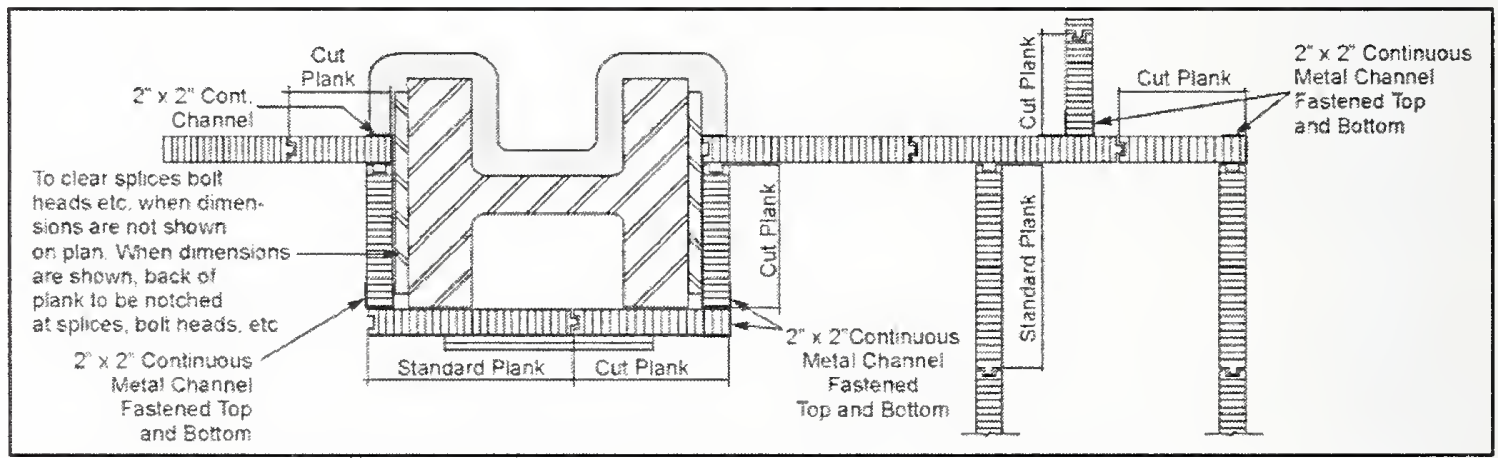

Source: WTC 1\&2 drawing $A^{*} A^{*} 209$. Reproduced with permission of The Port Authority of New York and New Jersey.

Figure 10-4. Gypsum plank installation. 
A large number of detail drawings were provided for attaching the planks to various ceiling constructions $(A * A * 209$ through $A * A * 212$, see Fig. 10-5). Finish layers were either one or two layers of $1 / 2$ in. gypsum board (moisture resistant was specified in some locations). Two layers on one side were specified in locations where the other side was a shaft or other unoccupied space, and two layers on one side with a single layer on the other was specified where both sides were in occupied spaces. The required number of layers was indicated on construction drawings (e.g., $A * A * 20, A^{*} A * 50$ ) by the numbers 1 or 2 in triangles (see Fig. 10-6).

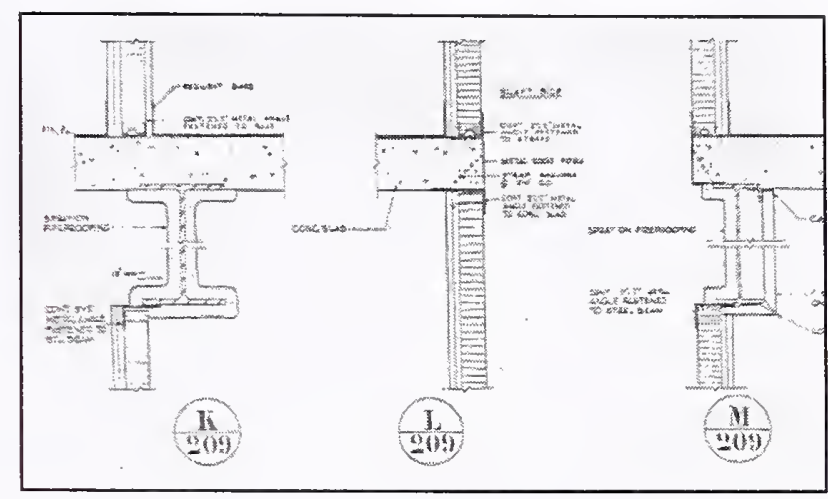

Source: WTC $1 \& 2$ drawing $A^{*} A^{*} 209$. Reproduced with permission from The Port Authority of New York and New Jersey.

Figure 10-5. Typical finish details.

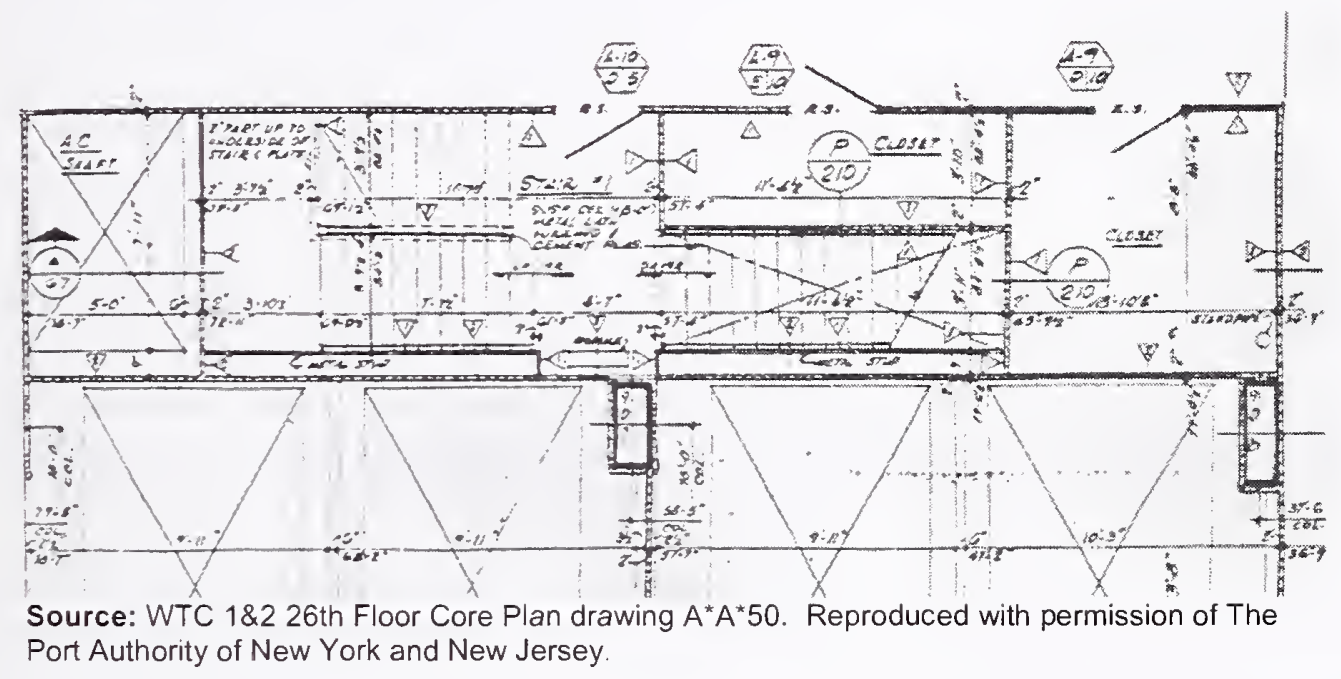

Figure 10-6. Stairway detail at 26th floor.

The 1978 edition of the Gypsum Association (GA) Fire Resistance Design Manual lists several, similar shaft wall constructions utilizing 2 in. gypsum layers consisting of two 1 in. gypsum core board panels with "metal channels on long edges." The GA Manual lists shaft walls of a single 2 in. metal edged plank (WP7015) having a $1 \mathrm{~h}$ fire rating, a single 2 in. metal edged plank with one layer of Type X gypsum board on the unexposed side (WP7112) having a $2 \mathrm{~h}$ fire rating, and a single $2 \mathrm{in.}$ metal edged plank with two layers of Type X gypsum board on the unexposed side (WP 7575) having a $3 \mathrm{~h}$ fire rating.

Partitions separating tenant spaces from other tenant spaces on the same floor were constructed of two layers of 5/8 in. Type X gypsum board on each side of steel studs, and ran slab to slab. This construction is commonly recognized as a $2 \mathrm{~h}$ fire separation. Above the ceiling, penetrations for ducts or to allow for return airflow were fitted with rated fire dampers to preserve the fire rating. This construction was not used in the original design but was specified later by the PANYNJ as tenant spaces were altered. 
Interior partitions not separating spaces occupied by different tenants were constructed of single or double layers of 5/8 in. Type X gypsum board on each side of steel studs and ran from the slab to the suspended ceiling but not above. Double layers of gypsum board were used when the tenant desired additional sound attenuation. These partitions were not required to be fire rated and did not utilize fire rated doors. However, a single layer of 5/8 in. Type X gypsum board on each side of steel studs (16 in. on center) is generally considered to have a $1 \mathrm{~h}$ fire rating, and two layers of 5/8 in. Type $\mathrm{X}$ gypsum on each side of steel studs ( $16 \mathrm{in}$. on center) is considered to have a $2 \mathrm{~h}$ fire rating. For a ceiling high partition to be considered as having a fire rating, the ceiling itself would have to be rated as well. The ceiling system used throughout these buildings was not fire rated.

\subsubsection{Tenant Separation Walls}

Section C26-504.3(a) of the 1968 NYC Building Code required that tenant spaces be separated "by fire separations having at least the fire resistance rating prescribed in Table 5-1, but in no case less than $1 \mathrm{~h}$, and shall continue through any concealed spaces of the floor or roof construction above." The Port Authority chose to stop tenant (demising) partitions (walls separating spaces occupied by different tenants) at the bottom of the suspended ceiling and use $10 \mathrm{ft}$ strips of $1 \mathrm{~h}$ rated ceiling on either side of the partition (Solomon 1969). The general contractor stated in a letter to the Port Authority “...we have been unable to find any precedent for the fire rated ceiling $10^{\prime}$ on either side of the demising partitions beyond the one you described from your construction experience on Port Authority hangers [sic] (Endler 1969)."

In a code compliance evaluation report written in 1997, it was stated "Tenant demising partitions, including separations from the public corridor, do not in all cases meet the requirement of being built to the slab above (Coty 1997)." The author of the report recommended that: "Generally, this condition has been and will continue to be remediated as a requirement of new tenant alterations. However, it is recommended that the Port Authority develop and implement a survey program to ensure that this remediation process occurs as quickly as possible."

The tenant alteration guidelines issued in 1998 required that tenant partitions have a $1 \mathrm{~h}$ fire rating, and the standard details for fire rated partitions indicated a continuous fire barrier from top of floor to bottom of slab (PANYNJ 1998). There were no requirements in the codes or in the PANYNJ guidelines for partitions wholly within tenant spaces.

\subsubsection{Egress Systems}

The primary egress system for the office spaces was the three stairways located in the building core. These included two 44 in. (designated A and C) and one 56 in. wide (designated B) stairs which provided exactly the code required capacity for an occupant load of 390 per floor $\left(39,000 \mathrm{ft}^{2}\right.$ net at $100 \mathrm{ft}^{2}$ per person). The layout within the building core was consistent with the building code requirements for maximum travel distance ( $200 \mathrm{ft}$ unsprinklered, $300 \mathrm{ft}$ sprinklered) and, while the separation was consistent with New York City requirements ( $15 \mathrm{ft}$ and later $30 \mathrm{ft}$ ), it was short of the more common requirements found in all current building codes (one half the diagonal of the space served if unsprinklered, or one-third the diagonal if sprinklered) on some of the floors where the transfer corridors brought the stair access closer together. 
The NYC Building Code uses the older "units of exit width" method for specifying exit capacity. Each 22 in. unit of exit width in an office stair provides the capacity for 60 people. Thus, each 44 in. stair provides for 120 people and the 56 in. stair provides $2 \frac{1}{2}$ units, or 150 people, for a total occupant load per floor of 390 . Also, the PANYNJ made a design decision to use $2 \mathrm{~h}$ corridor walls to permit longer dead ends ( $100 \mathrm{ft}$ rather than the $50 \mathrm{ft}$ limit if the walls had been the minimum $1 \mathrm{~h}$ rating) to provide additional flexibility in tenant layouts. For a detailed description of the stairways, see NIST NCSTAR 1-7.

\subsubsection{Elevators}

There were 99 passenger elevators and 7 freight elevators in each tower, arranged in three vertical zones to move occupants in stages to skylobbies on the 44th and 78th floors. The elevators were arranged as express (generally larger cars that moved at higher speeds) and local elevators in an innovative system first introduced in WTC 1 and WTC 2. There were eight express elevators from the concourse to 44 and ten express elevators from the concourse to 78 as well as 24 local elevators per zone, which served groups of floors in those zones. There were seven freight elevators, only one of which served all floors. All elevators had been upgraded to incorporate firefighter emergency operation consistent with ASME A17.1 and Local Law 5 (1973). See also NIST NCSTAR 1-7.

\subsubsection{Active Systems}

\section{Fire Alarm Systems}

Consistent with practice at the time, the original fire alarm system in WTC 1 and WTC 2 was a manual system with four smoke detectors on each tenant floor, positioned to monitor smoke entering the HVAC returns and arranged to stop the fans and prevent smoke circulation to non-fire areas. Local Law 5 (1973) included retroactive requirements for fire alarm systems and emergency voice communication systems in business occupancies over $100 \mathrm{ft}$ in height. Subsequently, such systems were installed in WTC 1 and WTC 2 with the required fire command center located in the underground parking garage where it was destroyed by the blast in the 1993 bombing rendering most fire safety features inoperable. Following the 1993 bombing, the fire command stations were relocated to the tower building lobbies with a third monitoring location in the Port Authority offices. The lobby location (within sight of the elevators) is specified in the NYC Building Code for fire command centers required in high-rise buildings. There are no code requirements for off-site monitoring of fire alarm systems in this occupancy. For a detailed description of the towers' fire alarm system on September 11, 2001, and prior systems back to the original, see NIST NCSTAR 1-4C.

\section{Fire Sprinkler Systems}

After the passage of Local Law 5, the Port Authority implemented a program to retrofit sprinklers and to offer tenants the option of sprinklering or compartmentation consistent with Local Law 5 provisions. Sprinklering of WTC 1 and WTC 2 was undertaken in three phases: Phase 1 was the sprinklering of below grade spaces completed with the original construction. Phase 2 was begun after Local Law 5 was adopted and included the installation of sprinkler risers and other infrastructure, and the installation of sprinklers in corridors, storage rooms, lobbies, and smaller tenant spaces for tenants not selecting the compartmentation option. Phase 3 involved sprinklering the remaining tenant spaces, initially as tenants changed, and later on negotiated schedules. This process was underway when, in 1984, Local Law 16 
was adopted, which required sprinklers in high-rise buildings, including new offices and new or existing hotels. Following the settlement of legal challenges to LL 5 (1973), LL 84 (1979) changed the effective date for compliance with LL 5 (1973) to February 8, 1988. By the new date, high-rise office buildings had to either be subdivided in accordance with the compartmentation requirement or sprinklered. A 1997 report states that there were four floors and the skylobbies (all in WTC 1) left to be sprinklered, and that the installation of sprinklers at these floors was underway (Coty 1997). In an October 1999 report, it is stated that sprinklering of the tenant floors was completed and sprinklering of the skylobbies was "currently underway" (PANYNJ 1999).

The sprinkler system in the towers was a high-quality, state-of-the-art system with a few features following New York City practice that differed from practice in the rest of the country. An example of the quality is the decision by the PANYNJ to install separate risers rather than to use the existing standpipes as was permitted. An example of New York City practice is the use of manually operated fire pumps and a so-called "standpipe telephone system" to communicate with the pump operator. Most codes and standards require automatic fire pumps. On September 11, 2001, the fire department was unable to deploy operators to the pumps, so they were not used. Since the risers were breached by the aircraft impact, the lack of pumps may have been inconsequential. For a detailed description of the towers sprinkler system see NIST NCSTAR 1-4B.

\section{Smoke Management}

The towers were originally constructed with vents in elevator and utility shafts in accordance with NYC Reference Standard RS 18-1. In addition, smoke detectors were installed at each of the four return vents on each floor to stop fans and prevent recirculation of smoke.

Later, LL 5 (1973) Section 7 (revised by LL 86, Sec. 2) added a requirement for smoke shafts (new) or pressurized stairways (existing) with an exemption for fully sprinklered buildings. The 1976 decision to sprinkler the towers relieved the need to add stair pressurization.

Local Law 16 (1984) Section 53 contained requirements for segregation of ventilation systems and a smoke purge capability. These were addressed through the design and installation of an active system of smoke management that provided a manually activated smoke purge and pressurization of corridors with 100 percent outside air. These systems are described in detail in NIST NCSTAR 1-4C. 


\section{Chapter 11 \\ MAINTENANCE AND MOdIFICATIONS TO FIRE SAFETY SySTEMS}

The Port Authority of New York and New Jersey (PANYNJ or Port Authority) was very conscientious in providing guidance to tenants about their use of space in the World Trade Center (WTC) buildings. The Port Authority published tenant alteration manuals that detailed how tenant space could be fitted. There were manuals for interfacing with the building fire alarm system, the building fire sprinkler system, and other special systems installed in the buildings. National Institute of Standards and Technology (NIST) located at least partial copies of most of these manuals.

When a tenant space was remodeled, such as to accommodate the needs of a new tenant, the process was for the tenant to hire an architect or interior designer to design the space, following the tenant alteration manual. If the tenant occupied less than an entire floor, they could opt to have the PANYNJ handle most of the modifications through their existing contracts, or they could contract independently as the larger tenants generally did. Creation or movement of interior partitions often required moving of sprinkler heads or fire detectors. Also, whenever the suspended ceiling was pulled the PANYNJ required that the sprayed fire-resistive material be inspected and upgraded (if needed) after the other trades had finished and before the ceiling was reinstalled. The PANYNJ office reviewed and approved plans at the start of a tenant project and conducted inspections prior to the tenant moving in.

Whenever work was done in the buildings, a project number was assigned by the PANYNJ under which all contracts, drawings, and correspondence were filed. These numbers are of the format W(yy)-1234 (where yy is the year initiated and 1234 is a 4 digit number). The reports include these numbers as reference for individual projects, and files retained by the PANYNJ are identified by these numbers.

The PANYNJ also conducted numerous inspections and condition surveys which were beyond any requirements in New York City and other codes and practices, and generally implemented corrective action to address problems identified.

\subsection{LOCAL LAWS 5 (1973) AND 16 (1984)}

In general, buildings are governed by the building code in force at the time the building permits are issued, except in the rare case of the adoption of retroactive requirements. Local Laws (LLs) 5 (1973) and 16 (1984) were adopted after completion of WTC 1 and WTC 2 but did contain some retroactive provisions. However, the PANYNJ chose to implement virtually all of the provisions of LL 5 (1973) and LL 16 (1984), which drove most of the modifications to the fire and life safety systems that occurred over the life of the buildings. These modifications included the complete sprinklering of the buildings and several upgrades to the fire alarm system.

Several requirements in LL 5 (1973) were retroactive to existing office buildings over $100 \mathrm{ft}$ in height. These included evacuation drills and planning, fire safety directors and wardens, and requirements for reentry from stairs every four floors with signs in the stairs identifying re-entry floors. Provisions regarding compartmentation requirements for unsprinklered spaces, smoke and heat venting, sprinklers in 
showrooms, permitting standpipes to be used as sprinkler risers, fire alarm and voice communication systems with a fire command center, and one elevator serving every floor supplied with emergency power that can be used by the fire department were also included. LL 16 (1984) extended retroactive provisions for sprinklers, fire alarm and communication systems (with fire command center), a fire service elevator connected to emergency power, and exit lighting and signage, to most occupancy types. LL 16 (1984) added construction class 1C (sprinklered high rise) and removed the compartmentation requirement added by LL 5 (1973), since these buildings were now required to be sprinklered.

\subsection{CODE COMPLIANCE SUMMARY FOLLOWING THE 1993 BOMBING}

In the aftermath of the 1993 bombing, the exemption of PANYNJ facilities from regulation under the NYC Building Code was once more being questioned. The Fire Commissioner and Commissioner of Buildings co-authored a report on the state of various properties in New York City that were exempt from City oversight (Rivera and Rinaldi 1993). They recommended that the States of New York and New Jersey enact legislation making all Public Benefit Corporations, including the Urban Development Corporation and The PANYNJ, subject to the New York City building regulations. The City had even drafted such legislation and submitted it to Albany in 1975 (Rivera and Rinaldi 1993, Attachment I). They report that as of the date of their report the legislation had not been enacted.

The Rivera and Rinaldi report includes a summary of code compliance at the WTC, including the history of code compliance discussions between City departments and PANYNJ, and that "the trend in recent years has been towards cooperation," citing the sprinklering of the towers (Rivera and Rinaldi 1993, page 6). The report goes on to say that, "since its compliance with fire code requirements was dependent upon economic and design feasibility, the PA[NYNJ] agreed to comply with selected provisions of the code, but has not fully done so. Moreover, it was difficult for the Fire Department to monitor code compliance by the WTC because the WTC consistently asserted its legal exemption from local law. Fire officials relied on persuasion and negotiation to gain compliance." (Rivera and Rinaldi 1993, page 6).

Regarding compliance at the time of the explosion, Rivera and Rinaldi report that "a preliminary review by the NYC Department of Buildings generally indicates that the WTC complies with the specific provisions of Local Law 5/73 and Local Law 16/84, or provides acceptable equivalent systems." (Rivera and Rinaldi 1993, page 7) They go on to say that the WTC exceeds the requirements of these local laws in several areas, including emergency power, smoke purge, and corridor pressurization. They cite the fire alarm system as a "major departure" from the requirements of the local laws because each building does not have its own fire command station, they have only one pull station per floor, and they do not provide public address to all areas on all floors. These deficiencies were addressed by the PANYNJ as discussed in NIST NCSTAR 1-4C. Several newly discovered deficiencies regarding occupant egress provisions are also mentioned (Rivera and Rinaldi 1993, page 10).

The position of the PANYNJ was summarized in a statement by Stanly Brezenhoff, Executive Director PANYNJ before the New York City Council, Committee on Housing and Buildings on March 26, 1993 (Rivera and Rinaldi 1993, Attachment F). On page 8 of his statement, Brezenhoff states that the PANYNJ has a "tradition of designing for high standards of structural integrity, and our policy of voluntarily meeting or even exceeding code requirements." Brezenhoff goes on to give examples of meeting or exceeding building code standards for structural integrity such as, 
- The towers have three stairs for fire egress, rather than two required by code

- The towers comply with or exceed code provisions controlling fire protection of structural members, floors and partitions, and enclosure of shafts

- The office floors can support $100 \mathrm{lb} / \mathrm{ft}^{2}$, twice the code requirement

- The towers were designed for wind speeds approximately twice those in the code.

\subsection{WTC DUE DILIGENCE STUDY OF NOVEMBER 22, 1996}

In late 1996, the PANYNJ contracted with Rolf Jensen \& Associates (RJA) and Jaros, Baum \& Bolles (JB\&B) to conduct a study of code compliance at the WTC buildings. These reports, along with issues identified by the World Trade Department of PANYNJ, were summarized in a report dated October 15 , 1999 (PANYNJ 1999). This study appears to be related to the Memorandum of Understanding between PANYNJ and the New York City Department of Buildings which provides for oversight by professionals licensed to practice in New York State reporting to PANYNJ with these reports available for review by the City.

Of particular interest is the division of the items identified in the report into categories:

- Category A was non-conforming code items which will remain as such or for which no plans will be prepared to accommodate the code,

- Category B was non-conforming items which have been remedied, or are currently in progress,

- Category $\mathrm{C}$ was non-conforming code items whose remediation plans are currently being prepared or will be prepared in the near future, and

- Category D was items of policy, business, leases, repair, and operations (RJA report only).

Items in Category A included the issue of the discharge of Stairways $\mathrm{A}$ and $\mathrm{C}$ on the mezzanine level when the Code required exit stair discharge to a level "opening onto a public way." This was resolved by an agreement between the PANYNJ and the NYC Department of Buildings that the Plaza was like a public way, and the Concourse was an "underground street." Also in this category is the issue of exit stair venting.

Category B included structural fireproofing, which was "judged adequate" by RJA providing that all floors in both towers were sprinklered and re-fireproofing "to the appropriate thickness for a $2 \mathrm{~h}$ rating" was continued. The 1997 RJA report (which is Attachment A to PANYNJ 1999) actually states, “... the protection provided by the automatic sprinkler systems will mitigate the fact that the towers' structural steel fireproofing fall somewhat short of that required to provide a $2 \mathrm{~h}$ rating." The RJA report also states that it is their understanding that the PANYNJ "has been currently been [sic] installing and will continue to install $1 \frac{1}{2}$ in. thick steel fireproofing based on UL Design No. G508." 
This category also includes the topic "remediating tenant separation walls and public corridor walls to conform to code requirements." Here the RJA report states that "Tenant demising partitions, including separations from the public corridor, do not in all cases meet the requirement of being built to the slab above."

Items also in this category that were mentioned by Rivera and Rinaldi as major departures from the local laws with regard to the fire alarm system included the lack of individual fire command stations for each building, additional manual stations and public address speakers needed.

Category $\mathrm{C}$ included mechanical rooms with doors directly into egress stairs (which is expressly prohibited), location of standpipe hose stations on some floors (as the stairways move closer together the standpipe connection may exceed the $145 \mathrm{ft}$ distance limit to any point on a floor), and egress issues at the Mall and B-1 levels.

The JB\&B report identified firestopping (at penetrations of fire rated assemblies such as pipes passing through floors) in Category $\mathrm{C}$ as a general issue in the towers. Their report also identified a number of electrical safety issues throughout the complex.

Category D included smoke control on the PATH mezzanine to prevent smoke from reaching the Mall, formal responsibility for overseeing code conformance for both base building and Tenant projects, and the lack of a Certificate of Occupancy for the buildings. 


\section{Chapter 12 \\ WTC 7 FUEL SYSTEM}

World Trade Center (WTC) 7 was constructed and owned by Silverstein Properties (Silverstein) on land owned by the Port Authority of New York and New Jersey (Port Authority). It was built and operated by Silverstein as a Port Authority tenant alteration. Many of the tenants conducted critical business operations in the building and required uninterruptible power to prevent the loss of information or operational continuity in the event of a power failure. Backup power was provided by diesel generators located in the mechanical spaces of the building. These generators were designed to start automatically in the event of an interruption of the utility supply. The total generator capacity and quantity of fuel stored in the building was sized to tenant needs.

\subsection{CODE REQUIREMENTS}

Design and installation of the WTC 7 emergency power and associated fuel systems was consistent with the 1968 New York City (NYC) Building Code. The base system was installed in 1987 with modifications occurring in 1990, 1994, and 1999. Over the period 1987 to 1999, the NYC Building Code provisions discussed below were not changed, so all systems were installed to the same requirements. Some of the key code provisions for the construction and location of fuel storage tanks, piping, and controls are discussed here, and additional details are contained in NIST NCSTAR 1-1A.

\subsubsection{Tanks $(27-828 \text { and } 27-829)^{50}$}

All tanks must be fabricated of steel and coated to prevent corrosion. Minimum thicknesses are specified by tank diameter for storage tanks and for so-called "day tanks" (60 gal or 275 gal). Large storage tanks (up to 20,000 gal) may be buried inside or outside the building or on the lowers floor of the building with protection related to the tank capacity. For example, tanks from 550 gal to 1,100 gal must be enclosed in $2 \mathrm{~h}$ fire rated, noncombustible construction and tanks larger than 1,100 gal in $3 \mathrm{~h}$ construction.

Tanks on floors above the lowest floor are limited to 275 gal and one such tank per story. These "day tanks" must be surrounded by a concrete curb or steel pan with the capacity to hold twice the volume of the tank in the event of a leak. The curb or pan must be provided with a float switch to sound an alarm and shut off the transfer pump in case of tank failure. Appropriate controls (generally a float switch in the day tank) must be provided to transfer fuel from the storage tanks to the day tank through a transfer pump and piping, with only one such transfer pump and piping network per day tank.

\subsubsection{Piping $(27-830)^{37}$}

Piping from transfer pumps to day tanks is required to be enclosed in a shaft of 4 in. thick concrete or masonry with a 4 in. clearance to the fuel pipe. Horizontal offsets may be enclosed in a steel sleeve two

\footnotetext{
${ }^{50}$ Sections of the NYC Building Code in which these requirements are found. These provisions are found in the subchapter on "Heating and Combustion Equipment."
} 
(pipe) sizes larger and enclosed in $2 \mathrm{~h}$ fire rated construction. The spaces between the fuel pipe and sleeve or shaft must lead to an open sight drain or an open sump so leaks can be detected.

\subsubsection{Power Systems Designs}

National Institute of Standards and Technology (NIST) located and reviewed specifications and drawings for each of the emergency power systems. Some of the fuel risers were installed in existing shafts containing other utilities. The NYC Building Code requires that pipe shafts containing piping from the transfer pump to storage tanks above the lower floors not be penetrated by or contain other piping or ducts $(27-830(f)(5))$. Correspondence relating to the system for the Mayor's Office of Emergency Management shows that this system was reviewed and inspected by the New York City Fire Department (FDNY), a list of necded corrections was produced, and each item was initialed as the corrections were verified.

\section{$12.2 \quad$ BASE BUILDING SYSTEM}

The initial base emergency power system was installed in 1987, and consisted of two $900 \mathrm{~kW}$ generators and a 275 gal day tank located on floor 5. Main fuel storage was in two 12,000 gal tanks buried under the loading dock on the south side of the building. The tanks were double wall fiberglass ${ }^{51}$ with leak detectors between the walls.

Fuel was transferred by one of the two pumps through a 2 in. supply line in an existing shaft containing other utilities, near the west bank of passenger elevators. The transfer pump was controlled by a float switch in the day tank with a low (pump on) and a high (pump off) position. An alarm would be sounded if the fuel level in the day tank fell below the low level or went above the high level. The day tank was located within a $550 \mathrm{gal}$ pan fitted with an alarm and another pump cutoff. The vent for the day tank terminated outside the south wall.

The 2 in. fuel lines were encased in a second pipe covered with 2 in. of calcium silicate to provide the required $2 \mathrm{~h}$ fire rating. Pipe supports were located approximately $10 \mathrm{ft}$ apart, and inspection plugs were provided approximately $50 \mathrm{ft}$ apart. Mechanical equipment rooms were sprinklered (ordinary hazard group I), and the fuel pump room was sprinklered (ordinary hazard group III). The generator area on floor 5 was not sprinklered.

\subsubsection{Modifications to System}

From 1990 to 1999 , four major modifications (additions) were made to the base emergency power system. These modifications are summarized in Table 12-1. Of significance are the 1990 modification (Salomon Brothers) that required a pressurized fuel supply system, because a day tank already existed on floor 5, and the 1999 modification (Mayors' Office of Emergency Management) that required a separate 6,000 gal tank on the first floor. Figure 12-1 is a schematic of the locations of the various components of the base system and the four major modifications.

\footnotetext{
${ }^{51}$ While the NYC Building Code requires steel tanks, effective in November 1985 the U.S. Environmental Protection Agency required (40CFR280) that all new underground fuel storage tanks be double wall fiberglass and that any steel tanks older than 20 years be replaced by double wall fiberglass.
} 
For the Salomon Brothers system, the transfer pumps were powered from the output of the generators. In the event of a failure of utility power, all nine generators were started automatically to cnsure that if any of the nine did not start there would be enough power. Once the generators were up to spced, the control system would shut down those that were not needed, but these could be restarted later if power demand increased. There was enough fuel and residual pressure in the lines to start the generators and to run them for a few minutes, but once running, the fuel pumps were powered to supply fuel. As long as any one generator was running, the pumps ran at full capacity.

Table 12-1. Summary of modifications to base emergency power system in WTC 7.

\begin{tabular}{|c|c|c|c|c|}
\hline Year & Day Tank/Generator & Storage Tank & Piping & Comments \\
\hline 1990 & $\begin{array}{l}\text { No day tank permitted since } \\
\text { base design included one on } \\
\text { floor } 5 / \text { nine generators on } \\
\text { floor } 5,1,750 \mathrm{~kW} \text { combined } \\
\text { capacity }\end{array}$ & $\begin{array}{l}\text { Two } 6,000 \text { gal next to } \\
\text { base tanks. }\end{array}$ & $\begin{array}{l}\text { Two } 2 \frac{1}{2} \text { in. pipes in } \\
\text { separate rated shaft }\end{array}$ & $\begin{array}{l}50 \text { psi pressurized } \\
\text { fuel system }\end{array}$ \\
\hline 1994 & $\begin{array}{l}50 \mathrm{gal} / 125 \mathrm{~kW} \text { on floor } 9 \\
\text { generator room sprinklered }\end{array}$ & $\begin{array}{l}\text { Used existing base } \\
\text { tanks }\end{array}$ & $\begin{array}{l}11 / 4 \text { in. in new } 2 \mathrm{~h} \\
\text { rated dedicated shaft }\end{array}$ & $\begin{array}{l}\text { New transfer pump } \\
\text { connected to existing } \\
\text { storage tanks }\end{array}$ \\
\hline 1994 & $\begin{array}{l}275 \mathrm{gal} / 350 \mathrm{~kW} \text { on floor } 8 \text {; } \\
\text { generator room sprinklered }\end{array}$ & $\begin{array}{l}\text { Used existing base } \\
\text { tanks }\end{array}$ & $\begin{array}{l}2 \text { in. in same } \\
\text { dedicated shaft as } \\
\text { above }\end{array}$ & $\begin{array}{l}\text { New transfer pump } \\
\text { connected to existing } \\
\text { storage tanks }\end{array}$ \\
\hline 1999 & $\begin{array}{l}275 \mathrm{gal} / \text { three } 500 \mathrm{~kW} \text { on } \\
\text { floor } 7 \text { : smoke detectors in } \\
\text { generator room }\end{array}$ & $\begin{array}{l}6,000 \text { gal on floor } 1 \text {, in } \\
4 \text { h rated enclosure; } \\
\text { gaseous (clean) fire } \\
\text { suppression system; } \\
\text { space below tank } \\
\text { sprinklered }\end{array}$ & $\begin{array}{l}10 \text { gauge conduit in } \\
2 \text { h rated enclosure }\end{array}$ & $\begin{array}{l}\text { Storage tank kept } \\
\text { filled from base } \\
\text { storage tanks. }\end{array}$ \\
\hline
\end{tabular}




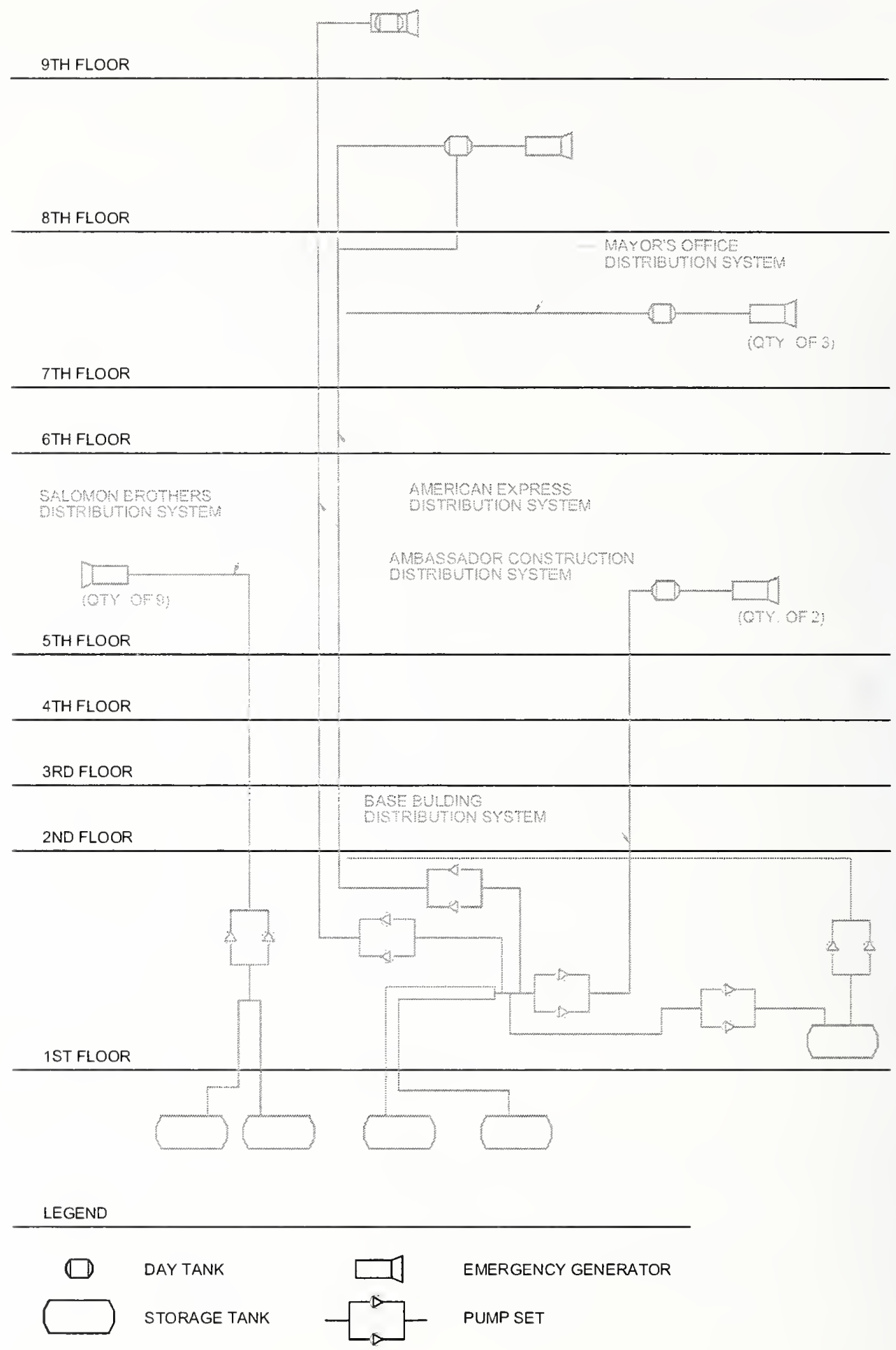

Figure 12-1. Section plan showing the final locations of the fuel oil distribution components. 


\subsubsection{Ambassador Modification}

The Ambassador modification to the base system was performed in 1994. A new transfer pump set (145 gph at $100 \mathrm{psi}$ ) was installed and connected to the existing main storage tanks. A new 11/4 in. supply riser was located in a new $2 \mathrm{~h}$ shaft dedicated for the fuel distribution system, constructed of $4 \mathrm{in}$. masonry and located at the south end of the center bank of passenger elevators. The line ran to a single $125 \mathrm{~kW}$ generator with a 50 gal day tank mounted in a 100 gal basin on the 9 th floor. Controls and alarms were the same as the base system. The transfer pipes were the same double wall design and, outside the masonry shaft, were covered with a $2 \mathrm{~h}$ vermiculite. The area of the generator on the 9 th floor was sprinklered. No design criteria were located, but the pipe sizes for the entire 9th floor are consistent with a light hazard pipe schedule design.

\subsubsection{American Express Modification}

At about the same time in 1994, American Express installed a system to supply their operations. Another new pump set rated $170 \mathrm{gph}$ (at $100 \mathrm{psi}$ ) was installed on the first floor and was tapped into the existing base system pipes and tanks. Another 2 in. supply pipe ran in the same masonry shaft used for the Ambassador system to a 275 gal day tank and a single $350 \mathrm{~kW}$ generator on the 8 th floor. Controls and alarms were the same as the base system. The 8 th floor generator room was protected with sprinklers designed to light hazard criteria.

\subsubsection{Mayor's Office of Emergency Management (OEM) Modification}

In 1999, the Mayor's Office of Emergency Management was constructed on the 7th floor. This system differed from the others because the specifications were to provice an independent source of power for full operations for at least one week, requiring the installation of a new, 6,000 gal storage tank and three $500 \mathrm{~kW}$ generators fed from a single 275 gal day tank on the 7 th floor. The main storage tank was located on the 1 st floor of the building in an existing storage room adjacent to the elevators. The room was modified by installing a raised structure on which the tank was installed, enclosed in 4 h masonry ( 8 in. concrete masonry unit) construction.

A new fill pump set rated 2,000 gph at a design pressure of 125 psi was located in the 1 st floor pump room along with a transfer pump set rated $700 \mathrm{gpm}$ at a design pressure of $125 \mathrm{psi}$. The $6,000 \mathrm{gal}$ OEM tank was kept filled from the two 12,000 gal base system tanks by means of the fill pump. The 1 st floor tank room was protected with an Intergen suppression system with the space below the tank still sprinklered (high hazard). The 7 th floor generator room was not sprinklered but was protected by smoke detectors connected to the building alarm system.

\subsubsection{Salomon Brothers Emergency Power System}

In 1990 Salomon Brothers installed a system to provide emergency power to their trading floor that was independent from the other systems in the building. The Salomon Brothers system involved two 6,000 gal tanks identical to and buried adjacent to the base system tanks under the loading dock on the south side of the building. Salomon Brothers had a contract with a fuel delivery service who always 
maintained the tanks full. ${ }^{52}$ Therefore, both tanks likely contained 6,000 gal of fuel on September 11, 2001.

The system utilized nine generators on the 5 th floor with a combined capacity of $1,750 \mathrm{~kW}$. Seven cooling fan sets (four fans per set) were installed to provide cooling and combustion air to the generators. Three fan sets were installed on the north end of the east wall and four fan sets on the north end of the west wall. There were exhaust louvers on the south end of the west wall. These fans were arranged to come on when the generators were running.

Since there was already a 275 gal day tank on the 5 th floor associated with the base system, the New York City (NYC) Building Code did not permit another tank on that floor. The Salomon Brothers system was designed with a pressurized fuel system without a storage tank near the generators. Two 70 gpm at 50 psi total head pumps were located in a separate enclosure in the existing fire pump room (not in the fuel pump room with the other transfer pumps). A double supply and return pipe (each $2 \frac{1}{2} \mathrm{in}$. covered in 2 in. of calcium silicate) were run in a separate shaft to the 5 th floor where the pipes ran outside the mechanical room to the generators in three groups. At the end of the pipe run, where the fuel supply pipe ended and the fuel return pipe began, there was a valve box containing a backpressure regulator, gauges, and a by-pass line. This liquid tight valve box was mounted to the underside of the floor slab for the 6th floor near generator \#1.

The transfer pumps were powered from the output of the generators. In the event of a failure of utility power, all nine generators were started automatically. This is to ensure that if any did not start there would be enough power. Once up to speed, the control system would shut down generators that were not needed, but they could be restarted later if demand increased. There was enough fuel and residual pressure in the lines to start the generators and to run them for a few minutes, but once running, the fuel pumps were powered to supply fuel. As long as any one generator was running, the pumps ran at full capacity.

The system also included cooling fan units (each consisting of four fans) with three units (rated $30,000 \mathrm{cfm}$ per fan, 12 fans) installed in the northeast corner of the 5 th floor near generators 1 through 4 , six units (rated 38,000 cfm per fan, 24 fans) in the northwest corner near generators 8 and 9, and exhaust louvers in the southwest corner near generators 5 through 7 . The fans were powered from the generators and ran whenever the generators were running. They brought outside air into the building and across the generators.

\subsection{POSSIBLE FAILURE MODES}

Fuel oil piping systems like these are fairly common and are used to operate diesel generators and oil fired furnaces in many applications. The systems generally use day tanks at the appliance kept filled from storage remote tanks through transfer pumps and piping. The pipe-in-pipe design used in WTC 7 is quite robust and reliable in preventing leaking fuel from escaping the system.

At the time WTC 7 was designed and built there were no seismic design requirements for buildings in New York City much less for piping systems. More recent research into the failure of fire sprinkler

52 Interview with Mike Catalano, maintenance person for Salomon Brothers, who was responsible for these systems. 
systems in earthquakes has resulted in seismic design requirements for critical piping systems in seismic zones. The research on sprinkler systems has shown the need for lateral bracing to prevent the failure of the piping systems due to differential movement between the pipes and the building in an earthquake.

A working hypothesis is that the impact sustained by WTC 7 from the collapse of WTC 1 resulted in fractures in the fuel piping system (both the fuel pipe and the containment pipe) especially at the point where the pipes entered the valve box, which was rigidly mounted to the underside of the floor slab. With the base system and all of the modifications thereto, such a fracture would result in a small leak of residual fuel in the pipes at the point of the fracture. A fracture of the pipe at the valve box would release fuel under pressure that, if ignited. could produce a spray fire and/or a pool fire very near column 79.

Rupture of a day tank would release more fuel, but it would be contained by the overflow pan. Not until the generators ran for long enough to drain the day tank to its low fuel level and bring on the transfer pumps would additional fuel and pressure in the transfer lines cause a more significant fuel leak. Depending on the number of generators connected to the day tank, this would require several hours.

The Salomon Brothers pressurized system is different. If the supply or return pipes were fractured along with the containment pipe and the generators started, the fuel pipes would be continuously pressurized, and any leak would continue until the storage tanks were empty as long as any one generator was running.

NIST reviewed the report of an environmental contractor (Langan 2002) hired in the months after the collapse of WTC 7 to recover remaining fuel and to mitigate any environmental damage from the Salomon Brothers tanks. The Salomon Brothers tanks were damaged and appeared to be empty, "... Neither the UST's (underground storage tanks) nor their associated piping contained any residual petroleum product. No residual free product or sludge was observed in either UST."

The tanks were installed on a concrete slab over existing silty sand. A layer of bedding gravel on the slab provided a foundation for the tank. Examination of the gravel below the tanks and the sand below the slab showed some fuel contamination but none was observed in the organic marine silt/clay layer below. Also, the sand and soil below the slab was continuous below the adjacent base system tanks, which contained a total of 24,000 gal of fuel. Thus, it is likely that a fuel leak in any of the tanks would result in fuel contamination in this soil. 
This page intentionally left blank. 


\section{Chapter 13 \\ FINDINGS}

\subsection{GENERAL}

Finding 1: The NYC Department of Buildings reviewed the WTC tower drawings in 1968 and provided comments to the PANYNJ concerning the plans in relation to the 1938 NYC Building Code. The architect-of-record submitted to the PANYNJ responses to those comments, noting how the drawings conformed to the 1968 NYC Building Code. All six comments made by the NYC Department of Buildings dealt with egress issues, but none questioned the large occupant loads for Windows on the World in WTC 1 or Top of the World in WTC 2.

Finding 2: In 1993, the PANYNJ and the NYC Department of Buildings entered into a memorandum of understanding that restated the PANYNJ's long-standing stated policy to ensure that its facilities in the City of New York meet and. where appropriate, exceed the requirements of the NYC Building Code. The agreement also provided specific commitments to the NYC Department of Buildings regarding procedures to be undertaken by the PANYNJ to ensure that buildings owned or operated by the PANYNJ are in conformance with the Building Standards contained in the NYC Building Code. Some salient points included in this agreement and the 1995 enhancement to the agreement are:

- Each project would be reviewed and examined for compliance with the Code.

- All plans would be prepared, sealed, and reviewed by New York State licensed professional engineers or architects.

- The PANYNJ engineer or architect approving the plans would be licensed in the State of New York and would not have assisted in the preparation of the plans.

- The person or firm performing the review and certification of plans for WTC tenants may be the same person or firm providing certification that the project had been constructed in accordance with the plans and specifications unless the proposed alteration would "change the character of the occupancy group under paragraph 27-237 of the New York City Building Code which would have been applicable to such space had such space been located in a privately owned building."

- Deviations from the Code, acceptable to the PANYNJ, would be submitted to the NYC Department of Buildings for review and concurrence. Disagreements between the PANYNJ and the NYC Department of Buildings over such deviations from the Code would be referred to the Port Authority Board of Commissioners for resolution.

Finding 3: While the PANYNJ entered into agreements with the NYC Department of Buildings in the 1990s with regard to conformance of PANYNJ buildings constructed in New York City to the NYC Building Code and sought review and concurrence as required by the agreements, the PANYNJ was not required to yield, and appears not have yielded, approval authority to New York City. The PANYNJ was 
created as an interstate entity "body corporate and politic," under its charter, pursuant to Article 1 Section 10 of the U.S. Constitution permitting compacts between states, and like many other nongovernmental and quasi-governmental entities in the United States is not subject to building and fire safety code requirements of any governmental jurisdiction.

Finding 4: State and local jurisdictions do not require retention of documents related to the design, construction, operation, maintenance, and modifications of buildings, with few exceptions. These documents are in the possession of building owners, contractors, architects, engineers, and consultants. Such documents are not archived for more than about 6 to 7 years, and there are no requirements that they be kept in safe custody physically remote from the building throughout its service life. In the case of the WTC towers, the PANYNJ and its contractors and consultants maintained an unusually comprehensive set of documents, a significant portion of which had not been destroyed in the collapse of the buildings but could be assembled and provided to the investigation. In the case of WTC 7, several key documents could not be reviewed since they were lost in the collapse of the building.

Finding 5: Consistent with the practice at the time the (code) architect was responsible for specifying the fire protection and designing the egress system in accordance with the prescriptive provisions of the building code. The architect and owner engaged the services of structural engineers to perform the structural design and to ensure that his/her design was properly implemented. At that time the fire protection engineering profession was not sufficiently mature to require the same standard of care employed with the structural design. There is no reason to believe that the involvement of a fire protection engineer at that time would have resulted in any differences in the design or performance of the fire protection systems. However, the technical base and sophistication of the practice of fire protection engineering today is well advanced of where it was then. Today, particularly when designing a building employing innovative features, the involvement of a fire protection engineer in a role similar to the structural engineer, and under the overall coordination of the Design Professional in Responsible Charge is central to the standard of care. Further, when designing the structure of selected tall buildings or selected other buildings to resist fires, or evaluating the fire resistance of such structures, it is essential for the structural engineer and the fire protection engineer to jointly provide the needed standard of care.

\subsection{STRUCTURAL SAFETY}

\section{Applicable Building Codes}

Finding 6: Although not required to conform to NYC codes, the PANYNJ adopted the provisions of the proposed 1968 edition of the NYC Building Code, more than three years before it went into effect. The proposed 1968 edition allowed the PANYNJ to take advantage of less restrictive provisions and of technological advances compared with the 1938 edition, which was in effect when design began for the WTC towers in 1962. The 1968 code:

- Changed partition loads from 20 psf to one based on weight of partitions per unit length (that reduced such loads for many buildings including the WTC buildings); and

- Permitted wind tunnel tests using models to establish design values for the wind load.

Many of these newer requirements, instituted in the 1968 NYC Building Code, are contained in current model codes and building regulations. 


\section{Structural Integrity}

Finding 7: Building codes lack explicit structural integrity provisions to mitigate progressive collapse. Federal agencies have developed guidelines to mitigate progressive collapse and routinely incorporate such requirements in the construction of new federal buildings. The United Kingdom incorporates such code requirements for all buildings. New York City adopted by rule in 1973 a requirement for buildings to resist progressive collapse under extreme local loads. The rules, which were adopted after the WTC towers were built but before WTC 7 was built, applied specifically to buildings that used precast concrete wall panels and not to other types of buildings.

Finding 8: Building Codes lack minimum structural integrity provisions for the means of egress (stairwells and elevator shafts) in the building core that are critical to life safety. In most tall buildings the core is designed to be part of the vertical gravity load carrying system of the structure. However, in many of those buildings, especially in regions where earthquakes are not dominant, the core may not be part of the lateral load carrying system of the structure. Thus, the core may be designed to carry only vertical gravity loads with no capacity to resist lateral loads, i.e., overturning moment and shear loads. In such situations, the structural designer may prefer the use of partition walls over structural walls in the core area to reduce building weight. The decision to have the core carry a specified fraction of the lateral design loads or be made part of a dual system to carry lateral loads, each of which would enhance the structural integrity of the core if structural walls were used, is left to the discretion of the structural engineer. Alternatively, stairway/elevator cores built with concrete or reinforced concrete block, which are not part of the lateral load carrying system, may be able to provide sufficient structural integrity if they meet, for example. ASTM E1996-03, or other more appropriate test for impact resistance. In the case of the WTC towers, the core had $2 \mathrm{~h}$ fire-rated partition walls with little structural integrity and the core framing was required to carry only gravity loads. Had there been a minimum structural integrity requirement to satisfy normal building and fire safety considerations, it is conceivable that the damage to stairways, especially above the floors of impact, may have been less extensive.

Finding 9: Standards and code provisions for conducting wind tunnel tests and for the methods used in practice to estimate design wind loads from test results do not exist. Building codes allow the determination of wind pressures from wind tunnel tests for use in design. Such tests are frequently used in the design of tall buildings. Results of two sets of wind tunnel tests conducted for the WTC towers in 2002 by independent commercial laboratories as part of insurance litigation, and voluntarily provided to NIST by the parties to the litigation, show large differences, of as much as about 40 percent, in resultant forces on the structures, i.e., overturning moments and base shears. Independent reviews by a NIST expert on wind effects on structures and a leading engineering design firm contracted by NIST indicated that the documentation of the test results did not provide sufficient basis to reconcile the differences. Wind loads were a major governing factor in the design of structural components that made up the frametube steel framing system.

\subsection{FIRE SAFETY}

\section{Applicable Building Codes}

Finding 10: Although not required to conform to NYC codes, the PANYNJ adopted the provisions of the proposed 1968 edition of the NYC Building Code, more than three years before it went into effect. The 
1968 edition allowed the PANYNJ to take advantage of less restrictive provisions compared with the 1938 edition that was in effect when design began for the WTC towers in 1962 . The 1968 code:

- Eliminated a fire tower ${ }^{53}$ as a required means of fire department access;

- Reduced the number of required stairwells from 6 to 3 and the size of doors leading to the stairs from 44 in. to 36 in. (by increasing stairway and door capacity allowances);

- Reduced the required fire rating of the shaft walls in the building core from $3 \mathrm{~h}$ to $2 \mathrm{~h}$; and

- Permitted a $1 \mathrm{~h}$ reduction in fire rating for all structural components (columns from $4 \mathrm{~h}$ to $3 \mathrm{~h}$ and floor framing members from $3 \mathrm{~h}$ to $2 \mathrm{~h}$ ) by allowing the owner/architect to select Class 1B construction for business occupancy and unlimited building height.

Many of these newer requirements, instituted in the 1968 NYC Building Code, are contained in current codes.

Finding 11: In 1993, the PANYNJ adopted a policy providing for implementation of fire safety recommendations made by local government fire departments after a fire safety inspection of a PANYNJ facility and for the prior review by local fire safety agencies of fire safety systems to be introduced or added to a facility. Later that year, the PANYNJ entered into an agreement with FDNY which reiterated the policy adopted by the PANYNJ, recognized the right of FDNY to conduct fire safety inspections of PANYNJ properties in the City of New York, provided guidelines for FDNY to communicate needed corrective actions to the PANYNJ, ensured that new or modified fire safety systems are in compliance with local codes and regulations, and required third-party review of such systems by a New York State licensed architect or engineer.

\section{Standard Fire-Resistance Tests}

Finding 12: Code provisions with detailed procedures to analyze and evaluate data from fire resistance tests of other building components and assemblies to qualify an untested building element do not exist. Based on available data and records, no technical basis has been found for selecting the sprayed fireresistive material (SFRM) used (two competing materials were under evaluation) or its thickness for the large-span open-web floor trusses of the WTC towers. The assessment of the fireproofing thickness needed to meet the $2 \mathrm{~h}$ fire rating requirement for the untested WTC floor system evolved over time:

- In October 1969, the PANYNJ directed the fireproofing contractor to apply $1 / 2$ in. of fireproofing to the floor trusses.

- In 1999 , the PANYNJ issued guidelines requiring that fireproofing be upgraded to $1 \frac{1}{2} \mathrm{in}$. for full floors undergoing alterations.

\footnotetext{
53 A fire tower (also called a smoke-proof stair) is a stairway that is accessed through an enclosed vestibule that is open to the outside or to an open ventilation shaft providing natural ventilation that prevents any accumulation of smoke without the need for mechanical pressurization.
} 
- Unrelated to the WTC buildings, an International Conference of Building Officials (ICBO) Evaluation Service report (ER-1244), re-issued June 1, 2001, using the same SFRM recommends a minimum thickness of 2 in. for "unrestrained steel joists" with "lightweight concrete" slab.

Finding 13: Code provisions that require the conduct of a fire resistance test if adequate data do not exist from other building components and assemblies to qualify an untested building element are needed. Instead, several alternate methods based on other fire-resistance designs or calculations or alternative protection methods are permitted with limited guidance on detailed procedures to be followed. Both the architect-of-record (in 1966) and the structural-engineer-of-record (in 1975) stated that the fire rating of the floor system of the WTC towers could not be determined without testing. NIST has not found evidence indicating that such a test was conducted to determine the fire rating of the WTC floor system. The PANYNJ has informed NIST that there are no such test records in its files.

Finding 14: Use of the "structural frame" approach, in conjunction with the prescriptive fire rating, would have required the floor trusses, the core floor framing, and perimeter spandrels in the WTC towers to be $3 \mathrm{~h}$ fire-rated, like the columns for Class 1B construction in the 1968 NYC Building Code. Neither the 1968 edition of the NYC Building Code which was used in the design of the WTC towers, nor the 2001 edition of the code, adopted the "structural frame" requirement. The "structural frame" approach to fire resistance ratings requires structural members, other than columns, that are essential to the stability of the building as a whole to be fire protected to the same rating as columns. This approach, which appeared in the Uniform Building Code (a model building code) as early as 1953, was carried into the 2000 International Building Code (one of two current model codes) which states: "The structural frame shall be considered to be the columns and the girders, beams, trusses and spandrels having direct connections to the columns and bracing members designed to carry gravity loads." The WTC floor system was essential to the stability of the building as a whole since it provided lateral stability to the columns and diaphragm action to distribute wind loads to the columns of the frame-tube system.

Finding 15: A technical basis to establish whether the construction classification and fire rating requirements in modern building codes are risk-consistent with respect to the design-basis hazard and the consequences of that hazard is needed. The fire rating requirements, which were originally developed based on experience with buildings less than about 20 stories in height, have generally decreased over the past 80 years since historical fire data for buildings suggested considerable conservatism in those requirements. However, for tall buildings, the likely consequences of a given threat to an occupant on the upper floors are more severe than the consequences to an occupant, say, on the first floor. It is not apparent how the current height and area tables in building codes consider the technical basis for the progressively increasing risk to an occupant on the upper floors of tall buildings that are much greater than about 20 stories in height where access by firefighters without the availability of firefighter elevators is limited by physiological factors. The maximum required fire rating in current codes applies to any building more than about 12 stories in height. There are no additional categories for buildings above, for example, 40 stories and 80 stories, where different building classification and fire ratings requirements may be appropriate, recognizing factors such as the time required for stairwell evacuation without functioning elevators (e.g., due to power failure or major water leakage), the time required for first responder access without functioning elevators, the presence of sky lobbies and/or refuge floors, and limitations on the height of elevator shafts. The 110-story WTC towers, initially classified as Class IA based on the 1938 NYC Building Code, were classified as Class 1B before being built to take advantage 
of the provisions in the 1968 edition of the code. This re-classification permitted a reduction of $1 \mathrm{~h}$ in the fire rating of the components (columns from $4 \mathrm{~h}$ to $3 \mathrm{~h}$ and floor framing membcrs from $3 \mathrm{~h}$ to $2 \mathrm{~h}$ ).

\section{Fire Performance of Structures}

Finding 16: Rigorous field application and inspection provisions and regulatory requirements to ensure that the as-built condition of the passive fire protection, such as SFRM, conforms to conditions found in fire resistance tests of building components and assemblies is needed. For example, provisions are not available to ensure that the as-applied average fireproofing thickness and variability (reflecting the quality of application) is thermally equivalent to the specified minimum fireproofing thickness. In addition, requirements are not available for in-service inspections of passive fire protection during the life of the building. The adequacy of the fireproofing of the WTC towers posed an issue of some concern to the PANYNJ over the life of the buildings, and the availability of accepted requirements and procedures for conducting in-service inspections would have provided useful guidance

Finding 17: Structural design does not consider fire as a design condition, as it does the effects of dead loads, live loads, wind loads, and earthquake loads. Current prescriptive code provisions for determining fire resistance of structures-used in the design of the WTC towers and WTC 7- are based on tests using a standard fire that may be adequate for many simple structures and for comparing the relative performance of structural components in more complex structures. A building system with $3 \mathrm{~h}$ rated columns and $2 \mathrm{~h}$ rated girders and floors could last longer than $3 \mathrm{~h}$ or shorter than $2 \mathrm{~h}$ depending upon the performance of the structure as a 3-dimensional system in a real fire. The standard tests cannot be used to evaluate the actual performance (i.e., load carrying capacity) in a real fire of the structural component, or the structure as a whole system, including the connections between components. Performance-based code provisions and standards are not available for use by engineers, as an alternative to the current prescriptive fire rating approach, to (1) evaluate the system performance of tall-building structures under real fire scenarios, and (2) enable risk consistent design with appropriate thickness of passive protection being provided where it is needed on the structure. Standards development organizations, including the American Institute of Steel Construction, have initiated development of performance-based provisions to consider fire effects in structural design.

Finding 18: Detailcd procedures to select appropriate design-basis fire scenarios to be considered in the performance-based design of the sprinkler system, compartmentation, and passive protection of the structure are needed. The standard fire in current prescriptive fire resistance tests is not adequate for use in performance-based design. While the NFPA 5000 model building code contains general guidance on design fire scenarios (the IBC Performance Code contains no such guidance), the details of the scenarios are left to the fire engineer and regulatory official. The three major scenarios that are not considered adequately are: frequent but low severity events (for design of sprinkler system), moderate but less frequent events (for design of compartmentation), and a maximum credible fire (for design of passive fire protection on the structure). The maximum credible fire scenario for passive protection of structures would assume that the sprinkler system is compromised or overwhelmed and that there is no active firefighting, as is explicitly considered for US Department of Energy facilities. These building-specific representative fire scenarios are similar in concept, though not identical, to the approach used in building design where the performance objectives and design-basis of the hazard are better defined (e.g., a twolevel design that includes an operational event with a 10 percent probability of occurrence in 50 years and a life safety event with a 2 percent probability of occurrence in 50 years). The design-basis fire hazards 
for the WTC towers and WTC 7 are unknown, and it is difficult to evaluate the performance of the fire protection systems in these buildings under specific fire scenarios.

Finding 19: Code provisions to ensure that structural connections are provided the same degree of fire protection as the more restrictive protection of the connected elements are needed. The provisions that were used for the WTC towers and WTC 7 did not require specification of a fire-rating requirement for connections separate from those for the connected elements. It is not clear what the fire rating of the connections were when the connecting elements had different fire ratings and whether the applied fireproofing achieved that rating.

Finding 20: A technical basis to establish whether the minimum mechanical and durability related properties of SFRM are sufficient to ensure acceptable in-service performance in buildings is needed. While minimum bond strength requirements exist, there are no serviceability requirements for such materials to withstand typical shock, impact, vibration, or abrasion effects over the life of a building. There are existing testing standards for determining many of these properties, but the technical basis is insufficient to establish serviceability requirements. Knowledge of such serviceability requirements is relevant to determine the post-impact fireproofing condition of the WTC towers.

Finding 21: Validated and verified tools for use in performance-based design practice to analyze the dynamics of building fires and their effects on the structural system that would allow engineers to evaluate structural performance under alternative fire scenarios and fire protection strategies are needed. Existing tools are either too simplified to adequately capture the performance of interest or too complex and computationally demanding and lack adequate validation. While considerable progress has been made in recent years, significant work remains to be done before adequate tools are available for use in routine practice. NIST has had to further develop and validate existing tools to investigate the fire performance of the WTC towers and WTC 7.

\section{Compartmentation and Sprinklers}

Finding 22: Building fire protection is based on a four-level hierarchical strategy comprising detection, suppression (sprinklers and firefighting), compartmentation, and passive protection of the structure.

- Detectors are typically used to activate fire alarms and notify building occupants and emergency services.

- Sprinklers are designed to control small and medium fires and to prevent fire spread beyond the typical water supply design area of about $1,500 \mathrm{ft}^{2}$.

- Compartmentation mitigates the horizontal spread of more severe but less frequent fires and typically requires fire-rated partitions for areas of about $7,500 \mathrm{ft}^{2}$. Active firefighting measures also cover up to about $5,000 \mathrm{ft}^{2}$ to $7,500 \mathrm{ft}^{2}$.

- Passive protection of the structure seeks to ensure that a maximum credible fire scenario, with sprinklers compromised or overwhelmed and no active firefighting, results in burnout, not overall building collapse. The intent of building codes is also for the building to withstand local structural collapse until occupants can escape and the fire service can complete search and rescue operations. 
Compartmentation of spaces is a key building fire safety requirement to limit fire spread. The WTC towers initially had $1 \mathrm{~h}$ fire-rated partitions separating tenants (demising walls) that extended from the floor to the suspended ceiling, not the floor above (the ceiling tiles were not fire rated). Over the ycars, these partitions were replaced with partitions that were continuous from floor to floor (separation wall) as required by the 1968 NYC Building Code. Some partitions had not been upgraded by 1997, and a consultant recommended to the PANYNJ that it develop and implement a survey program to ensure that the remediation process occurred as quickly as possible. It appears that with few exceptions, nearly all of the floors not upgraded were occupied by a single tenant, and it is not clear whether separation walls would have mattered in terms of meeting the 1968 code. The PANYNJ adopted guidelines in 1998 that required such partitions to provide a continuous fire barrier from top of floor to underside of slab.

Finding 23: Building codes typically require $1 \mathrm{~h}$ fire-rated tenant separations but do not impose minimum compartmentation requirements (e.g., 13,000 $\mathrm{ft}^{2}$ ) for buildings with large open floor plans to mitigate the horizontal spread of fire. This is the case with both the 1968 NYC Building Code, which did not require sprinklers in occupied spaces on or above the ground floor, and the 2001 NYC Building Code, which requires sprinklers in Group E (Business) buildings over 100 feet in height. The sprinkler option was chosen for the WTC towers in preference to the compartmentation option in meeting the subsequent requirements of Local Law 5 adopted by New York City in 1973. Thus, if there was only one tenant on a WTC floor there would be no horizontal compartmentation requirement. Conversely, if there were a large number of tenants on a WTC floor, it would be highly compartmented with separation walls. The affected floors in the WTC towers were mostly open-with a modest number of perimeter offices and conference rooms and an occasional special purpose area. Some floors had two tenants and those spaces, like the core areas, were partitioned (slab to slab). Photographic and videographic evidence confirms that even non-tenant space partitions (such as those that divided spaces to provide corner conference rooms) provided substantial resistance to fire spread in the affected floors. For the duration of about $50 \mathrm{~min}$ to $100 \mathrm{~min}$ prior to collapse of the WTC towers that the fires were active, the presence of undamaged $1 \mathrm{~h}$ fire-rated compartments may have assisted in mitigating fire spread and consequent thermal weakening of structural components.

Finding 24: State and local building regulations are needed that require installation of sprinklers in existing buildings on a reasonable time schedule, not as an option in lieu of compartmentation.

Functioning sprinklers can provide significant improvement in safety for most common building fires and prevent them from becoming large fires. NYC promulgated local laws in 1973 and 1984 to encourage installation of sprinklers in new buildings and is now considering a law to require sprinklers in existing buildings. The WTC towers were fully sprinklered by 2001 , about 30 years after their construction. Sprinklering of the tenant floors in the WTC towers was completed by October 1999, while sprinklering of the skylobbies was still underway at that time. The sprinkler system was installed in three phases. Phase 1 was completed during initial building construction and included the sub-grade areas. Phase 2 was completed in 1976, in compliance with Local Law 5, and included sprinklering the corridors, storage rooms, lobbies, and certain tenant spaces. Phase 3 was begun in 1983 and completed in 2001 and resulted in fully sprinklering the buildings.

Finding 25: Modern building codes allow a lower fire rating for structural elements when a building is sprinklered. This trade-off provides an economic incentive to encourage installation of sprinklers. Sprinklers provide better intervention against small and medium fires, fires which are more likely to occur than a WTC disaster, as long as the water supply is not compromised and there is redundant technology in 
place. The required technical basis is not available to establish whether the "sprinkler trade-off" in current codes adequately considers fire safety risk factors such as: (1) the complementary functions of sprinkiers and fire-protected structural elements, (2) the different fire scenarios for which each system is designed to provide protection, and (3) the need for redundancy should one system fail. It is noteworthy that the British Standards Institution has established a group to review all the sprinkler trade-offs contained in their standards. No such formal review has yet been initiated in the United States. Although the classification and fire rating of the WTC towers did not take advantage of the sprinkler-tradeoff since such provisions were not contained in the 1968 NYC Building Code, had such provisions existed, they would have permitted a lower fire rating for many WTC building elements.

\section{Use of Elevators in Emergencies}

Finding 26: With a few special exceptions, building codes in the United States do not permit the use of fire-protected elevators for routine emergency access by first responders or as a secondary method (after stairwells) for emergency evacuation of building occupants. The use of elevators by first responders would additionally mitigate counterflow problems in stairwells. While the United States conducted research on specially protected elevators in the late 1970s, the United Kingdom along with several other countries that typically utilize British standards have required such "firefighter lifts," located in protected shafts, for a number of years. Without functioning elevators (e.g., due to a power failure or major water leakage), first responders carrying gear typically require about a minute per floor to reach an incident using the stairs. While it is difficult to maintain this pace for more than about the first 20 stories, it would take a first responder about an hour to reach, for example, the 60th floor of a tall building if that pace could be maintained. Such a delay, combined with the resulting fatigue and physical effects on first responders that were reported on September 11, 2001, would make firefighting and rescue efforts difficult even in tall building emergencies not involving a terrorist attack. Each of the WTC towers had 106 elevators, and WTC 7 had 38 elevators. By code, the elevators could not be used for fire service access or occupant egress during an emergency since they were not fire-protected, nor were they located in protected shafts. The elevators were equipped through normal modernization with fire service recall. Most were damaged by the aircraft impacts; though prior to the impact in WTC 2 the elevators were functioning and contributed greatly to the much faster initial evacuation rate in WTC 2. 
This page intentionally left blank. 


\section{Chapter 14 \\ REFERENCES}

AIA (American Institute of Architects). 2000. AIA Masterspec Section 07811, Sprayed Fire-Resisting Materials. Washington DC.

AWCI (Association of Wall and Ceiling Industries). 1997. Technical Manual 12-A, 3rd ed. Standard Practice for the Testing and Inspection of Field Applied Sprayed Fire-Resistive Materials; An Annotated Guide. Falls Church, VA.

ASME (ASTM International). 2000. Safety Code for Elevators and Escalators ASME 17.1, American Society of Mechanical Engineers, New York, NY.

Bell and Stanton, Public Relations. 1964. Polytechnic Institute of Brooklyn, 757 Third Avenue, New York, NY.

BOCA/BBC (Building Officials and Code Administrators/Basic Building Code). 1965. BOCA Basic Building Code, Fourth Edition, Building Officials Conference of America, Chicago, IL.

Bhol, S. 2005. Email from Saroj Bhol to Richard Bukowski confirming the dates that Windows on the World opened and when it reopened following the bombing. March 25.

Bukowski, R.W. 2003. Protective Elevators for Egress and Access During Fires in Tall Buildings, Proceedings of the CIB-CTBUH Conference on Tall Buildings, Kuala Lumpur, Malaysia. October 20-23.

Coty, Eric H. (Rolf Jensen \& Associates). 1997. Included as Attachment A to World Trade CenterCode Compliance Evaluation compiled by PANYNJ October 15, 1999, March 14.

CTB\&UH (Council on Tall Buildings and Urban Habitat). 1980. Monograph on Planning and Design of Tall Buildings, Volume CL-Tall Building Criteria and Loading, American Society of Civil Engineers, Reston, VA.

ENR (Engineering News Record). 1964. Tall Towers, Engineering News Record, July 9, McGraw-Hills Construction Weekly, New York, NY.

Fasullo, E. (Port Authority of New York and New Jersey). 1995. Letter to R. Visconti, Deputy Commissioner, New York City Department of Buildings, confirmation of December 6, 1994, meeting on agreement for plan regarding egress requirements from World Trade Center 1, floors 106 and 107 , January 29 (WTCI-159-P).

Feld, L.S. 1987. Memorandum from Lester S. Feld to Robert J. Linn, Deputy Director for Physical Facilities, WTD, January 15 (WTCI-19-P). 
IBC (International Building Code). 2000. International Building Code, International Code Council, Falls Church, VA.

Kahn, Fazlur R. and El Nimeiri, Mahjoub M. 1983. Structural Systems for Multi-Use High-Rise Buildings, Volume SC-1, Developments in Tall Buildings, Council on Tall Buildings and Urban Habitat, Huchinson Ross Publishing Company, Stroudsburg, PA.

Langan. 2002. Oversight Report for Removal of Salomon Smith Barney, Inc. UST's Former 7 World Trade Center Building New York, New York prepared by Langan Engineering \& Environmental Services, P.C., for Silverstein Properties, Inc., Langan Project 5544403, August 22.

LERA (Leslie E. Robertson Associates). 1996. One and Two World Trade Center Damper Testing. May (WTCI-230-L).

MCC (Municipal Code of Chicago). 1967. Municipal Code of Chicago Relating to Buildings (As Amended to and including January 1, 1967), Index Publishing Corp., Chicago, IL.

NBS (National Bureau of Standards). 1935. Design and Construction of Building Exits, National Bureau of Standards Miscellaneous Publication M151, U.S. Government Printing Office, Washington, DC.

NFPA (National Fire Protection Association). 1966. Life Safety Code, NFPA 101, Quincy, MA.

NFPA (National Fire Protection Association). 2003. Building Construction and Safety Code, NFPA 5000, Quincy, MA.

NYCBC (New York City Building Code). 1968. Building Code-Local Law 76 of the City of New York, New York, NY.

NYCBC (New York City Building Code). 2001. Building Code of the City of New York, 2001 Edition, Gould Publications, Binghamton, NY.

NYSBC (New York State Building Code). 1964. State Building Construction Code Applicable to General Building Construction, Building Code Bureau, State of New York, New York, NY, December 1.

PANYNJ (Port Authority of New York and New Jersey). 1997. Port Authority Facility Condition Survey Program - 7 World Trade Center. Engineering Quality Assurance Division, Engineering Department. April. (WTCI-122-P).

PANYNJ (Port Authority of New York and New Jersey). 1999. World Trade Center - Code Compliance Evaluation, October 15 (WTCI-161-P).

Rivera and Rinaldi. 1993. Report on Fire and Building Codes and the Jurisdiction and Compliance of Federal, State, State Authorities and Foreign Government Buildings, Carlos M. Rivera, Fire Commissioner and Rudolph J. Rinaldi, Commissioner of Buildings, March 25. 
Robertson. Leslie, and See, Saw-Teen. 1987. Preliminary Design of High-Rise Buildings, Chapter 11, Building Structural Design Handbook, Richard White and Charles Salmon, editors, John Wiley \& Sons, New York, NY.

Schaffner, Charles E. 1964. The New Building Code for New York City - The Performance specification, The Magazine of Standards, October.

SHCR (Skilling, Helle, Christiansen, \& Robertson). 1967. Viscoelastic Damping Units, The World Trade Center Report No. DU-3 (WTCI-1006-L).

Simiu, Emil, and Scanlan, Robert H. 1996. Wind Effects on Structures, John Wiley \& Sons, Inc, New York, NY.

Solomon, Joseph H. (Emery Roth \& Sons). 1975. Letter to Malcolm P. Levy (General Manager, World Trade Center Operations), February 18.

Sullivan, Richard C. 1964. New Concept in Vertical Transport, Westsider, 29, Fall.

UBC (Uniform Building Code). 1988. Uniform Building Code, International Conference of Building Officials, Whittier, CA.

UL (Underwriters' Laboratories). 2001. Fire Resistance Directory 2001, Underwriters Laboratories, Inc. Northbrook, IL 60062. 
This page intentionally left blank. 


\section{Appendix A \\ SUPPORTING DOCUMENTS FOR CHAPTER 1}

This appendix contains the supporting documents that are referenced in Chapter 1 of this report. All of the documents contained in this appendix are reproduced with permission of The Port Authority of New York and New Jersey. Table A-1 contains a summary of supporting documents and their location within this appendix. The footnote numbers given in the table correspond to those in Chapter 1 .

Table A-1. Supporting documents for Chapter 1.

\begin{tabular}{|c|l|c|}
\hline $\begin{array}{c}\text { Footnote } \\
\text { Number }\end{array}$ & \multicolumn{1}{|c|}{ Document Title } & Page(s) \\
\hline 2 & $\begin{array}{l}\text { Letter dated May 15, 1963, from Malcolm P. Levy (Chief, } \\
\text { Planning Division, World Trade Department) to Minoru Yamasaki } \\
\text { (Minoru Yamasaki \& Associates) }\end{array}$ & 194 \\
\hline 3 & $\begin{array}{l}\text { Letter dated September 29, 1965, from Malcolm P. Levy (Chief, } \\
\text { Planning Division. World Trade Department) to Minoru Yamasaki } \\
\text { (Minoru Yamasaki \& Associates) }\end{array}$ & 195 \\
\hline 4 & $\begin{array}{l}\text { Memorandum dated June 22, 1965, from John M. Kyle (Chief } \\
\text { Engineer, PANYNJ) to Malcolm P. Levy (Chief, Planning } \\
\text { Division, World Trade Department) }\end{array}$ & 196 \\
\hline 5 & $\begin{array}{l}\text { Memorandum dated January 15, 1987, from Lester S. Feld (Chief } \\
\text { Structural Engineer, World Trade Department) to Robert J. Linn } \\
\text { (Deputy Director for Physical Facilities, World Trade Department) }\end{array}$ & 197 \\
\hline 6 & $\begin{array}{l}\text { Letter dated February 18,1975, from Joseph H. Solomon (Emery } \\
\text { Roth \& Sons) to Malcolm P. Levy (Chief, Planning Division, } \\
\text { World Trade Department) }\end{array}$ & 199 \\
\hline
\end{tabular}




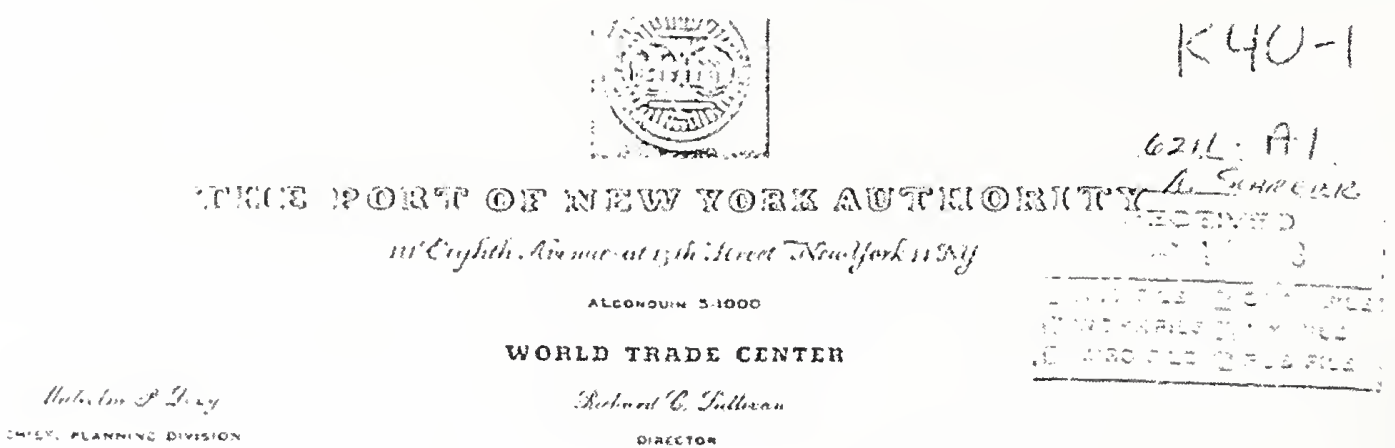

Myy 15, 1963

ME. Minoru Yamasaki

Minoru Yacasaki \& Associates

1025 East Maple Road

Birwingham, Kichigan

Dezx Yama:

At a recent meeting with $M$. John Kyle, Chief Eneineer, the subject of New York city Code compliance was further amended as follows:

"All consulting engineers and architects working on the world Trade Center have been instructed to comply with the Code in preparing their desigrs. Questions have arisen, however, in arcas where the fode is not explicit. It was agreed that in such cases and, where technological advances malce portions of the Code obsolete, the consultants way propose desigas based on acceptable engineering practice. M11 such Instances will be called to the attention of The World Trade Center plenting Division. When preliminary designs have been completed, the Chief Eagineer will review all design concepts with the approprate municipal agencies before the consultants proceed with the final design".

$L F: d b$

ce: Mr. J. Roth (ERS)

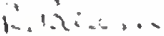

$\because\langle i+i+i<|$

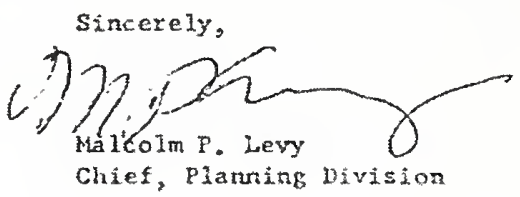

Chief, Platuing Division 

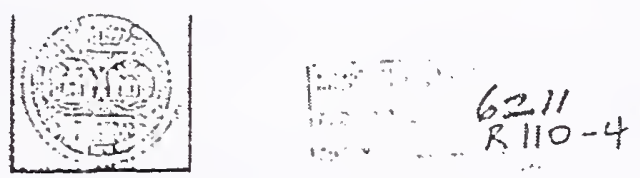

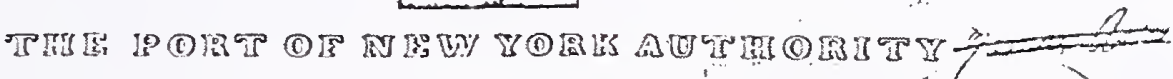

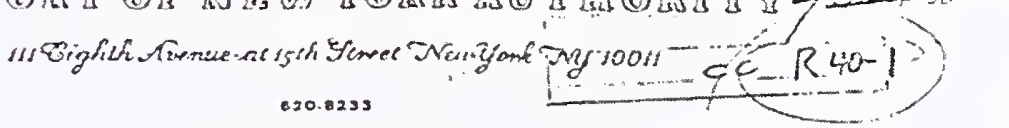

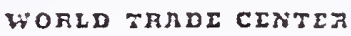

Hododim SP SEg

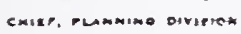

Gevanad Solliwam

pinecron

Mr. Minoru Yamasaki

Minoru Yamasaki \& Assoclates

1025 East Maple Road

Binaingham, Michigan 48011

Dear Yama:

We have decided to adopt the new Building Code presericly existing in second and third draft form for The World Trade Center.

The Roth office is requested to revise floor plans as quickly as possible and on an accelerated basis to comply with the provisions of this code. It is my understanding that the present drawings have been prepared to permit rapid conversion to the new code. Generally the tower core should be redesigned to elininate the fire towers and to take advantage of the more lenient provisions regarding exit stairs. No other major change to the core should be undertaken without review by this office.

The structural consultants are instructed, by copy of this letter, to revise structural design in accordance with the more realistic critcria for partition weight allowance. The majority of interlor partitions, as noted in a previous letter, w11 consis of reinforced gypsum plank.

The Roth office is requested to provide me with the dates on which we can expect revised floor plans and also to indicate any changes in design schedule caused by these instructions.

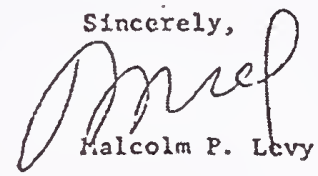

cc: R. P.ata! (JBB). J. Loring (JRIA), J. Roth (ERS), J. Sk1lling and 2 . Robertson (WSHJ)

Siollar letter sent to Mr. Julian Roth (ERS) 


\section{$\frac{\cos 20-A}{5-63}$}

To: Bustcotra " Levy, Chicf, Plonning Riv., U.T.C.

FROM:

DATE:

SUDJECT:

RCFERENCE

COPY TO

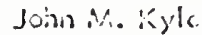

Juac 22,1905

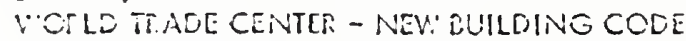

\section{MEMORANDUM}

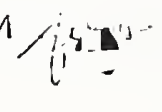
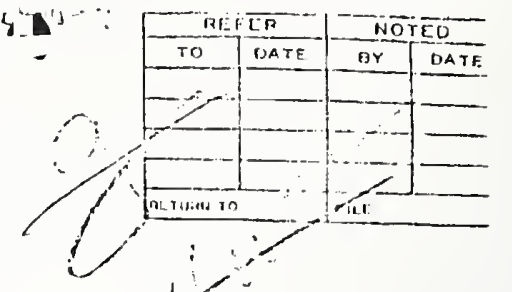

This will confirm ing edvice thel, in view of the mere lïcral provisions of the proposed ncwe Vivew Yoril Ciry Builciing Cede, I fecl we

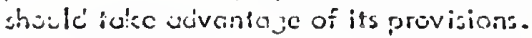

This ciccision is boscd on the following:

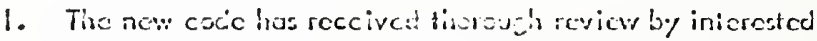

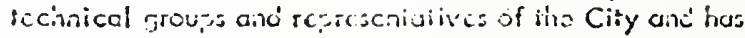
beca mocificu to meci all mojor ojjections.

2. Ii is scheciulca so be officidily subiaifice to the Ciiy in sestcminer ane should be ejorovec well berure we construci our buildinja.

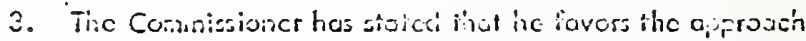
ioken by the fort Ausizerity in usiaj civaneed iceliniques in the cesign of the V'orld: Trade Cciter. Hic also stated that the Fort rushority is not sujicet to the provisions of line Building Code.

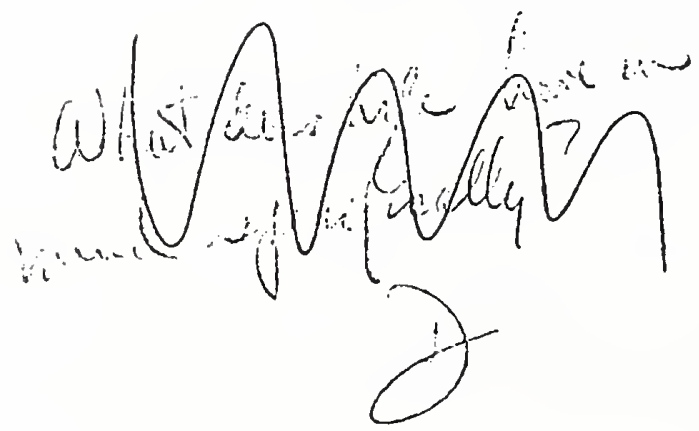

Jusin M. Kylo

Chief Engincer 


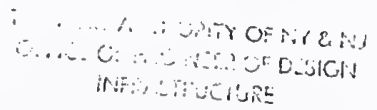

TO:

FROM:

Robert J. Linn, Deputy Director for Physical Facilities, wTD,$\cdots ?$

DATE:

Lester S. Feld

SUBJECT:

January 15,1987

$$
\text { MTET: I:LCE IVED }
$$

THE WORLD TRADE CENTER - TOWERS \& PLAZA BUILDINGS BIFHITRALING PER NYC BUILDING CODE REVISION EFFECTIVE 12-6-68.

REFERENCE: (1) - Memo - M. Levy to File - dated 4-20-65

(2) - Letter - L. Robertson (WSHJ) to M. Levy - dated 4-26-65

(3) - Letter - M. Levy to M. Gerstman (TRCC) - dated 5-14-69

(4) - Office Memo - W. Bracco (TRCC) to J. Endler (TRCC) - dated 5-26-69

(5) - UL Fire Test Report from T. P. Feit - dated 7-26-69

(6) - Letter - A. F. Abbasi (UL) to T. P. Peit (Zonolite) - dated 3-26-70

$\Rightarrow(7)$ - Buckslip - V. Dovletian to D. Bais - dated 1-9-87

(8) - Page 4 - Item IC of Issue A entitled "Office Space Design Guide"

COPY TO:

D. Bais, J. Carlock, A, Cracchiolo, V. Dovletian, P. Martinez

D. Montalbano, A. Preschle, J. Pugh (LERA), L. Robertson (LERA)

A. Vaccaro - All w/Reference $1-8$ atrached.

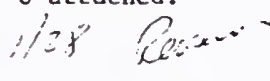

$$
\checkmark
$$

1. On January 13, 1982 I contacted Richard Roth, Jr. (ERSS) regarding the subject fire ratings, normally established by the Architect. Mr. Roth referred me to Phil Martinez for the required information.

2. Phil's recollection (since ER\&S had given all their WTC tracings to our Planning Division) was as follows:

A. The egress requirement and fire ratings used to design the WTC Towers \& Plaza Bulldings were in accordance with the provisions of the planned NYC Bullding Code revisions effective December 8,1968 . Normally fire ratings are not shown on the Architectural Working Drawings or in the General Notes. The fire ratings are given only on the application forms filed with the plans for NYC Bullding Department Approval. Since the Port Authority is not subject to the NYC Building Code Requirements, no plans or forms were filed.

B. For office bulldings there is no economic advantage in using Class IA Construction, and ER\&S used Class 1B Construction for the HTC Towers and Plaza Buildings which are Occupancy Group " $E$ " (Business) with a fire Index of 2 hours. As such, columns must have 3 hour fire-rating and floor construction with a 2 hour rating.

3. Please note that Reference 3 by Mal Levy was concurred in by W. Bracch (TRCC) in Reference 14 , with regard to class 1-B Construction cited by Mr. Martinez. In addition, References 1 \& (written in 1965) are superseded by References \#3 \&4 (written in 1969).

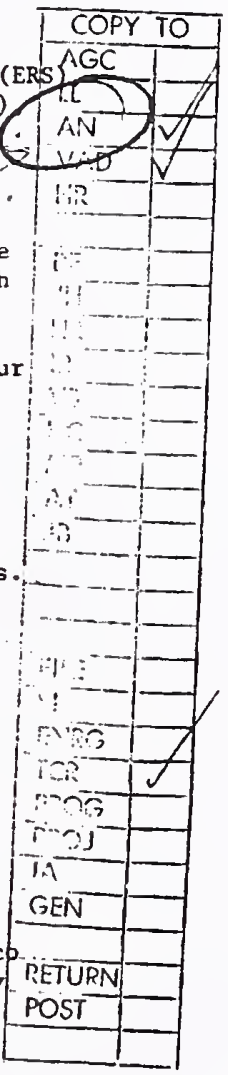


4. For your information and use I have also attached References \#5 \& \#6 on the UL Test of floor construction showing a 3 hour rating. Please note that the UL Test is based on the use of $1 \frac{1}{2}$ " thick Monokote Fireproofing on joists and $\frac{1}{2} "$ thick Monokote on steel deck. Actually Cafco - Type " $D$ " spray-on was used at the WTC on joists only, in lieu of Monokote. In addition, the UL Test used stone-concrete slab with a thickness of $23 / 4^{\prime \prime}$ over top of corrugated deck, as compared to the 4 " lightweight concrete slab used at the WTC.

5. With regard to Reference $\# 7$, no joists were used in the floor construction of 3 WTC, 4 WTC, or 5 WTC - rolled beam are used in all Plaza Buildings. Mr. Martinez (ER\&S) Mal Levy (Reference \#3) \& TRCC (Reference \#4) all concur that the Plaza Buildings are Class IB Construction.

6. In addition, Issue "A" of the "Tower Office Space Design Guide" prepared by the WTC Planning and Construction Division (with Errata Sheet \#1 to Issue A - dated March 23, 1970) - Page 4 - Item C1 (attached as Reference \#8) verifies that the towers are class $1 \mathrm{~B}$ Construction.

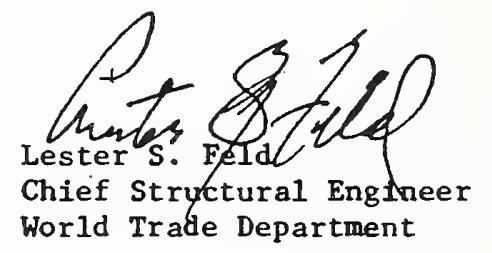


EMERY ROTH \& SONS

BSO THIRO AVENUE. NEW YORK, N. Y 1002 Z

$(212) 753-1733$

RICMARO ROTM, S*. r A. A

HAFRY J. HARMAN, A. A A

RICMARO ROTH, JA. A. A..R.I E.A

SOSEDM H. EOLOMON, A.1.A.

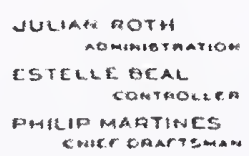

February 18, 1975

Mr. Nalcoln P. Levy

General Manager

World Trade Center Operations

Port Authority New York, New Jersey

1 World Trade Center

Lew York. liew York 10047

RE: WORID TRADE CENTER

\section{Dear Mal:}

In accordance with the instructions issucd by the port Authority at the start of the project, construction drawings for the World Trade Center were to conform with requirements of the Building Code of licw lork City, and any variations therefrom were to be called to the attention of the Port Authority for final decision and authorization. 'This procedure has been followed in production of the contract drawings and, with the exceptions authorized by lhe port huthority noted below. the drawings are in accordance with the new Building code adopted in December, 1968. The Building Department reviewed the tower drawings in 1960 and made six comments concerning the plans in relation to the old code. Specific answers noting how the drawings conformed to the new code with regard to these points were submitted to the Port Authority on March 21. 1968.

We were instructed by the port Authority to deviate from code with respect to the following areas:

1. Omission of vents from closed shafts. loted to the Port futhority by letter dated April 20. 1967.

2. Demising partitions to stop at suspended ceiling or bottom of truss instead of ruming from slab to slab. Noted to the Port Authority by letters dated November 9, 1967 and June 6, 1969 with response on December 12, 1967. Prior instruction on procedure from Port huthority dated January $26,1966$.

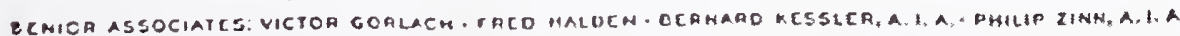

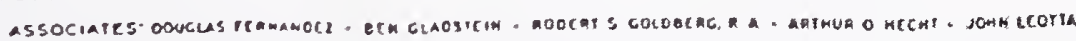

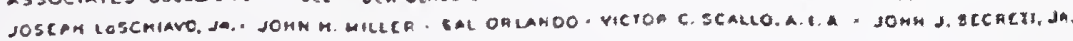


3. Omission of fire prolccted opcnings on exterior walls with separation of less than 30 feet. Noted to Port nuthority by copy of letter to MyA dated January 26, 1966.

4. Treatment of concourse level as "Underground Strect" noted by letter to the lort nuthority on npril 6. 1971, January 11. 1972 and kay 7. 1973.

Fire detection and protection requirements specified for the World Trade Center meet or cxcced Building Code requirements prior to the adoption of Local Law $\frac{45}{7} 5$. Most other office towers in the city of lew york meet the minimum code recuirements :

A. Telephone systom for Fire Department use connecting pump room and gravity tank room with all floors. A six inch gong provided at permanent telephone at purp room, first floor and gravity tank room. Telcphone jacks at all other flooss protected by break glass boxes.

B. Standpipe signalling device: an elght inch gong located in the pump room and every 10 floors in the elevator shaft: an approved closed circuit strap key enclosed in a shect mctal box at each telephone station for fire department use.

The Building code permits lhe use of louvered doors on toilet rooms, janitor and clcctric closets located in 1 hour rated corridors. There is no size limit specified for the louver. but the Board of Standards and Appeals permits louvers of 2 square feet in $3 / 4$ hour ralod doors (which are required in 1 hour rated partitions). Up until about 1968 most office buildings had 1 hour mininum ralcd enclosures and louvered doors in telephone closets and slecves or small slots through the floor. Since 1968, alout 25 percent still have louvers in the doors. In more recent buildings the floor openings have been slabbed over.

Since corridor construction is required by code to be 1 hour rated. it follows that louvered doors were acceptable in tele- 
phone closets. Corridor partitions in the Irade Center Towers, however. were designed to meet 2 hour rated construction at the request of the Port nuthority, to forestall any problems with dead end limitations in the new code. It would require investigation of individual floor tenant layouts to determine if the dead end limitation of 50 feet for 1 hour construction has been exceeded.

The original contract drawings, dated $7 / 31 / 67$ and the contract Bid Sets dated $12 / 18 / 67$ and $2 / 9 / 68$ indicate 2 hour rated enclosures for the telephone closcts with louvers in a FPSC, 1$1 / 2$ hour label door. The hollow metal door specification written in 1967 and reccived by the Port Authority on 10/24/67 called for fusible link dampers on louvers in labeled doors. Letters to the port Authority dated $8 / 23 / 67$ and $9 / 6 / 67$ incated that variances had been obtained for omission of dampers and requcsted instruction xcgarding this advice. The requirement for dampers was delcled from the final draft of the specification revicwcd by the P.A. in Nay. 1968. Re quirement to meet provisions of underwriter's labs, B.S. $\mathrm{A}$. and Building Department was retained, however, for doors with F.F.S.C. and hourly ratings.

Based on Port futhority comments on drawings received $4 / 17 / 69$ and pursuant to a letter from the Port Authority to Tishman Construction Company datcd $4 / 20 / 69$ instructing that such changes be made, the wall of the telephone closet was changed to $I$ hour rated construction on $5 / 23 / 69$ and the door was changed to F.P. with a $l-1 / 2$ hour rating. Since the telephone closet was no longer a shaft with a 2 hour rated enclosure. all floor openings left for future installation of cables had to be firestopped. This admonition was reiterated in a letter to the Port Authority dated June 25, 1973.

Please inform us if any additional information is desired.

Jis : am

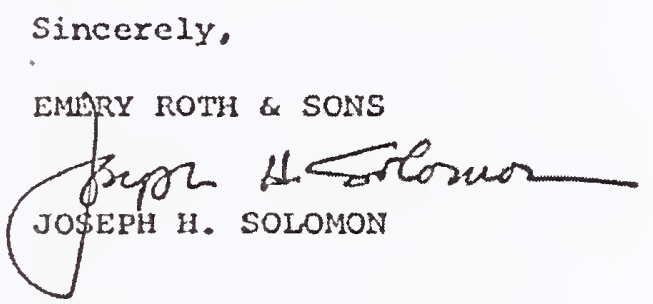

CC: Mr.R. Monti, Chlof Ingincer/PA 
This page intentionally left blank. 


\section{Appendix B \\ SUPPORTING DOCUMENTS FOR CHAPTERS 2 AND 3}

This appendix contains the supporting documents that are referenced in Chapters 2 and 3 of this report. All of the documents contained in this appendix are reproduced with permission of The Port Authority of New York and New Jersey. Table B-1 contains a summary of supporting documents and their location within this appendix. The footnote numbers given in the table correspond to those in Chapters 2 and 3 .

Table B-1. Supporting documents for Chapter 3.

\begin{tabular}{|c|l|c|}
\hline $\begin{array}{c}\text { Footnote } \\
\text { Number }\end{array}$ & \multicolumn{1}{|c|}{ Document Title } & Page(s) \\
\hline 13 & $\begin{array}{l}\text { Memorandum of Understanding Between the New York City } \\
\text { Department of Buildings and the PANYNJ 1993 (WTCI-160-P) }\end{array}$ & 204 \\
\hline 14 & $\begin{array}{l}\text { Supplement to Memorandum of Understanding Between the New } \\
\text { York City Department of Buildings and the PANYNJ 1995 } \\
\text { (WTCI-113-P) }\end{array}$ & 208 \\
\hline 15 & $\begin{array}{l}\text { Original letter dated January 25, 1968 from Joseph H. Solomon } \\
\text { (Emery Roth \& Son) to Malcolm P. Levy (General Manager, } \\
\text { World Trade Center Operations). Illegible copy received from } \\
\text { PANYNJ. }\end{array}$ & 212 \\
\hline 15 & $\begin{array}{l}\text { Letter dated January 25, 1968, from Joseph H. Solomon (Emery } \\
\text { Roth \& Son) to Malcolm P. Levy (General Manager, World Trade } \\
\text { Center Operations) reconstructed by NIST. }\end{array}$ & 214 \\
\hline
\end{tabular}




\section{THE POTT KUTHORITY (OS WYSMO}

November 5,1993
One Wortd lizoe Center New York. New York s0048

Law Depanmen!

Jeltrey S Grees Genetal Counsel

Lawence S Halichter Chwel rinance Dinsken

(212) 435.6223

(201) $401.6500 \times 6220$

THE PORT AUTHORITY OF N.Y \& N 3 TENANT CONSTRUCTION REVIEW UNIT

RECEIVED

1.0V 091993

NOTED

REFERRED 10

Dear Mr. Sturcken:

Enclosed please find a fully executed original of the Memorandum of Understanding between the Port Authority and the New York City Department of Buildings.

For your information, the gubernatorial review period for the enclosed agreement will end at midnight Wednesday. November 17. 1993. II has been a pleasure working with you on this matter.

Very truly yours.

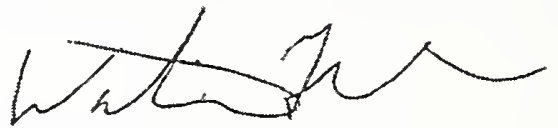

Walter M. Frank

Deputy Chief. Finance Division

Law Department

\section{Enclosures}

cc: Wiltam H. Goldstein. Deputy Executive Director. Cadital Proarams

bcc: J.S. Green. P.S. Cooper (51N). A.A. DiNome (68S), E.J. Fasullo (72S),

L.S. Hofrichter, F.J. Lombardi (72S). C.J. Maikish (35E), A.J. Raiola,

S.T. Van de Walle 
MEMORANDUM OF UNDERSTANDING BETWEEN THE NEW YORK CITY DEPARTMENT OF BUILDINGS AND THE PORT AUTHORITY OF NEW YORK AND NEW JERSEY

This Memorandum shall govern the relationship between the New York City Department of Buildings (the "Department") and the Port Authority of New York and New Jersey (the "Port Authority"), both parties entering into this agreement with the intention to establish procedures to be followed by the Port Authority for any building construction project ("Project"), to be undertaken by the Port Authority or any of its tenants at buildings owned or operated by the Port Authority and located in the City of New York (the "City), to assure conformance of Projects at such buildings with the standards set forth in the New York City Building Code (the "Code").

While the facilities of the Port Authority, an agency of the States of New York and New Jersey, are not technically subject to the requirements of local building codes, the long-standing policy of the Port Authority has been to assure that its facilities meet and. where oppropriate, exceed Code requirements.

The purpose of this Memorandum is not only to restate that longstanding policy as part of an understanding with the City but to provide specific commitments to the Department, as the agency of the City responsible for assuring compliance with the Code, regarding procedures to be undertaken by the Port Authority for any Project at its facilities in the City to assure that the buildings owned or operated by the Port Authority within the City are in conformance with the Building Standards contained in the Code.

as follows:

Accordingly, the Department and the Port Authority hereby agree

1. Port Authority Review. To assure conformance with the building standards set forth in the Code at the time of the design and construction of any Project, the Port Authority shall, in the case of each Project, thoroughly review and examine all plans in connection with such Project for conformance with the building standards set forth in the Code. Plans prepared for Projects to be undertaken by Port Authority tenants shall be prepared and sealed by a New York State licensed professional engineer or architect retained or employed by tenant: plans prepared for Projects to be undertaken by the Port Authority shall be prepared by a New York State licensed professional engineer or architect employed or retained by the Port Authority. The Port Authority's examination of plans shall be conducted by New York State licensed architects and engineers retained or employed by the Port Authority. The Port Authority engineer or architect approving the plans for any Project from the standpoint of Code conformance shall be a New York State licensed architect or engineer who shall not have assisted in the actual preparation of such plans.

2. Project File, The Port Authority shall maintain a file (the "Project File") for each Project which file shall at all times contain the most recentlv 
prepared drawings. plans and any other documents required in connection with the review of the Project from the standpoint of Code conformance. In the case of any Project being effectuated by a tenant of the Port Authority (a "Tenant Project") such file shall also include the Tenant Alteration Application prepared by the Tenant. In the case of any project administered by a line department of the Port Authority. such file shall include any consiruction application prepared in connection with such Project. The Line Depadments of the Port Authority are currently its Wortd Trade. Aviation. Interstate Transportation, Port, and Regional Development Departments.

3. Project Certification. For each Tenant Project, the Port Authority shall require the Tenant to obtain the certification of a New York. State licensed architect or engineer that such Project was constructed in accordance with the approved plans and specifications for such Project. For any Project effectuated by the Port Authority, the Chief Engineer or his successor in duties shall certify that the Project was constructed in accordance with the approved plans and specifications for the Project. Certifications for each Project shall be maintained in the Project File.

4. Copies of Project File. The Department. may at any time request the Port Authority to provide it with a copy of any Project File and the Port Authority shall promptly provide a copy of the Project File to it.

5. Variances. The Port Authority shall promptly advise the Department of any Project approved by the Chief Engineer of the Port Authority which involves, in the judgment of the Chief Engineer of the Port Authority or his successor in duties, a variance from the clear requirements of the Code. In the event that the Department disagrees with the manner in which questions of Code conformance have been or are proposed to be dealt with in connection with such Project, it may so advise the Authority. The Port Authority shall seek expeditiously to resolve the matter. Any matter of Code conformance in connection with such Project which the Department believes involves an unacceptable variance from the requirements of the Code shall be subject to the further review of the Port Authority Board of Commissioners. The Commissioners shall be advised of the Department's views on the matter.

6. Inspections and Surveys. The Port Authority shall continue to conduct or cause to be conducted all building inspections, during both construction and post-construction periods, required under the Code. In addition, the Port Authority will continue to perform structural integrity inspections on a cyclical basis for all of its structures located in the City.

7. Port Authority Responsibility. As indicated above, the purpose of this Agreement is to set forth certain basic understandings between the Department and the Port Authority. It is understood. however, that the Port Authority with its tenants shall continue to bear the responsibility for life safety in buildings at its facilities and nothing in this Agreement is intended to impose any obligations of inspection or review on the Department. The Department shall refer back to the Chief Engineer of the Port Authority any requests for 
information or interpretation which it may receive from tenants of the port Authority with respect to any Project.

8. No Personal Liability. No Commissioner, officer, agent or employee of the Port Authority or the Department shall be held personally liable under any provision of this Agreement or because of its execution or attempted execution or because of any breach or alleged breach thereof.

IN WITNESS WHEREOF, the parties hereto hove caused this instrument to be signed, sealed and attested.

ATTEST:

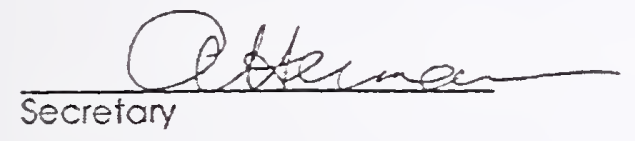

DATE: $\quad 11 / 3 / 13$

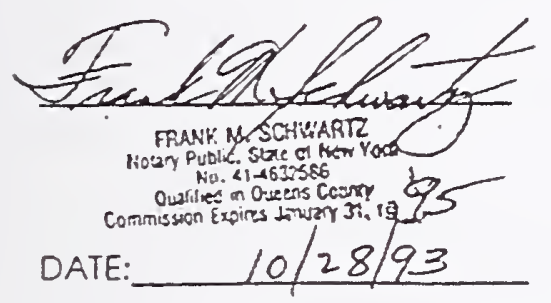

THE PORT AUTHORIN OF NEW YORK AND NEW JERSEY

BY:

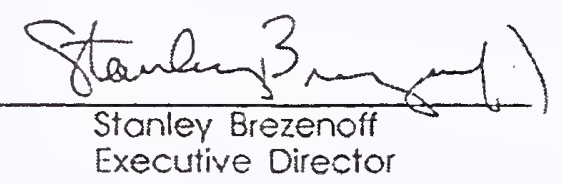

THE NEW YORK CIN DEPATTMENT BUILOINGS
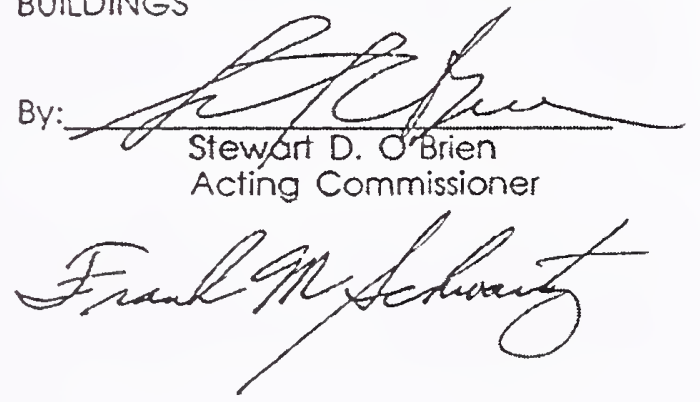
THEYQRT AUTHORTY OF NEW YORK AND NEW JERSEY

Commercial Litigation Division (68E)

?18 All: 02

TO: Lysa Meduri, Acting Secretary

FROM: Walter M. Frank

DATE: October 16,1995

SUBJECT: Transmittal of Letter Agrecment - NYC Department of Buildings

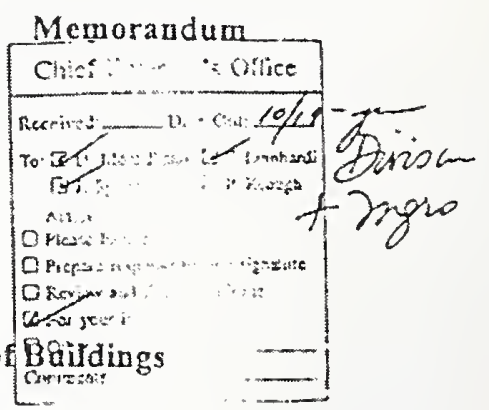

Copy to: J. Green, N. Chanfrau, P. Cooper, W. Goldstein, H. Henschel, F. Lombardi

Transmitted for the official records of the Port Authority is a Letter Agreement between the Port Authority and the New York City Department of Buildings providing for a change to the recent Supplement to the Basic Memorandum of Understanding between the Department and the Port Authority in connoction with the Port Authority's Tenant SelfCertification Program at the World Trade Center.

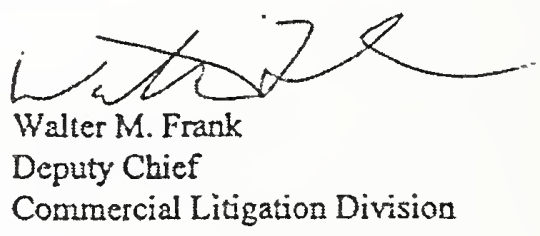

WMF:gk

Encl. 
THE POT AUTHORTY OPWMBW

Soptember 15, 1995

\author{
One Worio Trase Cente: \\ Nen Yorm NY 10046 \\ Willam H Goldsten \\ Deputy Execulve Director? \\ Capual Programs \\ (212) 435.8415 \\ (201) $961.6000 \times 8415$
}

Honorable Joel A. Mlele. S.. Commissioner

Department of Bulldings

City of New York

60 Hudson Streat

New York. Now York 10013

Dear Commisstonor Miele:

As you know, the Port Authortly of Now York and Now Jorsey the "Pot Authority") and the New York City Department of Bulldings (the "Department") recentty executed a supptement (the "Supplement") to the Momorandum of Understanding betwern the Department and the Port Authortly to provide that the Port Authorth's tenant of the Ward Trode Confer could, In lleu of any reviow by the Port Authortty. use New York State llcensed architects or engineers moeting qualifications to be established by the Port Authortty to: (A) prepare and reviow such tenant's plans for the construction of any projoct and certify that such plans conform with the building standards set forth in the Now York Clty bullding Code and $(B)$ certify that such profoct has been constructed in occordance with the approved plans and spocifications tor such projoct.

As you also know. the Supplement provides that the person or firm performing the revlew and certification described in ( $A$ ) above strall not be the same person or firm provlding the certification descrlbed in (B) above. A copy of the supplement ts ottoched.

This letter will-confirm the ogreoment of the Port Authority and the Department that, notwithstanding the last sentence of paragraph 1 of the Supplement, a single llcensed consultonf may make both certficotions described in (A) and (B) of such paragraph, except where the alteration would change the character of the occupancy group under paragraph 27-237 of the New York City Bullding Code which would hove boen applloble to such spoce had suct space boen bocated in a pitvately owned building.

If the forogolng moots with your approval, please be good onough to stan thls letter on bethalf of the Department where Indicated below and retum one of the orfinals to me. In thaht of the fact that three atginals of the supplement were fumlshed to the Dopartment, we hove, for your record pumposes, executed in total four ariginals of this letter.

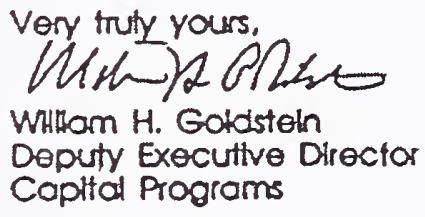

THE NEW YORK CTY DEPARTMENT OF BUILDINGS

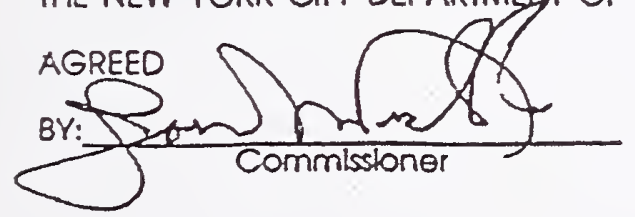




\section{SUPPLEMENT TO MEMORANOUM OF UNDERSTANOING \\ BETWEEN THE NEW YORK CITY DEPARTMENT OF \\ BUILDINGS ANO THE PORT AUTHORTY OF NEW \\ YORK AND NEW JERSEY}

In November, 1993 the New York Clty Department of Buildings the "Department") and the Port Authority of New York and Now Jersey (the "Port Authority") entered into the oftached Memorandum of Understanding (the "Mernorandum") estoblishing certain procedures for the purpose of helping to assure conformance of construction projects to be undertaken at bulidings owned or operated by the Port Authority in New York Clty with the standards set forth in the Now York 'City Building Code.

Recently, the Department impiemented its own optional plan revlew system provlding for professional certificotions of applicatlons and plans and subsequent construction work falling under its jurisdiction.

The purpose of this Supplement to the Memorandum is to provide under the Memorandum for the adoption by the Pat Authority of a procedure under which any Port Authority tenants at the World Trade Center may utllize New York Stote llcensed archifects or engineers to certify. In lieu of any review by the Port Authortly, that (i) the tenant's construction plans are in conformance with the standards set forth in the New York City Bullding Code, and (ID construction has boen performed in accordance with such plans. It being understood that the persons making the certifications described in (i) and (in) shall not be the same.

Accordingly, the Department and the Port Authortty hereby agree that the Memorandum is amended as follows:

1. Professional Centfication. Notwithstanding anything to the contrary in the Memorandum, the Port Authority moy, in lieu of any revlews or certificotions by the Port Authority provided for in the Memorandum, provide procedures pursuont to which lts tenants of the World Trade Center may utilize New York Stote llcensed archltects or engineers meeting qualifications to be establistred by the Port Authority to (A) prepare and revlew such tenant's plans for the construction of ary project and certify that such plans conform with the bullding standord's set forth in the New York City Buitding Code and (B) certlify that such project has been constructed in accordance with the approved plans and specifications for such project. The person or firm performing the revlew and certiflcation described in (A) above sthall not be the same person or firm providing the certification described in $(B)$ obove.

2. Other Provisions. Except as provdded herein, all the terms and conditions of the Memorandum shall remain in full force and effect.

3. No Personal Uability. No Commissioner, officer, agent or employee of the Port Authority or the Department shall be held personally 
llable under any provision of this Supptement or becouse of ifs execution or cttempted execution or becouse of any breach or alleged breach thereor.

iN WTINESS WHEREOF, the porties hereto have coused this insirument to be signed. sealed and attested.

ATIEST:

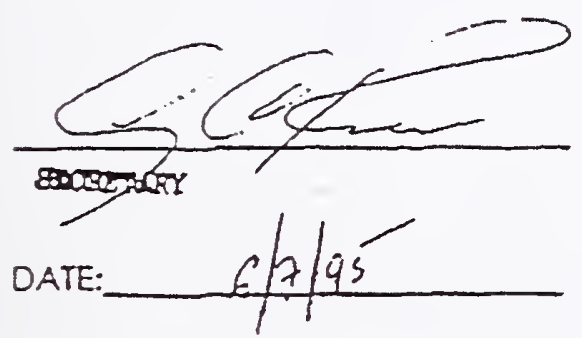

WINESS:

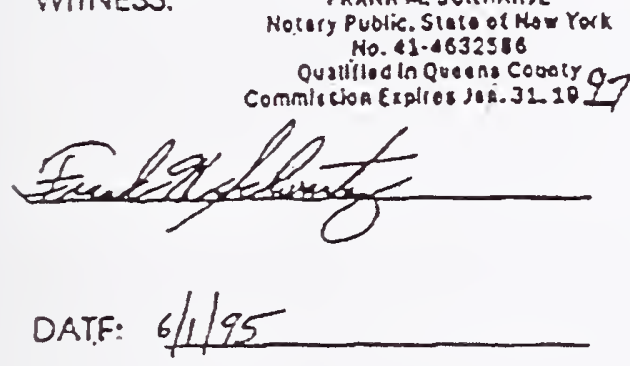

THE PORT AUTHORTY OF NEW YORK ANO NEW JERSEY

By:

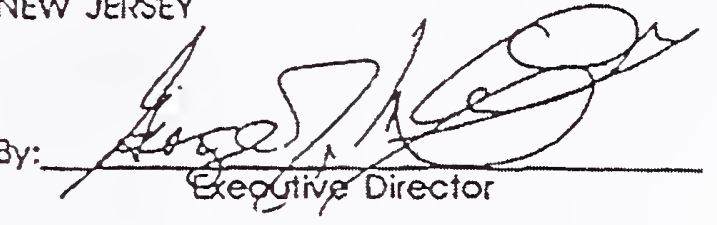

THE NEW YORK CIY DEPARTMENT OF BULLINGS

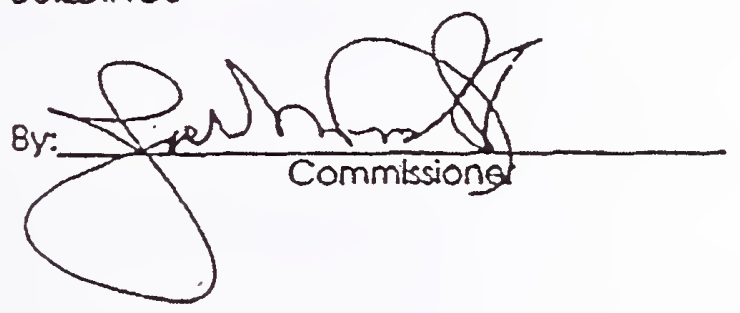




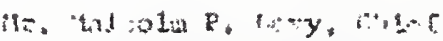

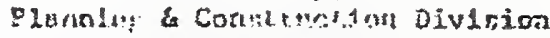

The sorids Tracie cinter

Ther Pore ot Haw iulk Auknordicy

2.L F.t. ith Averws

fNes Forik. Lew York

Lment rath a sonom

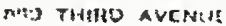

NEY YORK. $N$. $Y$. 1 WUiz
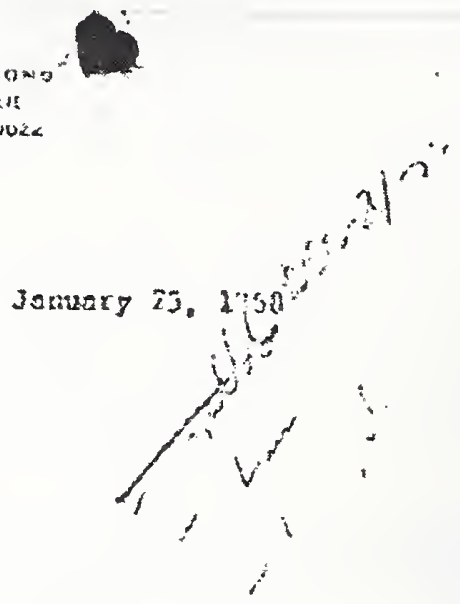

Ro: Tie Wor hat Tiab Cruter

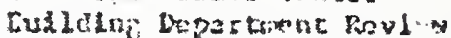

mar Pind:

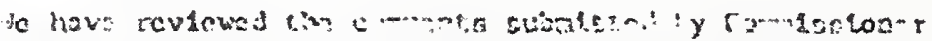

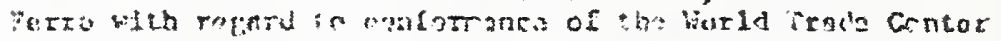

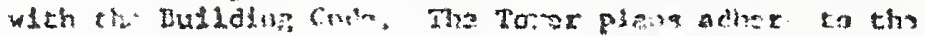

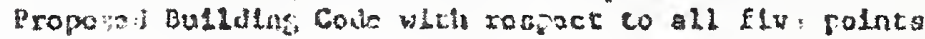
lot:ed.

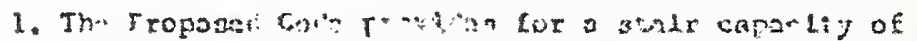

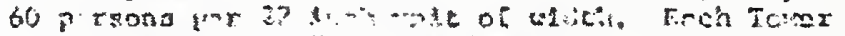

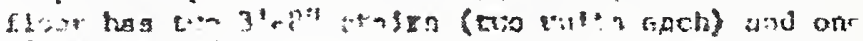

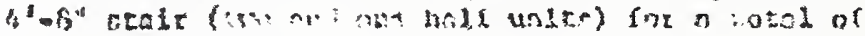

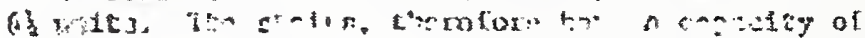

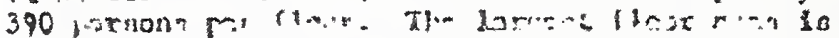

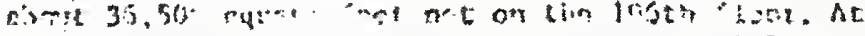

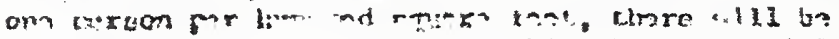

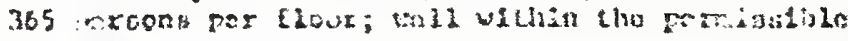
कू in.

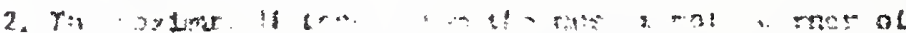

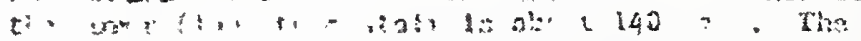

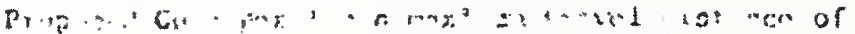

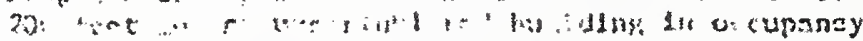

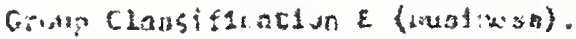

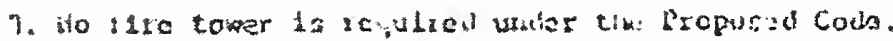




\section{¿OPY}

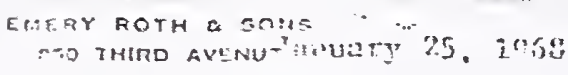

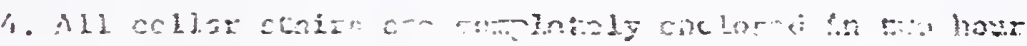

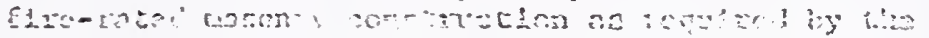

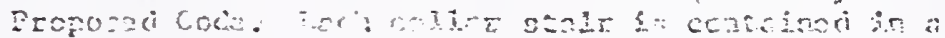

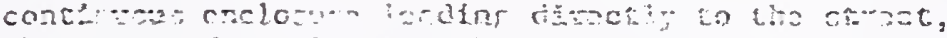

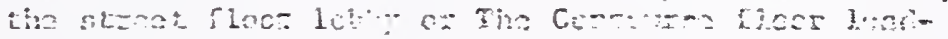

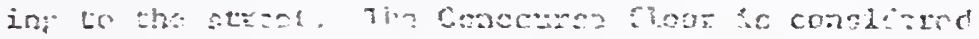

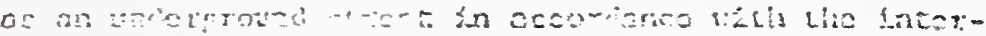

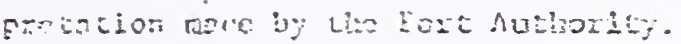

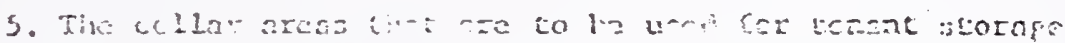

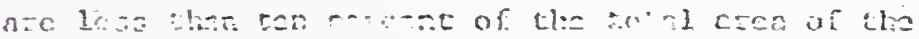

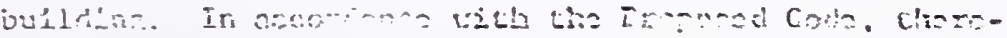

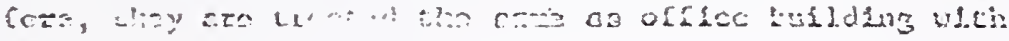

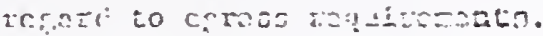

T'” :

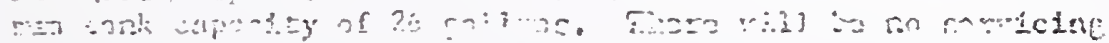
,E $=0$ -

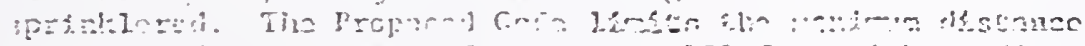

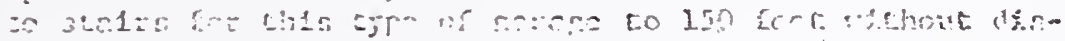

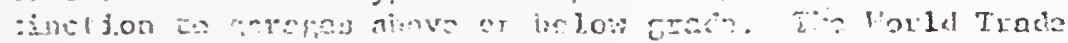

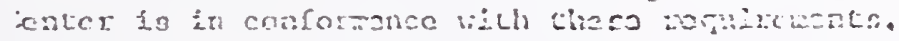
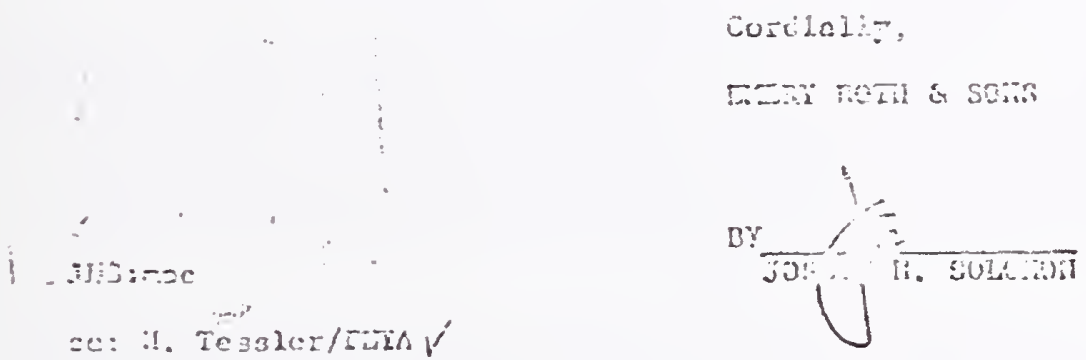
January 25,1968

Mr. Malcolm P. Levy, Chief

Planning and Construction Division

The World Trade Center

111 Eighth Avenue

New York, New York

Re: The World Trade Center Building Department Review

Dear Mal,

We have reviewed the comments submitted by Commissioner Ferro with regard to conformance of the World Trade Center with the Building Code. The Tower plans adhere to the Proposed Building Code with respect to all five points noted.

1. The Proposed Code provides for a stair capacity of 60 persons per 22 inch unit of exit width. Each

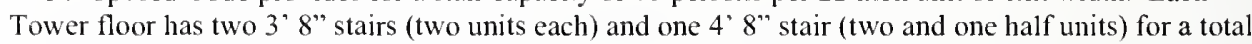
of $6 \frac{1}{2}$ units. The stairs, therefore, have a capacity of 390 persons per floor. The largest floor area is about 36,500 square feet net on the $106^{\text {th }}$ floor. At one person per hundred square feet, there will be 365 persons per floor, well within the permissible maximum.

2. The maximum distance ---corner of the --- is about 140---. The Proposed Code permits a maximum travel distance of 200 feet in an unsprinklered building in occupancy group classification E (business).

3. No fire tower is required under the Proposed Code.

4. All cellar stairs are completely enclosed in two hour fire-rated masonry construction as required by the Proposed Code. Each cellar stair is contained in a continuous enclosure leading directly to the street, the street floor lobby, or the Concourse floor landing to the street. The Concourse floor is considered as an underground street in accordance with the interpretation made by the Port Authority.

5. The cellar stairs that are to be used for tenant storage are less than ten percent of the total area of the building. In accordance with the Proposed Code, therefore, they are treated the same as office building with regard to egress requirements.

The garage spaces are limited to storage of cars with a maximum tank capacity of 26 gallons. There will be no servicing of cars or dispensing of fuel. All garage areas will be sprinklered. The Proposed Code limits the maximum distance to stairs for this type of garage to 150 feet without distinction to garages above or below grade. The World Trade Center is in conformance with these requirements.

Cordially,

Signed by Joseph H. Solomon

Emory Roth \& Sons 
. 
